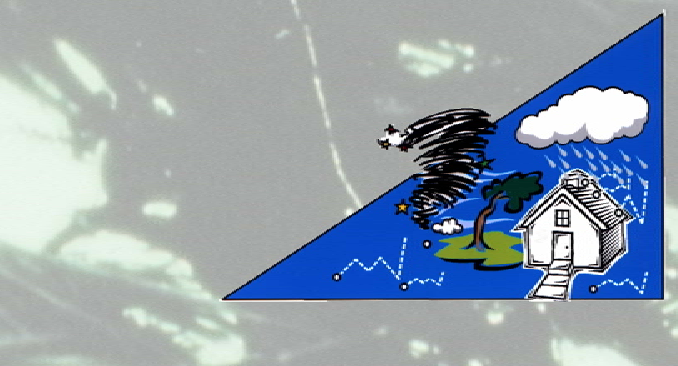

\title{
Ricow1. Ine.
}

Roofing Industry Committee on Weather Issues, Inc.

Hurricane Katrina

Wind Investigation Report

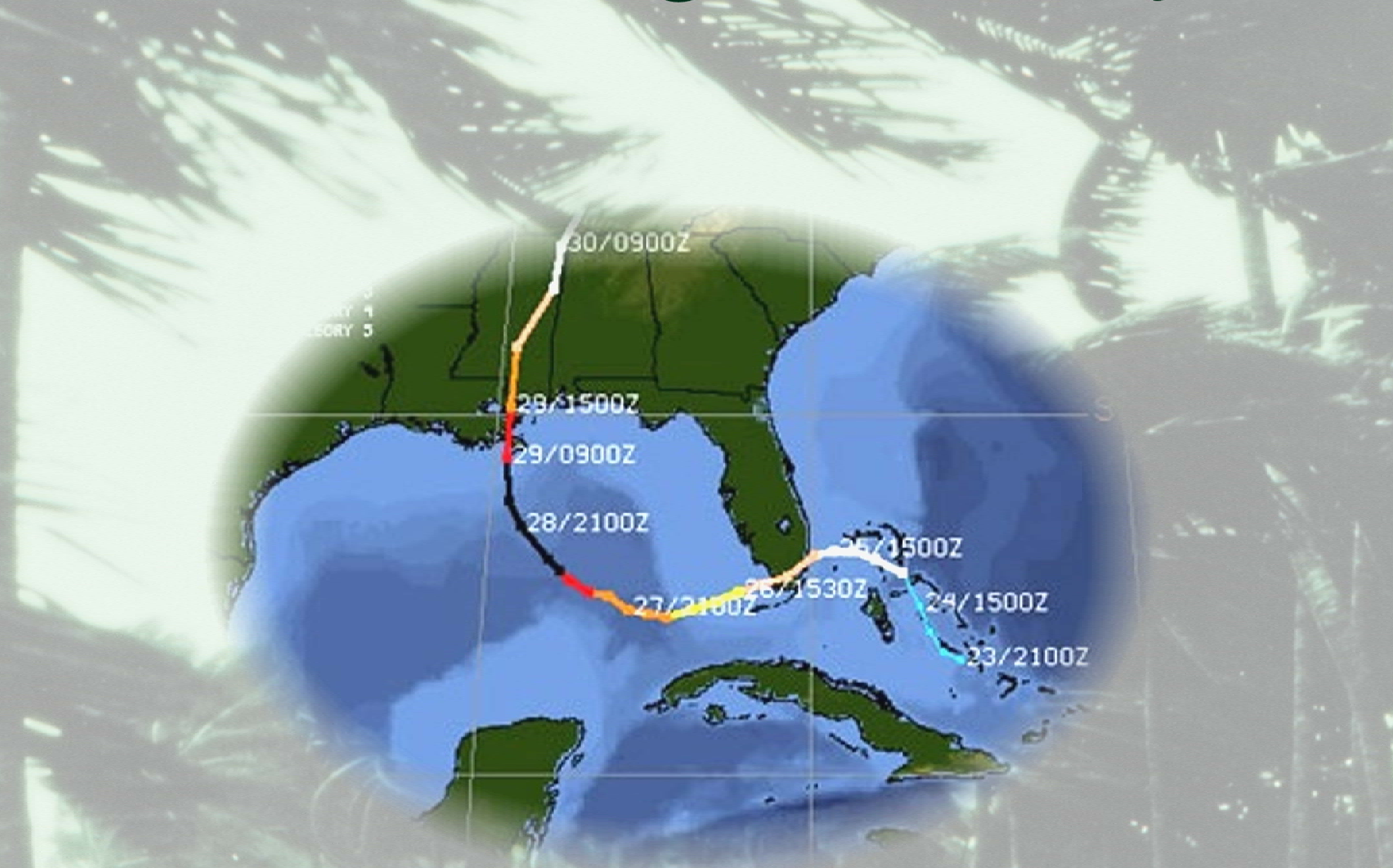

In cooperation with the

OAK RIDGE NATIONAL LABORATORY U. S. DEPARTMENT OF ENERGY

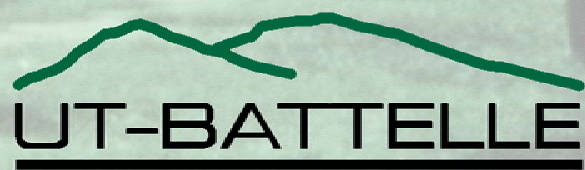





\title{
HURRICANE KATRINA INVESTIGATION REPORT
}

August 2007

\section{Contributing Report Writers}

\author{
André Desjarlais \\ Oak Ride National Laboratory \\ Eric Haefli \\ State Farm Insurance \\ John Kurtz \\ International Staple, Nail, and Tool \\ Association \\ James McDonald \\ McDonald-Mehta Engineers, LLP \\ David Roodvoets \\ Rose Grant \\ State Farm Insurance \\ Tom Kelly \\ 2001 Company \\ Phil Mayfield \\ PSM Consultants, Inc. \\ Cheri Panasik \\ ITW Buildex

\section{DLR Consultants/Single Ply Roofing Industry} \\ Lee Shoemaker \\ Metal Building Manufacturers Association \\ Joe Wilson \\ Metro Roof Products/Metal Construction \\ Association \\ Walter Rossiter \\ National Institute of Standards and Technology \\ Robb Smith \\ Amtech Roofing Consultants, Inc./Roof \\ Consultants, Inc.- - The Institute of Roofing, \\ Waterproofing, and Building Envelope \\ Professionals \\ Patty Wood-Shields \\ RICOWI
}

\section{Project Managers}

Patty Wood-Shields

RICOWI
André Desjarlais

Oak Ridge National Laboratory

Published by

Roofing Industry Committee on Weather Issues, Inc.

Powder Springs, Georgia 



\section{CONTENTS}

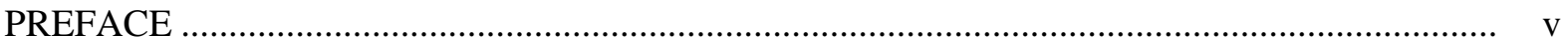

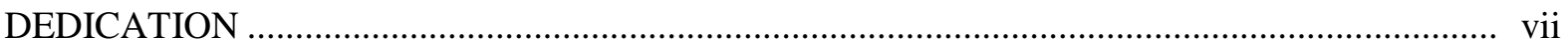

ABBREVIATIONS, ACRONYMS, AND INITIALISMS ................................................... ix

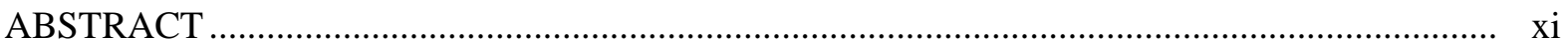

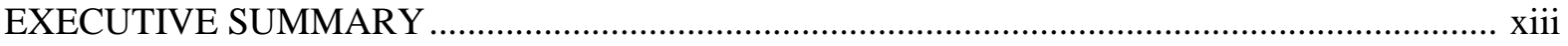

INTRODUCTION

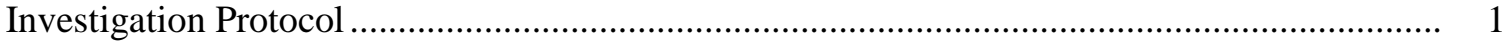

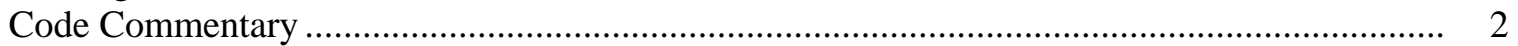

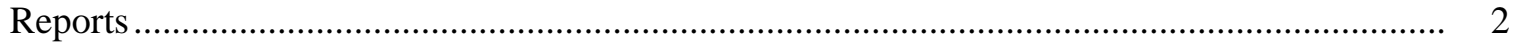

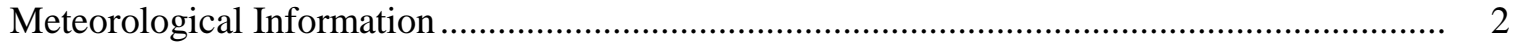

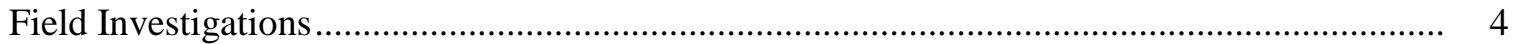

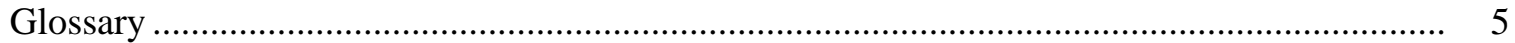

\section{TEAM REPORTS}

Low Slope Roof Systems

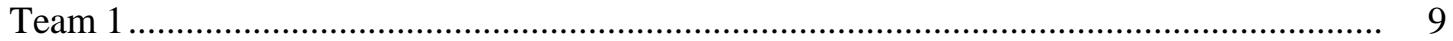

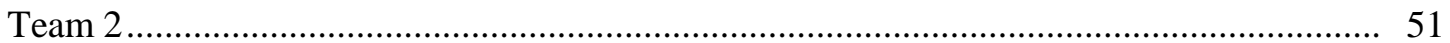

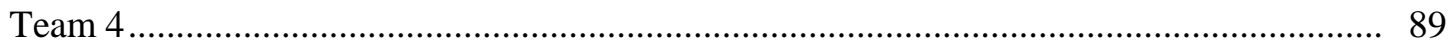

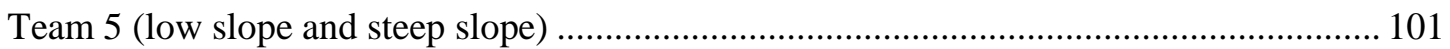

Steep Slope

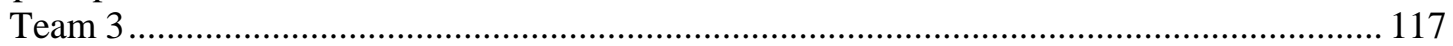

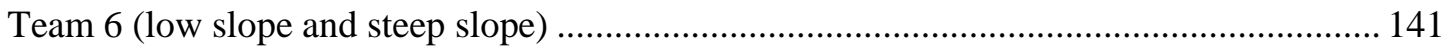

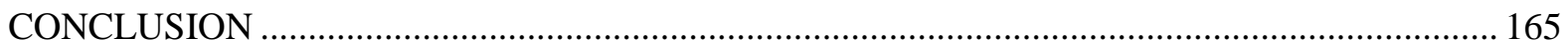

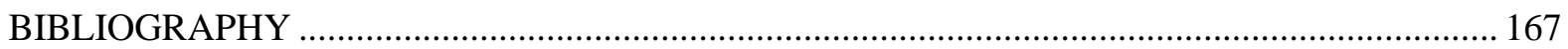

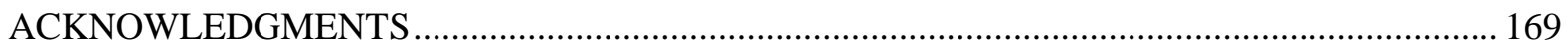

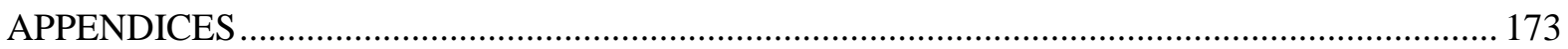

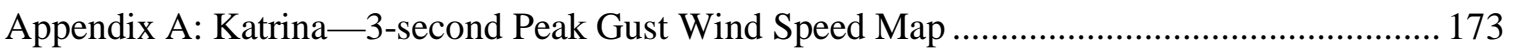

Appendix B: NOAA—National Data Buoy Center C-MAN Program ........................................ 175

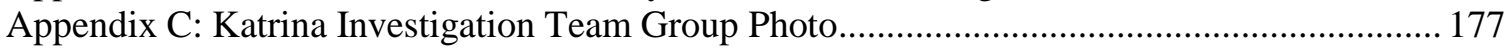

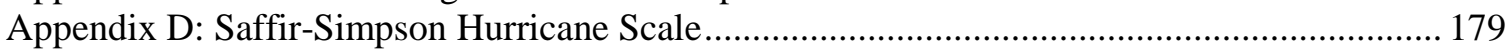

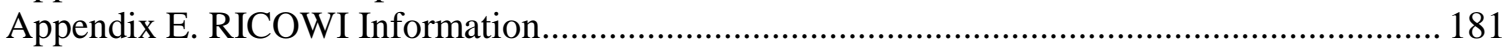





\section{PREFACE}

This document was prepared and published by the Roofing Industry Committee on Weather Issues, Inc. (RICOWI).

The following organizations are Sponsor Members of RICOWI:

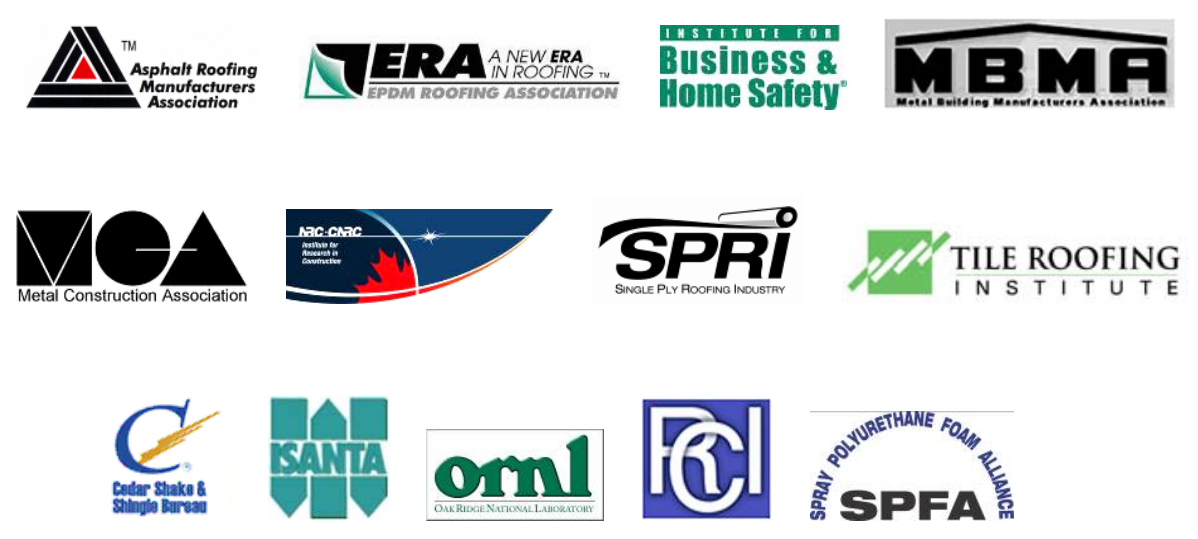

RICOWI and its member organizations, their agents, representatives and employees maintain that the inspections, the reporting, and the Wind Investigation Program (WIP) Final Report presented hereafter have been undertaken with reasonable care. In no event, however, do the aforementioned parties represent that the referenced inspections, reporting, and RICOWI WIP Final Report are "perfect," or are otherwise to be held out, be interpreted, or be relied upon to present an express or implied warranty for any individual, business, governmental agency, or other third party using or otherwise impacted by the WIP Final Report. Moreover, RICOWI and the aforementioned parties expressly disclaim any responsibility for damages caused by, or any third party's reliance upon, said inspections, reporting, or the WIP Final Report. This document shall not be reproduced in whole or in part without written permission from RICOWI. 



\section{DEDICATION}

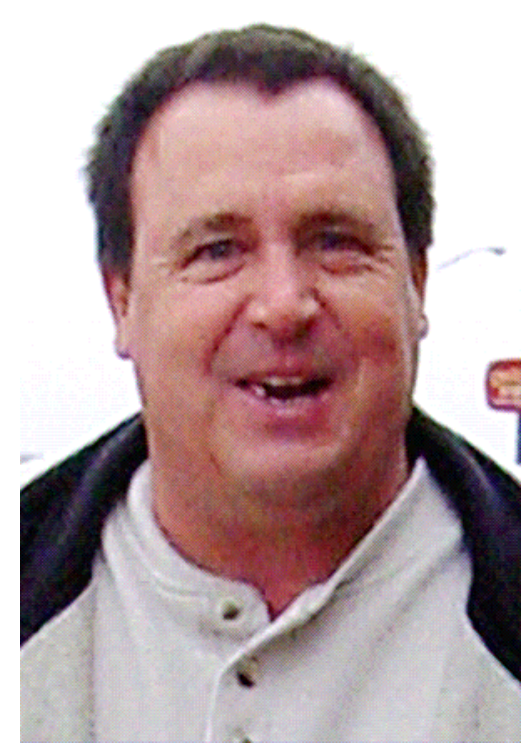

\section{ROSS HARTFORD ROBERTSON}

February 13, 1953 — January 29, 2007

It is with great pride that the Roofing Industry Committee on Weather Issues, Inc. (RICOWI) Board of Directors dedicates this report to Ross Hartford Robertson, who passed away unexpectedly from a heart condition on January 29, 2007.

Ross was a Senior Systems Engineer with Firestone Building Products Company where he dedicated 25 years of loyal service. He was an Affiliate member of RICOWI, was active on committees, and participated on investigation teams to assess roofing damage from Hurricane Charley and the Oklahoma City hail storm. The team members who worked with Ross on the investigations commented on how detail-oriented he was and on his vast experience and overall knowledge in the science of roofing. The weekend prior to his death, he plotted all of the hurricane investigation site maps in the Hurricane Katrina report. We owe a debt of gratitude to Ross for his immense contributions to RICOWI and the roofing industry. We miss our colleague and friend. 



\section{ABBREVIATIONS, ACRONYMS, AND INITIALISMS}

ANSI

APP

ARMA

ASCE

ASTM

BUR

CMU

CRADA

CSSB

CWF

DOE

EIFS

EP

EPDM

EPS

ERA

FEMA

FM

HOA

HVAC

IBHS

ISANTA

LTP

LWC

LWIC

MB

MBMA

MCA

NCDC

NMP

NOAA
American National Standards Institute

atactic polypropylene

Asphalt Roofing Manufacturers Association

American Society of Civil Engineers

American Society for Testing and Materials

built-up roofing membrane/built-up roof

concrete masonry unit

Cooperative Research and Development Agreement

Cedar Shake and Shingle Bureau

cementitious wood fiber

U.S. Department of Energy

exterior insulation finished system

ethylene propylene

ethylene propylene diene monomer

expanded polystyrene

EPDM Roofing Association

Federal Emergency Management Agency

Factory Mutual

Homeowners Association

heating, ventilating, and air-conditioning

Institute for Business and Home Safety

International Staple, Nail, and Tool Association

light-transmitting panel

lightweight concrete

lightweight insulating concrete

modified bitumen

Metal Building Manufacturers Association

Metal Construction Association

National Climatic Data Center

non-membrane penetrating

National Oceanic and Atmospheric Administration 
NRCC National Research Council of Canada

NWS National Weather Service

o.c. on-center

ORNL Oak Ridge National Laboratory

OSB oriented strand board

PVC polyvinyl chloride

RCI Roof Consultants Institute, Inc., The Institute of Roofing, Waterproofing, \& Building Envelope Professionals

RICOWI Roofing Industry Committee on Weather Issues, Inc.

SBS styrene butadiene styrene

SPF spray polyurethane foam

SPFA Spray Polyurethane Foam Alliance

SPRI Single Ply Roofing Industry

TPO thermoplastic polyolefin

TRI Tile Roofing Institute

USGS United States Geological Survey

WIP Wind Investigation Program 


\section{ABSTRACT}

\section{InVESTIGation Protocol-HuRRICANe KatRina}

The Roofing Industry Committee on Weather Issues, Inc. deployed six teams to investigate damage caused by Hurricane Katrina in the landfall regions in Louisiana and Mississippi. This report covers investigations conducted between September 7 and September 9, 2005.

Nearly every type of building and roof system was encountered in these investigations. Results from these studies are included in the damage reports provided by the six investigation teams. Best estimated wind speed data are included, as are criteria for site selection and general observations. The report contains the investigation protocol, meteorological data from the storms, and team information. 



\section{EXECUTIVE SUMMARY}

This investigation of roof damage caused by Hurricane Katrina is a joint effort of the Roofing Industry Committee on Weather Issues, Inc. (RICOWI) and the Oak Ridge National Laboratory/U.S. Department of Energy (ORNL/DOE). The Wind Investigation Program (WIP) was initiated in 1996. Hurricane damage that met the criteria of a major windstorm event did not materialize until Hurricanes Charley and Ivan occurred in August 2004. Hurricane Katrina presented a third opportunity for a wind damage investigation in August 29, 2005. The major objectives of the WIP are as follows:

- to investigate the field performance of roofing assemblies after major wind events

- to factually describe roofing assembly performance and modes of failure

- to formally report results of the investigations and damage modes for substantial wind speeds

The goal of the WIP is to perform unbiased, detailed investigations by credible personnel from the roofing industry, the insurance industry, and academia. Data from these investigations will, it is hoped, lead to overall improvement in roofing products, systems, roofing application, and durability and a reduction in losses, which may lead to lower overall costs to the public. This report documents the results of an extensive and well-planned investigative effort.

The following program changes were implemented as a result of the lessons learned during the Hurricane Charley and Ivan investigations:

- A logistics team was deployed to damage areas immediately following landfall.

- Aerial surveillance-imperative to target wind damage areas-was conducted.

- Investigation teams were in place within 8 days.

- Teams collected more detailed data.

- Teams took improved photographs and completed more detailed photo logs.

Participating associations reviewed the results and lessons learned from the previous investigations and many have taken the following actions:

1. Moved forward with recommendations for new installation procedures

2. Updated and improved application guidelines and manuals from associations and manufacturers

3. Launched certified product installer programs

4. Submitted building code changes to improve product installation

Estimated wind speeds at the damage locations came from simulated hurricane models prepared by Applied Research Associates of Raleigh, North Carolina. A dynamic hurricane wind field model was calibrated to actual wind speeds measured at 12 inland and offshore stations. The maximum estimated peak gust wind speeds in Katrina were in the 120-130 mph range.

Hurricane Katrina made landfall near Grand Isle, Louisiana, and traveled almost due north across the city of New Orleans. Hurricane winds hammered the coastline from Houma, Louisiana, to Pensacola, Florida. The severe flooding problems in New Orleans made it almost impossible for the investigating teams to function inside the city. Thus the WIP investigations were all conducted in areas east of the city. The six teams covered the coastal areas from Bay Saint Louis, Mississippi, on the west to Pascagoula, Mississippi, on the east.

Six teams involving a total of 25 persons documented damage to both low slope and steep slope roofing systems. The teams collected specific information on each building examined, including type of structure (use or occupancy), wall construction, roof type, roof slope, building dimensions, roof 
deck, insulation, construction, and method of roof attachment. In addition, the teams noted terrain exposure and the estimated wind speeds at the building site from the Katrina wind speed map.

With each team member assigned a specific duty, they described the damage in detail and illustrated important features with numerous color photos. Where possible, the points of damage initiation were identified and damage propagation described.

Because the wind speeds in Katrina at landfall, where the investigations took place, were less than code-specified design speeds, one would expect roof damage to be minimal. One team speculated that damage to all roofs in the area they examined was less than $10 \%$ when improper installation and deterioration were eliminated as causes. Roofs designed to code and installed according to manufacturers' recommendations performed very well.

\section{LOW SLOPE ROOFS}

Evidence from field reconnaissance indicated that low slope roof failures in hurricane winds are generally system failures associated with the integrity of the composite system and the attachment of the system to the building structure. Many examples of damage appeared to originate at failed edge details. Other failures were attributed to inadequate adhesive strength of the membrane/insulation installation. Failures occurred within the bond line and within the insulation layers. Insufficient or improperly installed mechanical fasteners also contributed to damage initiation.

Cementitious wood fiber (CWF) panels were commonly used on school building roofs. Lack of anchors, or inadequate anchors, allowed the CWF panels to be uplifted, which in turn caused a peeling back of the roof membrane. Panels in overhangs were especially susceptible to uplift.

In some cases, inadequate uplift resistance of the membrane/insulation assembly led to membrane failure even if the edge metal remained intact. A poor bond between membrane and insulation, or insulation and the roof deck, was frequently attributed to the asphalt's not being hot enough to form good adhesion.

As most buildings inspected were where the gust wind speeds were $130 \mathrm{mph}$ or less, and the roofs were not downstream from taller buildings, the damage to roof membranes caused by windborne debris was minimal. A few minor cuts and rips were observed. Damage from dislodged mechanical equipment on the roof caused more severe damage. Many examples of poor anchorage of mechanical equipment on roofs were noted.

Failure to account for higher negative wind pressures at eaves and corners and pressurization due to door or window failures were blamed for the initiation of roof system damage.

Gravel blowoff was not found to be a serious problem. Some scour occurred, but gravel was retained on the roofs where parapets were installed.

\section{Steep Slope RoOfS}

Several types of steep roof products were included in the investigations.

Many asphalt shingle blowoffs were observed. These were attributed to a method of attachment on older roofs that is generally not recommended by manufacturers today. Instead of being staggered, the shingles are laid in vertical rows beginning at the roof edge. The shingles overlap but generally have three nails or less. This is a very poor practice in a hurricane zone. 
Unexpected damage was found in areas close to large projections in the roof, such as dormers and chimneys. Additional attention to fastening patterns is needed in these areas.

Roof alterations to older buildings created construction anomalies that led to wind damage. These anomalies require special detailing to provide better protection against the wind.

The only wood shake roof observed had sporadic loss of wood shakes as a result of improper nailing.

Metal roofs designed and installed in the past 5 or 6 years using recent codes and standards performed very well. Improved test methods, coupled with higher roof load requirements, appear to have improved the performance of standing seam roofs. Isolated damage was attributed to installation lapses and/or internal pressurization caused by failure of non-roof components. When a standing seam roof on metal supports failed, the failure mode was almost always clip separation from the panel seam.

Poor eave and rake details, such as gutter attachments and flashing, were found to be weak points where roof failures are likely to originate.

Overhead door failures contribute to rapid internal pressurization and subsequent roof failure initiation, especially in older structures. Although newer doors performed much better than the older ones, there is still a need to improve the door and building interface and to ensure that tested assemblies accurately reflect real-world conditions.

\section{RESULTS}

The main lesson learned appears to be that roofs designed and detailed according to current codes and standards will perform satisfactorily. Older roofs constructed with little concern for the magnitude of the wind pressures at eaves and corners, and roofs installed with poor practices that lead to progressive failure of the roof membrane, were consistently the ones with significant damage.

Many of the observations for Katrina were very similar to those recorded for Hurricanes Charley and Ivan. The studies indicate that the same mistakes that were made in the Charley and Ivan damage areas are also being made in the Katrina damage area. Many roof designers do not seem to understand that winds produce uplift forces that affect not only the roofing system but the roof deck as well. All elements of a composite system-which will consist of some or all of the following: deck, base sheet, insulation layers, cap sheet, and membrane — must be adhered or fastened to resist the wind uplift loads.

Some progress has been made in roofing technology, codes and standards, and installation inspection. Information gained from wind damage investigations such as Katrina and others will help identify the problems with the design and construction process. The problems will not be solved until the information gets into practice through extensive educational activities directed to everyone from the architects to the installers who apply the fasteners or mop on the hot mix.

\section{FUtURE RESEARCH}

Certainly there is a need for continuing research to develop new and less expensive materials. Given the current emphasis on "Green Buildings," the use of recycled roofing materials should be of interest to both researchers and manufacturers. The practice of reroofing with reusable materials continues to 
cause problems that result in wind damage. This practice would be less popular if there were economical uses for the old roofing materials.

Much work has been done on in situ testing of roofs to determine uplift resistance. Simple practical tests need to be developed and calibrated that would verify that a new roof possesses the codespecified resistance.

A fresh look at wind loads on coping and metal edge flashing is needed. Testing in wind tunnels at full scale is very difficult but needs to be done. With a better knowledge of the loads, construction details can be improved.

A better fastening system is needed for CWF panels. Numerous damage investigations besides the current one have shown the anchorage to be inadequate and susceptible to improper installation.

Aggregate and stone blowoff was not identified as a major problem in this investigation. Most buildings inspected in the investigation would not have qualified for aggregate covering of built-up roofing systems or stone ballast for single ply roofs, as use of these systems is now limited by current building codes.

The protection of buildings from water intrusion after a roof has been damaged should be researched. Better methods for temporary protection, other than the blue plastic sheeting or tarps, should be available.

\section{Need for Engineered Edge Design}

Perimeter and corner areas of low slope roofs have long been recognized as the most vulnerable areas of the roof. The relatively higher uplift forces that can occur in these areas have been factored into the model national building codes, and resisting these loads has been a requirement of the codes for many years. However, wind damage continues to occur at these vulnerable parts of the buildings because both design and installation practices are inadequate. The negative forces at the perimeter must be resisted by adequate mechanical attachment or bonding of the roofing membrane to the substrate and deck. Many designs allow building pressurization, which can significantly increase the design load. Roof systems must be evaluated through testing to resist the design loads. The wind loads to be resisted are dynamic, yet most tests used to evaluate roofing systems are static or quasi-static. Current tests also focus on the vertical force of uplift; but the vertical forces, once they break the initial bond or mechanical attachment, become peel forces that are not measured. In current testing, the first mechanical failure (screw withdrawal) or separation of the membrane stops the test. In reality, roofs often survive with limited amounts of damage if propagation of damage by peel forces is resisted. Without damage propagation by peel forces, catastrophic damage is usually avoided.

\section{FUTURE INVESTIGATIONS}

RICOWI and ORNL/DOE have renewed their Cooperative Research and Development Agreement and are prepared to conduct another hurricane investigation event. The most important element is the publication of the report on a timely basis. To this end, RICOWI has purchased new software for the teams' report writers. A FileMaker Pro training workshop was held March 2, 2007. In addition to the report writers, several of RICOWI's trained investigators purchased the software and also took the course. This improved method for data input in the field will accelerate the production of future reports. 


\section{INTRODUCTION}

\section{InVestigation Protocol-HuRricane Katrina}

The Roofing Committee on Weather Issues, Inc. (RICOWI) sent teams to investigate the condition of roofs in the areas impacted by Hurricanes Charley and Ivan in 2004, and that report has been published and posted on RICOWI's website. The valuable experience that the team members gained during these investigations was applied to the Hurricane Katrina investigation. We realized the importance of deploying the logistics team immediately following landfall and the value of having the teams on site shortly thereafter. Because access was delayed after Hurricanes Charley and Ivan, cleanup had started when the teams arrived, and valuable information was lost.

For these investigations, the following scope of work was established as a collaborative effort under the Cooperative Research and Development Agreement (CRADA) between Oak Ridge National Laboratory/the U.S. Department of Energy (ORNL/DOE) and RICOWI.

Scope of Work: To investigate and report the field performance of low slope and steep slope roofing systems after major hurricanes, e.g., those with sustained wind speeds of $95 \mathrm{mph}$ (1 minute, minimum) or greater, making landfall on the continental United States in a populated area.

Hurricane Katrina met those basic criteria.

ORNL hosted an initial training seminar for RICOWI investigation team members in 1996. Subsequent training workshops were held in September 2000 and March 2005. DOE supplied identification badges to each trainee attending the workshop at its facility in Oak Ridge, Tennessee. DOE badges were instrumental in gaining access to disaster areas.

Generally, team members are wind engineers, roofing material specialists, insurance analysts, structural engineers, and/or roofing consultants. Some teams were accompanied by roofing contractors or other interested parties who aided in arranging inspections or in providing access and equipment.

Inspector training, which focused on wind dynamics, damage modes, and documentation, was attended by all ORNL-badged participants. Training was conducted by several of the country's leading wind engineers, scientists, roof consultants, and others qualified in examining wind-related roof damage.

Each team had four positions: (1) report writer, (2) photographer, (3) data recorder, and (4) sample collector. All team members acted as observers, combining their expertise and observations to maximize the data obtained from each investigation. Members were assigned to specific teams based on their respective fields of expertise. Each team was balanced by assigning two manufacturing members and two members from academia, the insurance industry, consulting firms, or other nonmanufacturer associations.

A logistics team was dispatched immediately following the storm to the landfall region in Louisiana and Mississippi on August 29, 2005, and their findings are the focus of this report. Site selection was based on data collected from local building officials, police officials, aerial photographs, news media, and industry members. The logistics coordinator was able to conduct an initial survey of each area, prepare a list of potential investigation sites, and work with the program coordinator to set up local building contacts before deploying the teams. 
The next step was obtaining advance clearance letters from state emergency management agencies and local jurisdictions in hurricane-damaged areas. Building owners, building managers, or other responsible parties were then contacted to obtain permission to inspect specific roofs.

Six teams were deployed on September 6, 2005, to Hurricane Katrina damage areas, and a command center was set up in Mobile, Alabama. Briefings were held each day to review safety protocols and site selections and to realign teams as necessary to maintain balance.

Inspections were conducted on buildings between Bay St. Louis (east of New Orleans) and Pascagoula, Mississippi, and some were conducted as far north as Hattiesburg, Mississippi. Teams did not go into the New Orleans storm surge area, as storm surge (see definitions) is not within the damage mode outlined in the scope of work. Teams initially viewed roofs for large-scale damage and then focused on individual details and the potential causes for noted damage. Photos were taken to document conditions observed and then recorded in photo logs. Inspection forms were used to document background information, details about the roof systems and substrates, type and severity of roof damage, and any wind direction/speed information available. Following the field investigations, information from the inspection forms was added to a central database. Digital photographs from each site were similarly consolidated.

More than 82 roof inspections were conducted on all types of roofing systems, including commercial, institutional, industrial, and residential. Where possible, reports documented roof and deck construction, damage conditions, and the likely initiation points of wind damage. Adjacent buildings, foliage, signs, fences, and surrounding elements offered clues to help establish wind direction and pathways. Building and facility managers also provided information. Roofing material was removed and examined where possible, e.g., when reroofing or repairs were in progress. Although inspections were nondestructive, samples were taken from a few locations when circumstances allowed, i.e., where taking such samples would not cause new damage or water infiltration. Structures that survived the storm or suffered minor damage were also documented for comparison with adjacent damaged structures.

\section{Code Commentary}

The post-hurricane evaluation of roofing performance must take into account the age of the building, and the codes in effect at the time of construction, to make reasonable comparisons with today's codes and standards. Our knowledge of wind effects and roof uplift resistance has made great strides over the past two decades, in part because of lessons learned from previous field studies of hurricane damage.

For example, current code requirements for wind uplift on a corner fastener in the hurricane regions call for over four times greater resistance than did the codes of the early 1980s. Consequently, observed roof damage on older buildings is not necessarily a predictor of the performance of buildings designed under current codes and standards. Nevertheless, side-by-side comparison of buildings from different eras is an excellent way to determine the effectiveness of newer code requirements.

\section{REPORTS}

These documents are divided into summary observations and more detailed damage reports on individual buildings that are based on team observations. Although the damage observed was generally considered to be caused by the recent hurricane, there may have been other causes. 
Wind speeds in this report are based on the available post-hurricane maps and refer to the wind speeds at 10 meters height in exposure C (see "Exposure Categories" in the following glossary). Listed wind speeds at each site are the best estimates based on these maps. They must be adjusted for building height to obtain the projected wind uplift pressures on each roof. Actual wind speeds may vary by $\pm 10 \mathrm{mph}$ from reported speeds and may vary even more as a result of downbursts or wind streaks that are known to occur in hurricanes.

\section{METEOROLOGICAL INFORMATION}

Hurricane Katrina first made landfall in the United States as a Category 1 hurricane near the border of Miami-Dade County and Broward County on August 25, 2005, with wind speeds of approximately $80 \mathrm{mph}$, according to the National Climatic Data Center (NCDC) of the National Oceanic and Atmospheric Administration (NOAA).

The eye feature became better defined while Katrina moved inland. Katrina continued westsouthwestward overnight, spending approximately 7 hours over land (mostly over the Everglades) before weakening to a tropical storm over mainland Monroe County. It then emerged into the southeastern Gulf of Mexico on August 26th, north of Cape Sable. Spinning over the Gulf, Katrina quickly strengthened and attained major hurricane status by late afternoon and almost doubled in size. A report from the National Hurricane Service stated, "The new eyewall that formed late on August 27 and contracted early on August 28 began to erode on its southern side very late on August 28, while another outer ring of convection consolidated. These structural changes likely contributed to the rapid weakening that was observed prior to final landfall."

On the morning of Sunday, August 28, Katrina reached maximum wind speeds of $170 \mathrm{mph}$ (Category 5) and the central air pressure dropped to $920 \mathrm{mb}$ (the lower the pressure, the more dangerous the storm's potential). This hurricane set a new minimum central pressure record for the Atlantic Basin (which includes the North Atlantic Ocean, Caribbean Sea, and Gulf of Mexico) while approaching the U.S. North Central Gulf Coast. It is also the third lowest at U.S. landfall, trailing only Hurricane Camille in 1969 (909 mb) and the Labor Day hurricane that struck the Florida Keys in $1935(892 \mathrm{mb})$.

Katrina turned north toward the northern Gulf Coast early on August 29 and remained a strong Category 4 hurricane until it made its second landfall at 7:10 a.m. EDT in Plaquemines Parish near Buras, Louisiana (west of Grand Isle). It is this chapter of the storm that is the focus of the present report.

Katrina pushed north and made a final landfall at 9:45 a.m. just east of Slidell, Louisiana, near the mouth of the Pearl River. The storm weakened as it moved inland over southern and central Mississippi.

The December 29, 2005, NCDC update stated "Hurricane Katrina was one of the strongest storms to impact the coast of the United States during the last 100 years. With sustained winds during landfall of $125 \mathrm{mph}(110 \mathrm{kts}) \ldots .$. (http://lwf.cdc.noaa.gov/oa/climate/research/2005/Katrina.html)

National Weather Service (NWS) single-Doppler radar in Mobile measured winds as high $132 \mathrm{mph}$ at 3,000 to 4,000 ft above ground level during the morning hours of August 29. NWS estimated that 80 to $90 \%$ (approximately 104-119 $\mathrm{mph}$ ) of the latter maximum wind speed value reached the ground (www.srh.noaa.gov/mob/0805Katrina/). NWS reported that "Katrina landfall winds at Grand Isle, Louisiana, were approximately $140 \mathrm{mph."}$ 
The storm surge caused by the hurricane was very severe (storm surge is the water height above normal astronomical tide level). Katrina's highest surge values were found in a zone from just east of the eye near Bay St. Louis, Mississippi, eastward to the northern reach of Mobile Bay. Although the surge was the highest on the east eyewall (area of intense winds just east of the center of circulation of the hurricane), it also caused significant damage to the west as it crossed Interstate 10 in several locations.

The U.S. Geological Survey (USGS) team measured the storm surge at just over $28 \mathrm{ft}$ at the Mississippi Baptist Convention Gulfshore Assembly at Pass Christian, Mississippi. The USGS team and RICOWI's inspection team 2 visited the site at the same time. (See team report 2.)

Figure 1 is a wind swath map showing approximate wind velocities experienced as Katrina made landfall and traveled inland. The map shows wind velocities at a height of $33 \mathrm{ft}(10 \mathrm{~m})$ in open terrain (Exposure C).

\begin{tabular}{l}
\hline Hurricane Katrina Track \\
Peak Gust (mph) \\
$20-30$ \\
$31-40$ \\
$41-50$ \\
$51-60$ \\
$61-70$ \\
$71-80$ \\
$81-90$ \\
$91-100$ \\
$101-110$ \\
$111-120$ \\
$121-130$ \\
$131-140$ \\
\hline
\end{tabular}

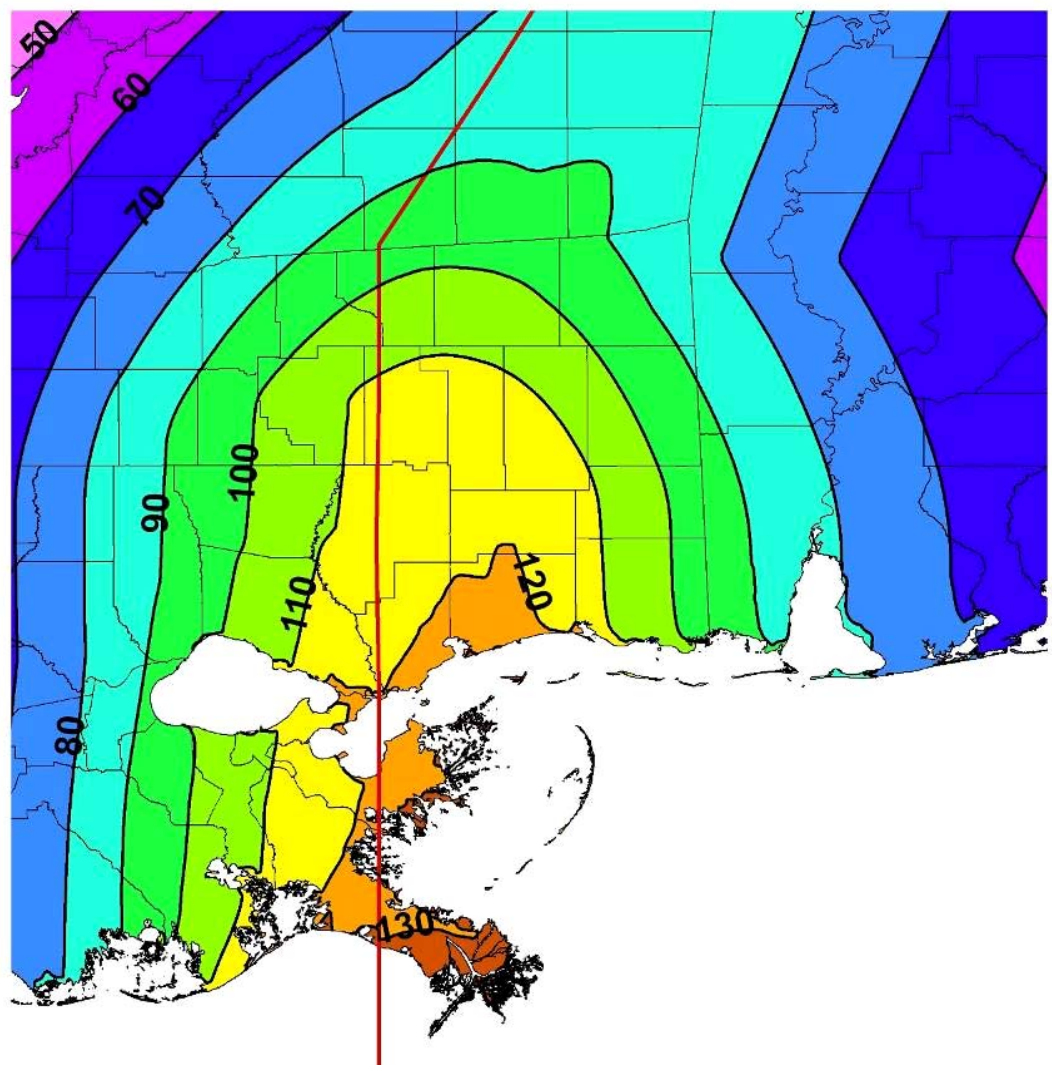

Figure 1. Hurricane Katrina 3-second peak gust wind speed map. Map used courtesy of Applied Research Associates (www.ara.com).

\section{FiELD INVESTIGATIONS}

Each Hurricane Katrina investigation team was assigned to inspect either low slope or steep slope roof systems. In some cases, a low slope team would inspect a steep slope roof and vice versa. Based on each team's primary objective, the teams' investigations are presented in the following order: 


\section{Low Slope}

Team 1

Team 2

Team 4

Team 5 (low and steep)

\section{Steep Slope}

Team 3

Team 6 (low and steep)

\section{Glossary OF TERMS}

Aggregate: In roofing, crushed stone, crushed slag, or water-worn gravel used for surfacing a builtup roof covering or modified bitumen roof covering.

APP: Atactic polypropylene

Ballast: Any item having weight that is used to hold or steady an object. In roofing, ballast comes in the form of large stones, paver systems, or lightweight interlocking paver systems, and is used to provide uplift resistance for roofing systems that are not adhered or mechanically attached to the roof deck.

BUR: Built-up roof membrane

CMU: Concrete masonry units

CWF: Cementitious wood fiber

Damage: Any wind-induced change to the pre-hurricane condition of the building. Noted damage conditions are subject to team observers' interpretations and may not concur with insurance or other repair-related interpretations or decisions.

Minor damage: Damage that was relatively limited (more cosmetic than structural) and unlikely to have prevented the roofing system from providing its primary function of weather protection. Minor damage generally involves only a small area of the roof.

Major damage: Damage that was more than cosmetic and may have affected structural integrity and/or water infiltration, i.e., damage that likely compromised the roofing system so that it could no longer provide its primary function of weather protection.

Dead-level: Absolutely horizontal, or zero slope

Eave height: The distance from the ground surface adjacent to the building to the roof eave line at a particular wall. If the height of the eave varies along the wall, the average height shall be used.

EIFS: Exterior insulation finishing system

EPDM: Ethylene propylene diene monomer

EPS: Expanded polystyrene

Extensive damage: Damage that involves large areas of the roof and other building components, such as roof decks and walls.

Failure: Failure of the roof assembly (from the deck up) to remain intact, to remain properly attached to the structure, and/or to prevent infiltration of water, air, or other contaminants.

Hurricane: A tropical cyclone in which maximum sustained surface wind is $74 \mathrm{mph}$ or greater. 
Hurricane-prone regions: (ASCE7-05 excerpt): Areas commonly vulnerable to hurricanes; in the United States and its territories, defined as

- The U.S. Atlantic Ocean and Gulf of Mexico coasts where the basic wind speed is greater than $90 \mathrm{mph}$

- Hawaii, Puerto Rico, Guam, Virgin Islands, and American Samoa

HVAC: Heating, ventilation, and air-conditioning

ISO Insulation board: Polyisocyanurate insulation board

LWC: Lightweight concrete

LWIC: Lightweight insulated concrete

MB or mod bit: Modified bitumen

Mineral-surface roofing: Built-up roofing materials with a top ply consisting of a granule-surface sheet.

Penthouse: An enclosed one story structure extending above the roof of a building, not exceeding $25 \%$ of the area of the roof at the level on which the penthouse is located. Commonly used to house elevator machinery, water tanks, or ventilating apparatus or to provide working space above the elevator shafts.

PVC: Polyvinyl chloride single ply

Racking: Stretching or straining by force, such as by thermal or wind action.

Roof covering pull-off: Roofing material pulling completely away from the fasteners, with the fasteners remaining in the deck; also referred to as "pull-through."

Roof height: Distance measured from the ground to the eave.

SBS: Styrene butadiene styrene

SPF: Spray polyurethane foam

Storm surge: The rising of the sea level due to the low pressure, high winds pushing on the ocean's surface, and the high waves associated with a hurricane as it makes landfall.

Street survey: A survey conducted by teams walking (or slowly driving) down streets to obtain an initial estimate of overall damage, especially damage to steep roofs. In some instances teams were able to discern roof types and even approximate dates of installation.

Surface roughness categories: (ASCE7-05 6.5.6.2 excerpt) A ground surface roughness within each $45^{\circ}$ sector shall be determined for a distance upwind of the site as defined in ASCE7-05, Section 6.5.6.3, from the categories defined in the following text, for the purpose of assigning an exposure category as defined in Exposure Categories (see below).

- Surface roughness B: Urban and suburban areas, wooded areas, or other terrain with numerous closely spaced obstructions having the size of single-family dwellings or larger.

- Surface roughness C: Open terrain with scattered obstructions having heights generally less than $30 \mathrm{ft}(9.1 \mathrm{~m})$. This category includes flat, open country; grasslands; and all water surfaces in hurricane-prone regions.

- Surface roughness D: Flat, unobstructed areas and water surfaces outside hurricane-prone regions. This category includes smooth mud flats, salt flats, and unbroken ice.

Exposure: (ASCE7-05 6.5.6 excerpt) For each wind direction considered, the upwind exposure category shall be based on ground surface roughness that is determined from natural topography, vegetation, and constructed facilities. 


\section{Exposure Categories (ASCE7-05 6.5.6 excerpt):}

- Exposure B: Exposure B shall apply where the ground surface roughness condition, as defined by surface roughness B, prevails in the upwind direction for a distance of at least $2630 \mathrm{ft}(800 \mathrm{~m})$ or 10 times the height of the building, whichever is greater.

- Exception: For buildings whose mean roof height is less than or equal to $30 \mathrm{ft}(9.1 \mathrm{~m})$, the upwind distance may be reduced to $1500 \mathrm{ft}(457 \mathrm{~m})$.

- Exposure C: Exposure C shall apply for all cases where exposures B or D do not apply.

- Exposure D: Exposure D shall apply where the ground surface roughness, as defined by surface roughness $\mathrm{D}$, prevails in the upwind direction for a distance greater than $5000 \mathrm{ft}$ $(1524 \mathrm{~m})$ or 20 times the building height, whichever is greater. Exposure D shall extend into downwind areas of surface roughness B or C for a distance of $660 \mathrm{ft}(200 \mathrm{~m})$ or 20 times the height of the building, whichever is greater.

For a site located in the transition zone between exposure categories, the category resulting in the largest wind forces shall be used.

Exception: An intermediate exposure between the preceding categories is permitted in a transition zone provided that it is determined by a rational analysis method defined in the recognized literature.

TPO: Thermoplastic polyolefin

Wind uplift: Wind that is deflected at roof edges, roof peaks or obstructions can cause a drop in air pressure immediately above the roof surface. This force can lift roof membranes from the roof deck if they are not adequately secured. The uplifting force is created by the deflection of wind at roof edges, roof peaks or obstructions resulting in a drop of air pressure immediately above the roof surface.

Wind speed, basic, $\boldsymbol{V}$ : Three-second gust speed at $33 \mathrm{ft}(10 \mathrm{~m})$ above the ground in Exposure $\mathrm{C}$ (see ASCE7-05 6.5.6.3) as determined in accordance with 6.5.4. 



\section{HURRICANE KATRINA: TEAM 1}

\section{OVERVIEW}

Team 1 conducted field reconnaissance of low slope roofing systems in the area of Mississippi ranging from Pascagoula westward to Ocean Springs. Maximum gust wind speeds in this region have been estimated to be in the 90-120 mph range, with higher values representative of wind speeds farther to the west. Team 1 inspected the roofs of 19 buildings or building complexes (i.e., schools or hospitals with multiple interconnected buildings or sections), of which the majority (ten) were commercial construction.

Inspections included seven schools and two hospitals. In many cases, the team's reconnaissance at each building or complex was limited to those sections with damaged roofing. The roof coverings on these 19 buildings were primarily bituminous systems, including aggregate-surface and smoothsurface built-up roofing (BUR) and APP (atactic polypropylene) and SBS (styrene butadiene styrene) modified bitumens. Four roofs had SPF (sprayed polyurethane foam) systems and three had EPDM (ethylene propylene diene monomer) systems-one mechanically fastened, two ballasted. One roof had an unidentified mechanically attached single ply system, which appeared to be either TPO (thermoplastic polyolefin) or PVC.

Some roof damage was observed on 12 of the 19 buildings/complexes (63\%).The ASCE7 design wind speed for most of the local area is $130 \mathrm{mph}$ or greater. It is generally expected that roofs be constructed to survive at wind speeds up to and exceeding the design wind speed. Consistent with the relatively low wind gust speeds, damage to the roofs was limited to no more than $10 \%$ of the roof areas in most cases. Still, a small amount of roof damage can result in considerable interior damage. At one hospital where roof sections were damaged on four wings, maintenance staff reported that water infiltration was so extensive that floors two through four were rendered unusable for an extended period of time.

\section{Team Members}

The following members participated on Team 1:

Tom Kelly, sample collector (one day)

Mason Knowles, sample collector

Walt Rossiter, data recorder and report writer

Robb Smith, report writer

All team members, photographer

\section{Summary Observations}

Evidence from the field reconnaissance indicated that roof failures in hurricanes are generally system failures associated with both the integrity of the composite system, including edge details, and securement of the system to the building. Of the roofs examined, the bituminous membranes (both BUR and modified bitumens) experienced most of the observed damage. Two EPDM systems, one mechanically attached and the other ballasted, were also found to be damaged. For most roofs, damage was limited to the membrane and insulation, although a few roofs also exhibited deck damage. Many examples of damage appeared to originate with failed edge details, but this was not universal. At one hospital, the edge detail was intact but sections of membrane and/or insulation blew off. The damage was attributed to the adhesive strength of the membrane-insulation; failure occurred both at the bond line and within the insulation layers. 
An uncommon low slope roof construction on a commercial building experienced extensive damage to about $70 \%$ of the area. An APP modified bitumen membrane system was mechanically fastened directly to a nailed plywood substrate supported by $2 \times 4 \mathrm{ft}$ sleepers and vertical members of varying height. This substrate was retrofitted to the original building deck to add slope. Two main failure modes were observed. Over a large area, the sloping plywood substrate system blew off (along with the membrane). Over other areas, the membrane peeled away from the plywood substrate as a result of tearing of its bottom ply around the mechanical fasteners, many of which remained in place. There was also extensive damage to the edge detail at the windward corner of the roof, which may have initiated the damage. It was not clear if the plywood substrate system had been engineered to withstand the hurricane-force winds in that area.

Three schools with damaged roofs had membranes mechanically fastened to decks comprising cementitious wood fiber (CWF) panels. The panels were generally set in channels created by bar joists and bulb Ts without any apparent securement other than their own weight. In these cases, the membrane-deck systems overhung the walls of the buildings. At all three schools, damage appeared to be initiated by uplifting of the panels at the overhangs, followed by peeling of the membrane from the roof edges. In some cases, this was followed by displacement of some CWF panels in the field of the roof near the overhang.

The mechanically fastened EPDM system on the roof of a two story freezer plant was the most extensively damaged roof observed. The membrane was blown off the entire $60,000 \mathrm{ft}^{2}$ roof. Membrane loss likely initiated on the windward side, as the edge detail was damaged at that location. This proprietary system used a "non-penetrating fastener" that was considered to play a major role in the blowoff. Although fastener screws remained well embedded in the steel deck, either fastener heads failed, allowing the membrane to blow away, or the membrane was torn at the fastener heads, resulting in release of the membrane. In addition, one minor section of steel decking blew out above an area that may have been pressurized from below.

In the case of the ballasted EPDM system, damage was caused by blowoff of a section of wood deck. An open area below that section allowed the underside of the deck in that location to become pressurized. There was also ballast scour from the surface of this EPDM, particularly at some of the vertical flashings.

Cases where damage was directly attributed to faulty workmanship were few. In a couple of places, damage to systems was exacerbated by delamination of the modified bitumen cap sheets from the base plies. In these cases, cap sheet loss was attributed to placement of the cap sheets in asphalt that was too cold. Other observations showed too few fasteners had been installed on some roofs. For example, on one SPF roof that overall survived the hurricane well, a small section (less than $1 \%$ of the roof) blew off. In this case, the SPF system design included wood fiber boards mechanically attached to the steel deck. The SPF was then applied to the wood fiber boards. Fasteners were missing in one section of the damaged area.

Hurricane damage to roofs in the area from Pascagoula to Ocean Springs was associated more with roof assembly or fastening design problems than with membrane material failure. Observations suggested that these problems were generally failures of roof system integrity, e.g., edge details and other forms of securement of roof assembly to building. Included among the undamaged roof systems were modified bitumen, SPF, a mechanically attached single ply, and BUR (both aggregate-surface and smooth-surface). We note that aggregate scour on BUR systems did not appear to be a problem on the roofs examined, regardless of whether they experienced membrane or other damage. Obviously, aggregate was missing from roofs from which BUR membranes blew off. However, 
sections of remaining aggregate-surface BUR membrane next to those that were blown away generally appeared to be well covered with aggregate.

Maps of the area visited by Team 1 are marked with numbers that correspond to the inspection report numbers.

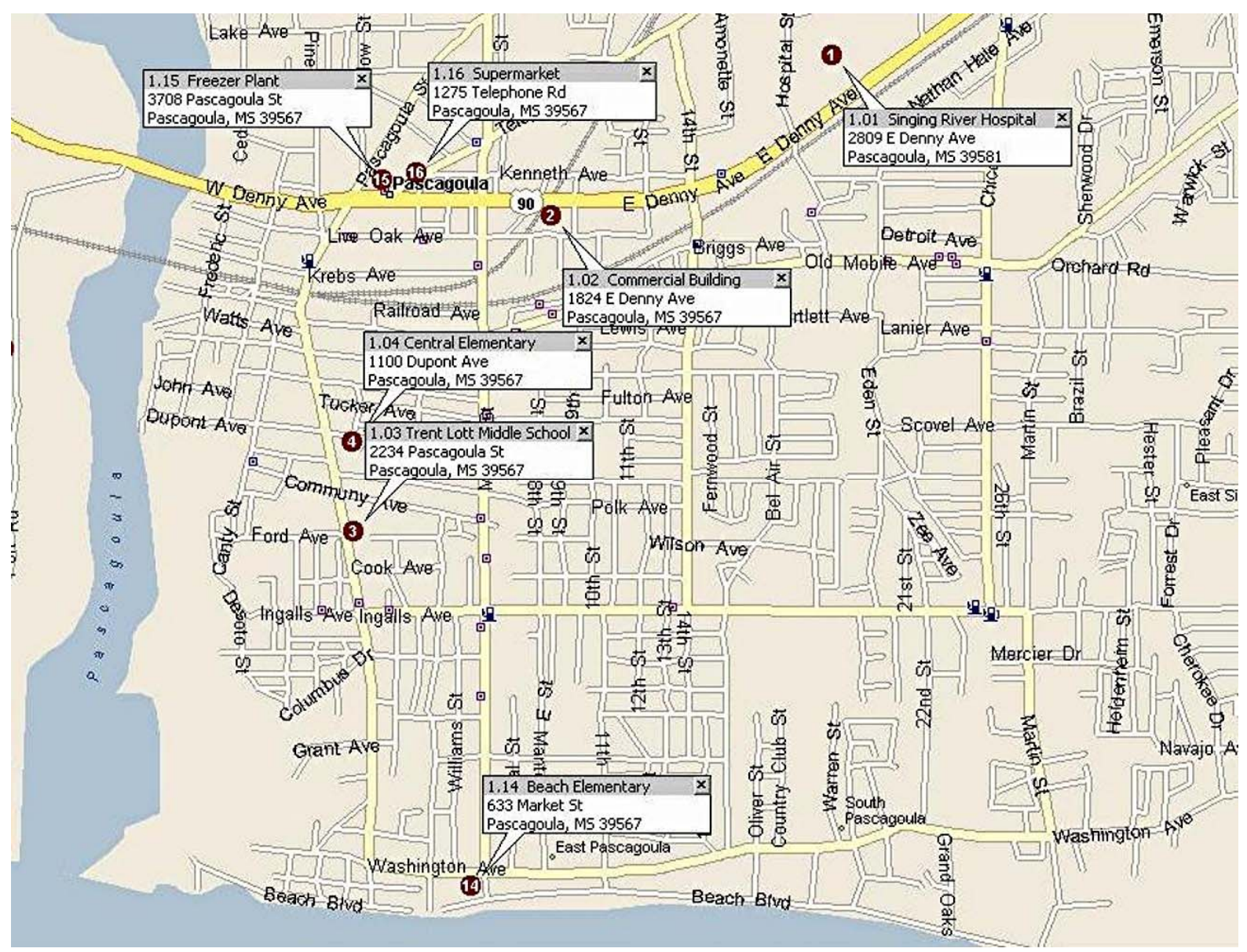

Map 1. Pascagoula area. 


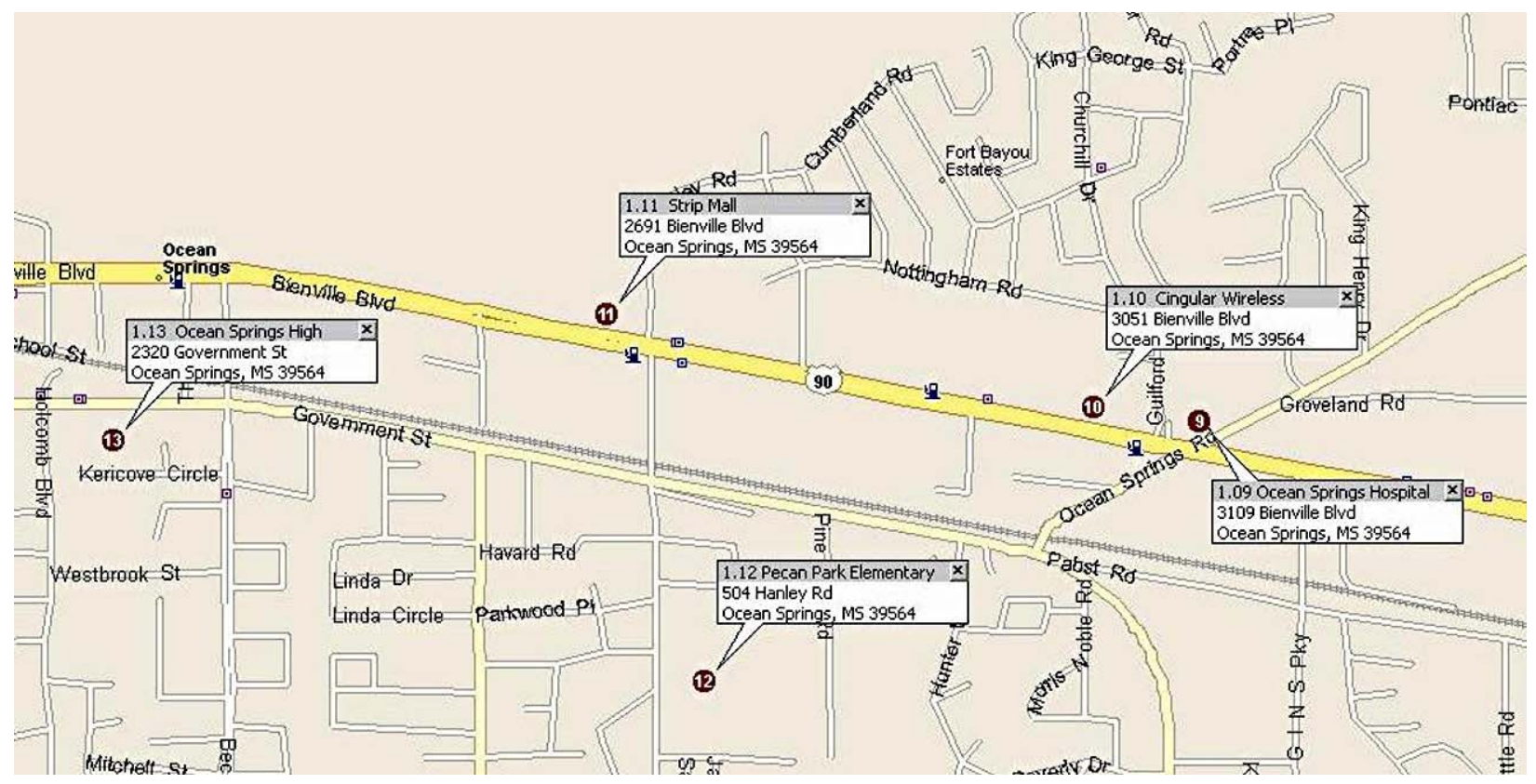

Map 2. Ocean Springs area.

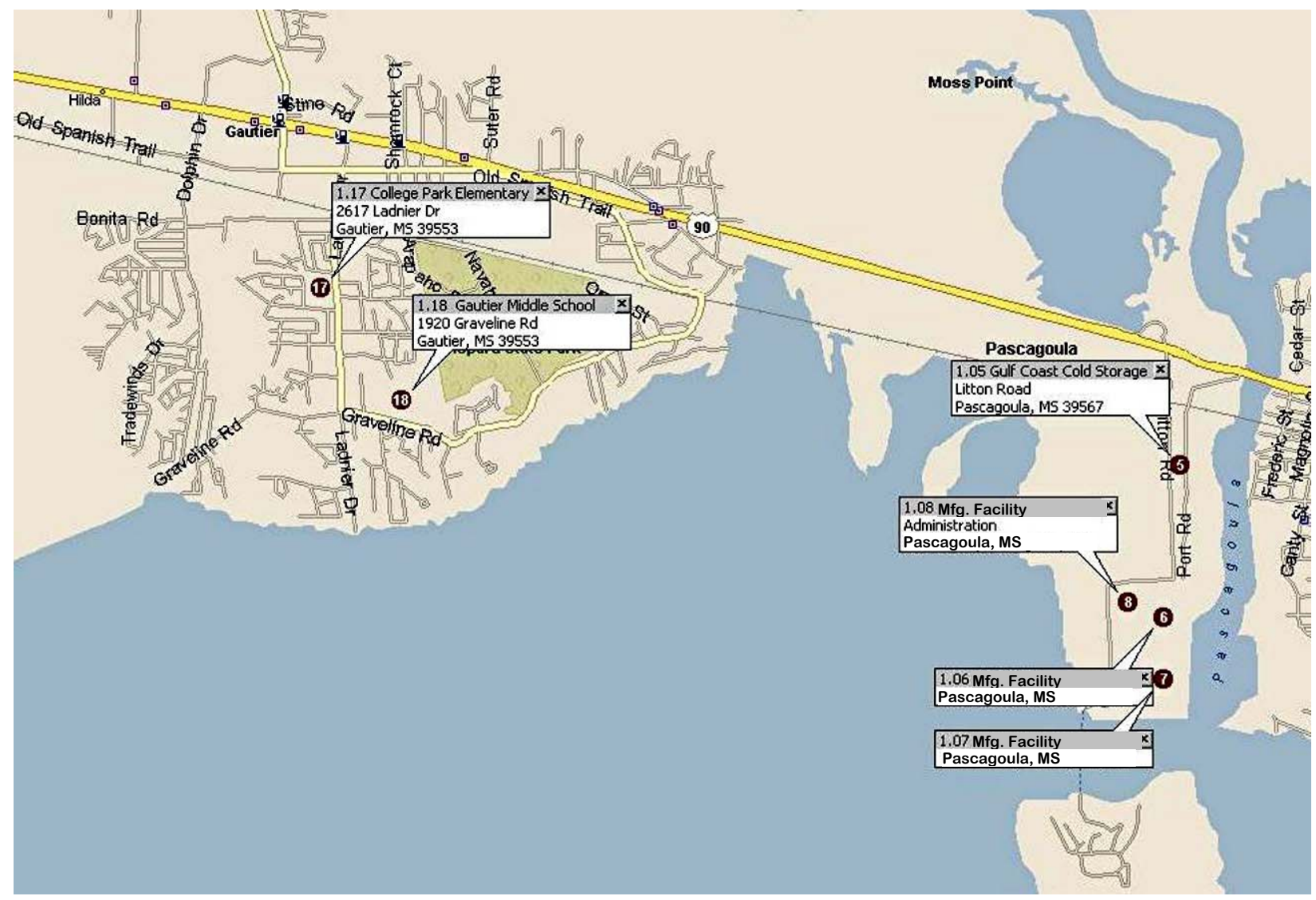

Map 3. Gautier and Pascagoula West area. 


\section{INDIVIDUAL ROOF REPORTS}

\subsection{Singing River Hospital, 2809 Denny Avenue, Pascagoula, MS 38591}

TYPE OF STRUCTURE-Hospital

EXPOSURE - $\mathrm{C}$ on windward side; $\mathrm{B}$ on leeward side

WALL CONSTRUCTION-Masonry with glass curtain wall

ROOF TYPE-APP modified bitumen membrane

SLOPE- $-1 / 4: 12$

ROOF HEIGHT $-40 \mathrm{ft}$

ROOF WIDTH $-150 \mathrm{ft}$

ROOF LENGTH $-150 \mathrm{ft}$

DECK - Cast-in-place concrete

INSULATION - Polyisocyanurate with a top layer of perlite

WIND SPEED—90-100 mph

BUILDING/ROOF CONSTRUCTION-Mineral-surface 3-ply assembly (APP cap ply over 2-ply glass and asphalt base) adhered to a layer of perlite insulation board mopped with hot asphalt to a layer of polyisocyanurate insulation board. Insulation was also mopped to the deck with hot asphalt.

METHOD OF ATTACHMENT-Mopped with hot asphalt (both plies and insulation layers)

NOTED DAMAGE - Sections of roof membrane and insulation were blown off.

DAMAGE INITIATION AND PROPAGATION-Most roof damage occurred on the southeast corner, which was the windward side of the roof. Damage was attributed to inadequate uplift resistance of the membrane-insulation assembly. The edge metal remained intact. An estimated $70 \%$ of the damage occurred because of cohesive failure and separation of the top portion (along with the roof membrane) from the bottom. An estimated $20 \%$ of total damage occurred at the interface of the isocyanurate board and the deck. An estimated $10 \%$ of membrane failure was attributed to a poor bond of the membrane to the perlite insulation board, caused by asphalt that was not hot enough to form good adhesion. In these cases, the membrane peeled from the surface of the perlite board. Similar damage occurred to the membrane at the southwest corner of this roof section. Again, the primary mode was delamination between the membrane and the perlite board. Other damage at the southwest corner involved detachment of isocyanurate board from the deck, isocyanurate board facer delamination, and minor cold asphalt application.

ADDITIONAL COMMENTS-Most of the roofing on this facility withstood storm winds without damage. The damage described here was to the roof of the four story high west front bay of the hospital. The roof membrane on this damaged section was 5 to 10 years old.

Roof damage also occurred to the windward (southeast) corner of the four story high front bay of the building, but this damage had been mostly repaired at the time of the inspection. Roofers described the damage as similar to that noted on the roof of the west (front) bay of the hospital. 


\section{Photographs of Roof DAmage}

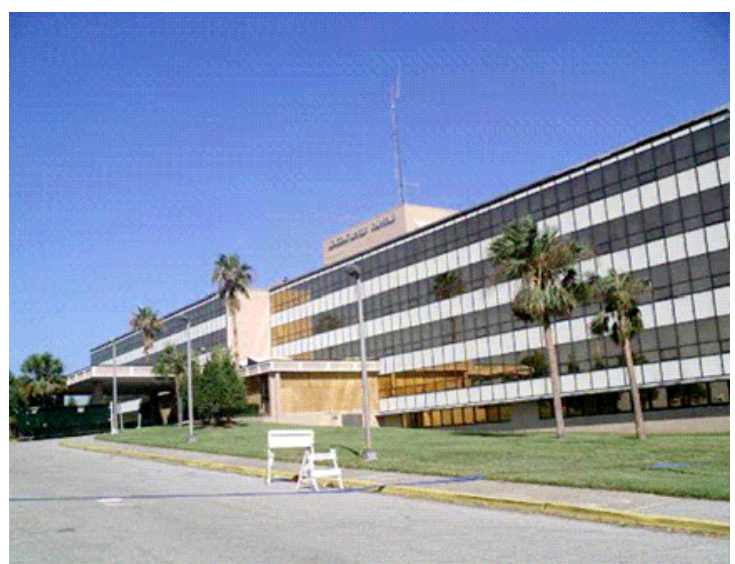

1.01-1. Singing River Hospital. View of the south face.

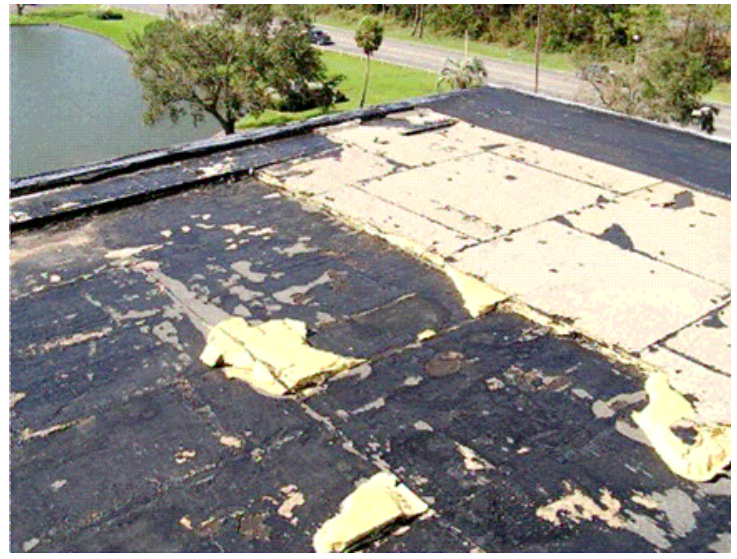

1.01-3. Singing River Hospital. Damaged insulation is all that's left after loss of the APP membrane at this roof corner.

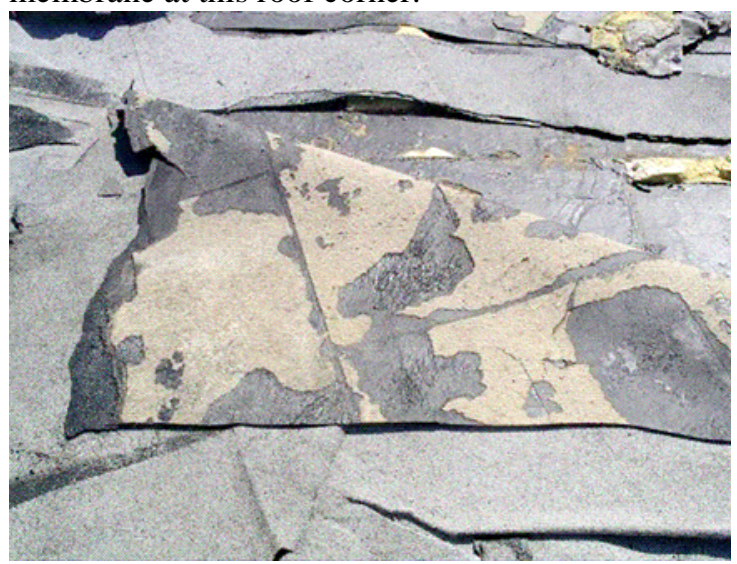

1.01-5. Singing River Hospital. A thin layer of perlite insulation is still adhered to this detached APP membrane.

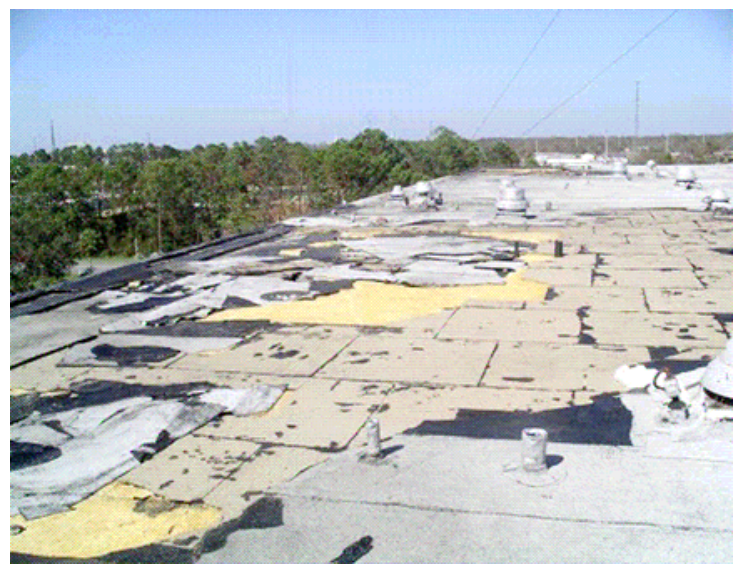

1.01-2. Singing River Hospital. Loss of the APP membrane and some perlite insulation boards is shown here.

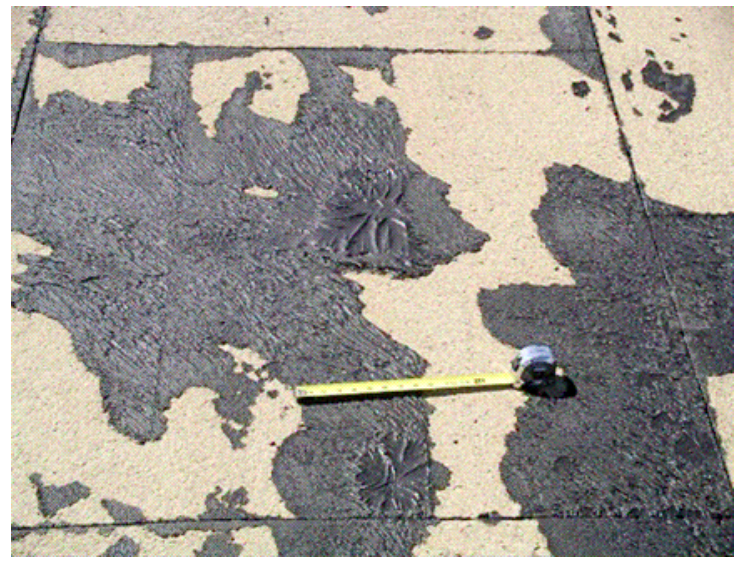

1.01-4. Singing River Hospital. Evidence of cold asphalt application. Note the shiny, wrinkled texture.

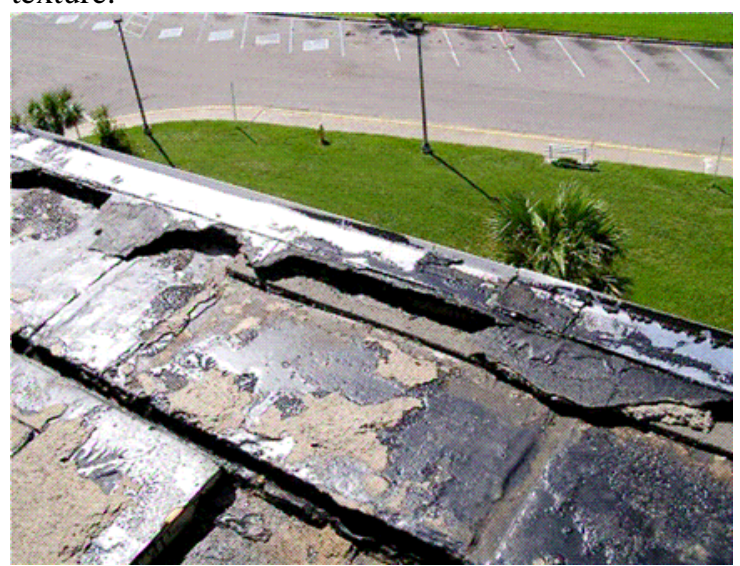

1.01-6. Singing River Hospital. Although the roof membrane blew off, the metal edge remained intact. 


\subsection{Commercial Building, 1824 Denny Avenue, Pascagoula, MS 39567}

TYPE OF STRUCTURE-Commercial marine showroom

EXPOSURE-C

WALL CONSTRUCTION_-Primarily masonry brick or block with a front side of glass in metal frame

ROOF TYPE-APP modified bitumen membrane

SLOPE-1/2-1: 12

ROOF HEIGHT $-15 \mathrm{ft}$

ROOF WIDTH $-100 \mathrm{ft}$

ROOF LENGTH $225 \mathrm{ft}$

DECK - Cast-in-place lightweight concrete (LWC) formed a base for a plywood deck. Plywood sheets were installed (8-12 in. o.c.) over an assembly of $2 \times 4 \mathrm{ft}$ sleepers and framing, mechanically fastened (using ramset anchors) to the concrete. Vertical $2 \times 4 \mathrm{ft}$ members, having progressively longer length to supply slope, were nailed to the sleepers $2 \mathrm{ft}$ apart; $2 \times 4 \mathrm{ft}$ top plates were in turn nailed to these vertical members. Next, $2 \times 8 \mathrm{ft}$ rafters set 16 in. o.c. were nailed perpendicular to the top sleepers. Finally, plywood sheets were nailed every $8-12$ in. to rafters.

INSULATION $\longrightarrow$ Wood fiber non-saturated; $1 \frac{1}{2}$ in.; asphalt adhesive on nailed base ply

WIND SPEED—90-100 mph

BUILDING/ROOF CONSTRUCTION-A felt ply was nailed to the plywood deck and next a $1 \frac{1}{2}$ in. wood fiber insulation was set in hot asphalt. A 3-ply granular-surface APP membrane was adhered to this thin insulation layer.

METHOD OF ATTACHMENT_Mechanically fastened base sheet; adhered assembly

NOTED DAMAGE—-Major sections of membrane, plywood deck, and edge detail were lost.

DAMAGE INITIATION AND PROPAGATION-Approximately $70 \%$ of the total roof area was damaged. Although the cause of roof failure was not determined conclusively, it appeared to be related to weakness in the edge detail or weakness in the plywood deck system, as both were greatly damaged at the windward corner of the building. Four modes of failure were observed:

1. At the windward (southeast) corner, the plywood deck and supporting members failed, beginning at the bottom sleeper plate, which remained secured to the LWC deck. At the nearby roof edge, wood nailers also failed.

2. The membrane lifted up from the plywood deck in places. In locations where this type of failure occurred, felt nailed to the deck generally tore away, leaving fasteners in place.

3. At the center of roof, the APP cap sheet peeled from the underlying plies. There was evidence that the asphalt was too cool to achieve proper adhesion.

4. At random small sections, the bottom membrane failed at its interface with wood fiber insulation.

ADDITIONAL COMMENTS-According to the building owner, this roof experienced considerable damage during Hurricane Georges in 1998. As part of the roof repairs, the plywood deck was installed over the concrete deck to provide slope. 


\section{Photographs of RoOf DAmage}

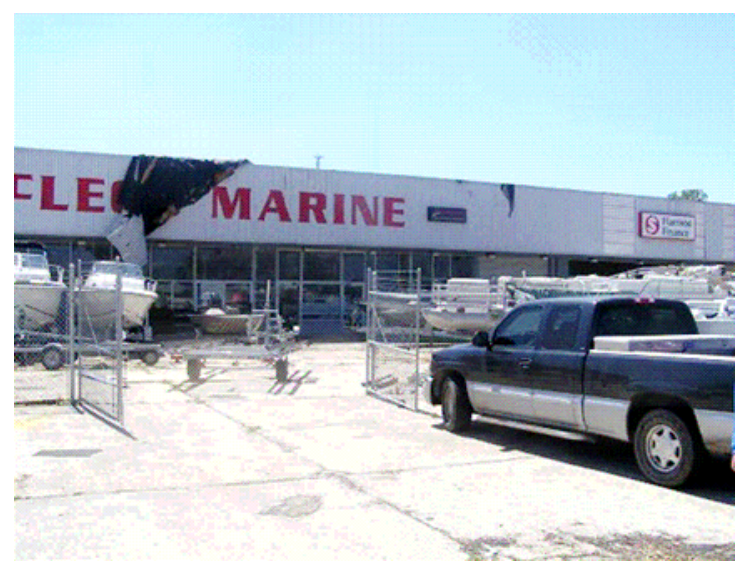

1.02-1. Commercial building. View of the front side of the marine showroom.

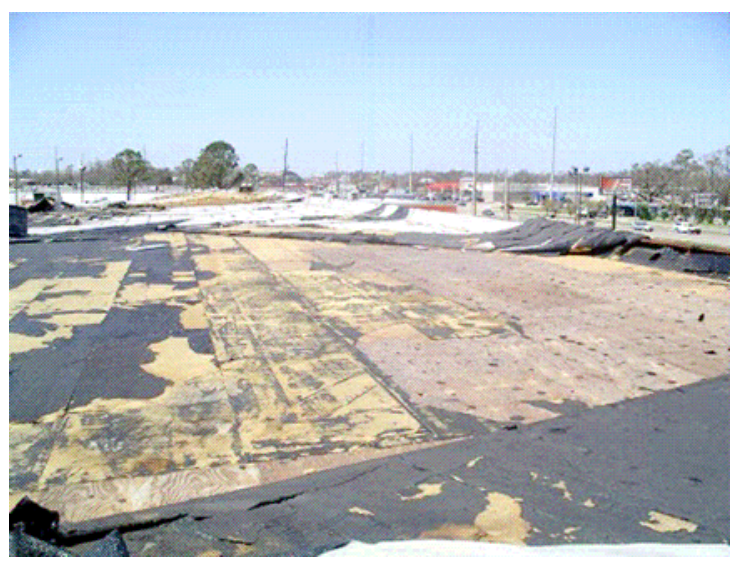

1.02.3. Commercial building. Three types of damage are shown here: tearing of felt nailed to the plywood, cohesive failure of insulation board, and delamination of the membrane.

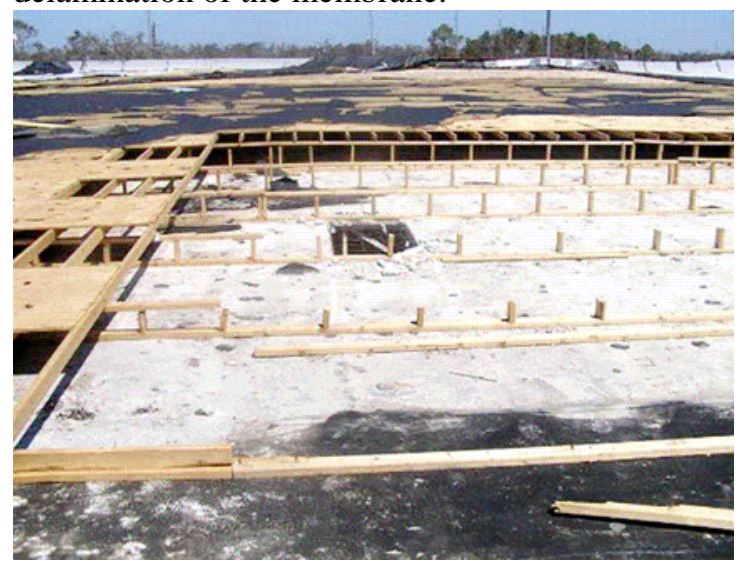

1.02-5. Commercial building. Damaged lightweight concrete decking is visible in this photo.

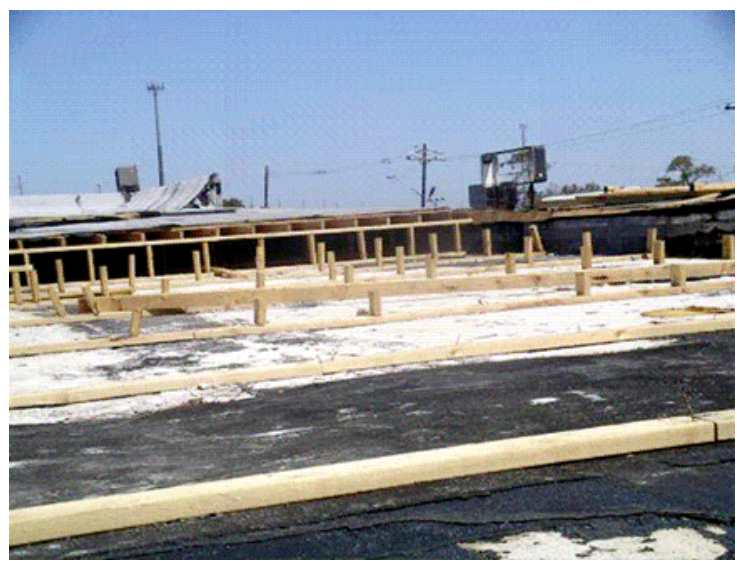

1.02-2. Commercial building. This is what is left of a plywood decking system retrofitted over the original roof to provide more slope.

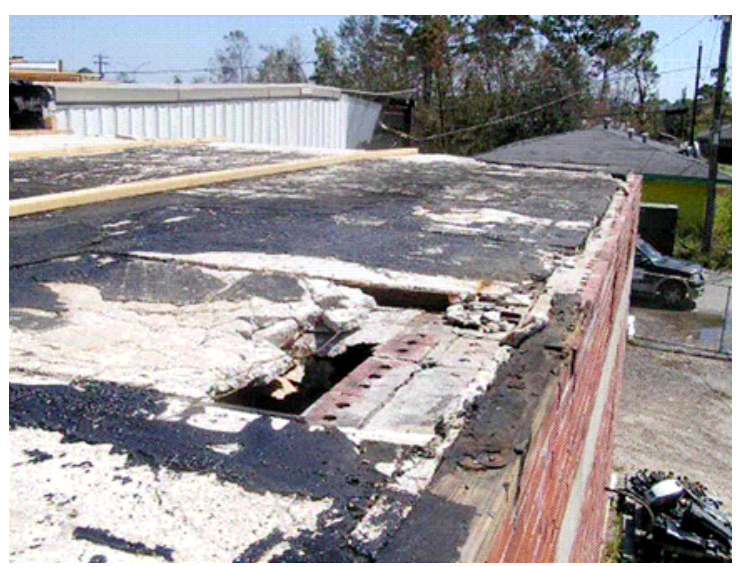

1.02.4. Commercial building. Metal edging and plywood decking were damaged at this windward corner.

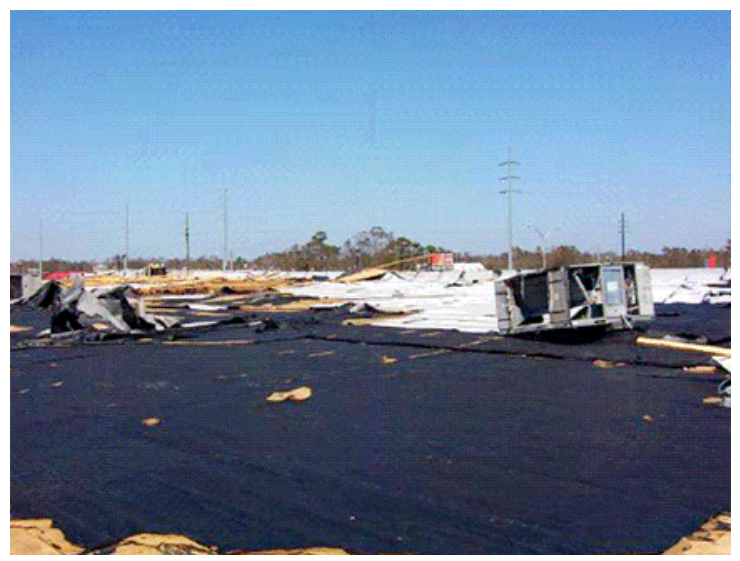

1.02-6. Commercial building. Damage shown here is separation of the plies. 


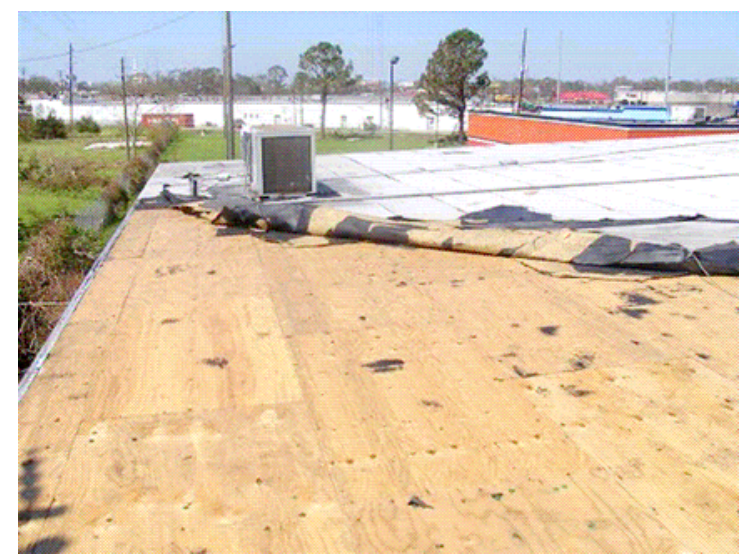

1.02-7. Commercial building. The roof assembly in this area was torn loose from the plywood deck.

\subsection{Trent Lott Middle School, 2234 Pascagoula Street, Pascagoula, MS 39567}

TYPE OF STRUCTURE-School

EXPOSURE-C

WALL CONSTRUCTION-Masonry brick

ROOF TYPE-Two-ply mineral-surface SBS modified bitumen membrane

SLOPE- $-1 / 4: 12$

ROOF HEIGHT $-17 \mathrm{ft}$

ROOF WIDTH $-45 \mathrm{ft}$

ROOF LENGTH $-80 \mathrm{ft}$

DECK-CWF panels

INSULATION - Perlite-1 in. hot-mopped to a ply of kraft paper

WIND SPEED—90-100 mph

BUILDING/ROOF CONSTRUCTION—A single story masonry building. The roof construction consisted of grid work of bar joist and bulb Ts into which were set CWF deck panels without any apparent securement other than their own weight.

METHOD OF ATTACHMENT - Kraft paper was secured to the CWF panels using expandable anchors. Perlite insulation boards 1 in. thick were then mopped to the kraft paper using hot asphalt.

NOTED DAMAGE-Membrane, insulation, and deck were displaced.

DAMAGE INITIATION AND PROPAGATION—CWF deck panels became detached from the windward southeast corner of the damaged building section. No secure attachment of deck panels was observed at a roof overhang in this area. Many of the CWF panels in the vicinity of the corner area were displaced, landing downwind. Puddle welds of the secondary supports (bulb Ts) to the bar joists were rusted, and many of the bulb Ts were dislodged. A section of SBS membrane and perlite insulation peeled from some CWF panels. This peeling occurred at the panel interface with the kraft paper. It was not determined whether this section of membrane-insulation assembly was displaced before or at the time of displacement of the CWF panels. 
ADDITIONAL COMMENTS-This building was constructed in the 1950s but was re-roofed in the early 2000s. The vast majority of the roof area (about 95\%) was not damaged by the hurricane.

A two-piece metal edge detail may also have played a role in the blowoff of the roof section, as its fascia was not well secured to the wall. First, a bottom fascia strip was nailed along the wall to a $2 \times$ $8 \mathrm{ft}$ wood nailer, which was also installed along the side of the wall. The second metal edge assembly consisted of a coping and fascia section that was secured to the coping with its fascia section. It was secured along the coping with its fascia section clipped to the bottom fascia strip, which was nailed to the $2 \times 8 \mathrm{ft}$ nailer.

\section{Photographs of Roof Damage}

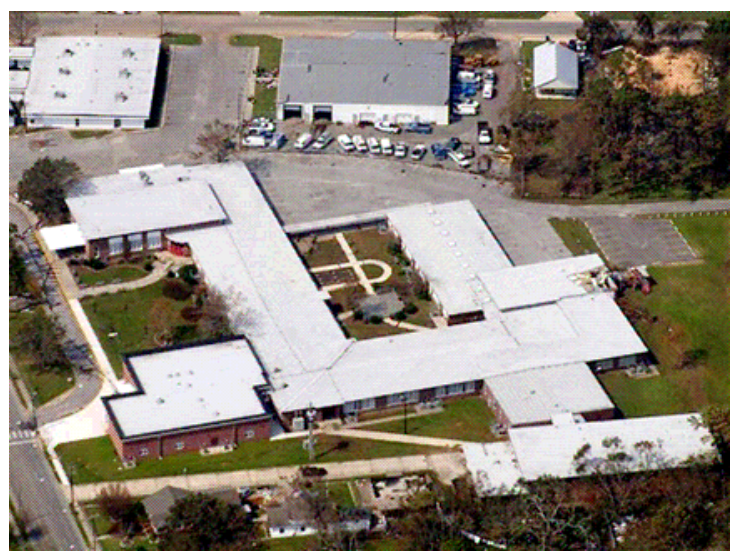

1.03-1. Trent Lott Middle School. Aerial view of Trent Lott Middle School.

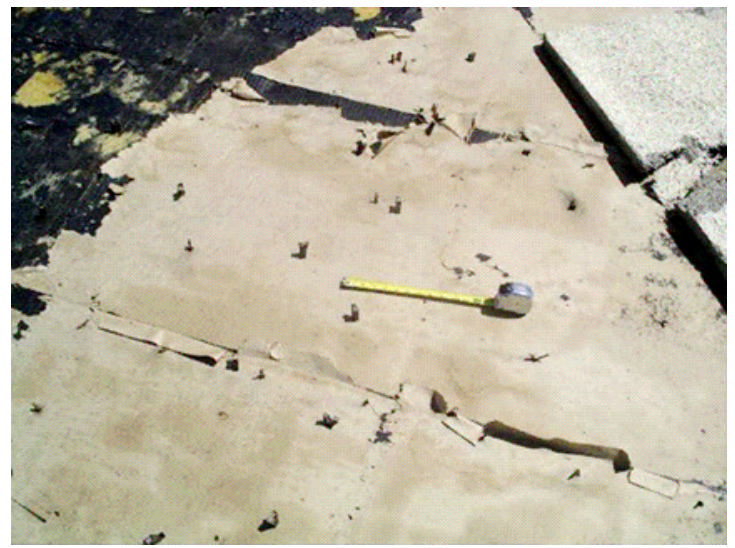

1.03-3. Trent Lott Middle School. Underside of the membrane-insulation assembly that peeled from the deck.

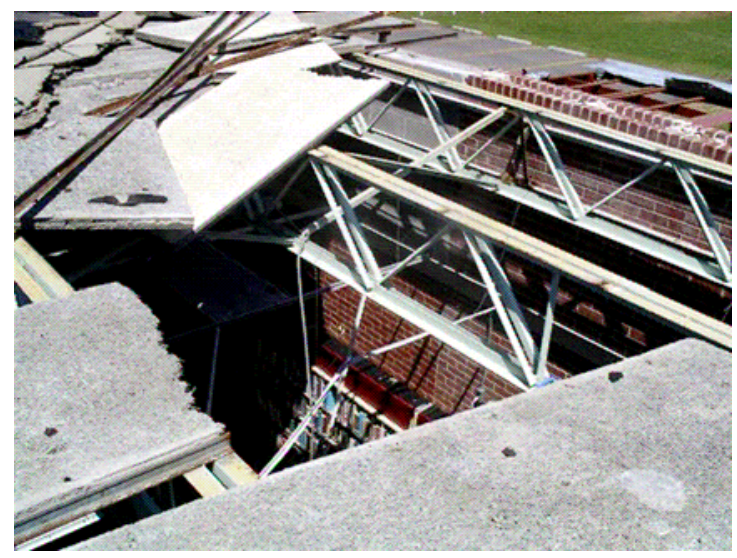

1.03-2. Trent Lott Middle School. CWF deck panels and bulb Ts were displaced because they were not anchored to the joists.

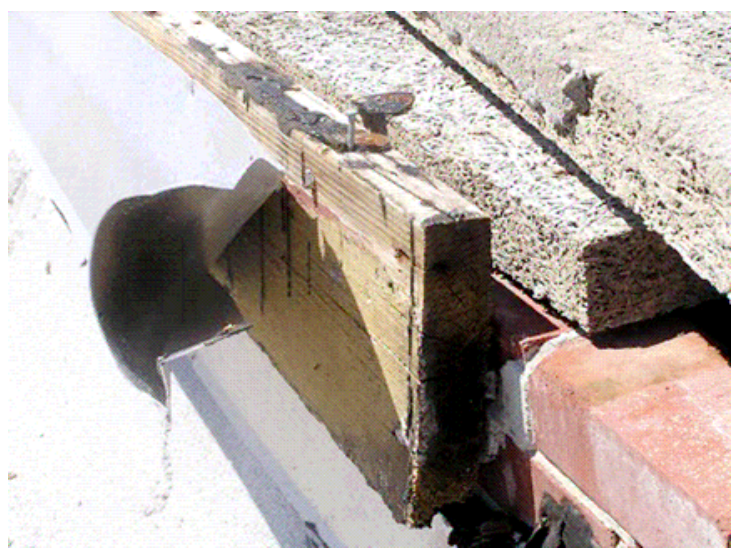

1.03-4. Trent Lott Middle School. Damaged edge flashing. 


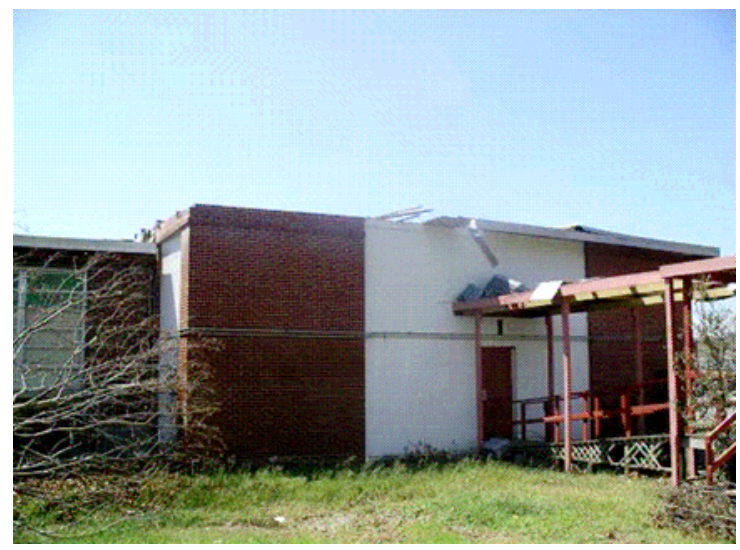

1.03-5. Trent Lott Middle School. The wall area at the damaged roof section showed no evidence of flashing attachment.

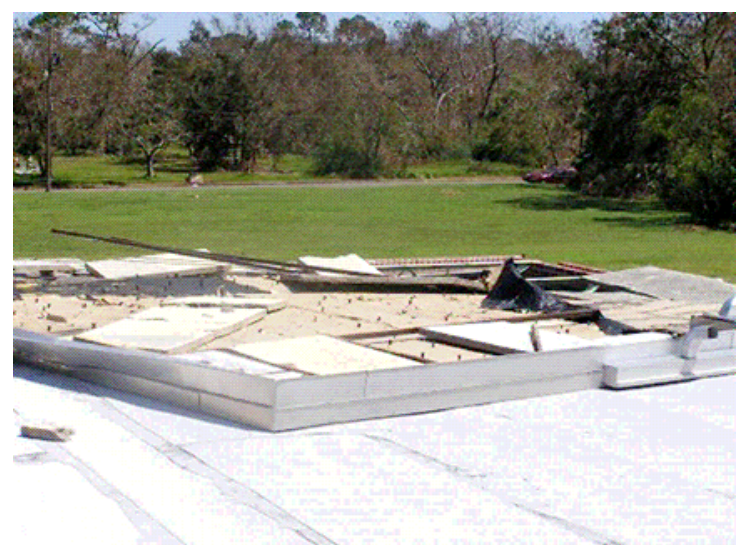

1.03-6. Trent Lott Middle School. Overall view of the damaged roof section.

\subsection{Central Elementary School, 1100 DuPont Avenue, Pascagoula, MS}

TYPE OF STRUCTURE-School

EXPOSURE-B

WALL CONSTRUCTION-Brick

ROOF TYPE-SBS modified bitumen membrane

SLOPE-1/4-1/2: 12

ROOF HEIGHT $-12-15 \mathrm{ft}$

ROOF WIDTH - Not estimated

ROOF LENGTH—Not estimated

DECK-Concrete plank

INSULATION—Unknown

WIND SPEED—90-100 mph

BUILDING/ROOF CONSTRUCTION—A single story masonry building with several wings

METHOD OF ATTACHMENT_Unknown

NOTED DAMAGE-None

DAMAGE INITIATION AND PROPAGATION—Not applicable

ADDITIONAL COMMENTS - This building had no apparent damage. It was located near another school that did experience damage. 


\section{Photographs of Undamaged Roof}

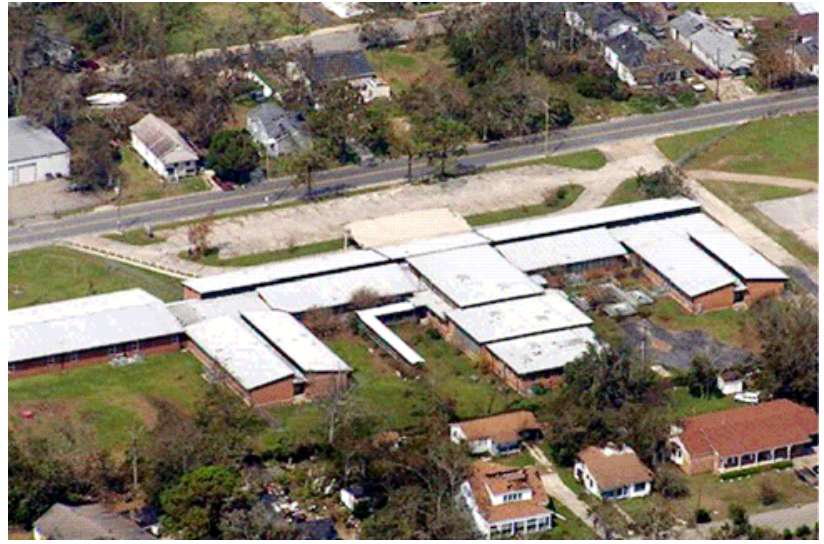

1.04-1. Central Elementary School. Aerial view shows an undamaged SBS membrane system.

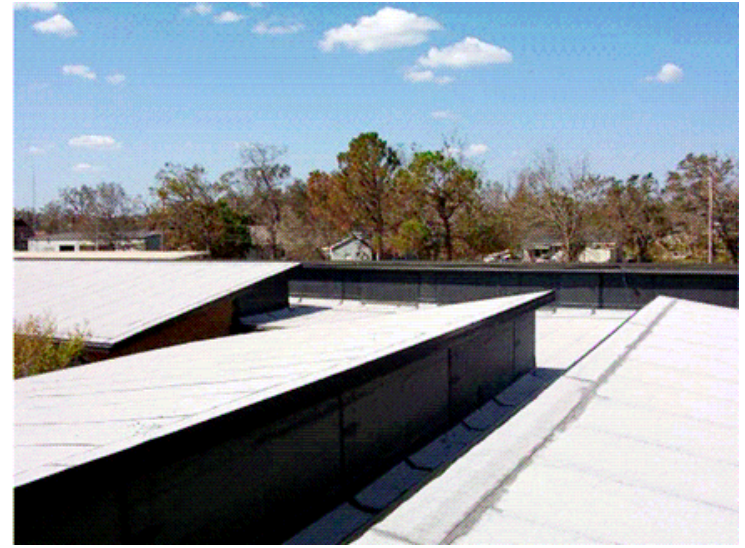

1.04-2. Central Elementary School. This photo shows a closer view of the undamaged SBS membrane system.

\subsection{Commercial Building, Litton Street, Pascagoula, MS}

TYPE OF STRUCTURE-Freezer plant

EXPOSURE-C

WALL CONSTRUCTION-Insulated metal panels

ROOF TYPE—EPDM single ply membrane

SLOPE $-0-1 / 4: 12$

ROOF HEIGHT $-30 \mathrm{ft}$

ROOF WIDTH $-250 \mathrm{ft}$

ROOF LENGTH $\longrightarrow 250 \mathrm{ft}$

DECK-Steel

WIND SPEED-90-100 mph

BUILDING/ROOF CONSTRUCTION-From the top down: EPDM single ply membrane mechanically fastened over a polyethylene vapor retarder, which was set on top of multi-layered insulation and held in place by a non-penetrating mechanical fastener system. Insulation layers consisted of $1 / 2$ in. wood fiber board, two staggered layers of 4 in. extruded polystyrene board, and a bottom layer of $1 / 2$ in. wood fiber board. EPDM membrane was held secure over the vapor retarder after the top sections of the non-penetrating fasteners were put in place. Pressure-equalization vents were installed at the roof corners.

METHOD OF ATTACHMENT-Non-membrane-penetrating (NMP) mechanical attachment (i.e., the 9 in. thick insulation layer was through-fastened to the deck).

NOTED DAMAGE-Approximately $80 \%$ of the EPDM membrane was blown off the roof; damage to the insulation was mostly minor. A section of decking, with attached insulation, was also blown off.

DAMAGE INITIATION AND PROPAGATION-It was not determined whether damage was initiated with failed edge flashings along the southeast edge of the building or with ripping of the 
membrane around fasteners. Nevertheless, the result was loss of most of the membrane of this $60,000 \mathrm{ft}^{2}$ roof area as a result of tearing and shredding. In many cases, the upper sections of the NMP fasteners pulled loose, whereas in other areas the membrane ripped around fasteners that remained in place.

At the southeast edge of the building, approximately $1200 \mathrm{ft}^{2}$ of the roof deck was blown off, whereas the membrane remained intact. This damage was attributed to pressurization below the roof deck. Loss of decking occurred when screw attachment to the structural members failed, either from screws pulling out or from the steel deck ripping away from the screws (which were still attached to the structural members). It was estimated that as many screws were still attached to the structural members as were pulled from them. Pressurization was also blamed for blow-out of the entire northwest wall.

ADDITIONAL COMMENTS - The building had the same type of EPDM roof system at two different elevations. The damage described was for the upper section. The lower section experienced similar damage but had already been replaced. Both levels had been reroofed with this type of EPDM system about one year before Hurricane Katrina.

\section{Photographs of Roof Damage}

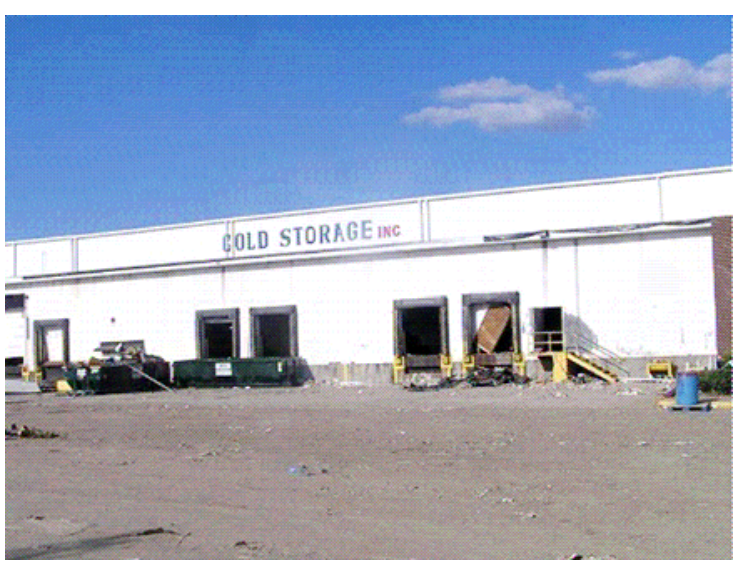

1.05.1. Commercial building. Front view of the commercial freezer plant.

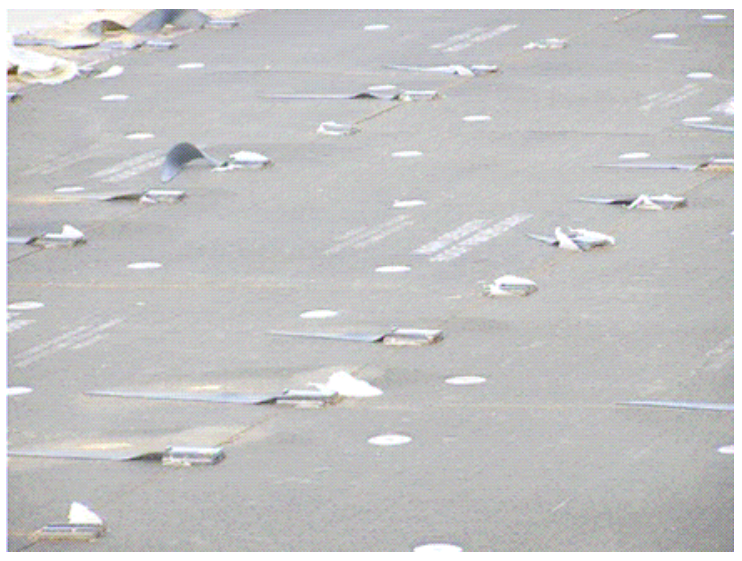

1.05-3. Commercial building. Only small, shredded strips of damaged membrane remain from where blowoff occurred. The EPDM either tore around fasteners or pulled the top sections of the fasteners loose.

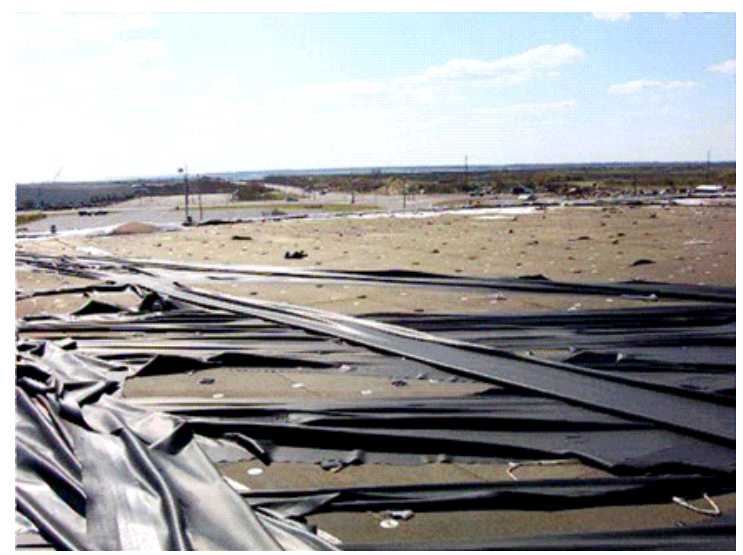

1.05-2. Commercial building. Overview of the roof damage.

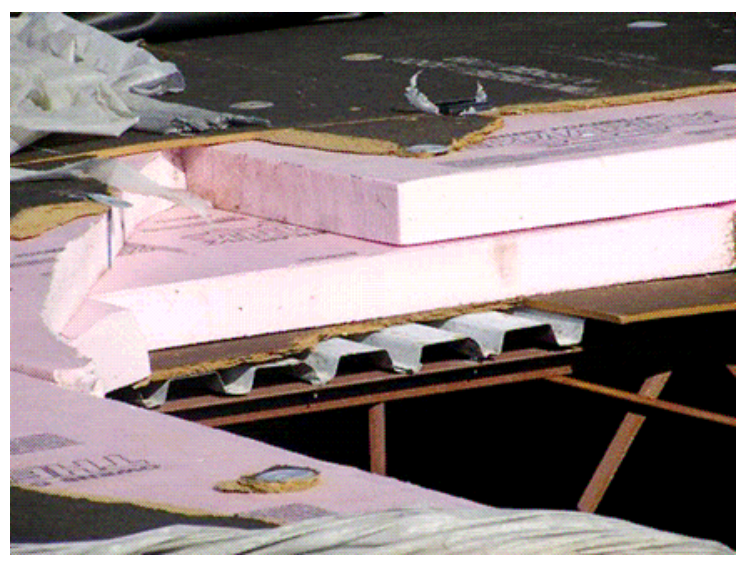

1.05-4. Commercial building. Exposed insulation is visible in this photo showing where decking was blown off. 


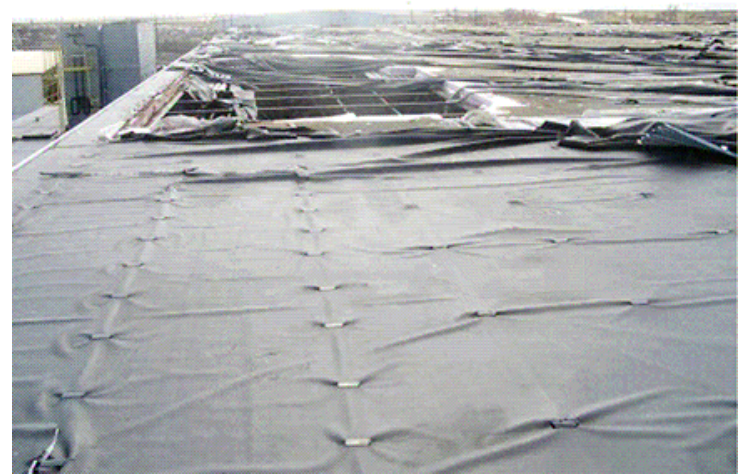

1.05-5. Commercial building. Section of undamaged membrane (with non-penetrating fasteners in place) next to a section of blown-off decking.

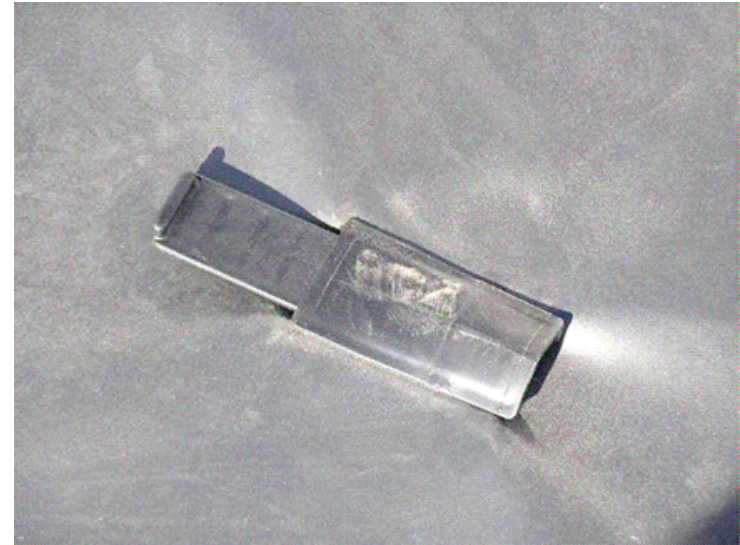

1.05-6. Commercial building. Top view of a nonpenetrating fastener.

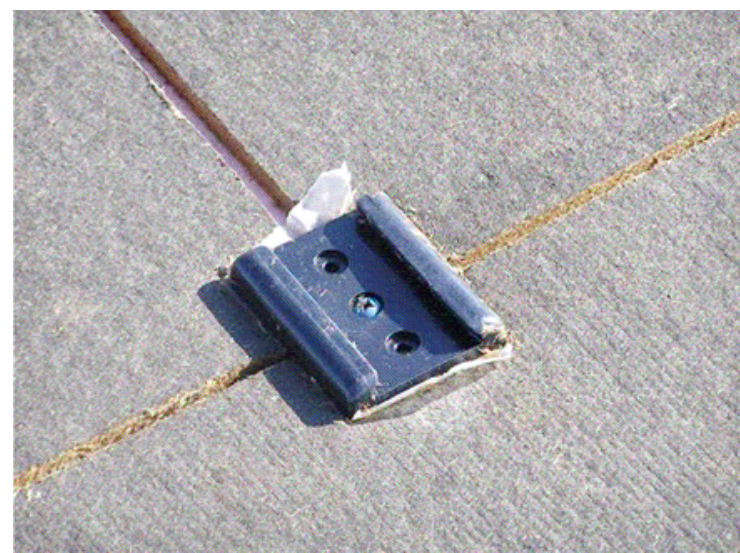

1.05-7. Commercial Building. Bottom piece of a damaged non-penetrating fastener secured to the steel deck.

\subsection{6(a) Commercial Building 1, Port Street, Pascagoula, MS}

TYPE OF STRUCTURE-Commercial building (computer facility)

EXPOSURE-C

WALL CONSTRUCTION-Metal panel

ROOF TYPE—SPF with polyurethane coating

SLOPE—0-1/4: 12

ROOF HEIGHT $-15-18 \mathrm{ft}$

ROOF WIDTH-120 ft

ROOF LENGTH $-150 \mathrm{ft}$

DECK-Steel

INSULATION $\rightarrow$ SPF 
WIND SPEED—90-100 mph

BUILDING/ROOF CONSTRUCTION-This was a typical metal building. The SPF was applied directly onto the metal deck and then coated with aromatic polyurethane.

METHOD OF ATTACHMENT_Adhered (sprayed-in-place onto the metal deck)

NOTED DAMAGE-None

DAMAGE INITIATION AND PROPAGATION—Not applicable

ADDITIONAL COMMENTS—The SPF was the original roof covering, circa 1980-1985. The SPF was recoated once around 1990. The roof had been well maintained.

The building was apparently pressurized, as evidenced by a blow-out of a section of the east wall.

\section{Photographs of Undamaged Roof}

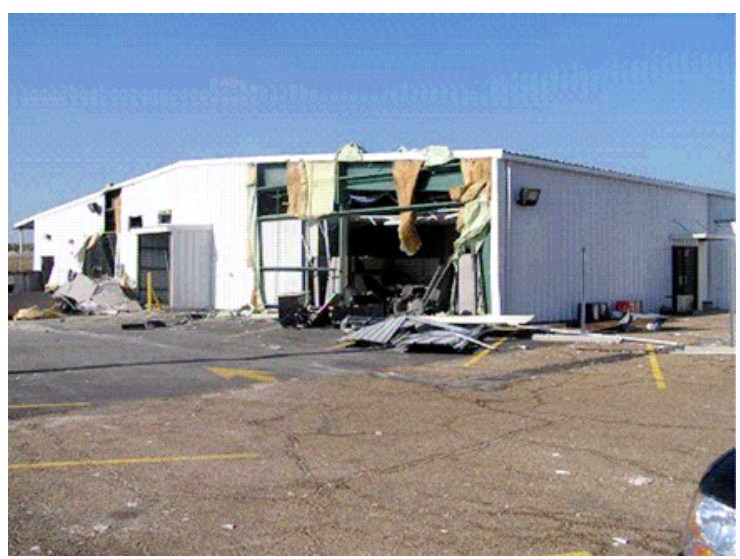

1.06(a)-1. Commercial building. Blown-out east wall of this commercial computer facility.

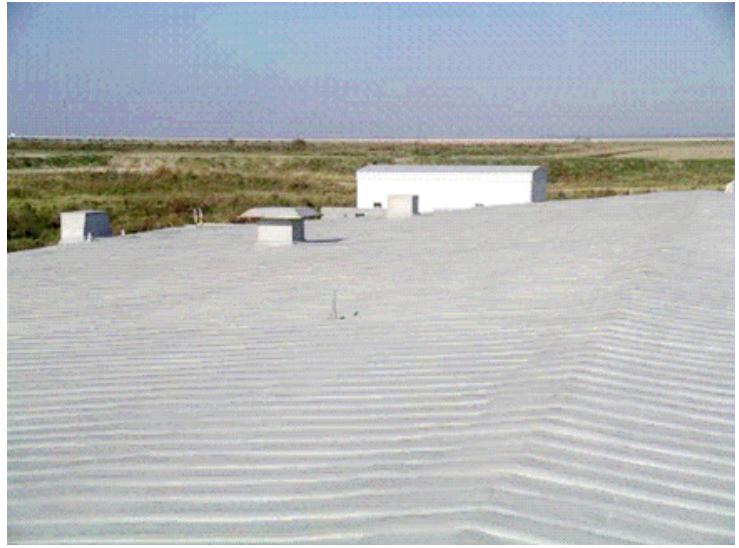

1.06(a)-2. Commercial building. View of the undamaged SPF roof, which had been well maintained.

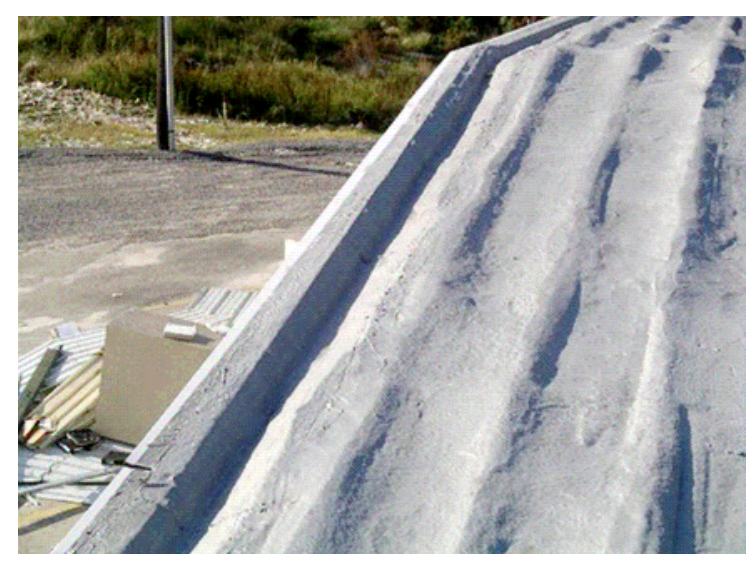

1.06(a)-3. Commercial building. Edge detail of the undamaged SPF roof.

1.06(b) Commercial Building 2, Port Street, Pascagoula, MS

TYPE OF STRUCTURE—Commercial building (computer facility)

EXPOSURE-C 
WALL CONSTRUCTION-Metal panel

ROOF TYPE—SPF with polyurethane coating

SLOPE-0-1/4: 12

ROOF HEIGHT $-15 \mathrm{ft}$

ROOF WIDTH-120 ft

ROOF LENGTH $-150 \mathrm{ft}$

DECK-Steel

INSULATION $\rightarrow$ SPF

WIND SPEED—90-100 mph

BUILDING/ROOF CONSTRUCTION-Typical metal building construction. The SPF was applied directly on the metal deck and then coated with liquid polyurethane.

METHOD OF ATTACHMENT — Sprayed-in-place on the metal deck

NOTED DAMAGE-None, other than deterioration and blistering not associated with Hurricane Katrina

DAMAGE INITIATION AND PROPAGATION—None

ADDITIONAL COMMENTS-The spray foam on this roof was the original installation, over 20 years ago. Little roof maintenance had been performed over the years, as evidenced from its deteriorated condition, which included large interlaminar blisters and sections of delaminated coating.

\section{Photograph of Undamaged RoOF}

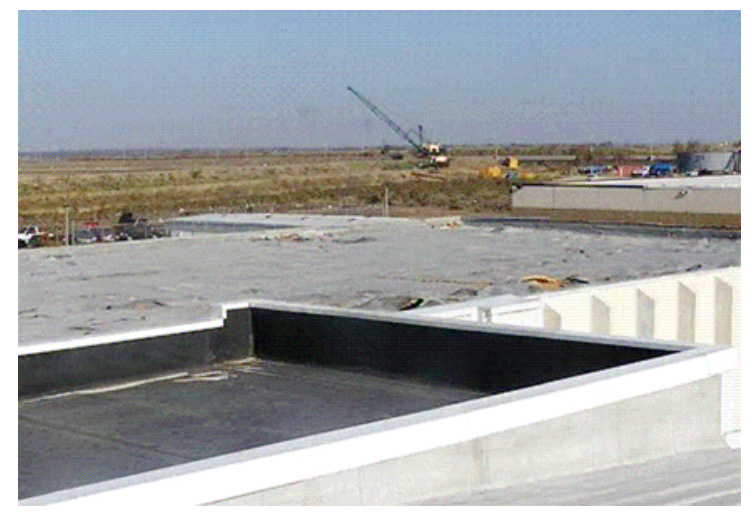

1.06(b).1. Commercial building. View of the undamaged, but poorly maintained, SPF roof covering.

\subsection{Commercial Building 3, Port Street, Pascagoula, MS}

TYPE OF STRUCTURE_Commercial administration building

EXPOSURE-C

WALL CONSTRUCTION-Metal

ROOF TYPE-SPF

SLOPE-0-1/4:12 
ROOF HEIGHT $-30 \mathrm{ft}$

ROOF WIDTH-160 ft

ROOF LENGTH $325 \mathrm{ft}$

DECK-Steel

INSULATION $\rightarrow$ SPF

WIND SPEED-90-100 mph

BUILDING/ROOF CONSTRUCTION-Most areas had SPF applied directly to mesh stretched over the metal deck. One section had wood fiber insulation and was covered with a base ply and $1 \mathrm{in}$. thick wood fiber insulation board mechanically fastened to the deck. SPF was spray applied in three lifts of $1 / 2$ in., $3 / 4$ in., and $3 / 4$ in. onto the wood fiber insulation.

\section{METHOD OF ATTACHMENT-Adhered}

NOTED DAMAGE - The vast majority of this SPF roof was undamaged by Hurricane Katrina. A $30 \times 12 \mathrm{ft}$ area of fiber board and SPF (less than $1 \%$ of the total roof area) was delaminated from the deck. About half of the base ply was in place. The mechanical fasteners also remained in place.

DAMAGE INITIATION AND PROPAGATION-The base ply, wood fiber insulation, and SPF detached from the deck, leaving fasteners in place. Insulation boards tore around the fasteners. About $10 \%$ of the damaged area at the east end had no fasteners. No evidence was observed to indicate that fasteners had been installed at that location.

ADDITIONAL COMMENTS - This SPF roof was more than 20 years old, and some sections had been poorly maintained. In those sections, the roof showed evidence of SPF sprayed over moisture and exhibited blistering and UV degradation. Hurricane-induced damage was not observed in those areas.

\section{Photographs of RoOf Damage}

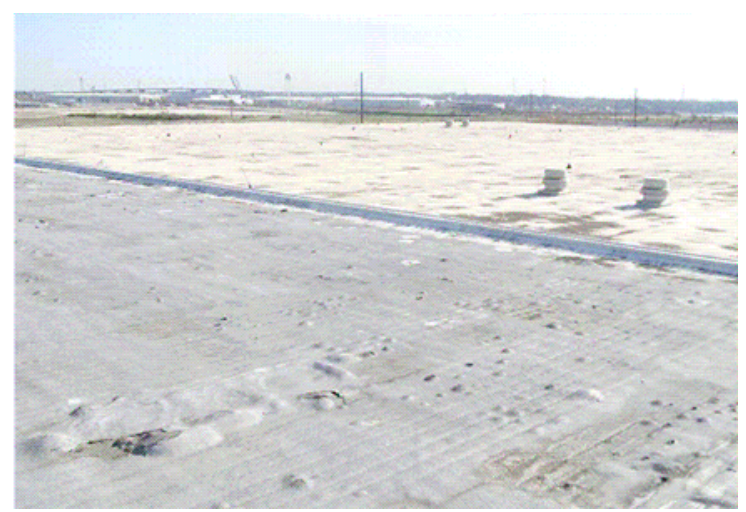

1.07-1. Commercial building. Well maintained SPF (background) and poorly maintained SPF (foreground) roofing on the administration building.

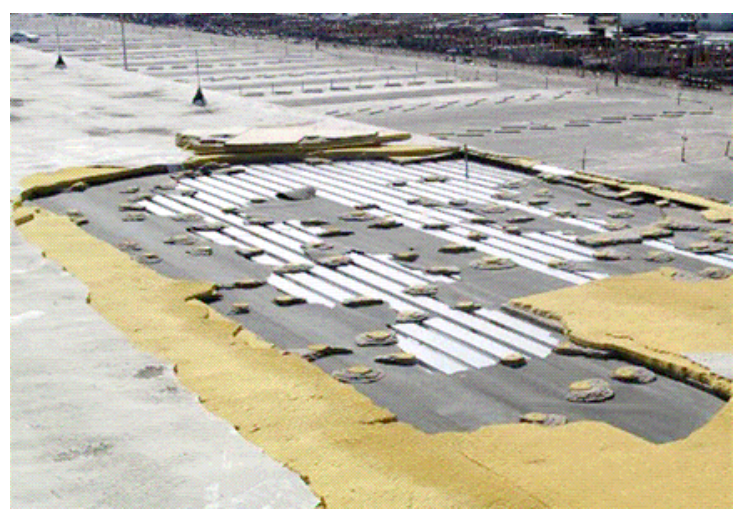

1.07-2. Commercial building. Damaged section where SPF had been applied over mechanically attached wood fiber board. No fasteners were installed in the far corner of the damaged area. 


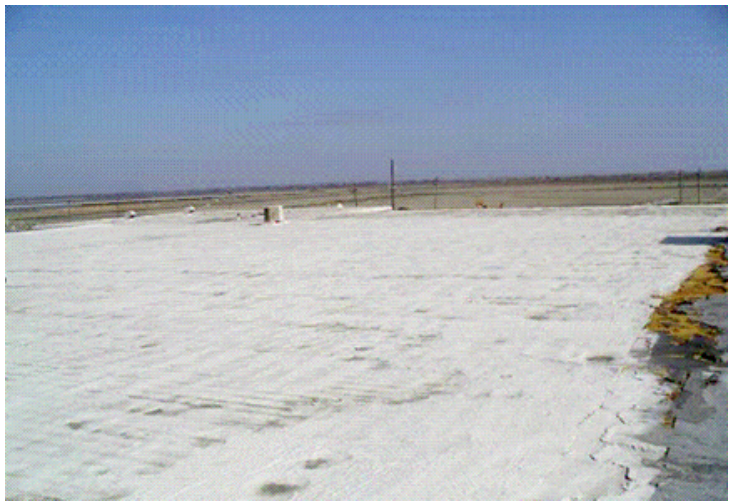

1.07-3. Commercial building. An area of well maintained SPF roof lies next to a section that was poorly maintained. However, the poorly maintained areas were not damaged by Katrina.

\subsection{Commercial Building 4, Port Street, Pascagoula, MS}

TYPE OF STRUCTURE—Commercial building (engineering facility)

EXPOSURE-C

WALL CONSTRUCTION-Metal and glass curtain wall

ROOF TYPE—BUR membrane (BUR smooth-surface with a roof coating)

SLOPE-1/4-1/2: 12

ROOF HEIGHT $-30 \mathrm{ft}$

ROOF WIDTH $-250 \mathrm{ft}$

ROOF LENGTH $-300 \mathrm{ft}$

DECK - Cast-in-place gypsum

INSULATION—Unknown

WIND SPEED-90-100 mph

BUILDING/ROOF CONSTRUCTION-Unknown

METHOD OF ATTACHMENT_-Not determined

NOTED DAMAGE - At a few locations along the outside of the perimeter flashing, metal strips covering joints between fascia sections were bent upward.

DAMAGE INITIATION AND PROPAGATION—See noted damage

ADDITIONAL COMMENTS—None 


\section{Photographs OF Undamaged RoOF}

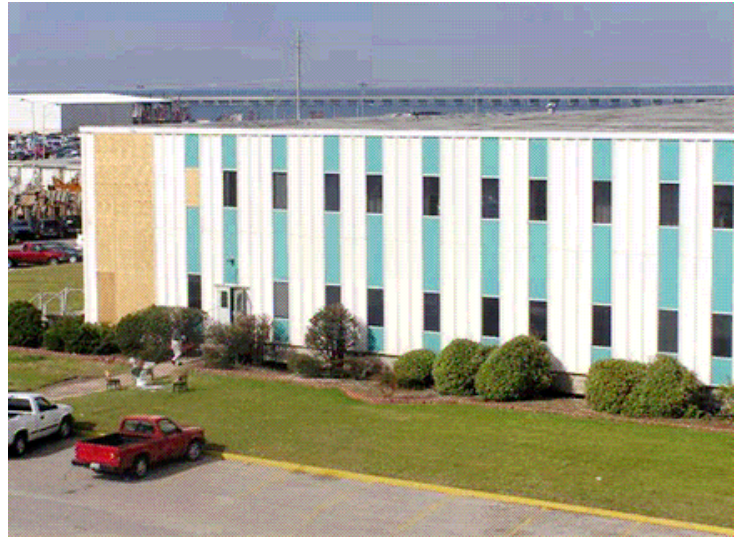

1.08-1. Commercial building. East wall of building.

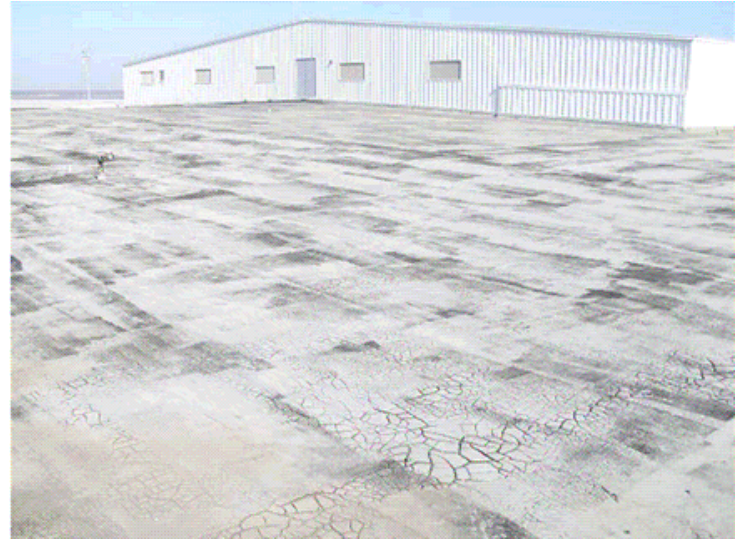

1.08-2. Commercial building. View of the undamaged BUR membrane with coating.

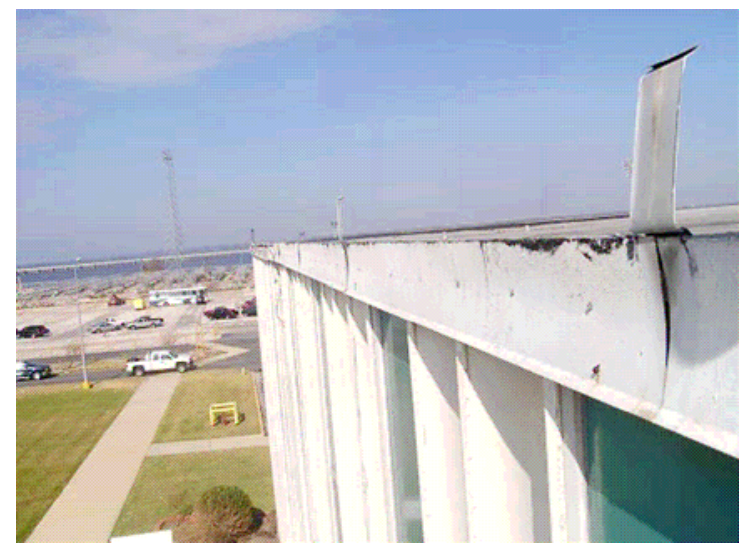

1.08-3. Commercial building. Bent cover strips at joints between sections of metal fascia.

1.09(a) Ocean Springs Hospital, 3109 Bienville Blvd., Ocean Springs, MS 39564

TYPE OF STRUCTURE-Hospital (front lower roof)

EXPOSURE-B

WALL CONSTRUCTION-Masonry and glass windows

ROOF TYPE_BUR membrane, aggregate-surface

SLOPE- $-1 / 4: 12$

ROOF HEIGHT $-20 \mathrm{ft}$

ROOF WIDTH $-130 \mathrm{ft}$

ROOF LENGTH $-380 \mathrm{ft}$

DECK-Unknown

INSULATION-Unknown

WIND SPEED-110-120 mph 


\section{BUILDING/ROOF CONSTRUCTION—Not determined}

METHOD OF ATTACHMENT—Not determined

NOTED DAMAGE-None

DAMAGE INITIATION AND PROPAGATION—Not applicable

ADDITIONAL COMMENTS-No Katrina storm damage was observed on this roof section. The aggregate-surface BUR was judged to be in very good condition with very good edge details. The gravel guard was well secured in a reglet on top of a curbed concrete-panel fascia. A 2 in. thick nailer was secured to the inside face of the curb. A cleat nailer was fastened to this nailer for securement of counter-flashing.

An adjacent section of roofing with a mineral-surface SBS membrane was also undamaged.

\section{Photographs of Damaged and Undamaged Roofs}

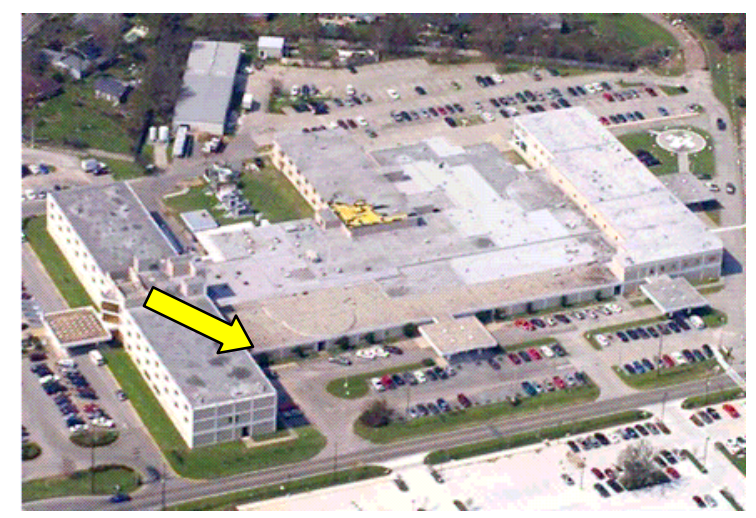

1.09(a)-1. Ocean Springs Hospital. Aerial view.

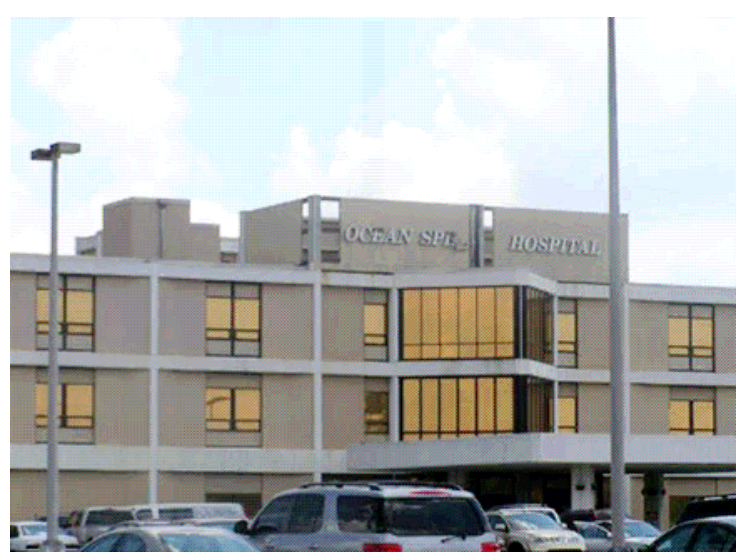

1.09(a)-2. Ocean Springs Hospital (front side). The screen at the top of this building (surrounding rooftop mechanical equipment) was damaged.

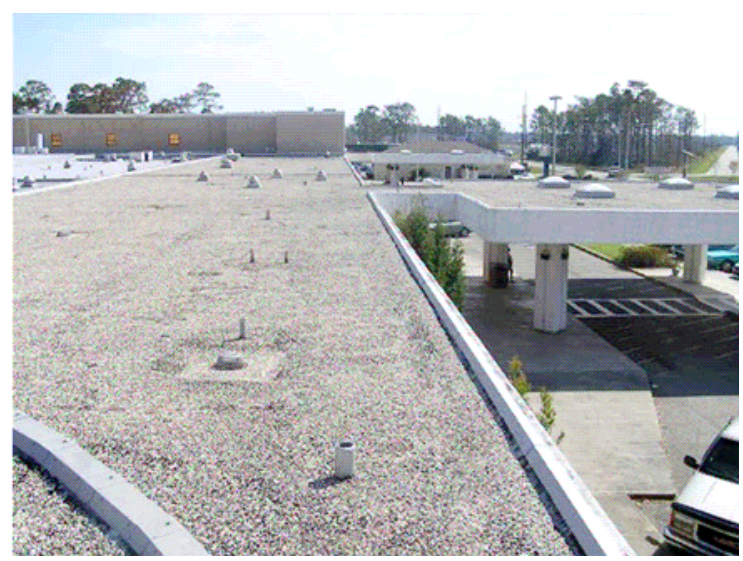

1.09(a)-3. Ocean Springs Hospital. Overview of the undamaged aggregate-surface BUR. 


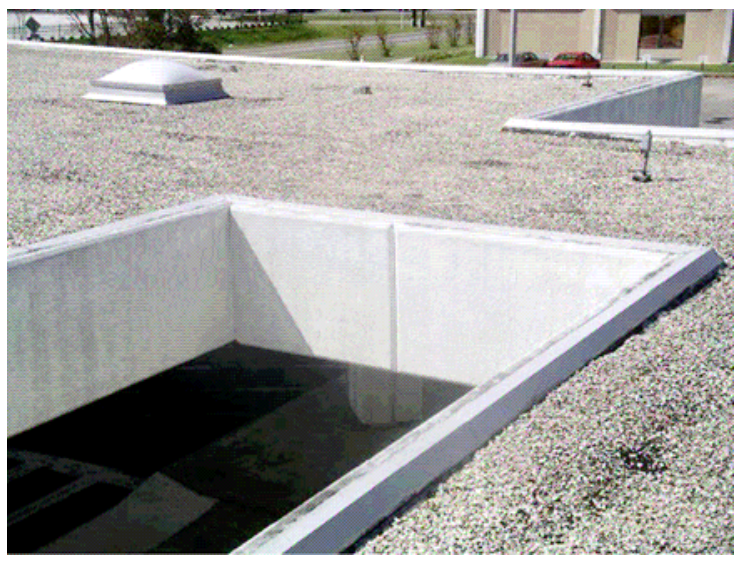

1.09(a)-4. Ocean Springs Hospital. View of a typical perimeter edge detail.

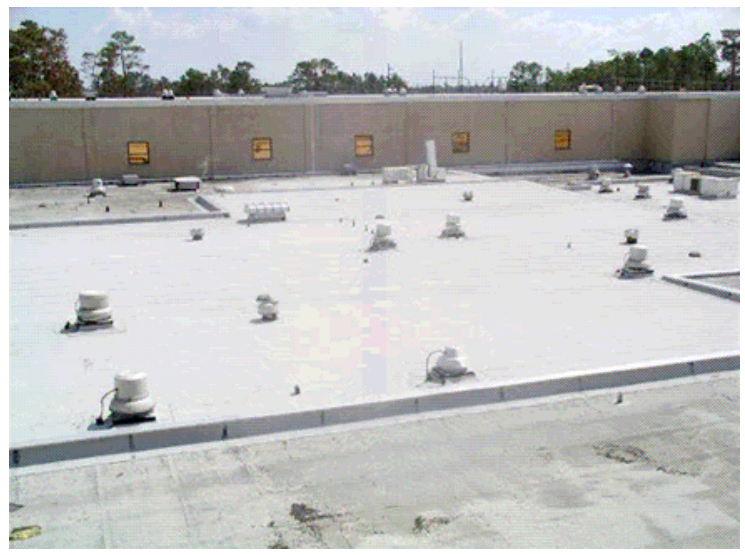

1.09(a)-5. Ocean Springs Hospital. This photo shows an SBS modified bitumen membrane system that was undamaged.

\subsection{9(b) Ocean Springs Hospital, 3109 Bienville Blvd., Ocean Springs, MS 39564}

TYPE OF STRUCTURE-Hospital (upper rear center wing)

EXPOSURE-B

WALL CONSTRUCTION-Masonry with brick façade

ROOF TYPE-SBS modified bitumen membrane with mineral surfacing, mopped to a two-ply BUR membrane

SLOPE- $-1 / 4: 12$

ROOF HEIGHT $-30 \mathrm{ft}$

ROOF WIDTH $-60 \mathrm{ft}$

ROOF LENGTH-190 ft

DECK-Unknown

INSULATION - The original insulation, if any, was unknown; a fiberglass insulation cover board, approximately $3 / 4$ in. thick, had been installed.

WIND SPEED-110-120 mph

BUIILDING/ROOF CONSTRUCTION-This assembly was retrofitted over a glass fiber re-cover board, approximately $3 / 4$ in. thick, which was hot-mopped with asphalt to a gravel-surface BUR. Not all the original gravel had been removed.

METHOD OF ATTACHMENT - Totally adhered using hot asphalt

NOTED DAMAGE-Edge flashing was detached at the corner. Sections of membrane and re-cover board were also blown off.

DAMAGE INITIATION AND PROPAGATION-The damage may have started at the edge flashing, which was not well attached at the perimeter. Where the edge detail blew off, there were two contributing causes: (1) inadequate nailing of the $1 \times 4$ in. nailer to the $2 \times 8 \mathrm{in}$. wood fascia board and (2) no face attachment of the metal, i.e., no cleats.

About $20 \%$ of the SBS membrane system was damaged. Damage consisted of peeling of the membrane at the southwest corner, extending $50 \mathrm{ft}$ along the western side and $60 \mathrm{ft}$ along the southern side. Three modes of membrane-system damage were observed: (1) the glass fiber re-cover boards 
detached from the original BUR (over about $20 \%$ of the damaged area), (2) the bottom ply of the recover membrane detached from the fiberglass cover board over about $75 \%$ of the damaged area, and (3) the cap sheet peeled away from the ply sheet below it, apparently as a result of cold asphalt application (over about $5 \%$ of the damaged area).

ADDITIONAL COMMENTS—Some rooftop equipment in damage areas was also damaged.

\section{Photographs of RoOf DAMAge}

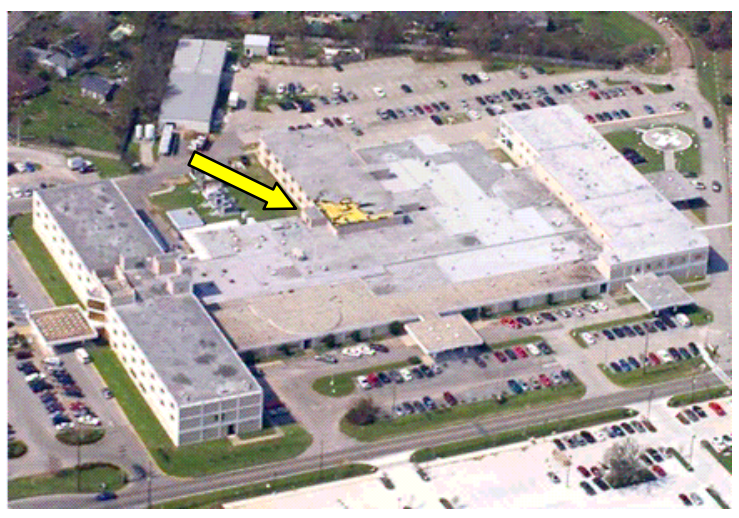

1.09(b)-1. Ocean Springs Hospital. Aerial view.

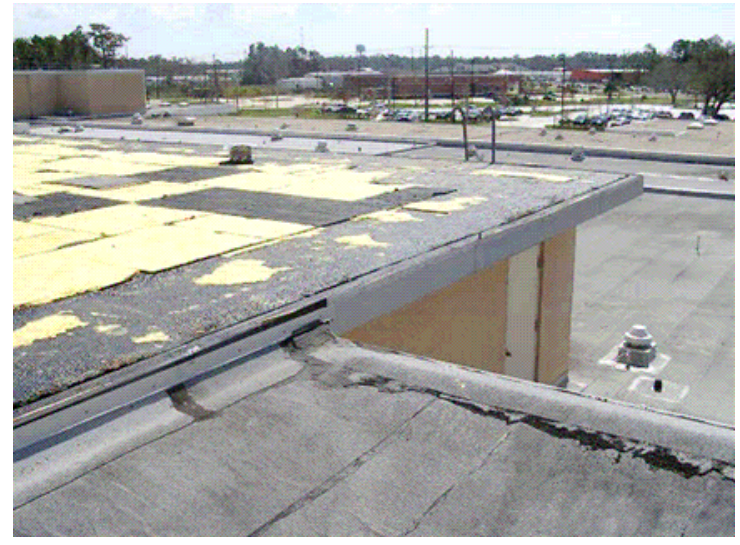

1.09(b)-3. Ocean Springs Hospital. The roof at left shows loss of re-cover board, as well as of flashing details along the edge of the SBS roof assembly.

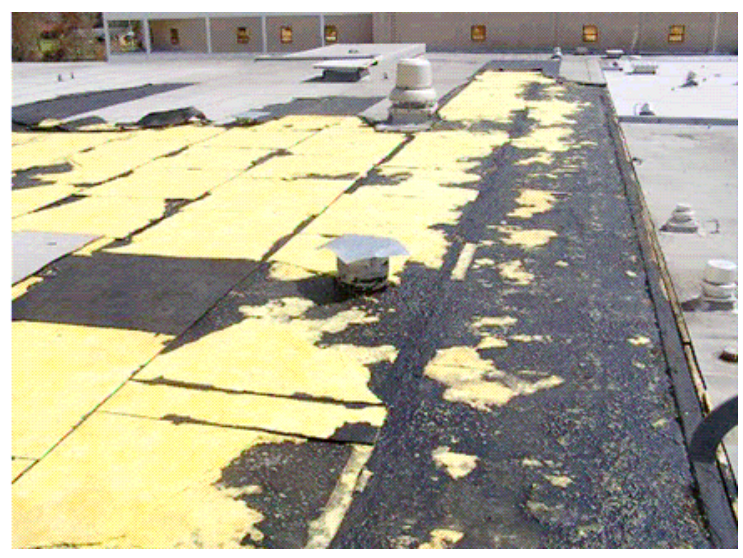

1.09(b)-2. Ocean Springs Hospital. Damage to the SBS membrane and edge flashings.

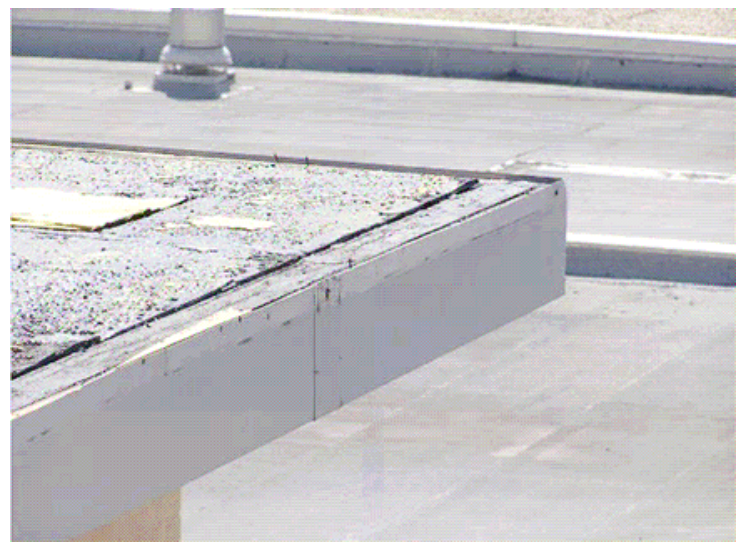

1.09(b)-4. Ocean Springs Hospital. No evidence of face attachment (cleats) of the edge flashing. 


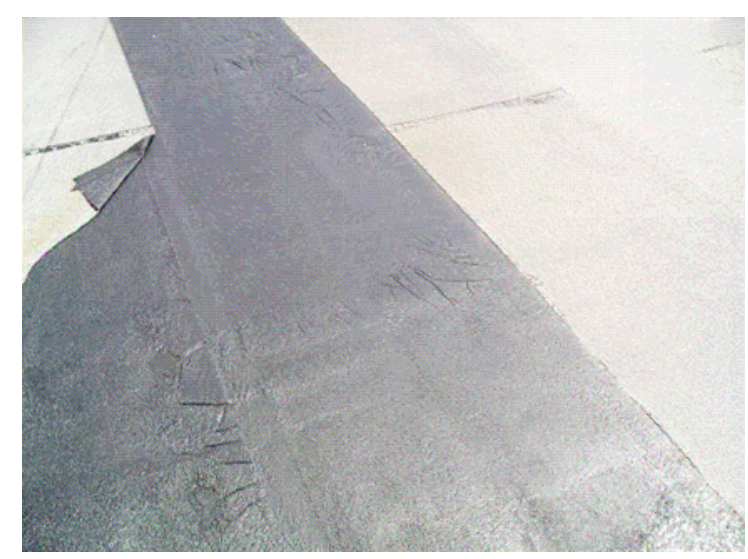

1.09(b)-5. Ocean Springs Hospital. Example of SBS cap sheet that delaminated from the built-up roofing plies below it. This appeared to be due to improper (too cold) asphalt application.

\subsection{Commercial Building, 3109 Bienville Blvd., Ocean Springs, MS}

TYPE OF STRUCTURE-Commercial

EXPOSURE-C

WALL CONSTRUCTION-Masonry block

ROOF TYPE—BUR, smooth-surface, with coating

SLOPE—1/4-1/2: 12

ROOF HEIGHT $-17 \mathrm{ft}$

ROOF WIDTH $-215 \mathrm{ft}$

ROOF LENGTH $\longrightarrow 245 \mathrm{ft}$

DECK-Unknown

INSULATION-Unknown

WIND SPEED—110-120 mph

BUILDING/ROOF CONSTRUCTION—This roof had a smooth-surface 4-ply BUR with coating; other details were not determined.

\section{METHOD OF ATTACHMENT—Unknown}

NOTED DAMAGE-No damage to the membrane system was observed. A $5 \mathrm{ft}$ section of metal edge fascia on the windward southeast corner bowed slightly outward. Some rooftop equipment was also damaged.

DAMAGE INITIATION AND PROPAGATION—Not applicable

ADDITIONAL COMMENTS-This BUR assembly was estimated to be 8 to 10 years old. 


\section{Photographs of RoOF DAMAge}

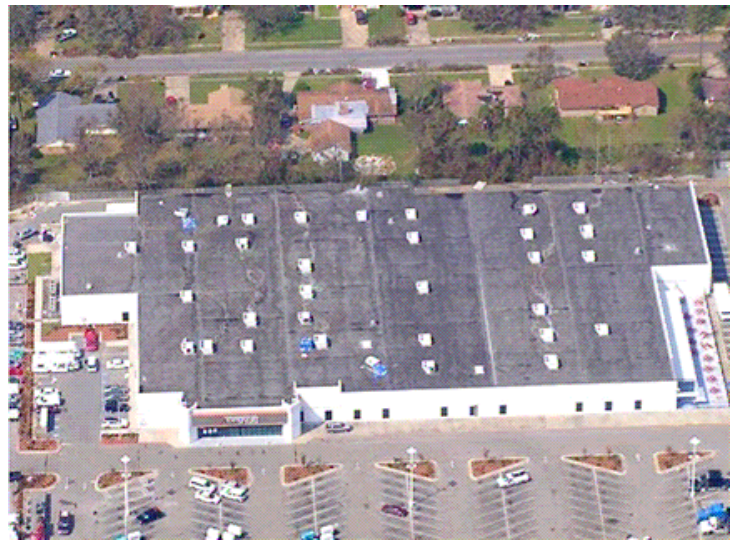

1.10-1. Commercial building. Aerial view of the Ocean Springs commercial building.

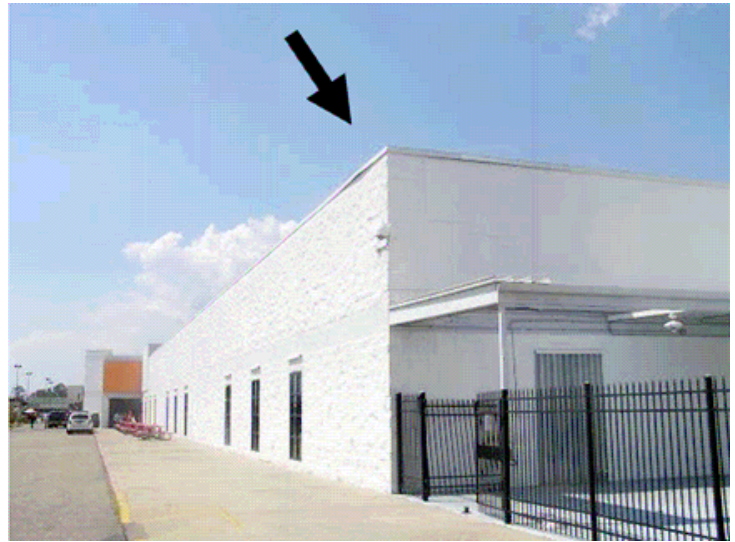

1.10-3. Commercial building. Outward bowing of the edge metal (arrow) can be seen in this photo of the southeast corner.

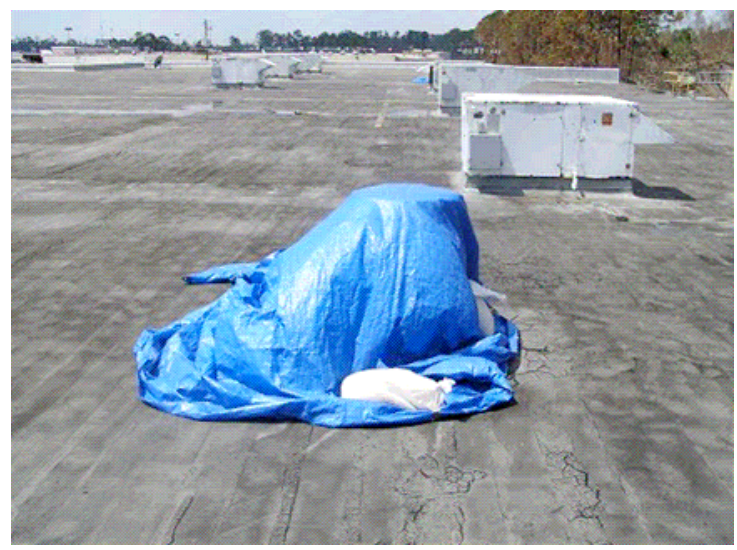

1.10-2. Commercial building. Damaged rooftop equipment was covered with plastic.

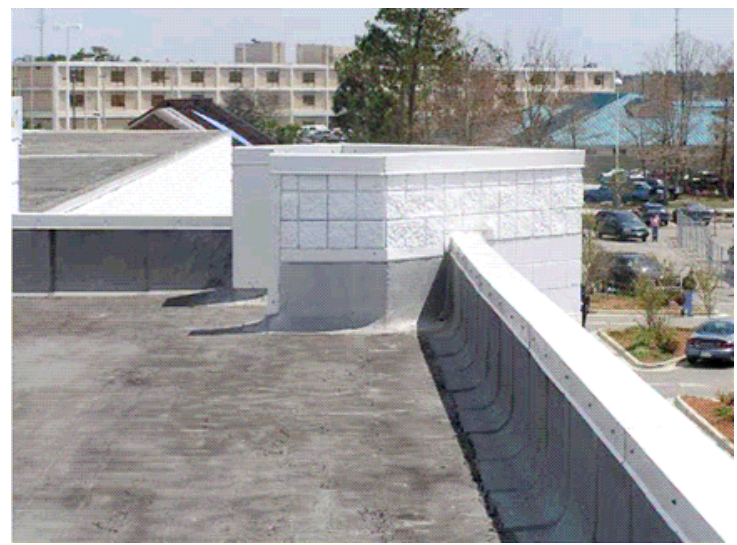

1.10-4. Commercial building. A parapet wall and flashing metal coping are shown in this photo of the front side of the building.

\subsection{Strip Mall, 2691 Highway 90, Bienville Blvd., Ocean Springs, MS}

TYPE OF STRUCTURE-Commercial

EXPOSURE-C

WALL CONSTRUCTION_Glass primarily in the front with masonry block side and rear walls ROOF TYPE-Gravel-surface BUR assembly

SLOPE- $-1 / 4: 12$

ROOF HEIGHT $-12 \mathrm{ft}$

ROOF WIDTH $-65 \mathrm{ft}$

ROOF LENGTH $-125 \mathrm{ft}$

DECK-Lightweight structural concrete

INSULATION-None

WIND SPEED-110-120 mph 
BUILDING/ROOF CONSTRUCTION-The roof had a gravel-surface BUR assembly (3 or 4 plies) with base sheet mechanically fastened to the deck.

METHOD OF ATTACHMENT-Mechanical attachment of the base ply with expandable anchors and cover disks (approximately 1 in. in diameter)

NOTED DAMAGE-Glass at the front of the building was blown out. The membrane above the glass damage was blown off.

DAMAGE INITIATION AND PROPAGATION-The roof assembly lifted away from the deck, leaving most fasteners in place. Although little remained of the roof membrane for examination, it was apparent that the base sheet tore around the expandable fasteners, allowing the BUR to blow away.

A contributing factor may have been the pressurization at the corner due to loss of the glass wall. There was an opening between the roof and the room below at the southeast corner of the building. This opening may have allowed the underside of the roof membrane to be pressurized. It was noted that the edge flashing at the damaged section was mostly intact with the exception of a short length of base flashing that may have pulled away when the membrane released.

ADDITIONAL COMMENTS-There was another section of roof just adjacent to that described here. It sustained similar damage.

\section{Photographs of Roof Damage}

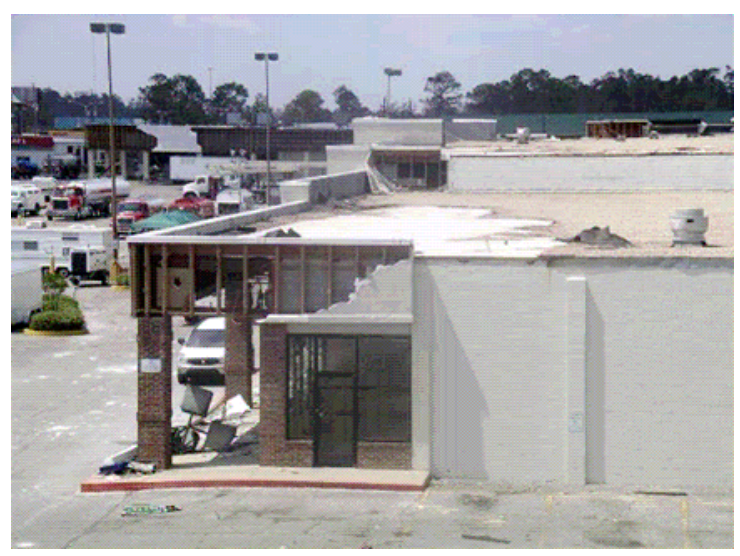

1.11-1. Strip mall. Damaged roofing is visible.

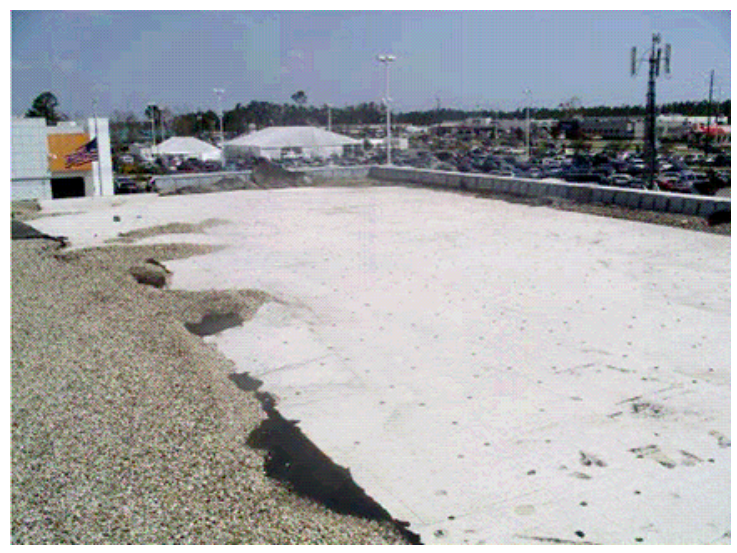

1.11-2. Strip mall. Damaged corner section. Note the exposed lightweight concrete decking.

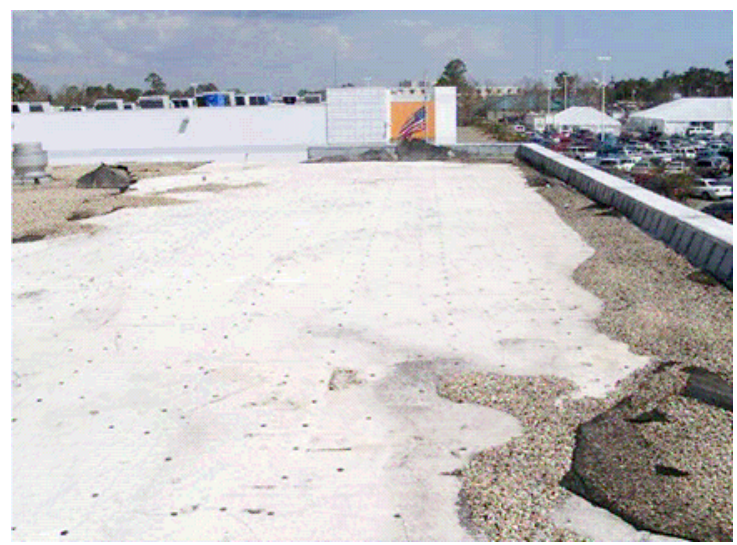

1.11-3. Strip mall. Fasteners remained in the deck. Coping at parapet is intact. 


\subsection{2(a) Pecan Park Elementary School (Area 1), 504 Hanley Road, Ocean Springs, MS}

TYPE OF STRUCTURE-School

EXPOSURE-C

WALL CONSTRUCTION-Brick veneer and window glass

ROOF TYPE—BUR assembly with aggregate surfacing

SLOPE- $-1 / 4: 12$

ROOF HEIGHT $-12 \mathrm{ft}$

ROOF WIDTH $-150 \mathrm{ft}$

ROOF LENGTH $-195 \mathrm{ft}$

DECK-CWF panels

INSULATION-None

WIND GUST SPEED-110-120 mph

BUILDING/ROOF CONSTRUCTION-The roof had a base and a 4-ply BUR. The base ply was mechanically attached to the CWF panels. The remaining plies were hot-mopped.

METHOD OF ATTACHMENT-Mechanical attachment of base ply to CWF panels

NOTED DAMAGE - CWF panels detached from an overhang at the south face; the BUR peeled from a section where the CWF panels remained intact.

DAMAGE INITIATION AND PROPAGATION_-There was poor attachment of the perimeter edge detail. At the overhang, four layers of nailers were observed. The nailer layer attached to the angle supports for the CWF panels remained attached because it was bolted in place. Damage typically occurred within the second layer of nailers, since they were not bolted in place. In fact, it was difficult to determine how the second nailer was attached to the bolted nailer. In addition, the metal frame supporting the CWF panels was severely corroded.

Along the south edge of an overhang, an entire row of CWF panels blew off. The damage was attributed to lack of attachment of panels to supports, since they were held in place only by their own weight. Back from the displaced panels at the overhang, the BUR detached from CWF panels, which remained in place. Fasteners holding the base sheet were severely corroded, causing most of them to pull loose from the CWF panels. It was noted that there were two rows of fasteners in some sheets. The individual fasteners were set $3 \mathrm{ft}$ apart and staggered. Other sheets had an additional row of fasteners down the center, which also were set $3 \mathrm{ft}$ apart.

There was no overhang at the southeast corner of the damaged section. Here, the base nailer detached from the masonry wall because bolts pulled out of the mortar. The bolts were severely corroded. The CWF panels remained in place, but the membrane released.

The east side of the roof section had a $2 \mathrm{ft}$ overhang. A $25 \times 20 \mathrm{ft}$ wide section of BUR was damaged. The CWF panels and nailer assembly blew off along the overhang. It was unclear how the missing nailer was attached. There were no bolts in the metal angle support indicative of mechanical fastening of the nailer. There was window damage below this roof section, suggesting that the membrane peeled after the overhangs failed.

ADDITIONAL COMMENTS - There was considerable damage to rooftop equipment on this section of the roof. A smooth-surface, coated BUR adjacent to this damaged section survived Katrina in good condition. 


\section{Photographs of RoOF DAmAge}

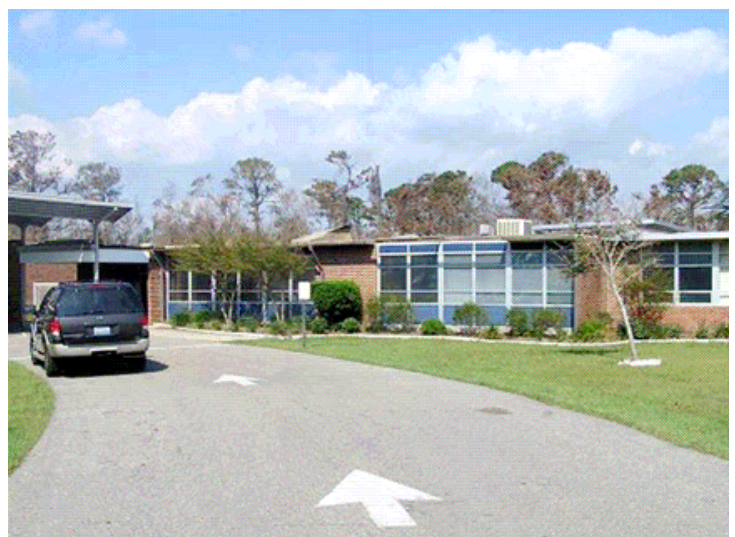

1.12(a)-1. Pecan Park Elementary School. Entrance.

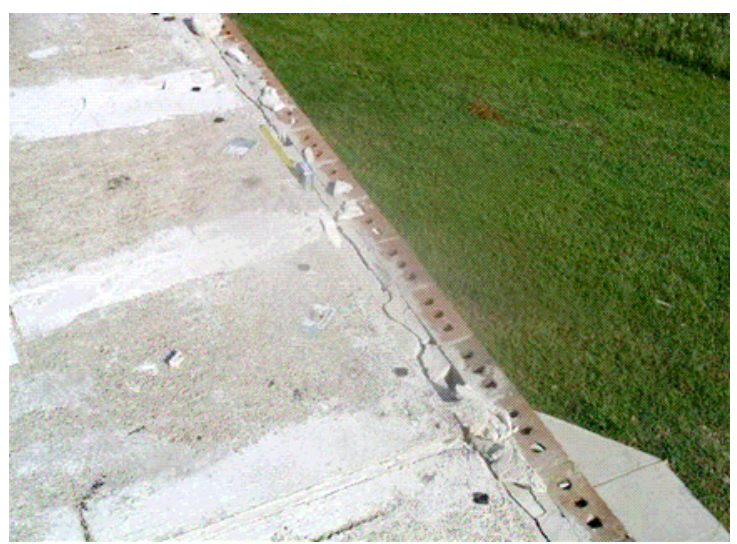

1.12(a)-3. Pecan Park Elementary School.

Damage at the southeast corner of the building, where bolts attaching a nailer pulled out of the mortar.

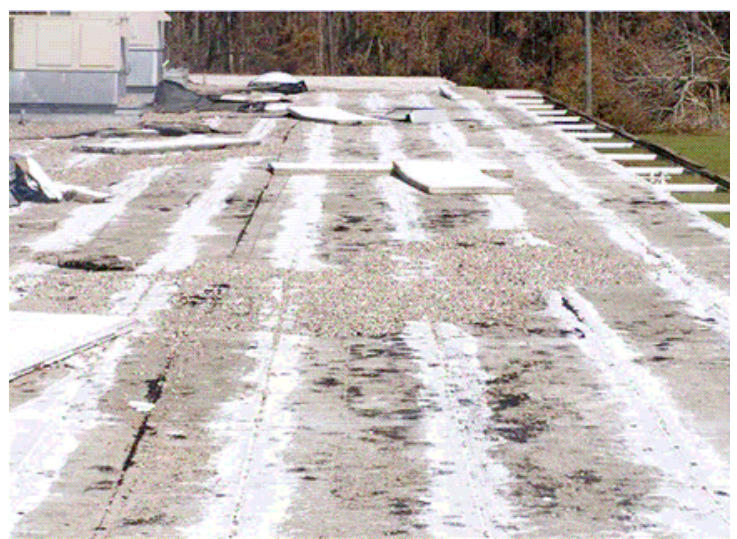

1.12(a)-2. Pecan Park Elementary School.

Damage was found along the southern edge of the roof.

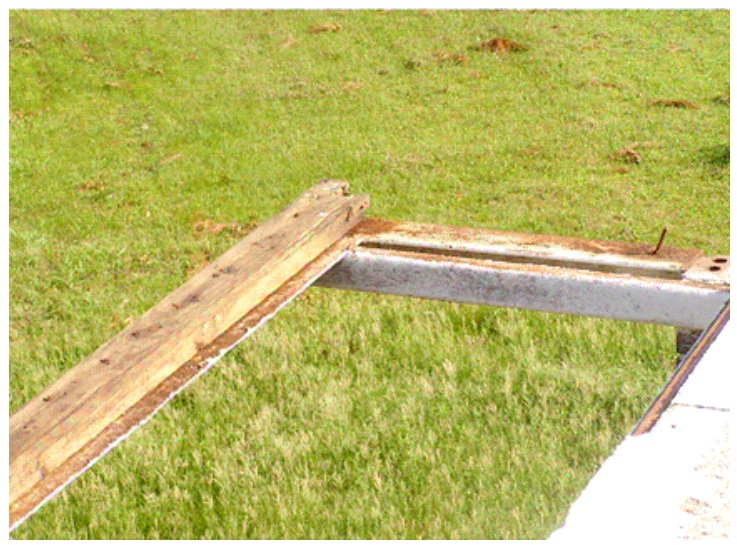

1.12(a)-4. Pecan Park Elementary School. This is an example of damaged edge detail at an overhang.

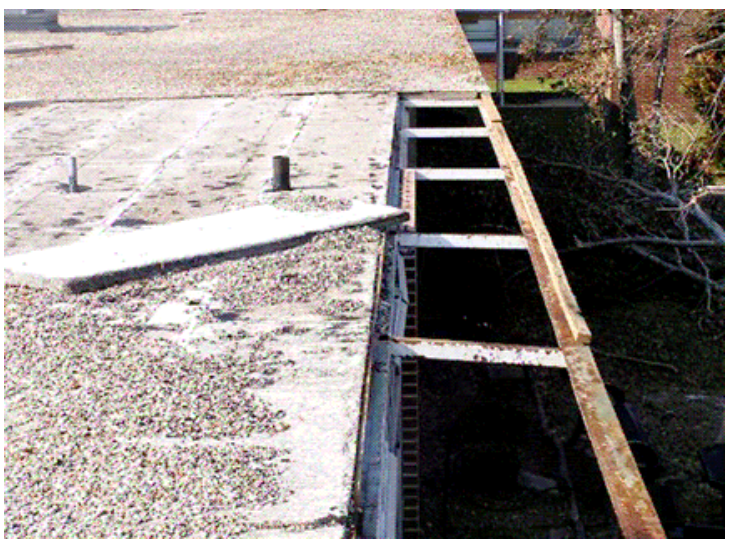

1.12(a)-5. Pecan Park Elementary School.

Damaged roof section at an overhang along the eastern edge of the building is shown here. 


\subsection{2(b) Pecan Park Elementary School (Area 2), 504 Hanley Road, Ocean Springs, MS}

TYPE OF STRUCTURE-School

EXPOSURE-C

WALL CONSTRUCTION-Brick veneer and window glass

ROOF TYPE—SBS modified bitumen system

SLOPE- $-1 / 4: 12$

ROOF HEIGHT $-12 \mathrm{ft}$

ROOF WIDTH $-40 \mathrm{ft}$

ROOF LENGTH $-60 \mathrm{ft}$

DECK-CWF panels

INSULATION - Perlite board

WIND SPEED-110-120 mph

BUILDING/ROOF CONSTRUCTION—SBS modified bitumen sheet was mopped onto a 2-ply BUR membrane made of glass fiber plies; this 3-ply assembly was mopped in hot asphalt onto three layers of perlite insulation boards, which were mopped to a base ply; the base ply was mechanically fastened to the deck.

METHOD OF ATTACHMENT_-Base ply was mechanically attached to the CWF panels, which were held in place by their own weight.

NOTED DAMAGE - Roof assembly, insulation, and CWF panels blew off around an overhang; away from the overhang, damage to the membrane and perlite insulation was observed.

DAMAGE INITIATION AND PROPAGATION_Damage was attributed to the following causes.

One cause was an inadequate edge detail at the overhang, which may have initiated the blowoff. Prior to blowoff, three wood nailers were attached to each other and to the base nailer bolted to the metal frame supporting the CWF panels. The bottom nailer appeared to be very old and was severely rotted in places. Only one severely corroded bolt was found securing the bottom nailer to the metal frame. However, bolt holes were observed that were 24-36 in. apart. Rust stains were observed in the bolt holes and structural metal. The middle and top nailers $(1 \times 4$ and $2 \times 4$ in., respectively) were nailed to each other and appeared to be new wood. To these nailers, a $2 \times 8$ in. fascia board was nailed into the side of the $2 \times 4 \mathrm{in}$. nailer. This nailer assembly came off in the damaged areas. Also, a $4 \mathrm{ft}$ section of the southern wall at the southwest corner lost the edge nailer assembly, but two bolts set $3 \mathrm{ft}$ apart in the brick mortar remained in place.

In addition to the overhang edge detail, the CWF panels (and membrane system) were blown off, with the exception of one panel at the southwest corner.

Damage to the membrane may have occurred upon loss of the inadequate edge detail and displacement of the CWF panels at the overhang. Following the roof damage in those areas, the membrane may have lifted from the substrate and peeled back from the edge of the building. Where the membrane was damaged, three modes were observed: (1) at the southwest corner, the nailed base sheet released from the CWF panels along with most of the fasteners. This mode constituted about $15 \%$ of membrane damage. (2) There was interlayer delamination of the perlite insulation in areas where interlayer mopping of asphalt did not completely cover the board surfaces. It was estimated that these moppings covered only about $65 \%$ of the surface. Also, the asphalt in these areas appeared to be very thin, which can be an indication that not enough asphalt was put in place. This mode was 
approximately $15 \%$ of the membrane damage. (3) There was a cohesive failure of the perlite insulation just below the top surface of the topmost board. Where this damage occurred, a thin layer of perlite insulation remained attached to the bottom of the membrane. This mode was approximately $70 \%$ of the membrane damage.

ADDITIONAL COMMENTS-This membrane system was estimated to be less than 10 years old.

\section{PhOtographS OF RoOF DAMAge}

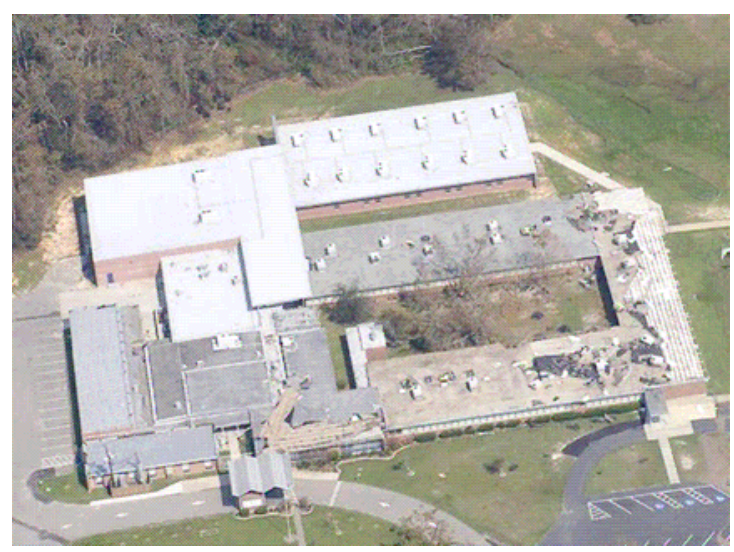

1.12(b)-1. Pecan Park Elementary School. Aerial view of the school.

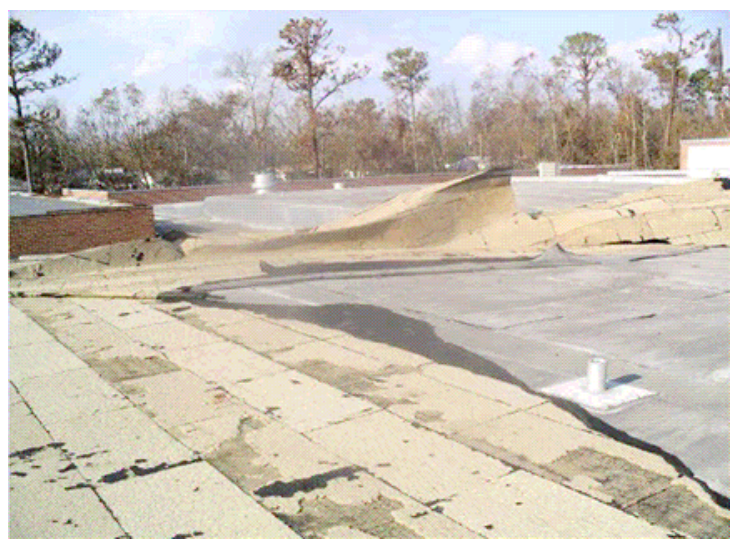

1.12(b)-3. Pecan Park Elementary School. Cohesive failure of the perlite insulation in this photo is associated with membrane blowoff.

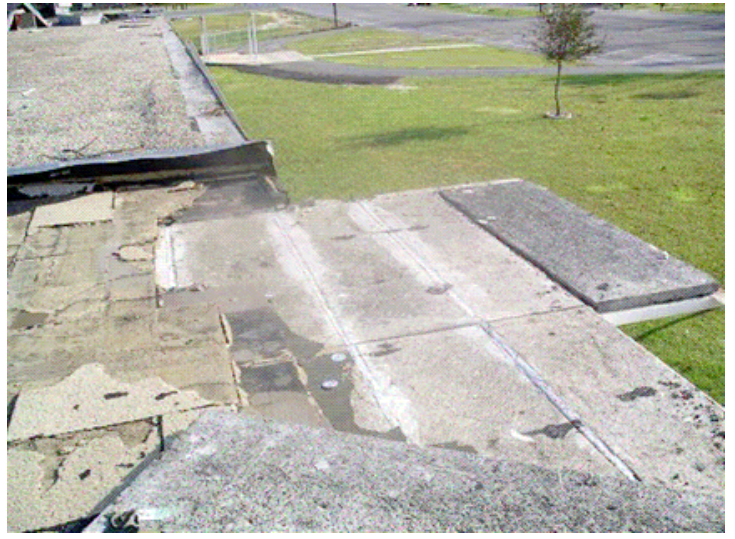

1.12(b)-2. Pecan Park Elementary School. Damage at the southwest corner occurred at the overhang shown here at upper right.

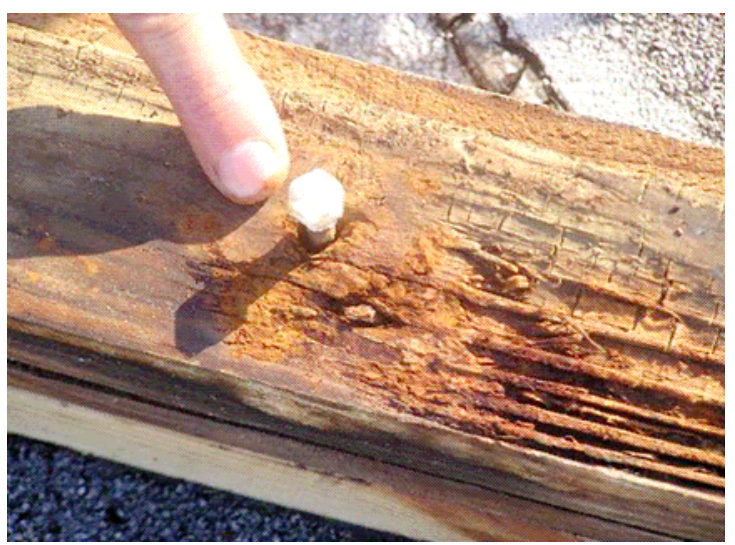

1.12(b)-4. Pecan Park Elementary School. A rotted section of this wood nailer could have instigated nailer detachment from the structural members. 


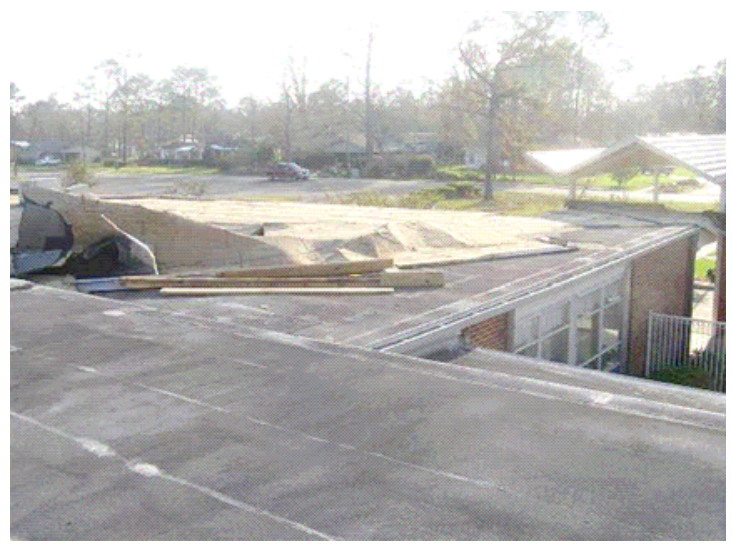

1.12(b)-5. Pecan Park Elementary School.

Sections of blown-off wood nailers from the western edge of this roof section.

\subsection{Ocean Springs High School, 2320 Government Street, Ocean Springs, MS}

TYPE OF STRUCTURE-School

EXPOSURE-C

WALL CONSTRUCTION-Masonry brick and glass

ROOF TYPE_BUR, smooth-surface

SLOPE-1/4-1/2: 12

ROOF HEIGHT $-12 \mathrm{ft}$

ROOF RADIUS $-65 \mathrm{ft}$

ROOF CIRCUMFERENCE- $120 \mathrm{ft}$

DECK-unknown

INSULATION - Perlite with asphalt adhesive

WIND SPEED-110-120 mph

BUILDING/ROOF CONSTRUCTION_BUR, smooth-surface, mopped to perlite insulation boards; this roof system was under repair; most debris had been removed and some damaged insulation had been replaced. Thus other roof construction data were not determined.

METHOD OF ATTACHMENT—Membrane secured with hot asphalt

NOTED DAMAGE—Missing edge detail and roof membrane (on the circular building)

DAMAGE INITIATION AND PROPAGATION_-Detailed analysis of roof system and damage modes was difficult because repairs were under way when the roof was inspected. Damage likely started as edge detail failure with subsequent peeling of the membrane. The majority of perlite insulation boards (about 90\%) remained in place, although some replacement boards had been installed at the edge of the damaged section. Roof damage consisted of delamination within the top layer of the perlite boards (cohesive failure) just under the surface of the membrane.

ADDITIONAL COMMENTS - The auditorium roof had also been damaged, but some repairs had been performed at the time of inspection. Thus it was not determined what caused damage there. 


\section{PhOtographS OF RoOF DAMAge}

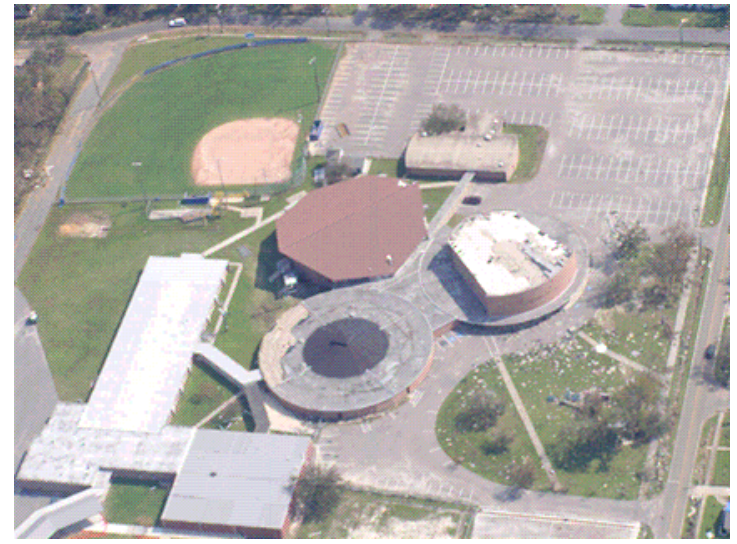

1.13-1. Ocean Springs High School. Aerial view.

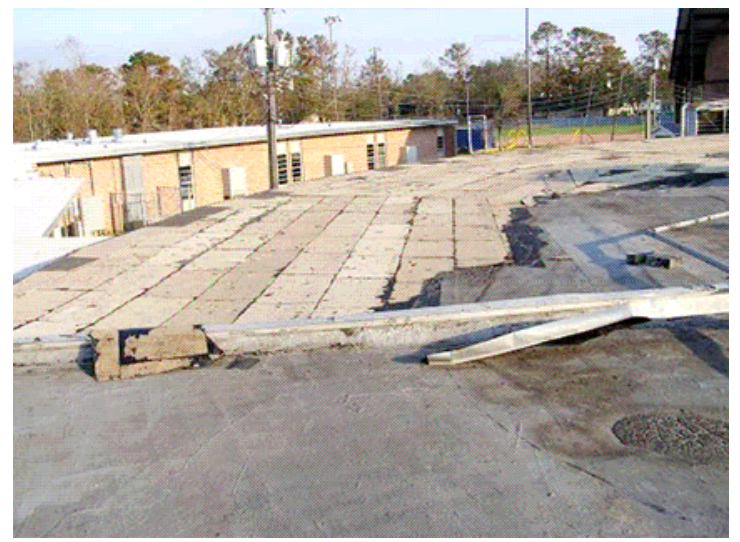

1.13-2. Ocean Springs High School. Overview shows the damaged BUR assembly.

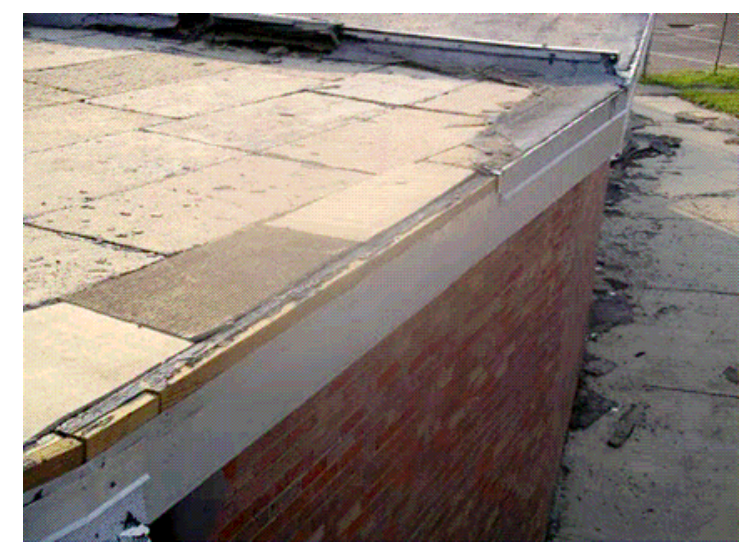

1.13-3. Ocean Springs High School. Damaged edge flashing is visible here. No evidence of proper fastening of the metal edge fascia to the wall was observed.

\subsection{Beach Elementary School, 633 Market Street, Pascagoula, MS}

TYPE OF STRUCTURE—School

EXPOSURE-C

WALL CONSTRUCTION-Masonry

ROOF TYPE—Single ply, smooth-surface

SLOPE-3-4:12

ROOF HEIGHT $-30 \mathrm{ft}$

ROOF WIDTH $-60 \mathrm{ft}$

ROOF LENGTH $\rightarrow 5 \mathrm{ft}$

DECK-Steel

INSULATION-Unknown 
WIND SPEED—90-100 mph

BUILDING/ROOF CONSTRUCTION-Mechanically attached single ply smooth-surface system; construction details not fully ascertained. The fasteners were placed only in the membrane seams at a spacing of about 12-14 in. There was a ventilated overhang along each long side of the building; the metal edge flashing was secure.

METHOD OF ATTACHMENT_Mechanically attached in membrane seams (12-14 in. o.c.) with plates and screws in overlap

NOTED DAMAGE-None

DAMAGE INITIATION AND PROPAGATION—Not applicable

ADDITIONAL COMMENTS-This school building was located within a mile of the Pascagoula coast and experienced considerable storm surge damage. The barrel roof was one of the few single ply systems that Team 1 encountered, which prompted the inspection.

The school building had two major wings adjacent to the barrel roof. These wings had adhered SBS modified bitumen membrane systems that were brand new. These roofs, also, did not sustain storm damage.

\section{PHOTOGRAPHS OF Undamaged ROOF}

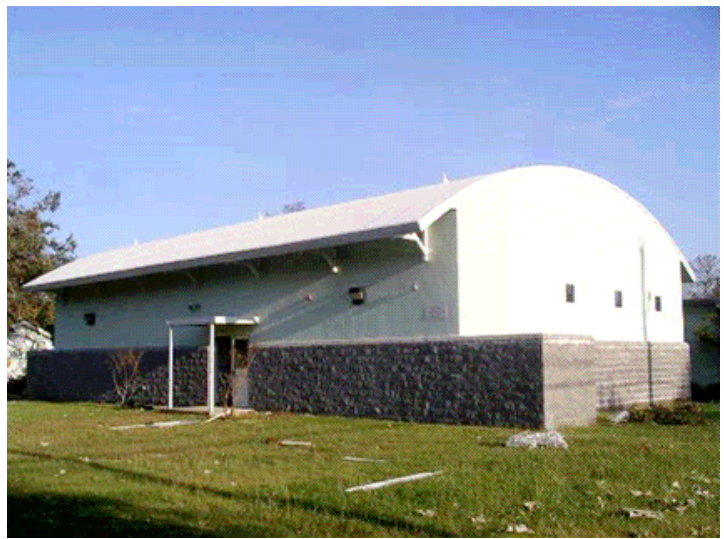

1.14.1. Beach Elementary School. Barrel roof.

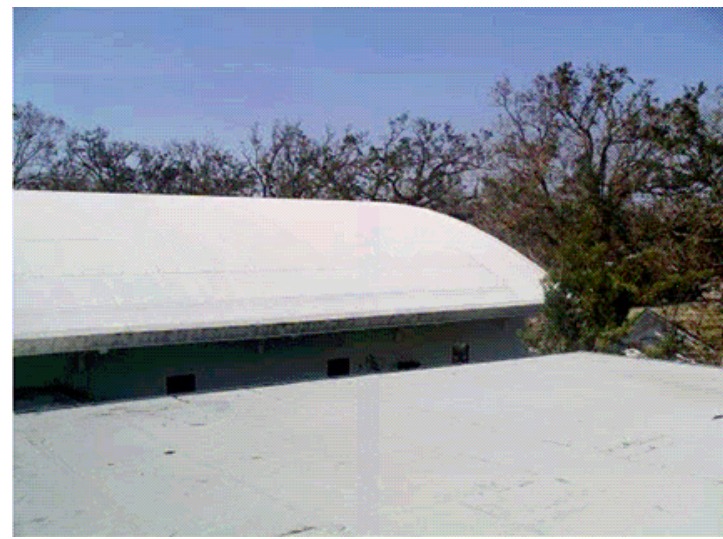

1.14-2. Beach Elementary School. Overview at the barrel roof.

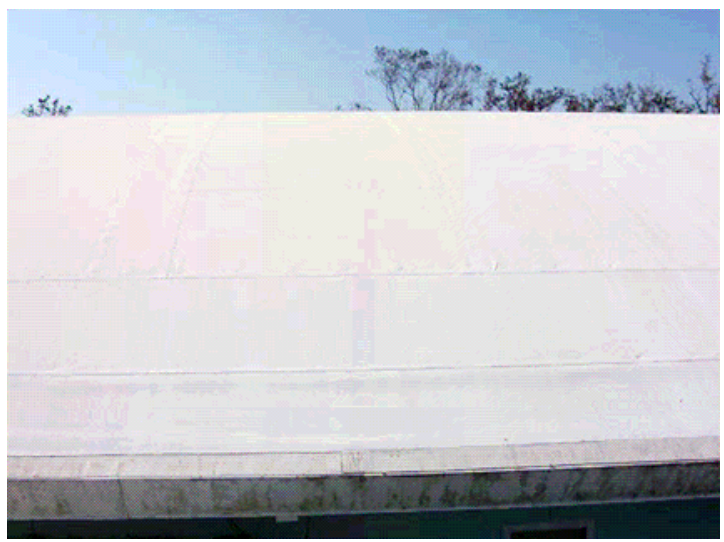

1.14-3. Beach Elementary School. Seams of the single ply membrane can be seen in this photo. 


\subsection{5(a) Freezer Plant, Pascagoula (Area 1), 3708 Pascagoula Street, Pascagoula, MS}

TYPE OF STRUCTURE-Commercial

EXPOSURE-B

WALL CONSTRUCTION-Concrete block with spray foam

ROOF TYPE—SBS modified bitumen with mineral surfacing

SLOPE-1/4-1/2: 12

ROOF HEIGHT $\rightarrow 15 \mathrm{ft}$

ROOF WIDTH $\rightarrow 50 \mathrm{ft}$

ROOF LENGTH- $150 \mathrm{ft}$

DECK-CWF

INSULATION - Composite: polyisocyanurate (11/2 in.) overlaid with perlite ( $3 / 4 \mathrm{in}$.)

WIND SPEED-90-100 mph

BUILDING/ROOF CONSTRUCTION-2-ply SBS modified bitumen with mineral surfacing. A base ply was mechanically fastened with expandable anchors to CWF panels; the isocyanurate-board was hot-mopped over the base ply; $3 / 4$ in. perlite insulation board was hot-mopped to the board, followed by the 2-ply SBS membrane.

METHOD OF ATTACHMENT_-The base sheet was mechanically fastened with expandable anchors to the deck.

NOTED DAMAGE—Loss of edge detail and membrane system

DAMAGE INITIATION AND PROPAGATION_-In some areas, the edge metal failed as a result of inadequate attachment to the wood nailer. The fastening pattern was not determined. Additionally, the base sheet (and the insulation and membrane assembly attached to it) released from the CWF panels. The anchors pulled loose from the panels. In other sections of the damaged roof, the system failed because of cohesive failure within the perlite board.

ADDITIONAL COMMENTS-This membrane system was estimated to be less than 5 years old.

\section{Photographs of Roof Damage}

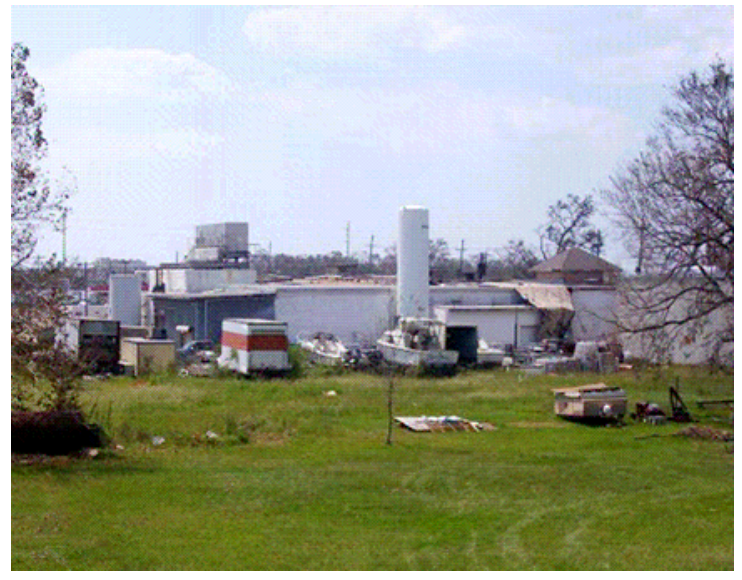

1.15(a)-1. Freezer plant. View of the commercial freezer plant shows damaged membrane hanging over the side of the building.

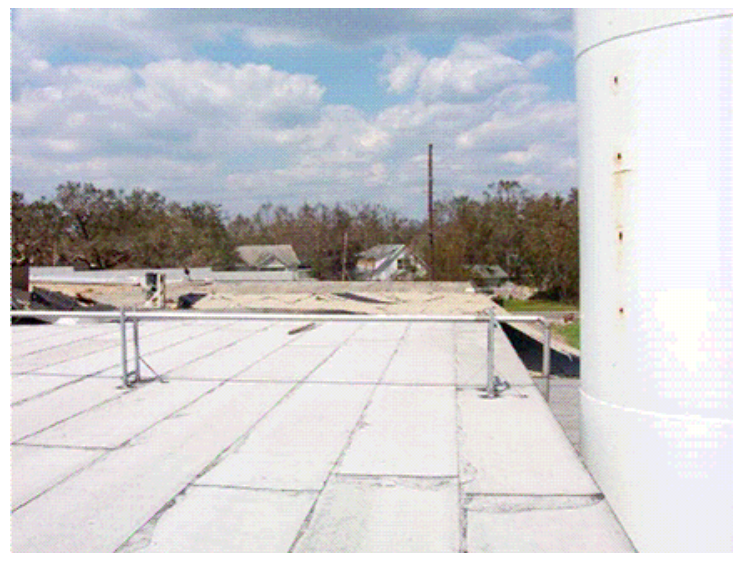

1.15(a)-2. Freezer plant. Overview shows the damaged SBS membrane system. 


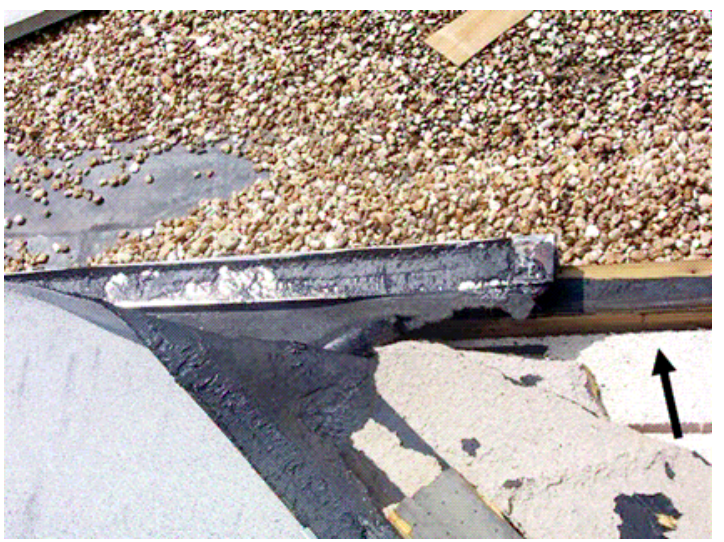

1.15(a)-3. Freezer plant. Damaged edge metal is visible in this photo. Note that it released from the nailer (black arrow), which remained in place.

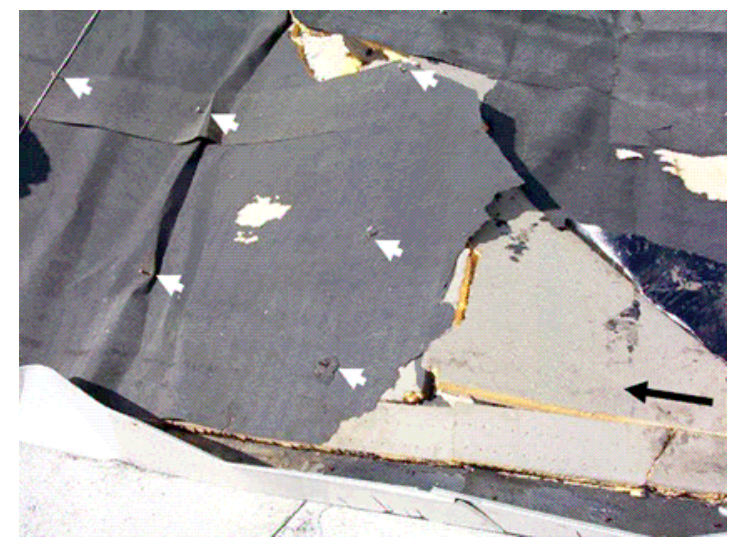

1.15(a)-4. Freezer plant. Underside of the membrane shows fasteners that remained in the base ply (white arrows). Note insulation board that is devoid of asphalt (black arrow) indicating spotty membrane attachment.

\subsection{5(b) Freezer Plant, Pascagoula (Area 2), 3708 Pascagoula Street, Pascagoula, MS}

TYPE OF STRUCTURE-Commercial

EXPOSURE-B

WALL CONSTRUCTION-Concrete block

ROOF TYPE—Ballasted EPDM single ply membrane system

SLOPE-1/4-1/2: 12

ROOF HEIGHT $-15 \mathrm{ft}$

ROOF WIDTH $-150 \mathrm{ft}$

ROOF LENGTH $\longrightarrow 200 \mathrm{ft}$

DECK-Tongue-and-groove wood plank

INSULATION—Expanded polystyrene (EPS)

WIND SPEED—80-100 mph

BUILDING/ROOF CONSTRUCTION—Ballasted EPDM single ply membrane system (loose-laid membrane). Insulation was mechanically fastened to wood deck (fastening pattern was not determined); ballast was 1-2 in. rounded stone applied uniformly at an estimated rate of $10 \mathrm{lb} / \mathrm{ft}^{2}$; bottom layer of insulation was $1 \mathrm{in}$. expanded EPS; top layer of insulation was 3/4 in. perlite.

METHOD OF ATTACHMENT_-Insulation mechanically attached; membrane ballasted

NOTED DAMAGE-The membrane and deck blew off a section of the roof; there was also loss of membrane and some gravel scour.

DAMAGE INITIATION AND PROPAGATION-Three types of membrane-related damage were observed, which may have been independent of one another.

- Approximately $10 \%$ of the roof deck blew upward, apparently from internal pressurization, taking roof membrane, insulation, and edge metal with it. This occurred in a roof area that was open below the deck. 
- The membrane was blown back from the roof edge. This occurred to about $30 \%$ of the damaged area.

- There was gravel scour in three roof sections including the west, east, and south sides. This occurred to about $20 \%$ of the damaged area.

Edge detail damage occurred in all areas of roof damage.

ADDITIONAL COMMENTS-This EPDM membrane system was approximately 20 years old and did not appear to be adequately maintained.

\section{Photographs of Roof Damage}

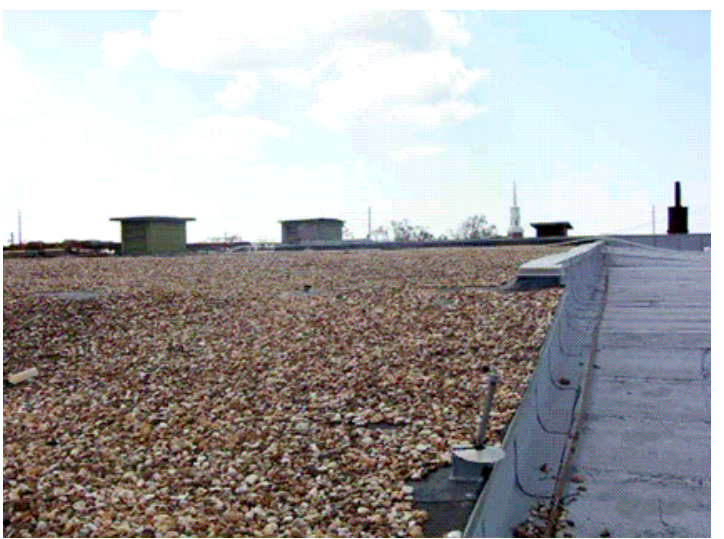

1.15(b)-1. Freezer plant. Overview of the ballasted EPDM system.

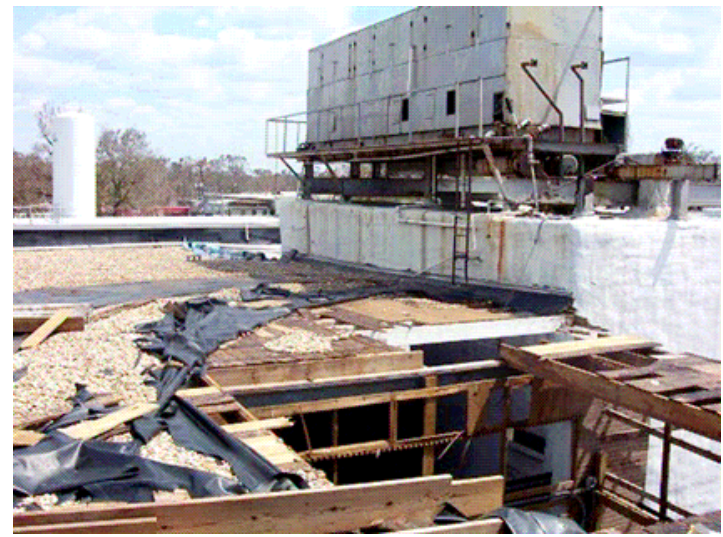

1.15(b)-2. Freezer plant. Photo shows an area where the decking and the roof assembly uplifted from the force of internal pressurization.

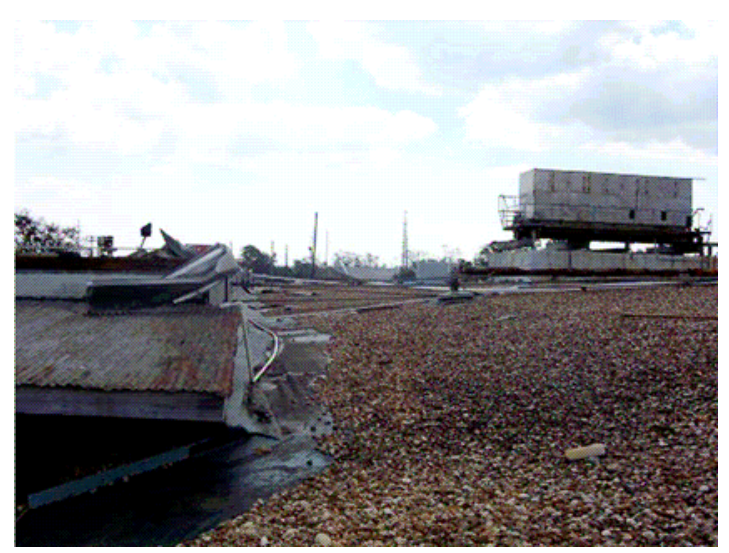

1.15(b)-3. Freezer plant. Ballast scour is visible here along the east edge of the roof system.

\subsection{5(c) Freezer Plant, Pascagoula (Area 3), 3708 Pascagoula Street, Pascagoula, MS}

TYPE OF STRUCTURE-Commercial

EXPOSURE-B

WALL CONSTRUCTION-Masonry

ROOF TYPE-SPF with acrylic coating

SLOPE- $-1 / 4: 12$ 
ROOF HEIGHT $-15 \mathrm{ft}$

ROOF WIDTH $-40 \mathrm{ft}$

ROOF LENGTH $-50 \mathrm{ft}$

DECK-Tongue and groove wood plank

INSULATION—Unknown

WIND GUST SPEED—90-100 mph

BUILDING/ROOF CONSTRUCTION-The SPF was applied directly to the wall and roof substrates. Two layers of the acrylic coating were applied to the SPF. Coating thickness was estimated to be about 0.002 in. ( 2 mil).

\section{METHOD OF ATTACHMENT_-Adhered}

NOTED DAMAGE-None. The tie-in to the adjacent roof section had failed prior to the hurricane.

DAMAGE INITIATION AND PROPAGATION—Not applicable

ADDITIONAL COMMENTS - SPF covered all exterior walls and the entire roof of this section of the building. The roof was surveyed because it was directly adjacent to the damaged EPDM membrane system. The SPF was estimated to be 15-20 years old.

\section{Photographs of Undamaged RoOF}

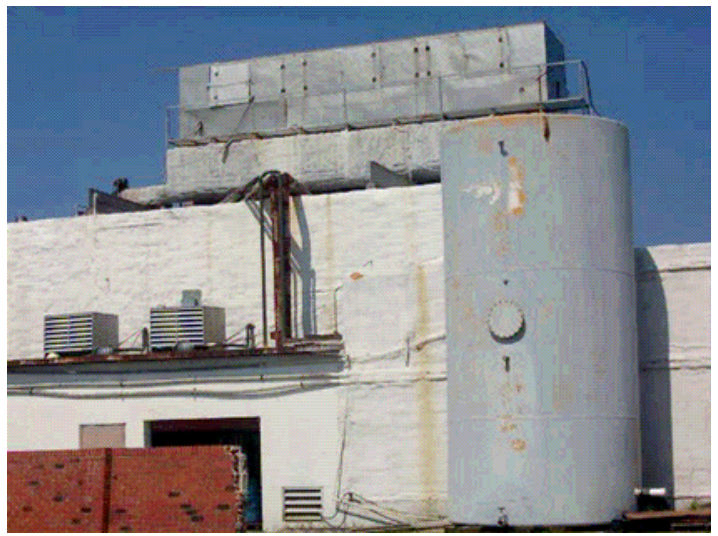

1.15(c).1. Freezer plant. South side of the plant. SPF on these walls was estimated to be 1520 years old.

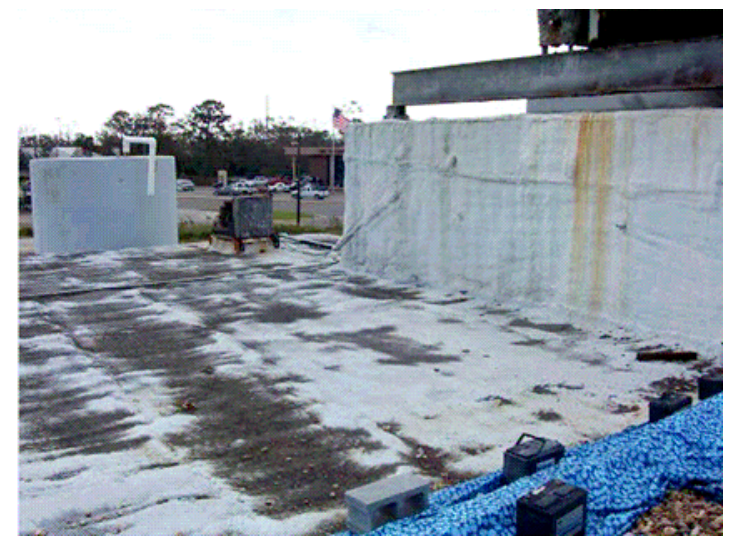

1.15(c)-2. Freezer plant. This is a view of the undamaged 15-20 year old SPF roof.

\subsection{Supermarket, 1275 Telephone Road, Pascagoula, MS}

TYPE OF STRUCTURE-Commercial

EXPOSURE-B

WALL CONSTRUCTION-Masonry

ROOF TYPE_EPDM ballasted system

SLOPE- $-1 / 4: 12$

ROOF HEIGHT $-15 \mathrm{ft}$

ROOF WIDTH $-160 \mathrm{ft}$ 


\section{ROOF LENGTH $250 \mathrm{ft}$}

DECK - Gypsum concrete over steel pan

INSULATION - Isocyanurate/urethane board

WIND SPEED-90-100 mph

BUILDING/ROOF CONSTRUCTION-The EPDM membrane system was a retrofit performed approximately 20 years before the inspection; underlying roof assembly consisted of steel pan deck that was filled with lightweight gypsum concrete to which $1 / 2$ in. wood fiber board was hot-mopped and covered with a BUR. Retrofit included 1 in. of polyurethane or polyisocyanurate board loosely laid over BUR and then covered with a loose-laid EPDM membrane. Ballast was uniformly applied at a rate estimated to be about $10 \mathrm{lb} / \mathrm{ft}^{2}$.

METHOD OF ATTACHMENT — The retrofitted EPDM system was ballasted; the underlying BUR was adhered, including the perlite-to-decking attachment.

NOTED DAMAGE-No major damage attributable to hurricane winds was observed. Some areas may have experienced minor scour in perimeter and penetration areas. The owner indicated that a small section of ballast and EPDM membrane had blown back from the windward southeast corner. As a repair, he had moved the displaced aggregate back to its original location. It was not clear whether EPDM repairs were needed or performed.

\section{DAMAGE INITIATION AND PROPAGATION—Not applicable}

ADDITIONAL COMMENTS - There was considerable evidence of past and present leaks, which were attributed primarily to age, deterioration, and inadequate maintenance. Membrane shrinkage was noted at many perimeter locations. Leakage was obvious in these areas. Many repairs had been made, in all areas, to punctures, seam delaminations, and membrane tears. The types of repair materials were not always apparent. In some cases, asphaltic materials (i.e., felts and mastics) were used. Many seams, as well as penetrations and edge flashings, were covered with plastic sheets. The owner said sheets were used to stop leaks, which he said were not hurricane related.

Ballast was missing in some areas. It appeared that the missing ballast had been pushed aside to look for or to repair leaks. It was not determined whether any displaced ballast was due to hurricane wind scour, as opposed to leak repair activities.

\section{Photographs of RoOf Damage}

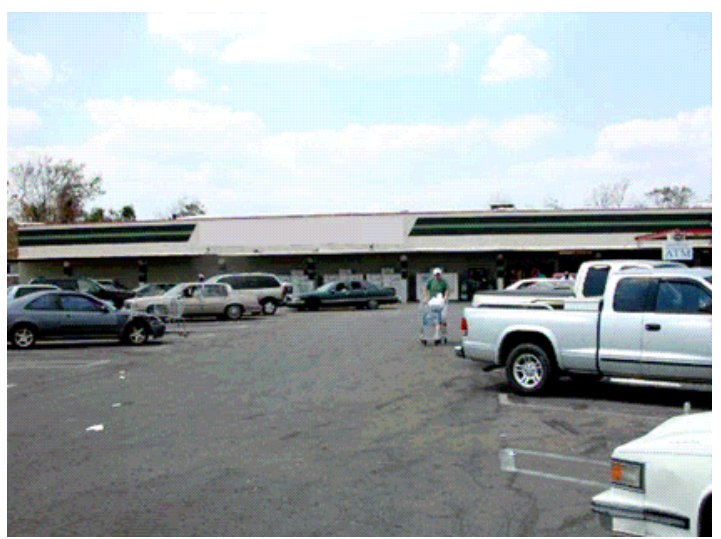

1.16-1. Pascagoula supermarket. Front view of the store.

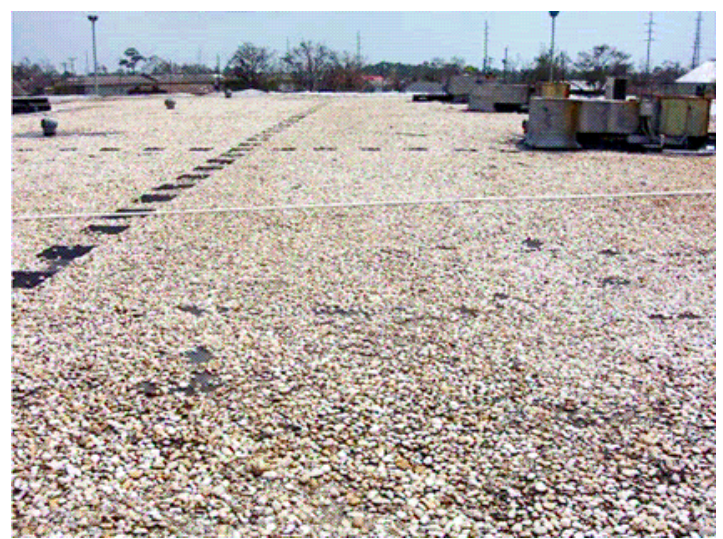

1.16-2. Pascagoula supermarket. Overview shows the field of the ballasted EPDM membrane system. 


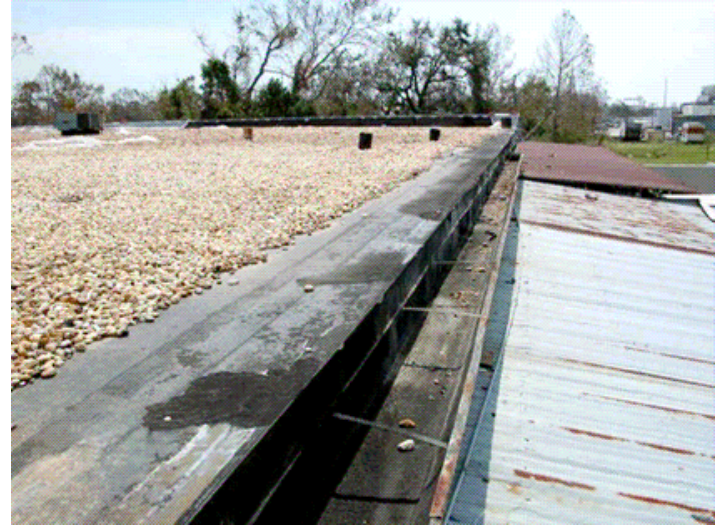

1.16-3. Pascagoula supermarket. View along the northern edge of the roof. Shows where ballast had apparently been pushed back to facilitate perimeter repair.

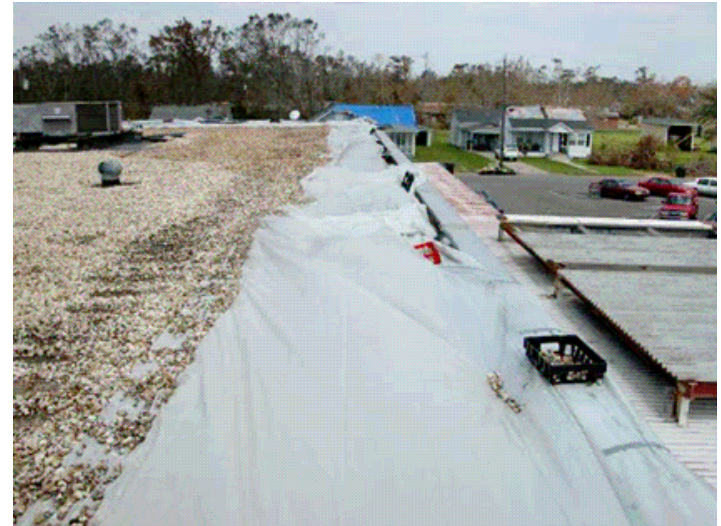

1.16-4. Pascagoula supermarket. Plastic sheets were used to cover perimeter flashings. They were intended to protect against leaks that had not been caused by the hurricane.

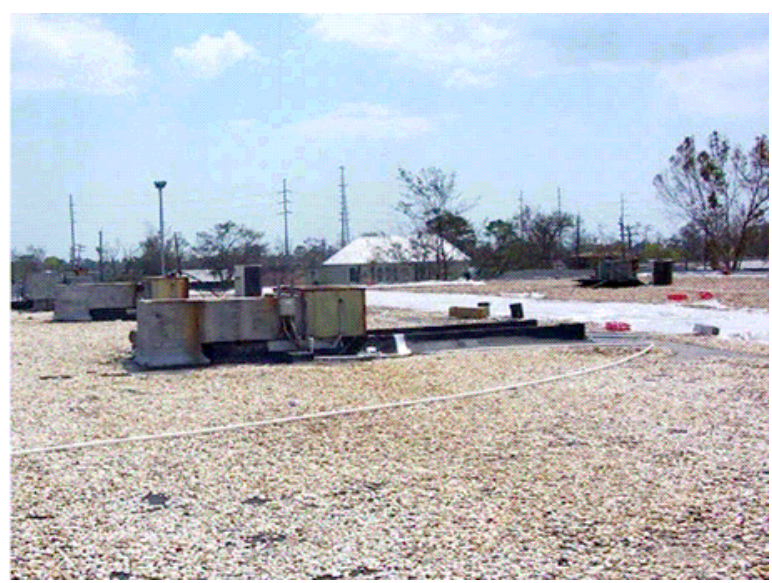

1.16-5. Pascagoula supermarket. View of the ballasted roof system. The plastic sheet covers a seam leak that occurred prior to the hurricane.

\subsection{College Park Elementary School, Ladnier Road, Gautier, MS}

TYPE OF STRUCTURE-School

EXPOSURE-B

WALL CONSTRUCTION-Masonry brick

ROOF TYPE—SBS mineral-surface

SLOPE- $-1 / 4: 12$

ROOF HEIGHT —Multiple levels, generally 14-20 ft high

ROOF WIDTH-Not determined

ROOF LENGTH $\rightarrow$ Not determined

DECK - Construction on one building was concrete single Ts with CWF panels spanning between the Ts; other areas were not determined.

INSULATION-Unknown 
WIND SPEED-110-120 mph

BUILDING/ROOF CONSTRUCTION-This was a large campus; buildings were multi-level and generally 14-20 ft high with roofs facing in multiple directions. SBS mineral-surfaced edge systems varied per building - some had single-piece metal flashing systems, whereas others had multicomponent systems. SBS membranes were estimated to be less than 5 years old. Most buildings were not examined in detail.

METHOD OF ATTACHMENT—Not determined

NOTED DAMAGE-None

DAMAGE INITIATION AND PROPAGATION—Not applicable

ADDITIONAL COMMENTS-This campus was inspected because the inspection team came across it while driving to another facility. This site appeared from the road to be damage-free. An on-theroof walkover inspection confirmed this.

\section{Photographs of Undamaged RoOF}

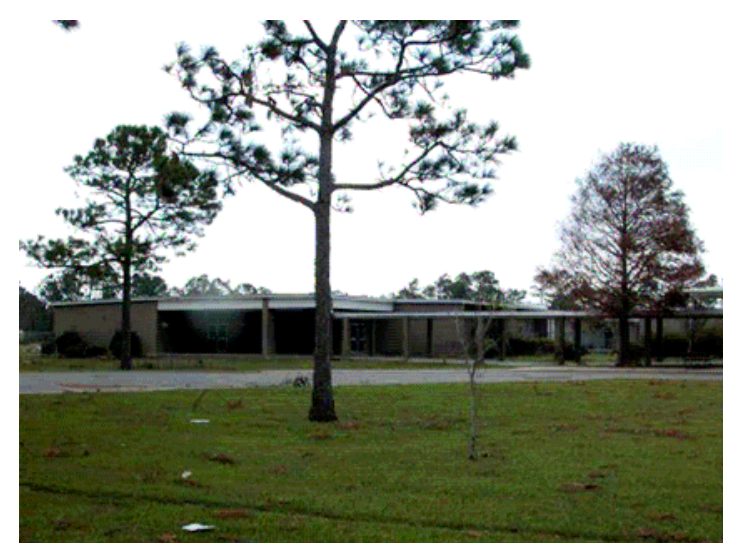

1.17-1. College Park Elementary. Front view of the campus.

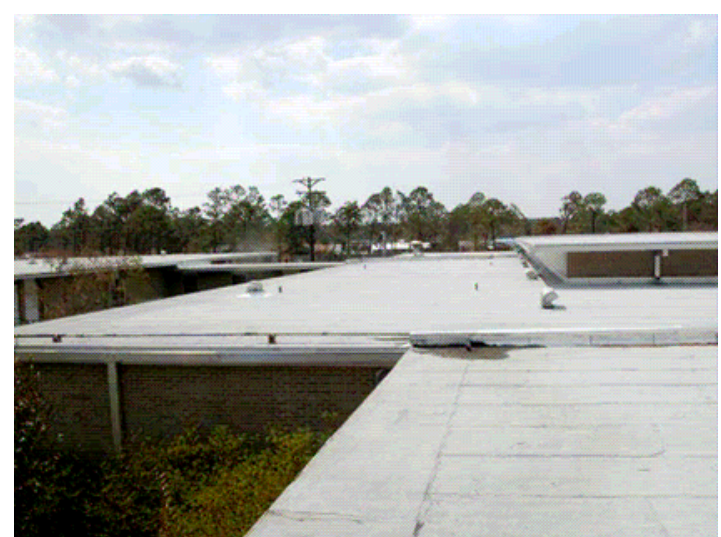

1.17-2. College Park Elementary. Undamaged SBS membranes were common on inspected buildings.

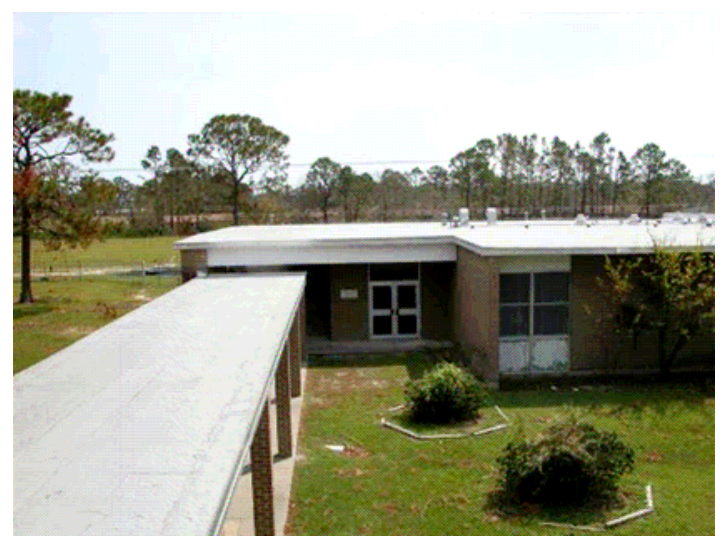

1.17-3. College Park Elementary. Walkway connecting two school buildings. 


\subsection{Gautier Middle School, Graveline Blvd., Gautier, MS}

TYPE OF STRUCTURE-School

EXPOSURE-C

WALL CONSTRUCTION-Masonry block with brick veneer

ROOF TYPE—BUR with aggregate surfacing

SLOPE- $-1 / 4: 12$

ROOF HEIGHT $-30 \mathrm{ft}$

ROOF WIDTH $-80 \mathrm{ft}$

ROOF LENGTH $-185 \mathrm{ft}$

DECK - Concrete single Ts and CWF panels; both were generally covered with LWC.

INSULATION Perlite (1 in.)

WIND SPEED-110-120 mph

BUILDING/ROOF CONSTRUCTION-The roof construction was generally as follows:

A. Structural deck: Structural concrete single Ts spaced $8 \mathrm{ft}$ o.c.; CWF panels bridged perpendicular between the Ts and supported at their ends by resting on the Ts and along their edges on steel bulb Ts. CWF panels were not fastened in place.

B. LWC with an embedded wire mesh was set in place on the concrete Ts and CWF panels. The LWC was observed in place on most but not all of the exposed deck areas. It was considered that, in areas where CWF panels did not appear to have had an LWC covering, panels might have been put in place during a reroofing operation.

C. A \# 30 bottom ply sheet was loosely fastened into the LWC/CWF panels with 1 in. cap nails.

D. Perlite (1 in.) was hot-mopped to this base ply.

E. A 4-ply BUR was hot-mopped to the perlite. Two plies were under the gravel stop and two on top of the gravel stop; membrane had a pea gravel aggregate surface.

F. Curbs were constructed of built-up, nailed-in-place wood members. The top layer consisted of $1 \times 4$ in. wood nailers fastened with coated box nails, 16 in. o.c. The bottom nailer, which remained in place after the blowoff, was either bolted to the steel angle supporting the CWF panels at the overhang (at the south edge) or power-fastened to the concrete Ts. Top nailers were poorly fastened to the well-attached bottom nailers. A short length of nailer along the south edge was rotted. The curb detail was found to be intact for about 18-24 in. along both roof edges at the southeast corner; the metal flashing detail was missing.

G. The fascia side of the metal cap flashing was face-nailed at some locations.

H. The membrane was a reroofing application. It appeared that the prior membrane also had a base ply mechanically fastened to the LWC. Apparently when the original membrane was torn off during reroofing, the fasteners remained in place in the LWC. These remaining original fasteners give the appearance that during Katrina, the bottom ply sheet of the current roofing system tore around fasteners at the LWC. However, sections of the hurricane-damaged roofing with cap nails embedded in the bottom ply sheet were found in some debris piles. That is, the hurricanedamaged membrane failed at the LWC, but the failure was due to the fasteners pulling from the LWC when the membrane released. 
METHOD OF ATTACHMENT-Mechanical attachment of a base ply to the LWC; the remaining layers were hot-mopped.

NOTED DAMAGE—Roof assembly, some CWF deck panels, and flashings blew off.

DAMAGE INITIATION AND PROPAGATION-In summary, the roof was damaged at the southeast corner because of the generally poor attachment of key system components, including weak attachment of upper layers of wood edge curb to the well-secured bottom nailer layer fastened to the deck; lack of attachment of CWF panels (held in place only by gravity); inadequate mechanical fastening of the bottom ply sheet to the LWC.

ROOF DAMAGE-Damage occurred at the windward southeast corner of the building. Perimeter edging on the south side of the roof was blown off, along with some CWF panels. The roof edge at this location had a $4 \mathrm{ft}$ wide overhang. CWF panels were missing at the overhang or immediately next to it. On the east side of the roof, the edge metal was missing, although some loosely secured nailers were still in place on the concrete Ts. Also on the east side, a $4 \mathrm{ft}$ wide roof section was missing the leveling fill, perhaps either LWC or perlite insulation board, on the pre-cast concrete Ts. The top surface of this concrete $\mathrm{T}$ was remarkably clean; i.e., it was not clear that the fill material had ever been adhered or fastened to the concrete T surfaces. In sections where the membrane blew off, failure occurred at the interface of the bottom ply sheet with the LWC or the CWF panels. Fasteners were pulled from these substrate materials along with the membrane. Some debris piles contained edge flashing nailers and metal gravel stops that were still connected to the displaced membrane.

ADDITIONAL COMMENTS-It was estimated that the membrane system was more than 10 years old. No damage occurred to any of the other buildings at this school.

\section{Photographs of RoOf DAMAge}

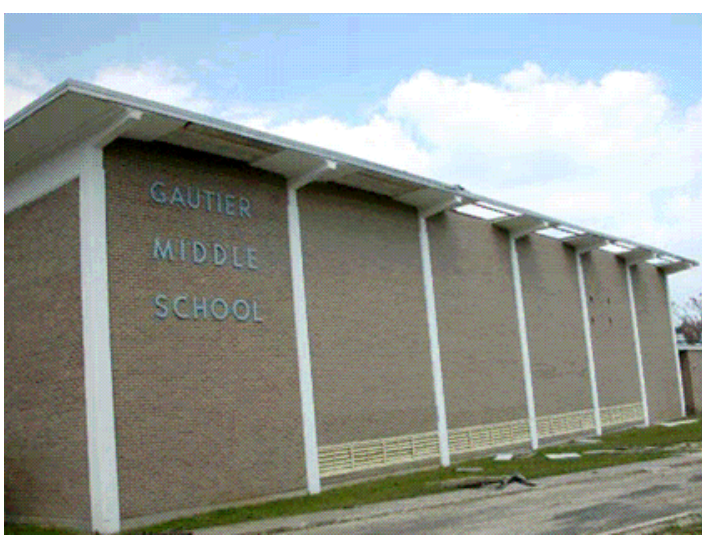

1.18-1. Gautier Middle School. This is the south side of the damaged building.

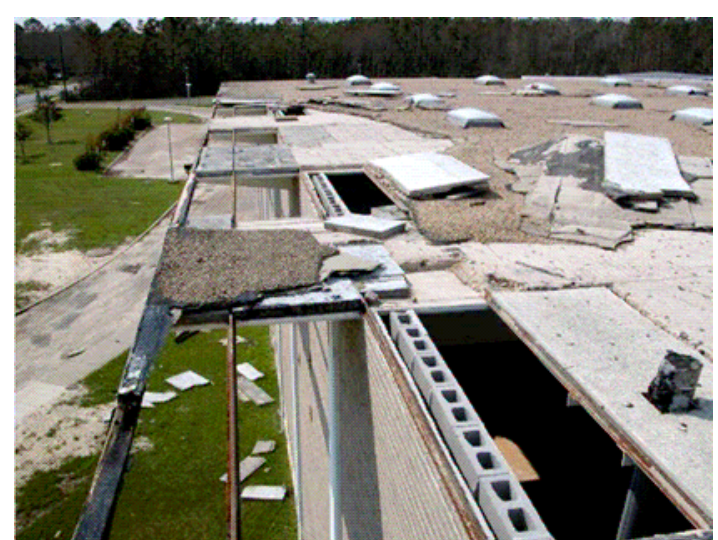

1.18-2. Gautier Middle School. Another view of roof damage along south side of the building. 


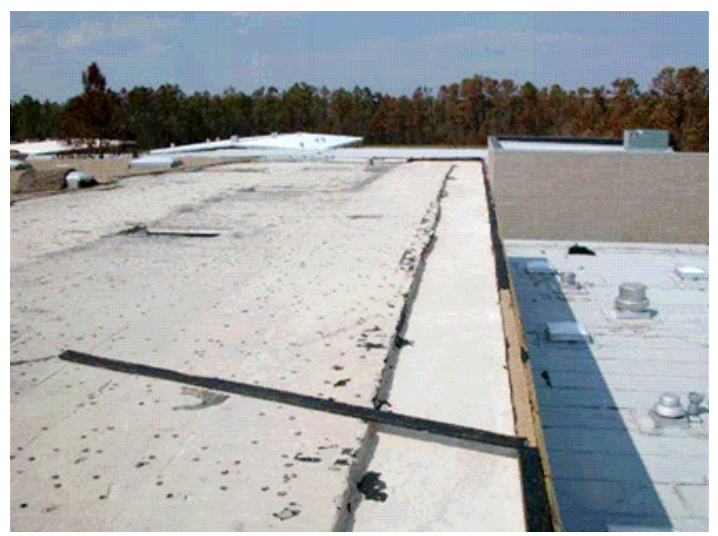

1.18-3. Gautier Middle School. Roof damage along the east side of the building is visible in this photo.

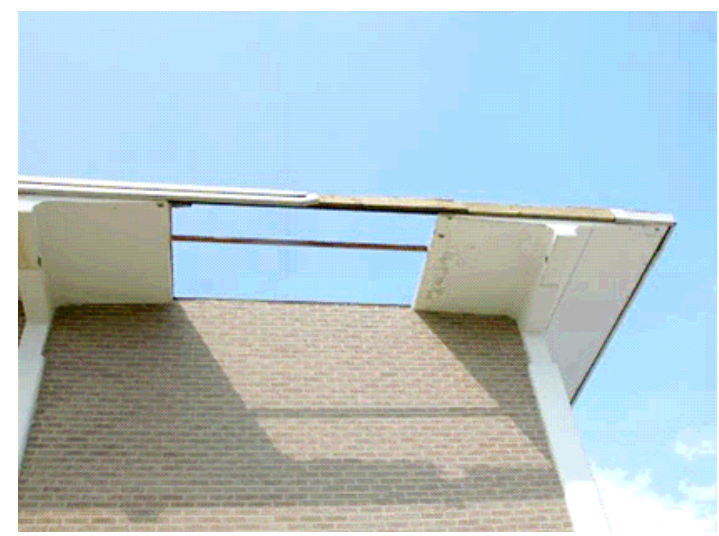

1.18-4. Gautier Middle School. Southeast corner of the roof. The CWF panels (forming the deck between the concrete single Ts) are missing.

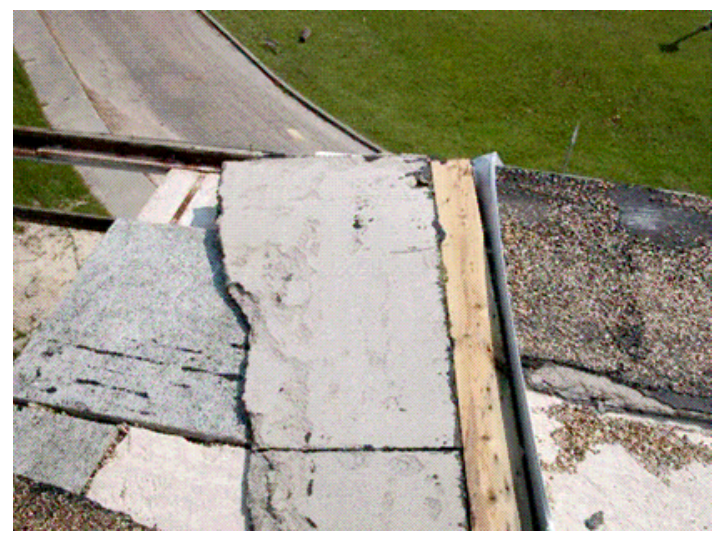

1.18-5. Gautier Middle School. Damage to the edge detail at the east side of the building is shown here. It was not apparent how the perlite board was secured to its substrate at this location. 


\section{HURRICANE KATRINA: TEAM 2}

\section{OVERVIEW}

One of the key objectives of the RICOWI Wind Investigation Program teams was to obtain impartial data for a variety of roofs, with a primary focus on what were termed "essential facilities." Team 2 focused on schools, a hospital, several supermarkets, and industrial facilities. Schools were important because they were used for shelter. Hospitals are obviously essential and must be kept in operation during a storm to treat the inevitable injuries. The need for continued access to food makes supermarkets essential. Finally, if the place where residents work is safe, knowing they still have jobs makes a great difference in their outlook for the future and their families' confidence and mental health.

Katrina's storm surge on the Mississippi coast left many of these essential facilities unusable and, in many cases, destroyed. It was useful, however, to examine roof damage to facilities even if storms had rendered them unusable. Despite the limited inspection time, owing to difficult travel conditions, teams were able to see most of the commonly used low slope roofs in the area and see how well they resisted 120-130 mph winds.

\section{Team Members}

The following members participated on Team 2:

Bas Baskaran, photographer

Jerry Beall, sample collector

John Goveia, photographer (day 1)

Dave Roodvoets, report writer

Patty Wood-Shields, data recorder

\section{Summary Observations}

As in previous examinations of storm damage from Hurricanes Charley and Ivan, edge failure propagation was one of the leading causes of significant roof damage. The mechanically attached single ply systems examined by Team 2 fared well. There was no evidence of punctures from debris resulting in tears or other failures. Several gravel-ballasted single ply systems were examined that had some stone scour. Stone typically remained on the roof, except in one case where a tornado-like occurrence may have hit the roof and displaced a few stones.

The aggregate-surface built-up roofing (BUR) we examined generally performed well. However, all such systems had significant aggregate scour, and where there were no parapets, the aggregate blew off the roof. Low slope roofs seemed to fare well where maintenance procedures were followed, with little or no damage.

Our primary objective was inspection of low slope roofs; however, the failure and performance of steep roofs intrigued us. On one school, where low slope membrane damage was prevalent and significant, there was limited metal roof failure on steep slopes facing in almost every direction. In addition, the repetitive nature of steep slope shingled roof damage led to a specific investigation that confirmed the cause of the failure of 3-tab shingles. It was most often related to a practice in the South of installing shingles in a racked fashion. The shingles are installed in a pattern that starts at the bottom of the slope and goes to the top of the roof in a vertical line, instead of the diagonal stairstepped pattern recommended by most manufacturers. The racking method typically results in at least 
one missing nail per shingle because it is necessary to lift the overlying shingle to access the nailing point; in many cases, two or more nails were missing.

Maps of the areas visited by Team 2 are marked with numbers that correspond to the inspection report numbers.

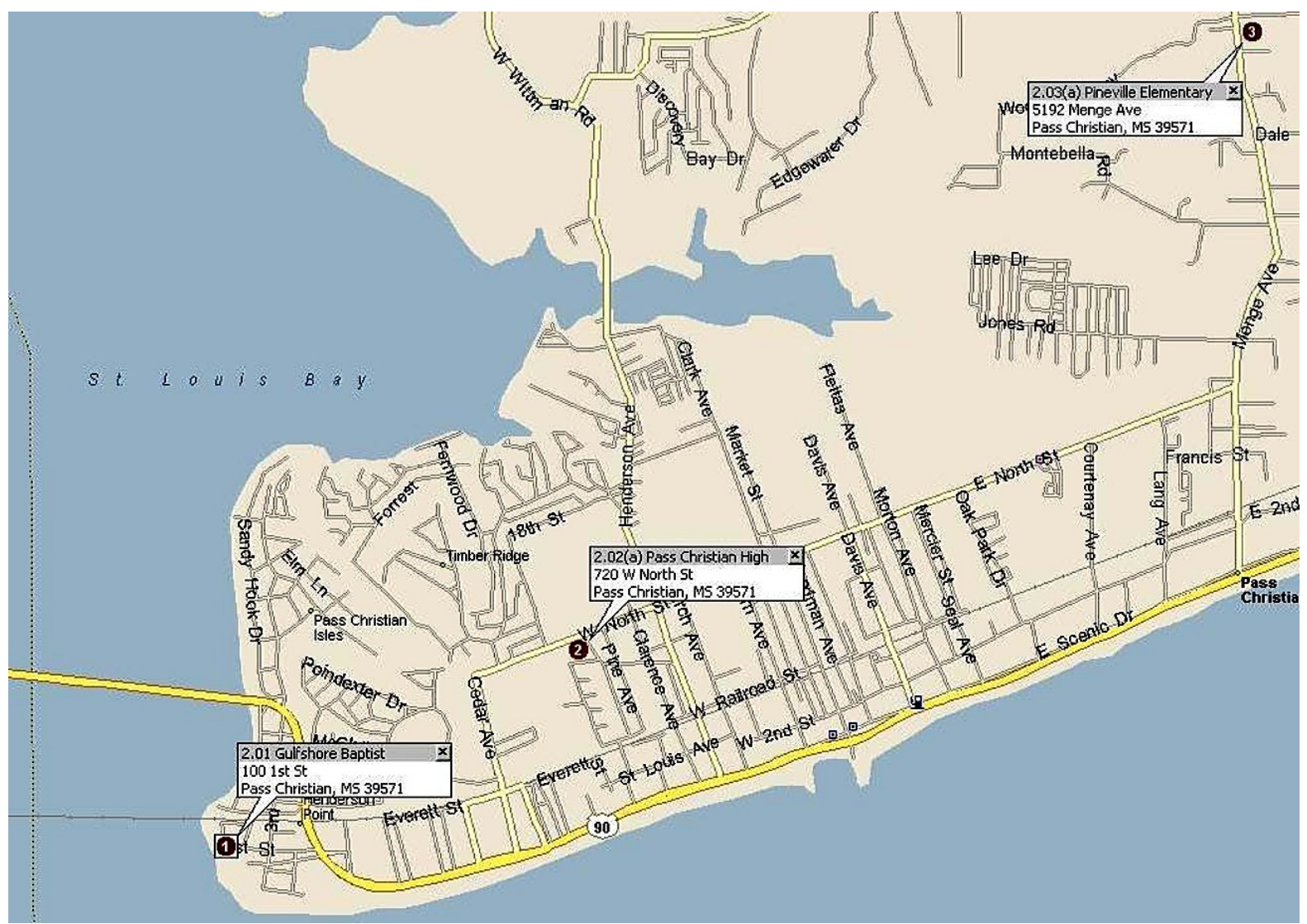

Map 1. Pass Christian area. 


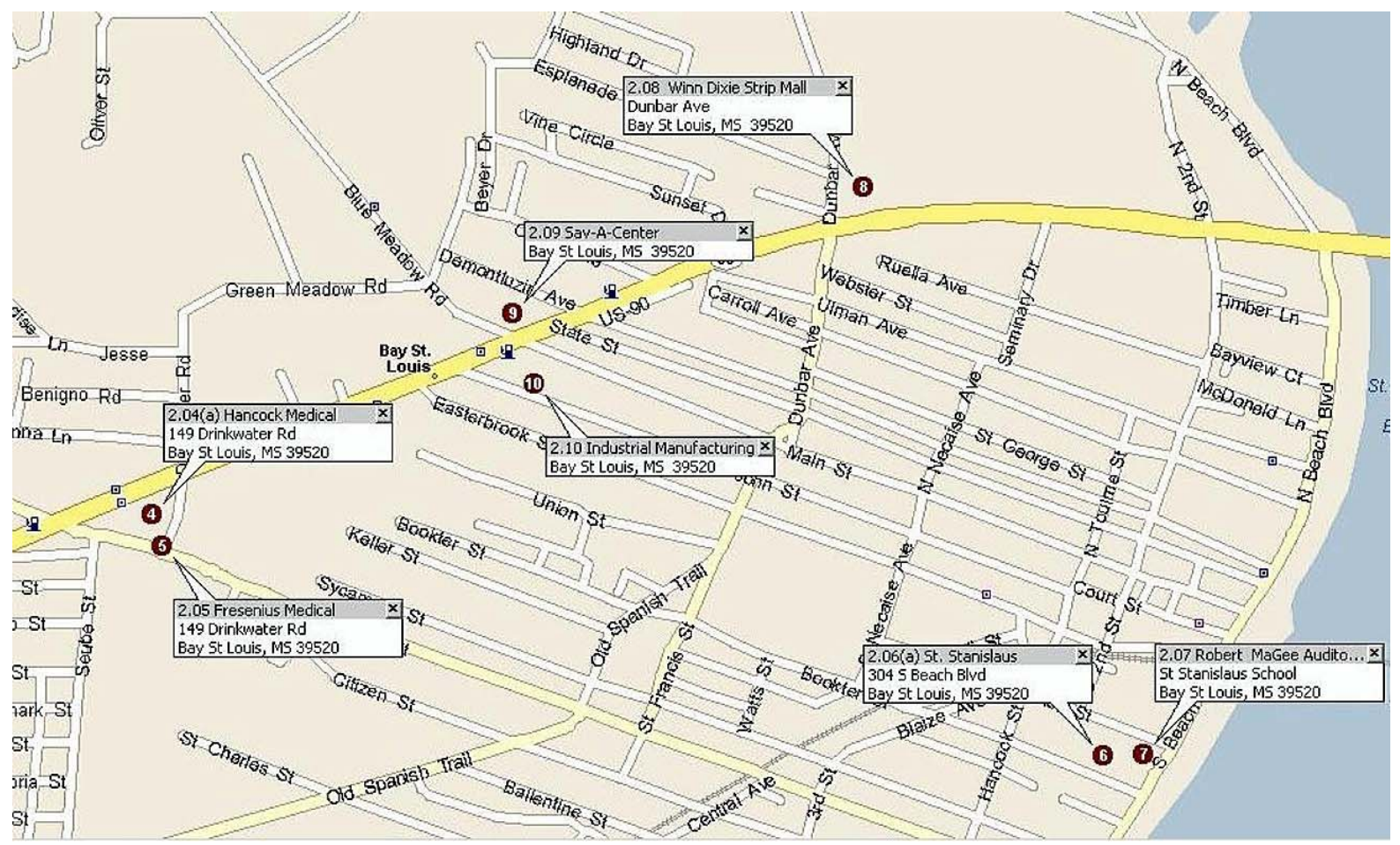

Map 2. Bay St. Louis area.

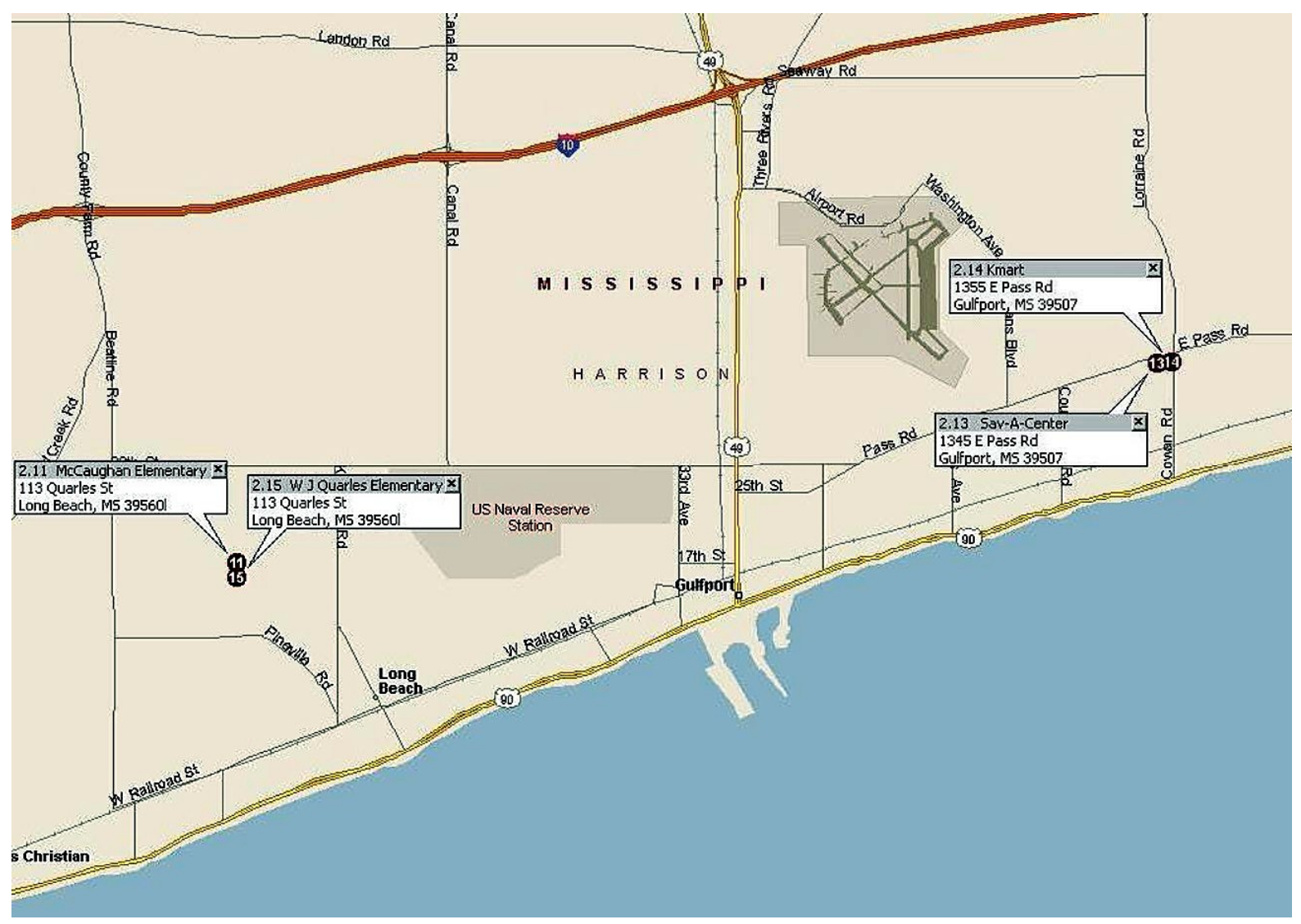

Map 3. Gulfport area. 


\section{INDIVIDUAL ROOF REPORTS}

\subsection{Mississippi Baptist Convention, Gulfshore Assembly, Bayview, Pass Christian, MS}

TYPE OF STRUCTURE-School

EXPOSURE-C

SITE COORDINATES-N30 $18^{\prime}$ W89 $17^{\prime}$

WALL CONSTRUCTION_-Infill wall panels on steel studs

ROOF TYPE—BUR aggregate-surface

SLOPE-0-1/4:12

ROOF HEIGHT $-45 \mathrm{ft}$

ROOF WIDTH- $105 \mathrm{ft}$

ROOF LENGTH-175 ft

DECK - Cast-in-place concrete

WIND SPEED-120-130 mph

BUILDING CONSTRUCTION_Cast-in-place concrete

METHOD OF ATTACHMENT-Membrane adhered to insulation adhered to concrete deck

NOTED DAMAGE-Roof assembly was basically intact with no apparent wind damage to membrane. Medium-size aggregate surfacing was scoured on all roof areas, but there were no signs of gravel blown off roof. Aggregate scour was stopped by height of parapet and lower expected lift forces on the membrane and surfacing because of the parapet heights. Parapet heights ranged from 42 to $48 \mathrm{in.} \mathrm{In} \mathrm{the} \mathrm{initial} \mathrm{upwind} \mathrm{direction,} \mathrm{there} \mathrm{were} \mathrm{double} \mathrm{parapets,} \mathrm{with} \mathrm{a} \mathrm{unique} \mathrm{grillwork} \mathrm{between}$ the first and second parapet. Scour patterns indicated that strong winds hit the building from several directions. Lightning air arresters in most cases were undamaged. Three exhaust fans were displaced from curbs, and several air conditioners were toppled. The two lower floors of the building interior were severely damaged from the storm surge, which was officially measured by the U.S. Geological Survey team at $28 \mathrm{ft}$ from ground level ( $5 \mathrm{ft}$ above sea level), with water at least $1 / 2 \mathrm{in}$. deep on the third floor. The first two floors had $100 \%$ wall openings, and the third floor had $30 \%$ wall openingsall due to storm surge.

DAMAGE INITIATION AND PROPAGATION—The roof can truly be considered a survivor, providing protection for the structure below with no actual damage to the membrane or consequential damage from gravel blowoff. Water would not have entered through the roof except in areas where the air handlers were displaced, or via direct access through holes in the deck where air handlers and duct work were missing.

ADDITIONAL COMMENTS - This building was in a unique exposed location at the Point of the Bay inlet, in the heart of the highest winds that made landfall. The lack of roof damage is likely due to several factors: the high parapet reduced the perimeter and corner uplift and, because the storm surge was at $28 \mathrm{ft}$ at the building, the roof was effectively $17 \mathrm{ft}$ in elevation for much of the storm. This reduced the potential wind uplift at the roof edges and, combined with the high parapets, resulted in a well-built roof surviving the storm.

Storm surge damage to the building was significant, wiping out the interior and walls of the entire first and second floors. The third floor, below the roof, had significant wind damage, but the concrete deck prevented interior pressurization of the roof membrane. In many places, it could have functioned as an open or unenclosed building. 


\section{Photographs of RoOf DAmage}

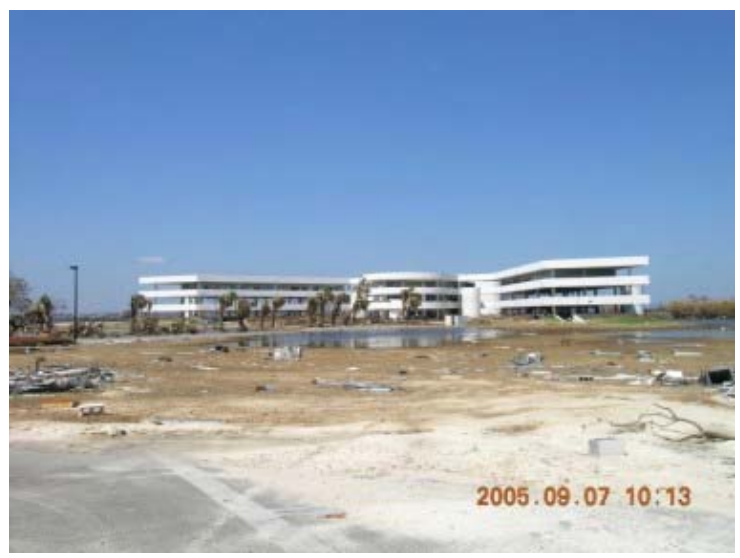

2.01-2. Gulfshore Assembly. This is a wide-angle view.

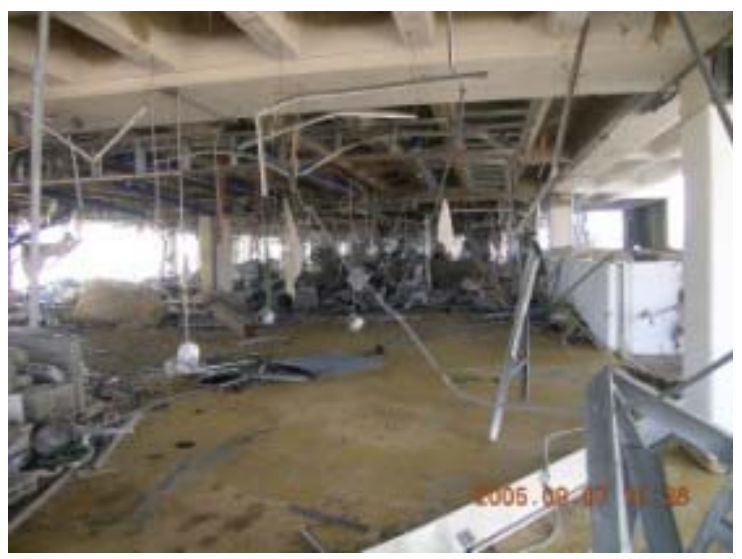

2.01-3. Gulfshore Assembly. Storm surge damaged this interior area.

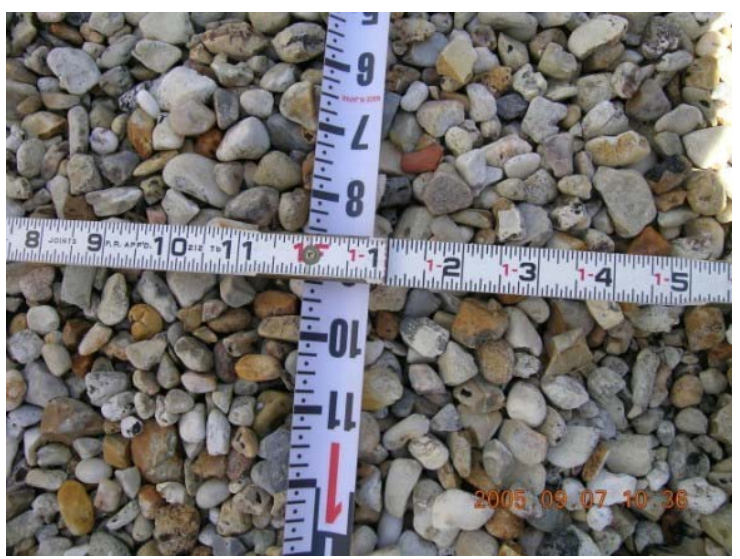

2.01-5. Gulfshore Assembly. Aggregate size was $1 / 2$ in. or less.

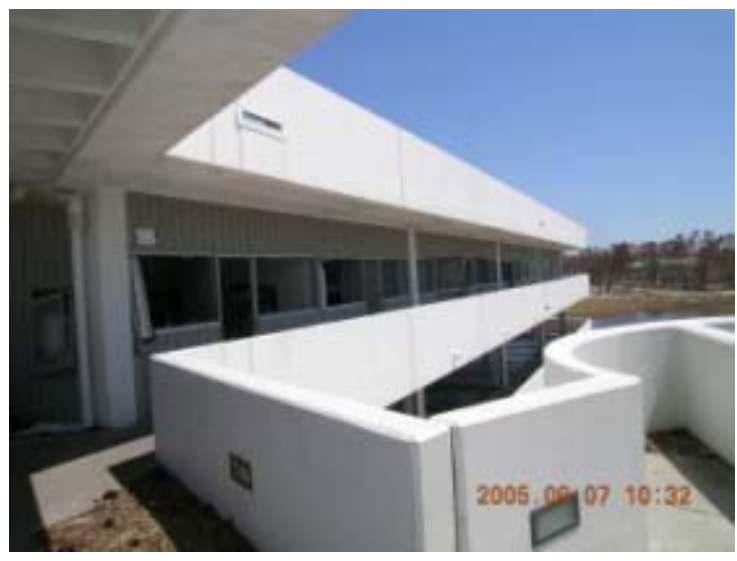

2.01-2. Gulfshore Assembly. The water line on this wall indicates a $28 \mathrm{ft}$ storm surge.

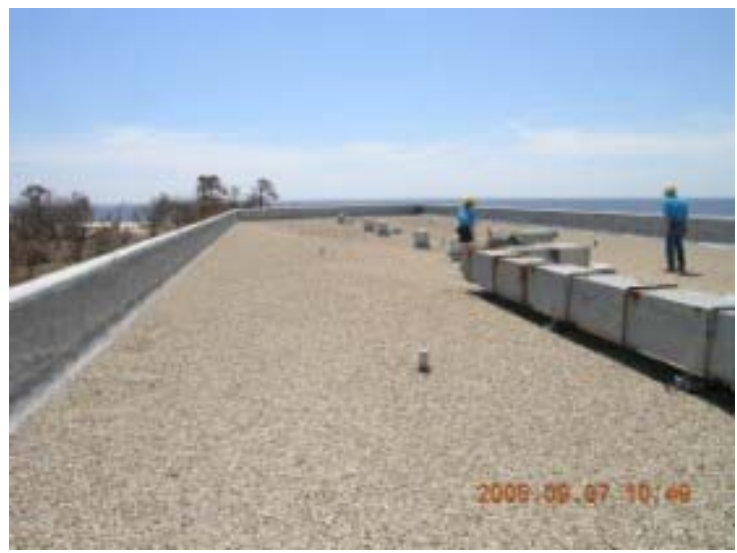

2.01-4. Gulfshore Assembly. An aggregatesurfacing scour pattern and high parapet can be seen on this roof.

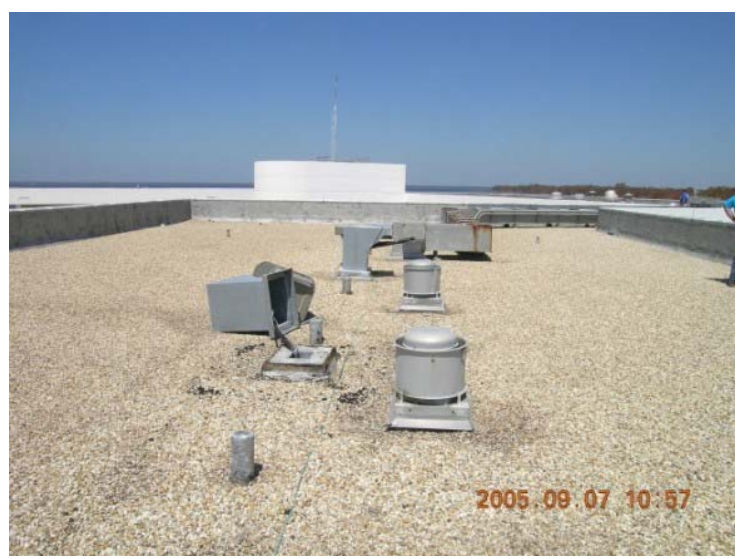

2.01-6. Gulfshore Assembly. This was typical of air-handler damage. Note the limited aggregatesurfacing scour. 


\subsection{2(a) Pass Christian High School, 720 West North Street, Pass Christian, MS (Gymnasium)}

TYPE OF STRUCTURE-School

EXPOSURE-C

SITE COORDINATES-N30 $19^{\prime}$ W88 $16^{\prime}$

WALL CONSTRUCTION—Brick masonry

ROOF TYPE—Granular-surface styrene-butadiene-styrene (SBS) modified bitumen 2-ply

SLOPE- $-1 / 4: 12$

ROOF HEIGHT-32 ft

ROOF WIDTH- $150 \mathrm{ft}$

ROOF LENGTH-150 ft

DECK-Steel

WIND SPEED-120-130 mph

BUILDING CONSTRUCTION-Steel frame

METHOD OF ATTACHMENT-Mechanical attachment of first layer of insulation. Top layer of insulation was mopped with asphalt, and membrane was mopped to insulation.

NOTED DAMAGE-Approximately $40 \%$ of the roof membrane was blown completely off the building. Edge securement was missing on most of the eastern side of the roof and the eastern half of the diagonal southeast edge. Although it was more than a mile inland, the building was subjected to significant storm surge, with the interior flooded up to approximately $8 \mathrm{ft}$ deep. Edge failure included the top layer of bricks on the southeast corner.

DAMAGE INITIATION AND PROPAGATION-It appears that edge failure led to peeling away of the membrane until a significant change in attachment occurred. The membrane peel stopped at the point of change from sloping toward the eastern edge of the roof to sloping toward the western edge. The east perimeter nailer was not well attached to the building. The metal gutter had spacer straps but no rigid supports; it relied on the gutter flange, which bent, creating a sail that caught the wind and pulled the nailer apart and off at the base. To further add to pressurization forces, the wood nailer was discontinuous - the installation used wood blocks approximately $2 \mathrm{ft}$ long, over which was a continuous nailer. Therefore, the space between the brick and the blocked-up nailer could allow air flow infiltration. The top layer of the brick wall also became dislodged in the upwind northeast corner.

ADDITIONAL COMMENTS-The walls were solid masonry. The few steel doors likely remained closed until the action of the water from the storm surge opened them, and then the building quickly filled with water to a height equal to the top of the doors. So it is unlikely there was any excessive internal pressure. The damage to the roof was almost certainly from exterior uplift. 


\section{Photographs of Roof Damage}

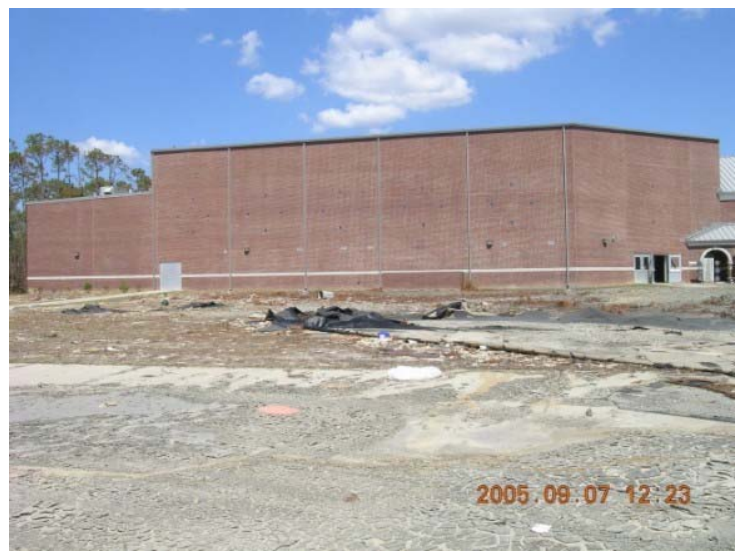

2.02(a)-1. Pass Christian HS. This is the west side of the gym, showing the roof membrane from the east slope on the ground.

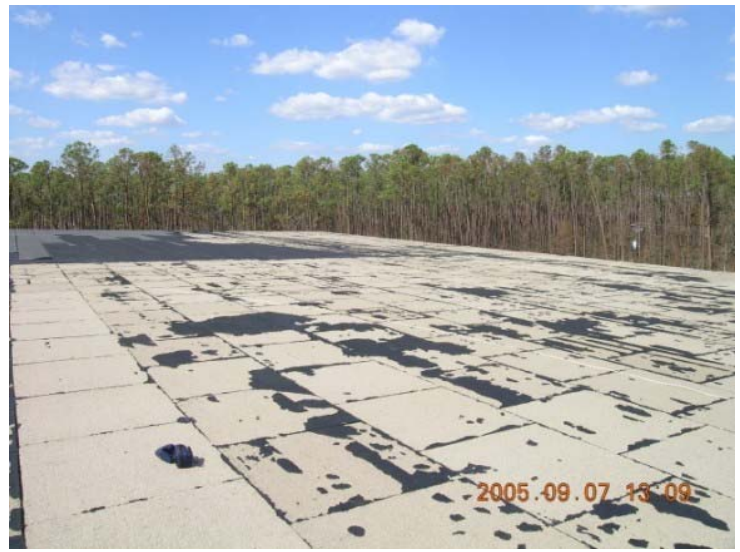

2.02(a)-3. Pass Christian HS. High winds caused the membrane to peel free from insulation in this area.

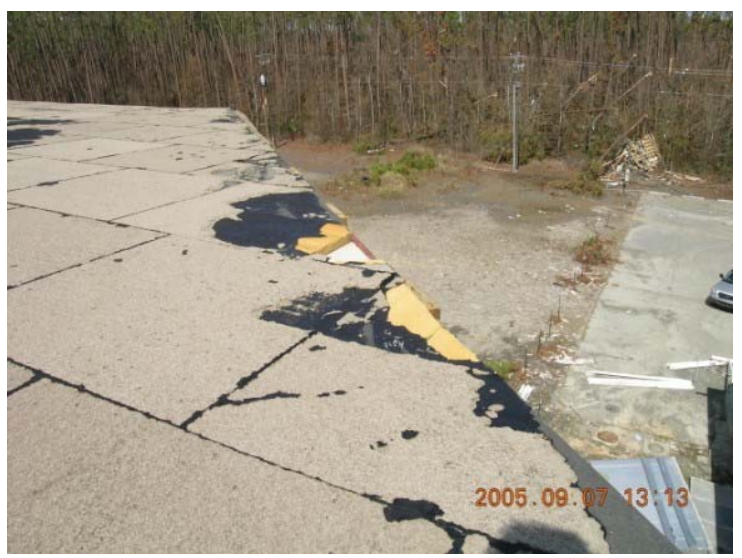

2.02(a)-5. Pass Christian HS. Edge failure typically begins at the weakest point, where the membrane peels free of the perlite insulation.

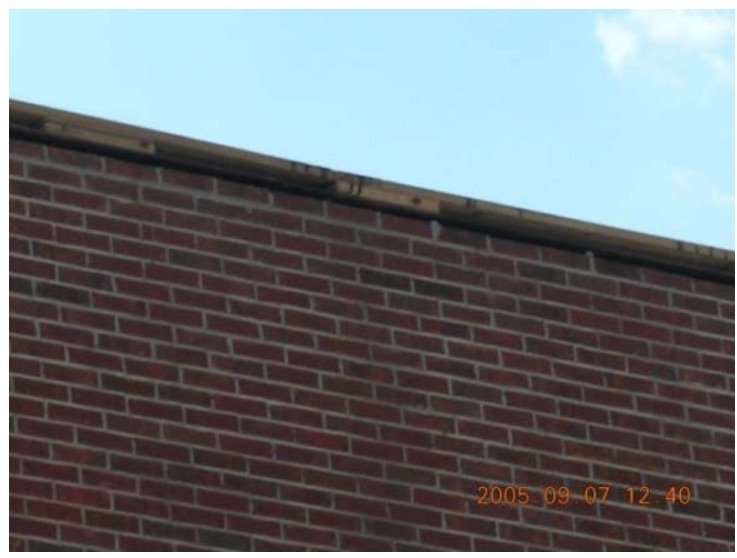

2.02(a)-2. Pass Christian HS. A look at the gym's east side shows where brick, spaced up nailer blocks, and edge metal are missing.

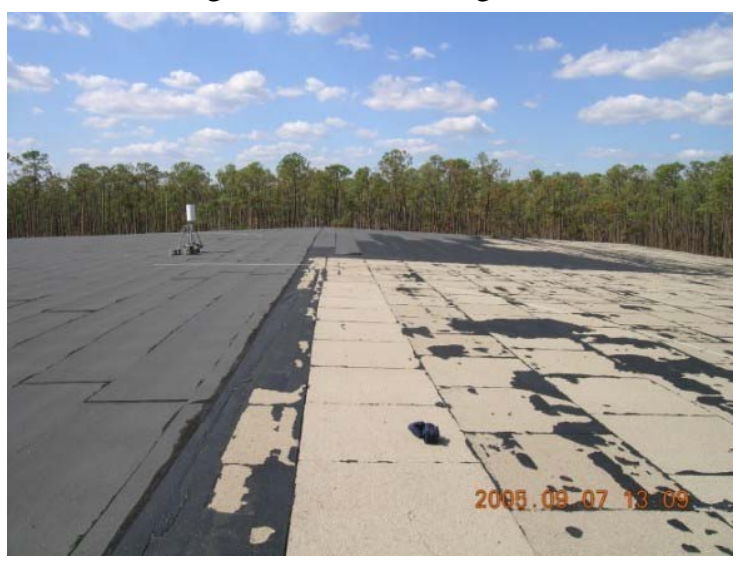

2.02(a)-4. Pass Christian HS. The membrane peel stopped at the center of this roof, likely a construction tie-in.

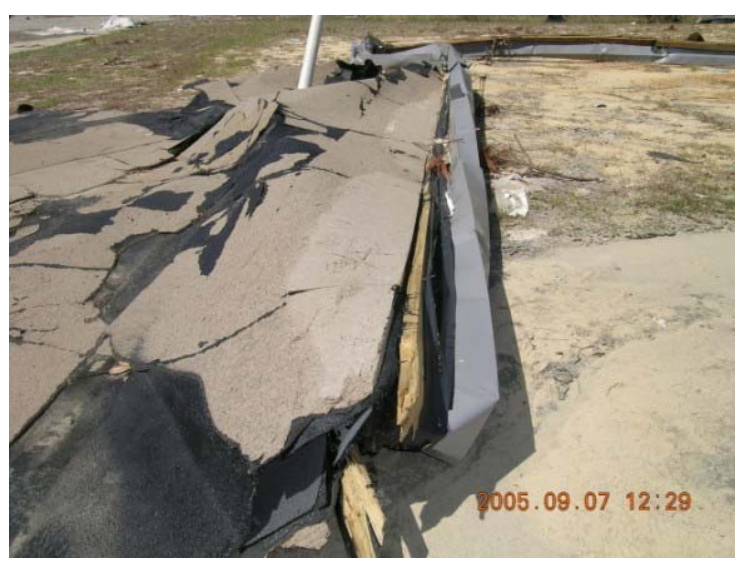

2.02(a)-6. Pass Christian HS. A common cause of edge failure is poor anchoring of wood blocking layers to each other or to the substrate. Membrane is on the ground to west of building. 


\subsection{2(b) Pass Christian High School, 720 West North Street, Pass Christian, MS}

TYPE OF STRUCTURE-School

EXPOSURE-C

SITE COORDINATES-N30 $19^{\prime}$ W8 $88^{\circ} 16^{\prime}$

WALL CONSTRUCTION-Brick

ROOF TYPE-Standing seam

SLOPE-4-6: 12

ROOF HEIGHT - $22 \mathrm{ft}$ to eave

ROOF WIDTH-100 ft

ROOF LENGTH-200 ft

DECK-Steel

WIND SPEED-120-130 mph

BUILDING CONSTRUCTION-Steel frame

METHOD OF ATTACHMENT—Standing seam with clips

NOTED DAMAGE-Two 161/2 in. snap-lock panels were blown off and there was a small amount of hip and ridge damage; remainder of field of roof was okay.

DAMAGE INITIATION AND PROPAGATION—Metal panels unzipped on exposed roof area.

ADDITIONAL COMMENTS-This roof was in generally good shape except for the two panels that were dislodged. Other more-protected metal roofs had no damage. The school was heavily damaged by storm surge.

\section{Photographs of Roof Damage}

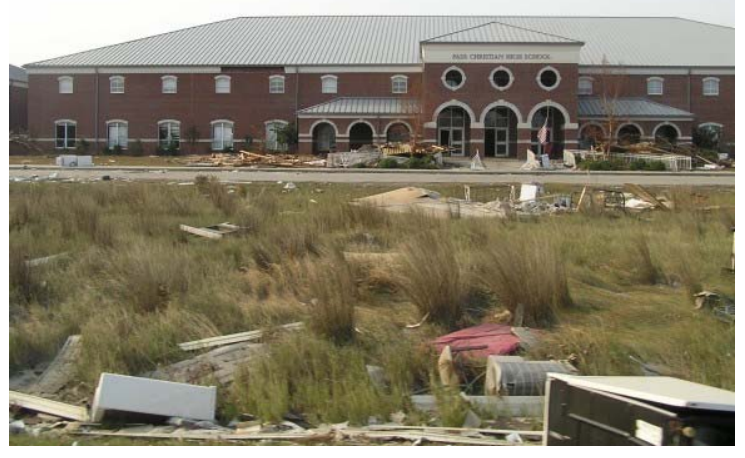

2.02(b)-1. Pass Christian HS. This is the southern exposure.

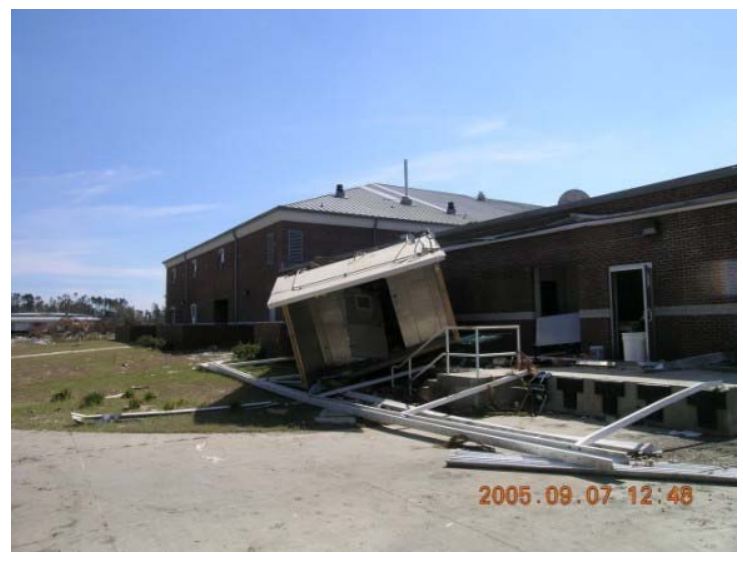

2.02(b)-2. Pass Christian HS. A view of the north exposure toward the east side shows missing panels. 


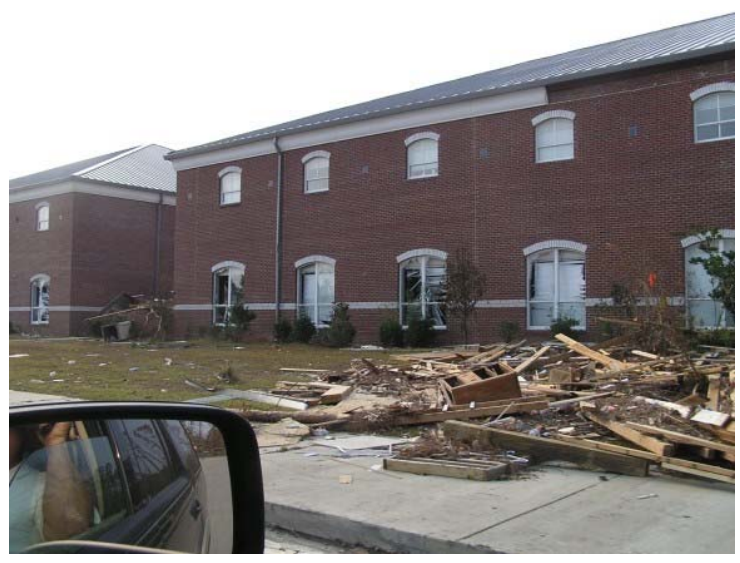

2.02(b)-3. Pass Christian HS. Soffit panels were missing on the south side.

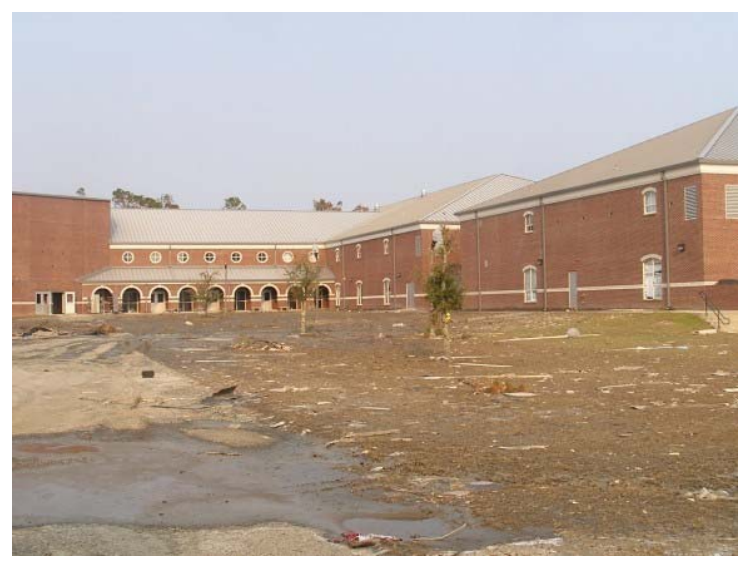

2.02(b)-4. Pass Christian HS. This is the west exposure of the building and north exposure on the right.

\subsection{3(a) Pineville Elementary, 5192 Menge Avenue, Pass Christian, MS}

TYPE OF STRUCTURE-School

EXPOSURE-B

SITE COORDINATES-N30 $21^{\prime} 89^{\circ} 13^{\prime}$

WALL CONSTRUCTION-Masonry with many windows, panel in-fill window wall sections

ROOF TYPE-Granular-surface modified bitumen SBS

SLOPE- $-1 / 4: 12$

ROOF HEIGHT-16 ft

ROOF WIDTH-275 ft

ROOF LENGTH- $42 \mathrm{ft}$

DECK-Cementitious wood fiber (CWF) manufactured panel units

WIND SPEED-120-130 mph

BUILDING CONSTRUCTION_-Typical school: steel-frame roof on masonry walls

METHOD OF ATTACHMENT_-Original: aggregate-surface BUR with nailed base sheet. Re-cover: multi-layer perlite insulation adhered to polyisocyanurate, asphalt adhesion to original membrane surfacing.

NOTED DAMAGE - Large area of complete displacement of membrane and insulation. Edge metal damaged, torn, and missing. Exhaust fans were displaced, building was subjected to a low-elevation storm surge. Debris from this roof damaged the upper elevation roof membrane and cooling equipment.

DAMAGE INITIATION AND PROPAGATION—CWF deck is somewhat air-permeable, resulting in pressure between the CWF and the membrane in the overhang area. The pressure on the underside of the membrane (positive pressure) and the uplift found the weakest link to be the rusted fasteners that secured the original membrane. Once there was an initial failure, the base sheet proved to have inadequate resistance to prevent nail pull-out ("pull-through"). The spread of the damage stopped where the uplift forces were reduced, e.g., away form the roof corner. Several of the CWF panels 
were blown off in the overhang area, and in the corner, both the steel structure and the brick wall were damaged.

ADDITIONAL COMMENTS-This re-covered roof demonstrates the need to assess the condition of the existing system before reroofing. The initial securement was rusted and not able to withstand the uplift loads because of the age of the original roof. A portable uplift tester might have identified this problem, and the problem might have been correctable with new fasteners, new base sheet, or a complete reroofing (tear off and replacement of the existing membrane with new materials).

\section{Photographs of Roof Damage}

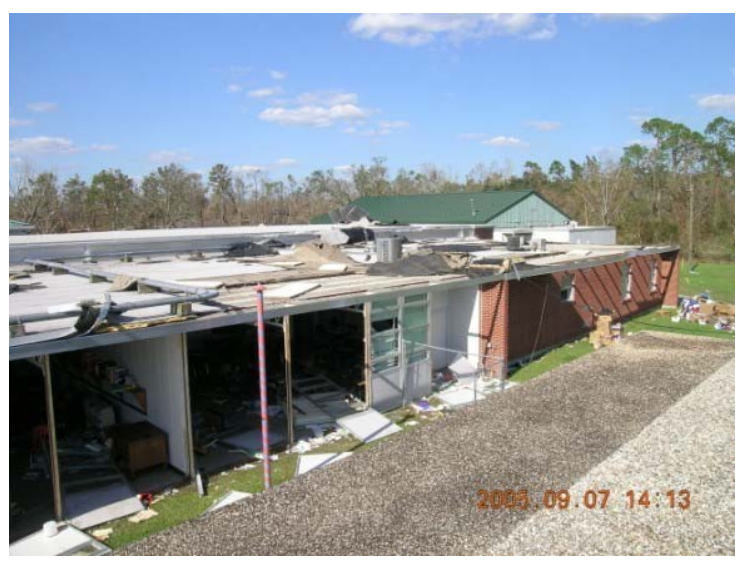

2.03(a)-1. Pineville Elementary. This photo shows a large area of the damaged roof and window and panel sections.

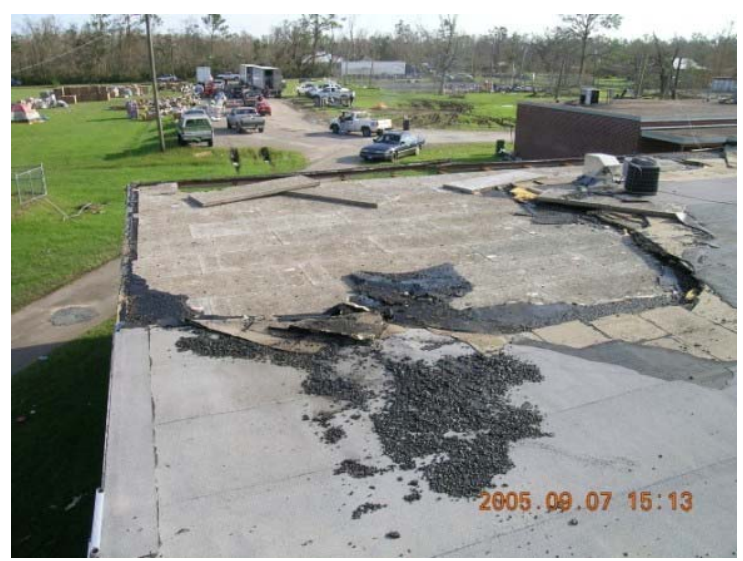

2.03(a)-3. Pineville Elementary. This corner view shows displacement of roof covering and CWF panels and SBS membrane delaminated from perlite.

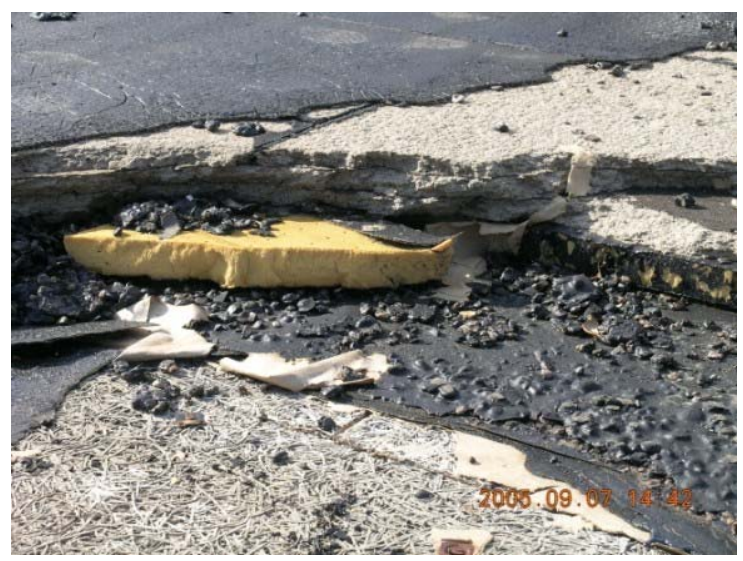

2.03(a)-2. Pineville Elementary. From the bottom up, this assembly consists of CWF decking, original membrane with aggregate surfacing, asphalt, polyisocyanurate foam insulation, perlite board and modified bitumen membrane.

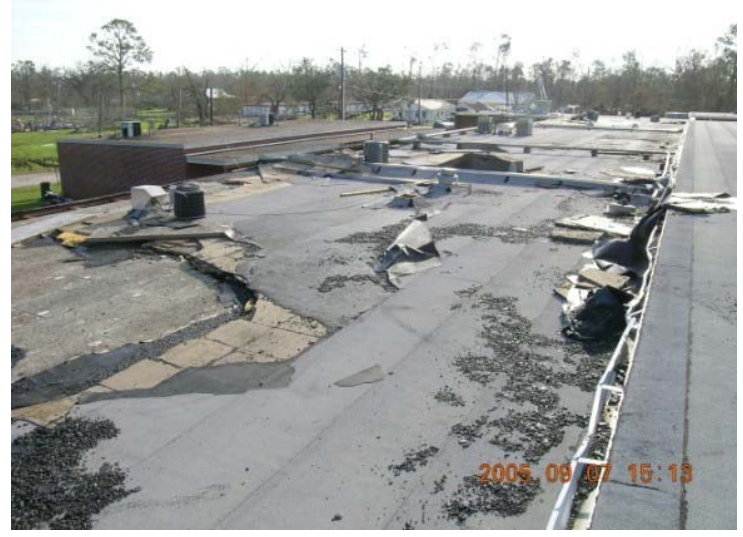

2.03(a)-4. Pineville Elementary. This damage pattern is what would be expected from an oblique cornering wind load. 


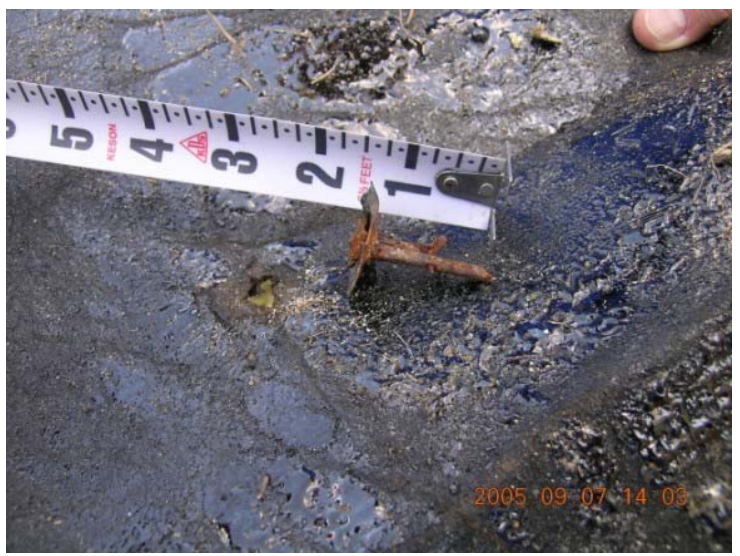

2.03(a)-5. Pineville Elementary. This is a typical corroded fastener.

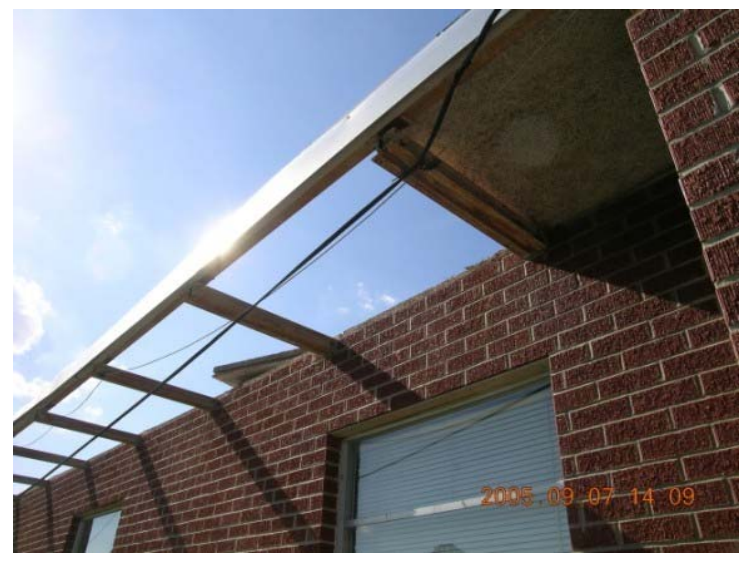

2.03(a)-6. Pineville Elementary. Panels were displaced from this overhang.

\subsection{3(b) Pineville Elementary, 5192 Menge Avenue, Pass Christian, MS}

TYPE OF STRUCTURE—School

EXPOSURE-B

SITE COORDINATES-N30 $21^{\prime}$ W89 $13^{\prime}$

WALL CONSTRUCTION_Brick

ROOF TYPE-BUR aggregate-surface

SLOPE- $-1 / 4: 12$

ROOF HEIGHT- $16 \mathrm{ft}$

ROOF WIDTH-78 ft

ROOF LENGTH-33 ft

DECK - CWF manufactured panel units

WIND SPEED-120-130 mph

BUILDING CONSTRUCTION—Typical school, steel-frame roof on masonry walls. This building was newer construction than surrounding school buildings.

METHOD OF ATTACHMENT—Unknown

NOTED DAMAGE-Some scour of aggregate surfacing. No other damage was noted.

DAMAGE INITIATION AND PROPAGATION-Not all of the aggregate surfacing was embedded in asphalt. Some was displaced, but it was not noted where it went; since there were no parapets, the gravel may have left the roof.

ADDITIONAL COMMENTS-This roof was performing its main function of keeping the building watertight. There would be no need to repair this section, whereas adjacent roofs with less exposure had significant damage. Re-dispersing the aggregate surfacing would be recommended. 


\section{Photographs of Roof Damage}

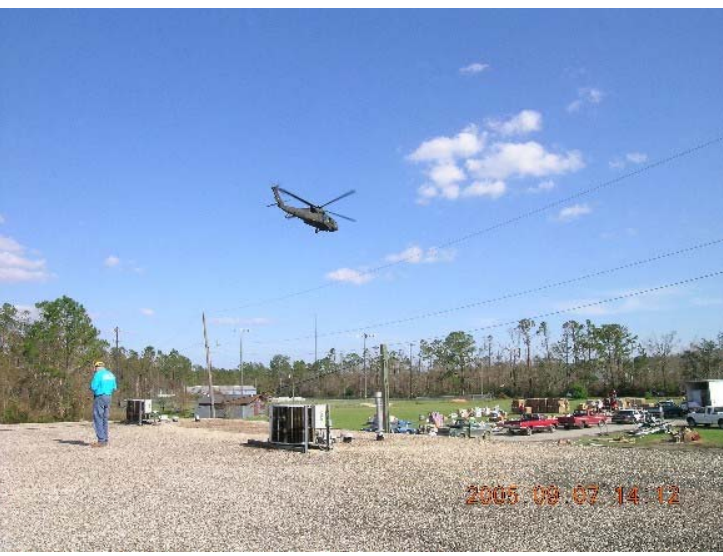

2.03(b)-1. Pineville Elementary. This is an overview of a roof where a cornering wind occurred.

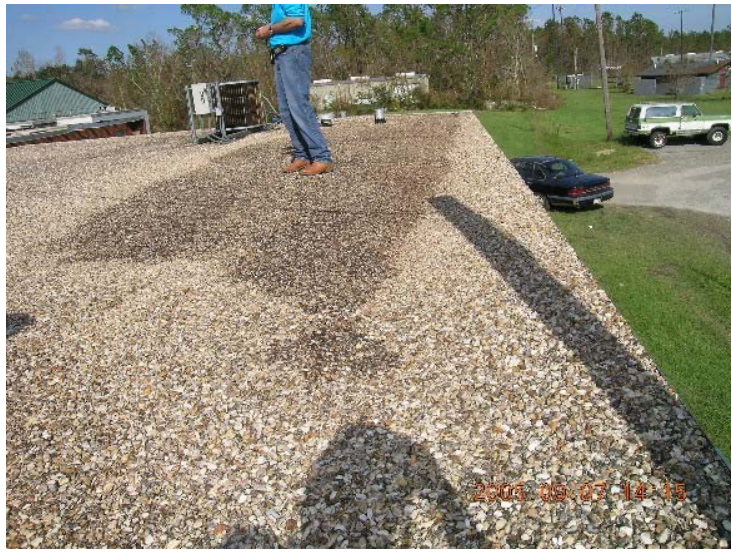

2.03(b)-3. Pineville Elementary. This is a typical scour pattern.

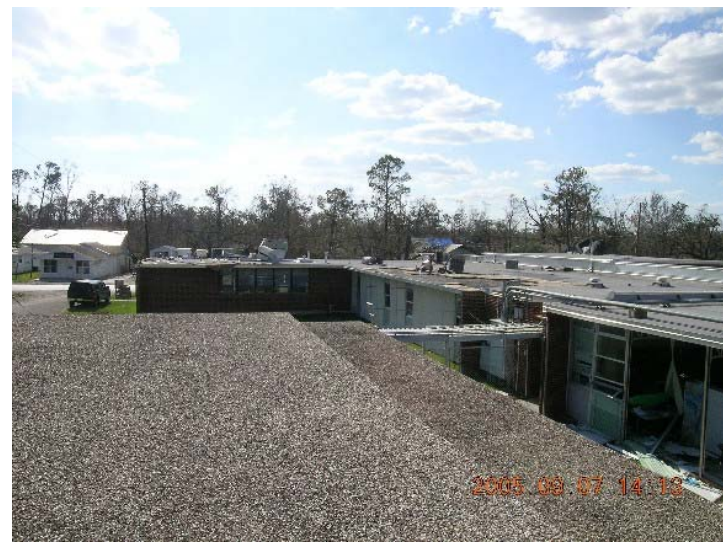

2.03(b)-2. Pineville Elementary. This is a view of the same roof from the opposite side.

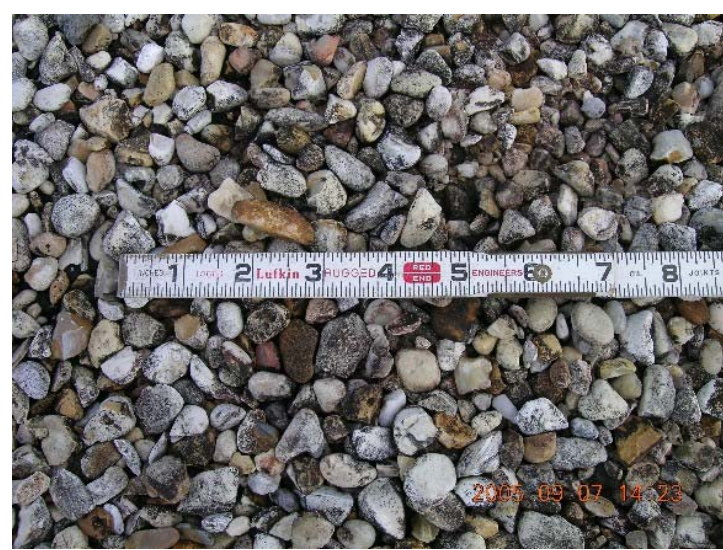

2.03(b)-4. Pineville Elementary. Average aggregate size about $1 / 2$ in., a slightly larger than common aggregate for surfaced BUR.

\subsection{3 (c) Pineville Elementary, 5192 Menge Avenue, Pass Christian, MS}

TYPE OF STRUCTURE-School

EXPOSURE-B

SITE COORDINATES-N30 $21^{\prime}$ W89 $13^{\prime}$

WALL CONSTRUCTION-Brick

ROOF TYPE-Modified bitumen

SLOPE— $1 / 4: 12$

ROOF HEIGHT- $16 \mathrm{ft}$

ROOF WIDTH- $51 \mathrm{ft}$

ROOF LENGTH-34 ft

DECK-Steel 
WIND SPEED-120-130 mph

BUILDING CONSTRUCTION_-Typical school; steel-frame roof on masonry walls

METHOD OF ATTACHMENT_-Hot-mopped with asphalt

NOTED DAMAGE—Displaced evaporative coolers and two punctures

DAMAGE INITIATION AND PROPAGATION-Evaporative coolers were on exposed wood sleepers that were not attached to the deck. Large pieces of airborne debris from the lower-elevation roof membrane and deck described in 2.03(a) hit the gutter, cooler units, and membrane; punctured membrane and insulation; and landed beyond this roof on the ground.

ADDITIONAL COMMENTS - The basic roof covering was intact and would require only minor repairs to relatively few damaged spots. An identical roof section was damaged in the same way. Both roofs could have been quickly made watertight. A nearby metal storage building was undamaged, and the architectural metal roof on the entrance of the building had only minor cosmetic damage.

\section{Photographs of Roof Damage}

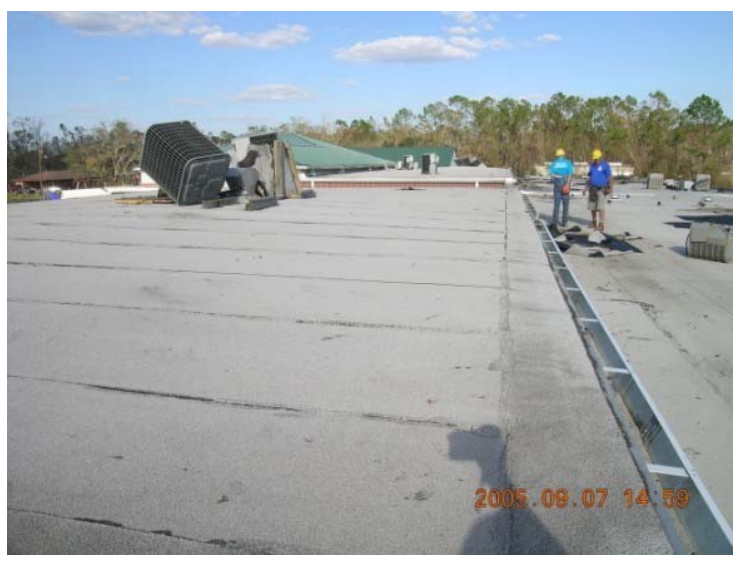

2.03(c)-1. Pineville Elementary. This modified bitumen roof was in relatively good condition overall.

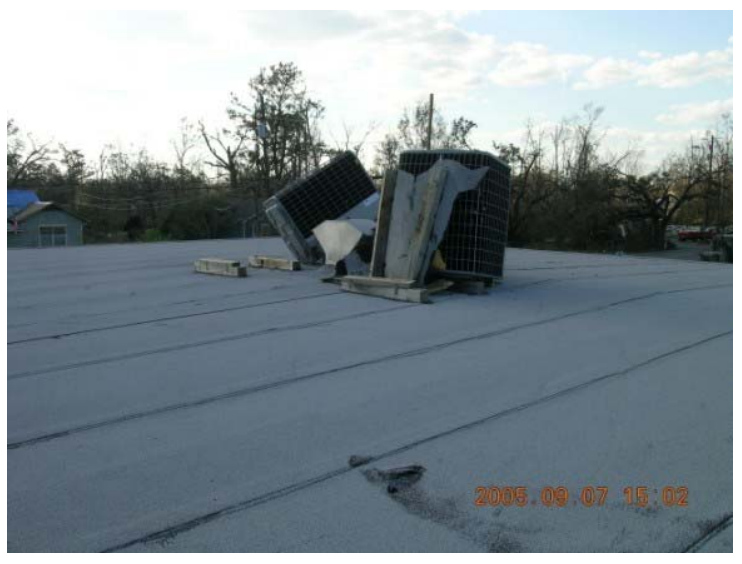

2.03(c)-3. Pineville Elementary. Wood supports in this photo were not secured to the deck. This resulted in HVAC displacement and roof punctures.

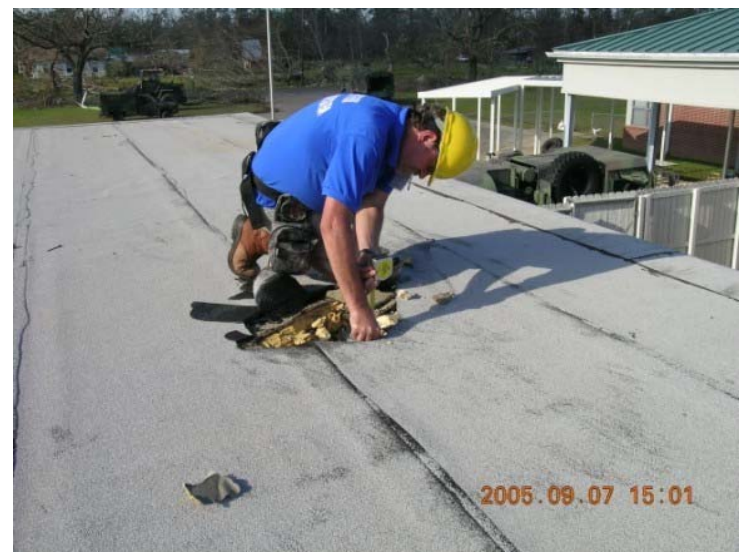

2.03(c)-2. Pineville Elementary. A gouge on this roof was apparently caused by windblown debris.

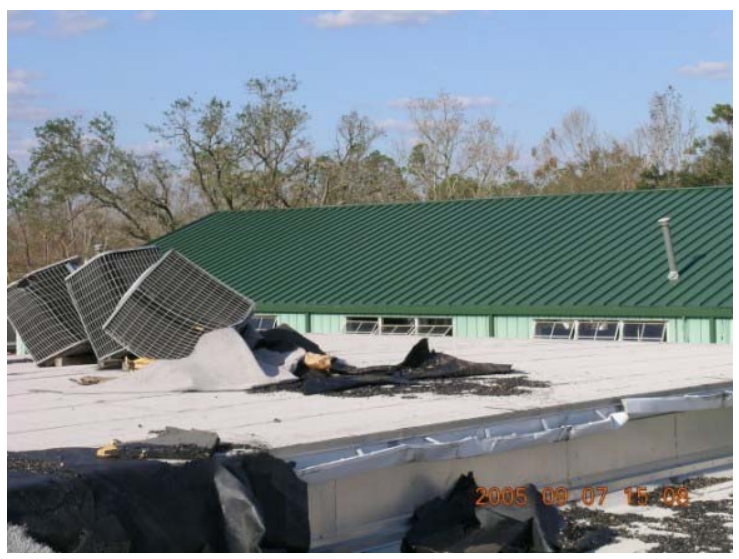

2.03(c)-4. Pineville Elementary. In foreground, edge damage, HVAC damage, and a membrane blown from an adjacent roof are all visible. In the background is an undamaged storage building roof. 


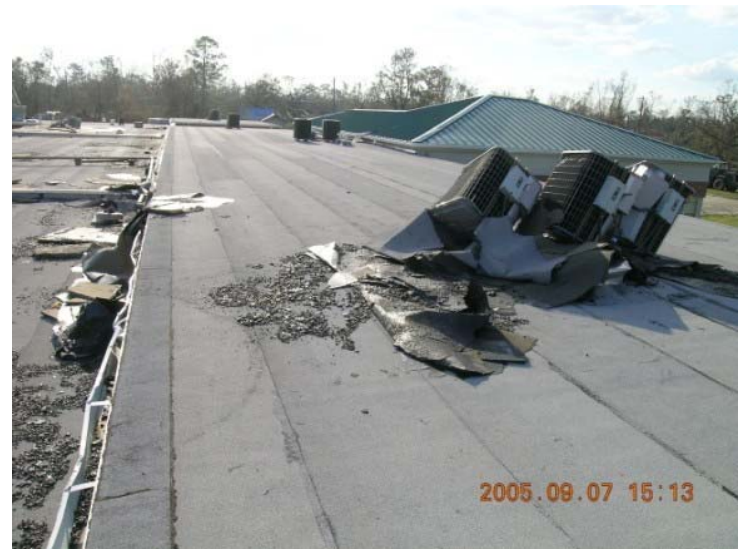

2.03(c)-5. Pineville Elementary. Evaporative coolers displaced by debris, including aggregatesurface membrane from the lower-elevation roof.

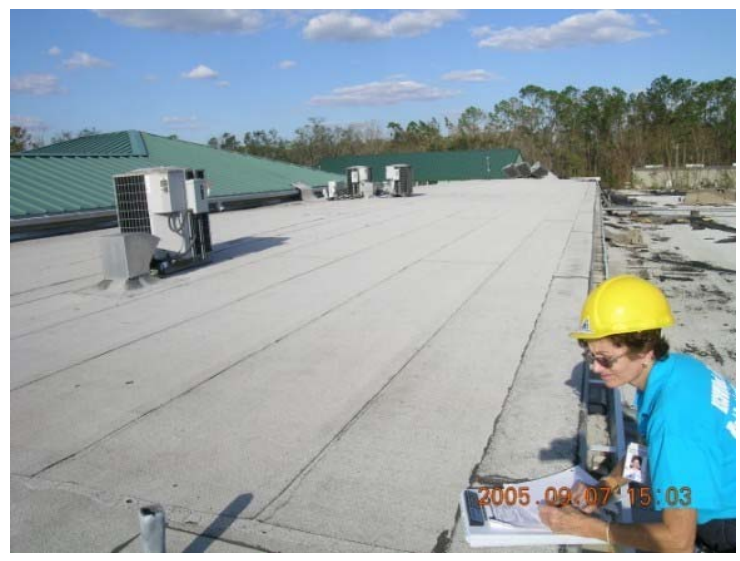

2.03(c)-6. Pineville Elementary. No damage is seen on this roof area.

2.04(a) Hancock Medical Center, 149 Drinkwater Blvd., Bay St. Louis, MS

TYPE OF STRUCTURE-Hospital

EXPOSURE-B

SITE COORDINATES-N30 27'16" W88 50' 01"

WALL CONSTRUCTION-Stucco on concrete masonry units (CMU)

ROOF TYPE-PVC

SLOPE-0-1/4:12

ROOF HEIGHT $-22 \mathrm{ft}$

ROOF WIDTH-50 ft

ROOF LENGTH-35 ft

DECK_-Lightweight insulating concrete over steel

WIND SPEED-120-130 mph

BUILDING CONSTRUCTION-Steel frame with CMU

METHOD OF ATTACHMENT - Mechanically attached single ply

NOTED DAMAGE-None

DAMAGE INITIATION AND PROPAGATION—No noted damage

ADDITIONAL COMMENTS-This roof had some small sections exposed to the primary wind but was not damaged, even though the system does not appear to be secured to manufacturer's standards for this wind zone (120-130 mph). It apparently survived because there was little or no air infiltration. 


\section{Photographs of Roof Damage}

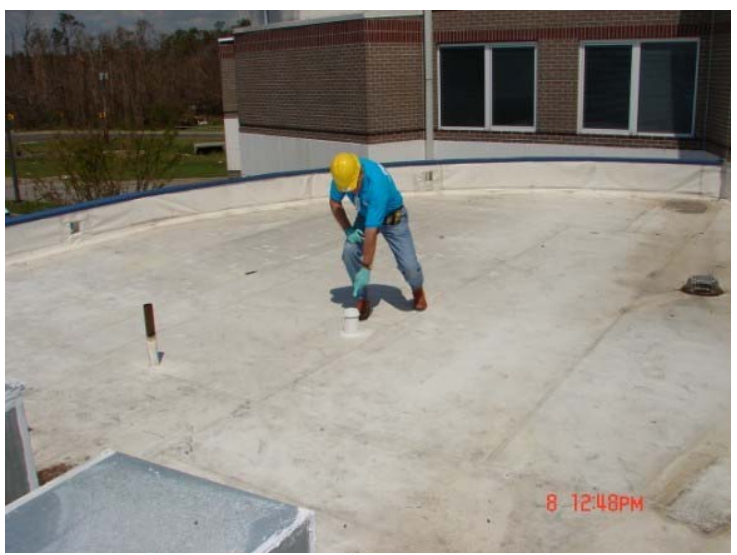

2.04(a)-1. Hancock Medical Center. This photo shows a mechanically fastened thermoplastic single ply membrane with no damage.

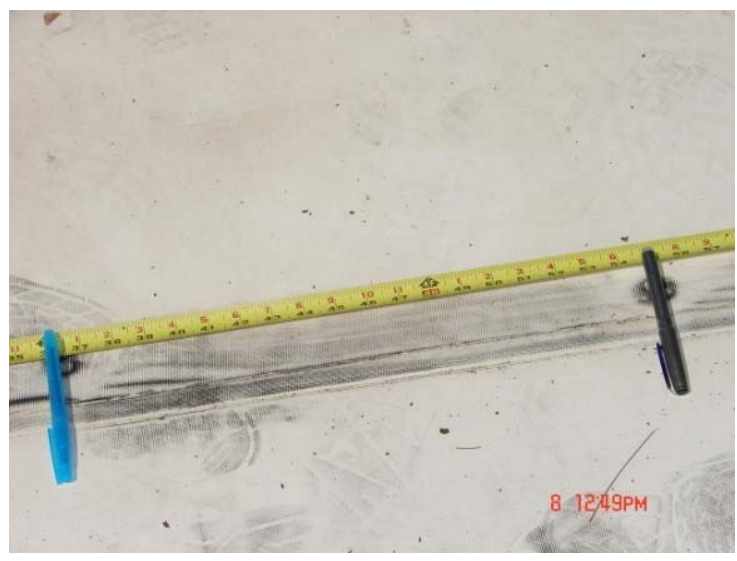

2.04(a)-2. Hancock Medical Center. Fastener spacing in this area was 18 in. o.c.

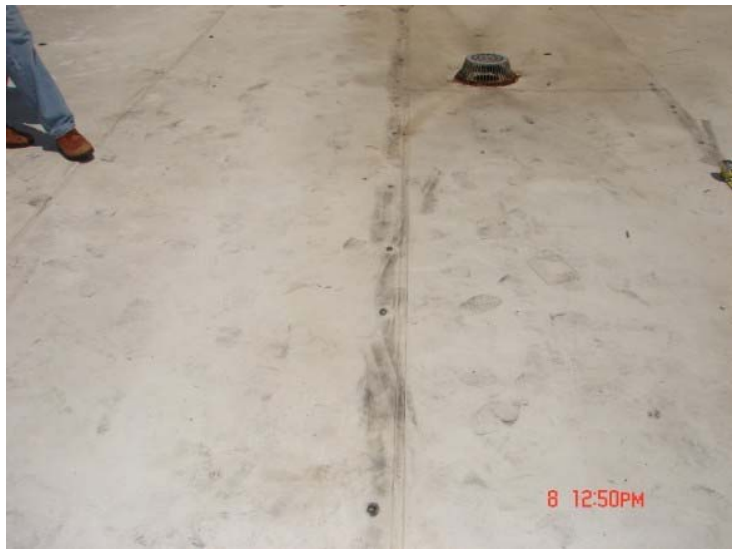

2.04(a)-3. Hancock Medical Center. Fastener rows were spaced $5 \mathrm{ft}$ o.c.

2.04(b) Hancock Medical Center, 149 Drinkwater Blvd., Bay St. Louis, MS

TYPE OF STRUCTURE-Hospital

EXPOSURE-B

SITE COORDINATES-N30 27' $16^{\prime \prime}$ W88 50' 1"

WALL CONSTRUCTION-CMU

ROOF TYPE_EPDM single ply

SLOPE- $-1 / 4: 12$

ROOF HEIGHT $-22 \mathrm{ft}$

ROOF WIDTH-250 ft

ROOF LENGTH-200 ft 
DECK-Steel

WIND SPEED-120-130 mph

BUILDING CONSTRUCTION—Steel frame with block walls

METHOD OF ATTACHMENT - Mechanically attached single ply

NOTED DAMAGE - The membrane was in good shape and, except for 19 penetrations from debris, there was no blowoff damage. One section of an HVAC unit came off, an air handler penthouse lost edge metal, and one air handler lost its top.

DAMAGE INITIATION AND PROPAGATION-Metal roofing over the entrance was damaged on the backside (leeward side), and metal blowing across the roof caused punctures. The punctures did not lead to rips or tears. This mechanically attached single ply was attached as recommended for a high-wind installation and the securement appeared to be undamaged. Most HVAC units were undamaged and still in place because they had better securement to their curbs.

ADDITIONAL COMMENTS-The roof damage was easily repaired and the building was nearly watertight from the roof. The storm surge exceeded $6 \mathrm{ft}$, however, and resulted in much damage to the building interior and equipment. Hospital maintenance staff estimated that the facility would be in full operation within 8 weeks.

\section{Photographs of Roof Damage}

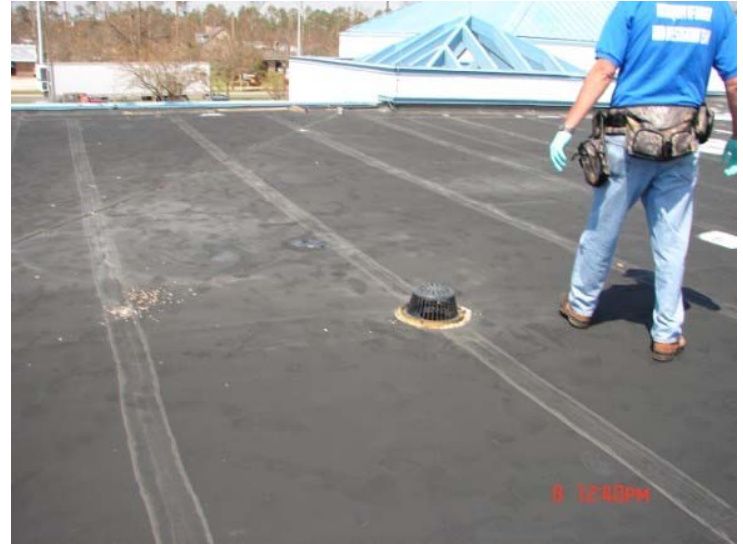

2.04(b)-1. Hancock Medical Center. A mechanically fastened single ply membrane.

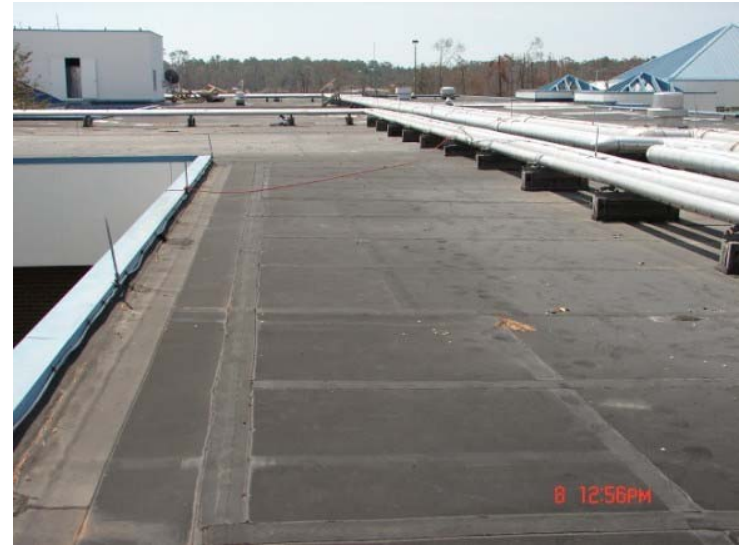

2.04(b)-3. Hancock Medical Center. This perimeter fastening is designed for high wind resistance.

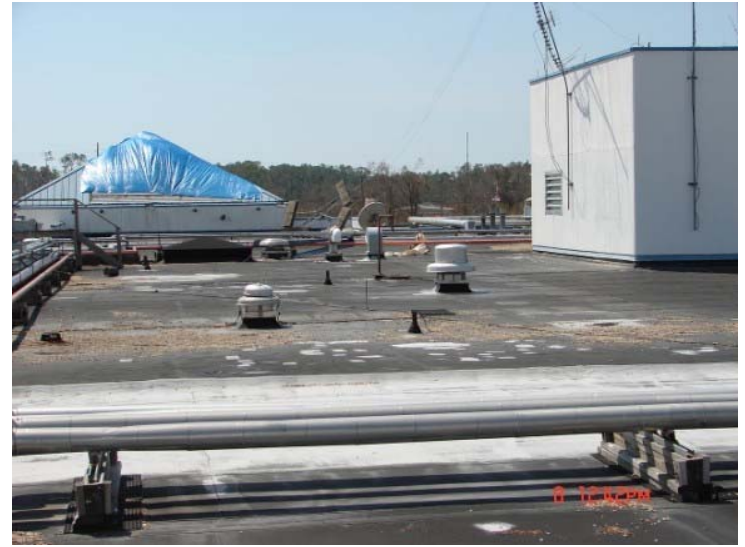

2.04(b)-2. Hancock Medical Center. The white spots are temporary repairs to membrane punctures.

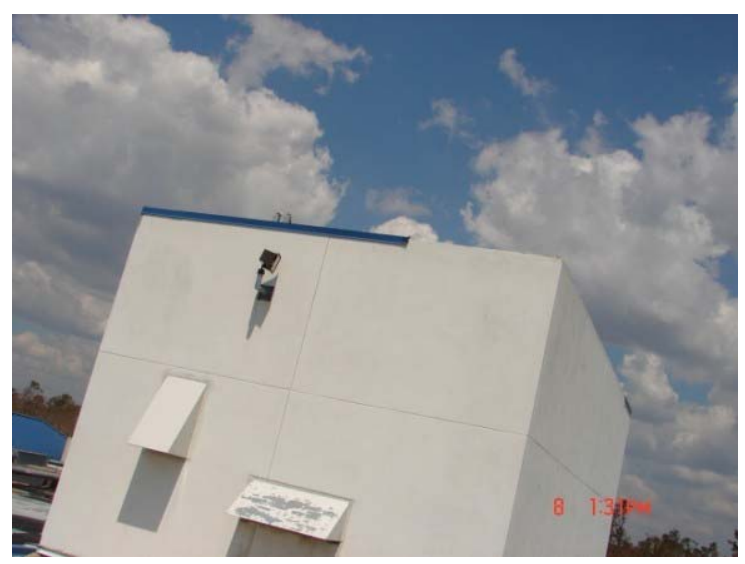

2.04(b)-4. Hancock Medical Center. Edge metal is missing from this penthouse. 


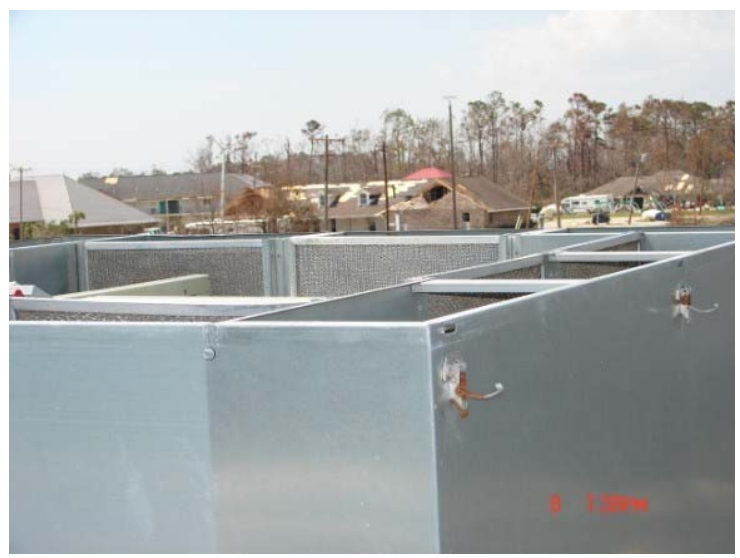

2.04(b)-5. Hancock Medical Center. The top was blown off of this air handling unit.

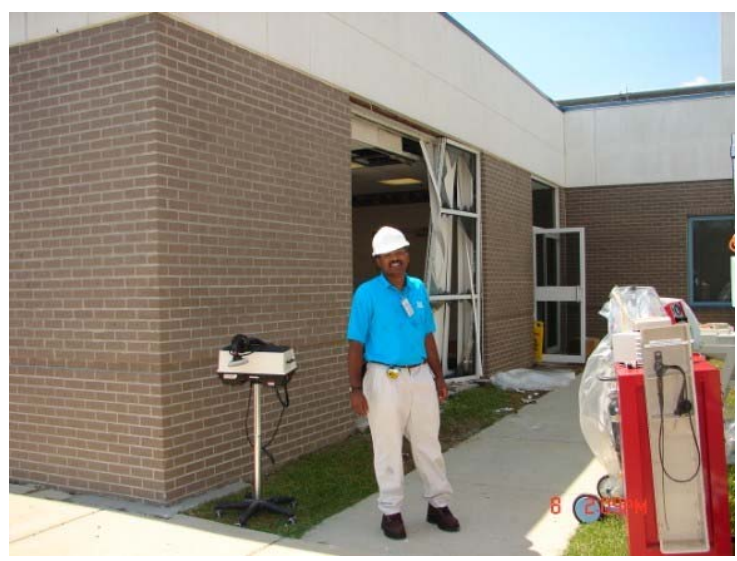

2.04(b)-6. This window wall failed as a result of excessive wind pressure.

2.04(c) Hancock Medical Center, 149 Drinkwater Blvd., Bay St. Louis, MS

TYPE OF STRUCTURE-Hospital

EXPOSURE-B

SITE COORDINATES-N30 27' $16^{\prime \prime}$ W8 $88^{\circ} 50^{\prime}$ ' $1^{\prime \prime}$

WALL CONSTRUCTION-Stucco on CMU

ROOF TYPE-BUR aggregate-surface

SLOPE- $-1 / 4: 12$

ROOF HEIGHT-22 ft

ROOF WIDTH-40 ft

ROOF LENGTH $-40 \mathrm{ft}$

DECK-Steel

WIND SPEED-120-130 mph

BUILDING CONSTRUCTION—Steel frame with block walls

METHOD OF ATTACHMENT—Fully adhered

NOTED DAMAGE-The membrane was intact and not leaking. As it was the most windward roof in the high wind event, there were no punctures noted from debris. The gravel was scoured and was found scattered over leeward sections of the roof.

DAMAGE INITIATION AND PROPAGATION—Pea gravel was not fully embedded and was scoured from the high wind uplift areas.

ADDITIONAL COMMENTS-The Hancock County Medical Facility was one of the bestmaintained roof systems encountered. There were four distinct roof types and they all performed well. There was one section with an architectural metal roof that was damaged; this team did not inspect it. Another metal roof that was not inspected appeared to have no damage. Most HVAC units were attached to curbs with three screws per side. The additional screw was adequate to keep the units in place, saving the roof and building from further damage. There was limited air intrusion into the building, as the primary windward wall had few windows and most were intact after the storm. 


\section{Photographs of Roof Damage}

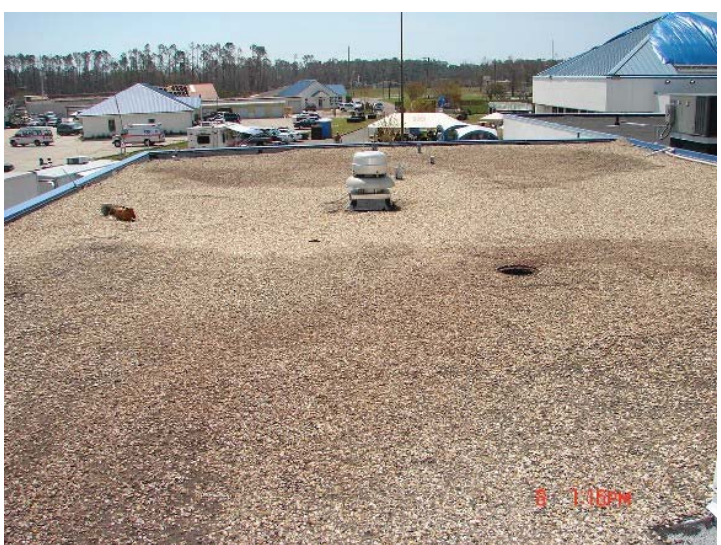

2.04(c)-1. Hancock Medical Center. Gravel scour in this photo was caused by the change in direction and velocity of the wind hitting the roof edge and penthouse.

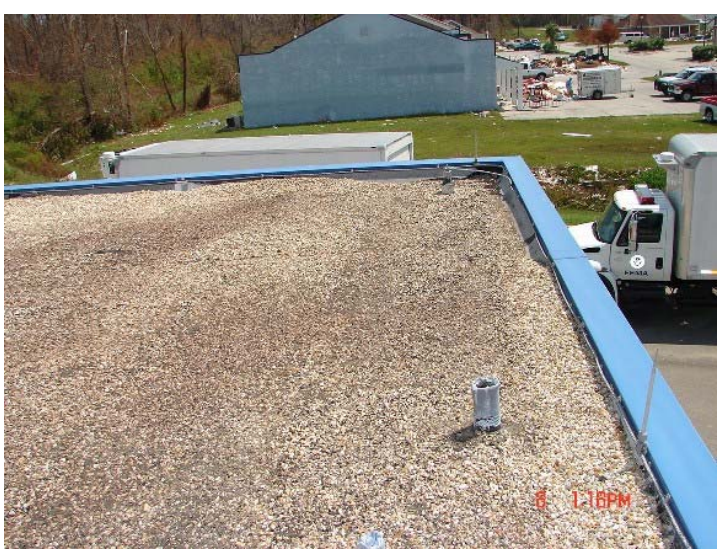

2.04(c)-3. Hancock Medical Center. Gravel scour in this photo shows a change in pattern from a second direction.

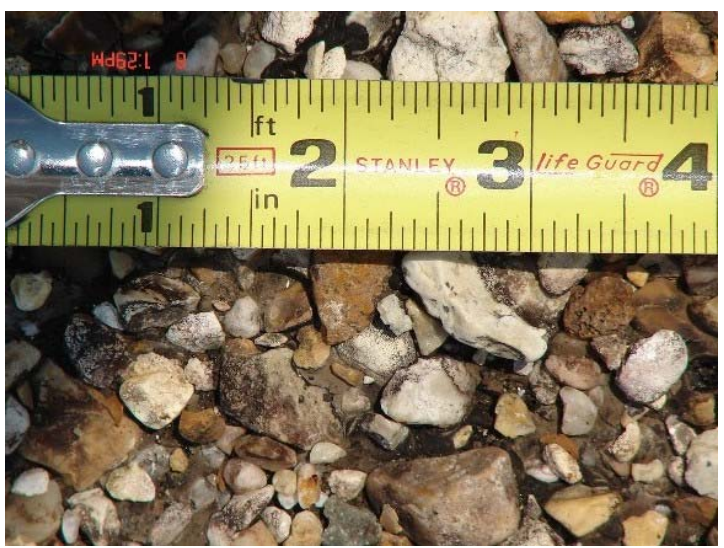

2.04(c)-5. Hancock Medical Center. The aggregate found here was larger than typical pea gravel.

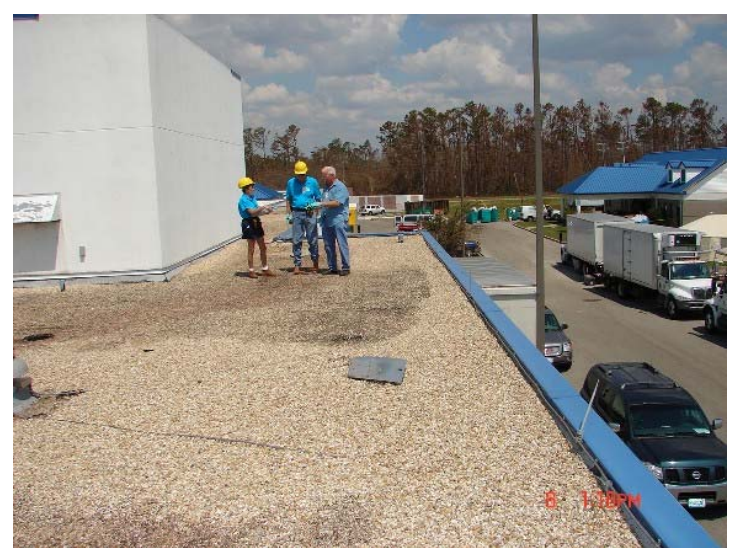

2.04(c)-2. Hancock Medical Center. Scour around the penthouse shows a wind burst pattern. This can occur when wind accelerates around the penthouse.

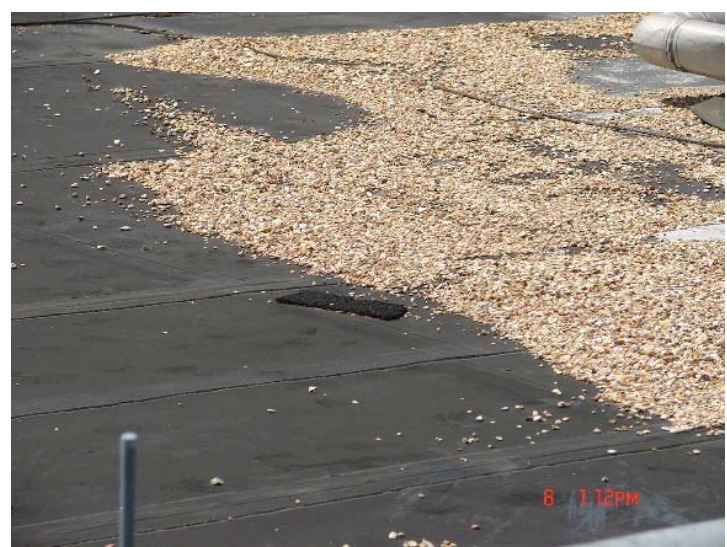

2.04(c)-4. This smooth-surface roof was downwind from the gravel-surface roofs.

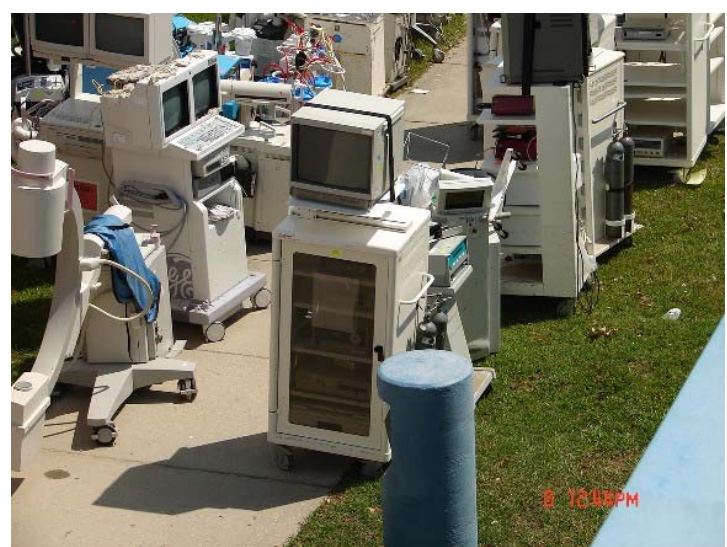

2.04(c)-6. Hancock Medical Center. Medical equipment removed because of the storm surge was being assessed for damage and possible refurbishing. 


\subsection{4(d) Hancock Medical Center, 149 Drinkwater Blvd., Bay St. Louis, MS}

TYPE OF STRUCTURE-Hospital

EXPOSURE-B

SITE COORDINATES-N30 27' $10^{\prime \prime}$ W88 $50^{\prime}$ ' 1 ”

WALL CONSTRUCTION-Stucco-coated CMU

ROOF TYPE—BUR with aggregate surfacing

SLOPE- $-1 / 4: 12$

ROOF HEIGHT-22 ft

ROOF WIDTH-40 ft

ROOF LENGTH— $40 \mathrm{ft}$

DECK-Steel

WIND SPEED-120-130 mph

BUILDING CONSTRUCTION—Steel frame with block walls

METHOD OF ATTACHMENT_Fully adhered BUR

NOTED DAMAGE—Stone scour in upwind corner

DAMAGE INITIATION AND PROPAGATION_Lack of total embedment of gravel (in asphalt) resulted in significant scour in upwind corner but no other damage.

ADDITIONAL COMMENTS—Same as for building described in 2.04(c)

No photographs were taken of this roof.

\subsection{Fresenius Medical Ultra Care Kidney Center, 149 Drinkwater, Bay St. Louis, MS}

TYPE OF STRUCTURE-Medical facility

EXPOSURE-B

SITE COORDINATES-N30 $27^{\prime} 16^{\prime \prime}$ W88 50 ' 1 ”,

WALL CONSTRUCTION—Brick façade over wood studs

ROOF TYPE-Asphalt shingles (3-tab)

SLOPE-4-6: 12

ROOF HEIGHT- $18 \mathrm{ft}$

ROOF WIDTH-70 ft

ROOF LENGTH-120 ft

DECK—Solid plywood

WIND SPEED-120-130 mph

BUILDING CONSTRUCTION—Residential/small office

METHOD OF ATTACHMENT_Nails (typically four nails)

NOTED DAMAGE-All roof covering on windward side of roof was blown off; most roof covering on leeward side was blown off. Wall covering on gable ends was missing. 
DAMAGE INITIATION AND PROPAGATION_-Asphalt shingles lacked nails, and nails were improperly placed. The roof was installed using the racking method that often limits the shingles to three nails, whereas six nails were required by the building code when this roof was installed.

ADDITIONAL COMMENTS-Resin transfer at the seal strip was apparent from the observed shingles. Because of the climate and exposure, this roof is likely to have as much seal strip bond as is possible; however, most shingles blew off as discrete units.

\section{Photographs of Roof Damage}

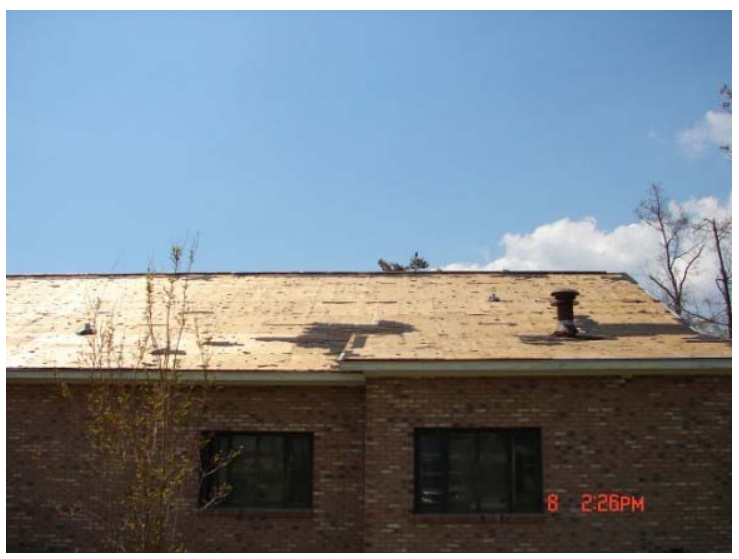

2.05-1. Fresenius Medical Kidney Center. Almost every shingle was stripped.

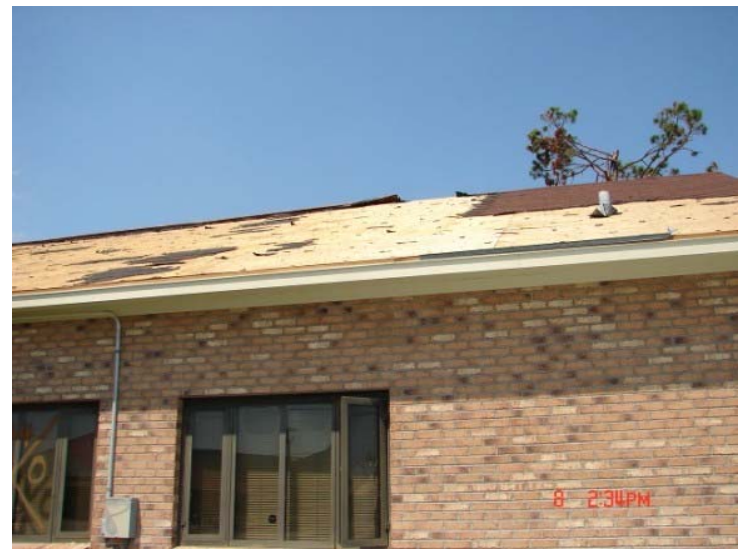

2.05-3. Fresenius Medical Kidney Center. Back (leeward) side of building; note straight line of shingle damage, indicating racked installation of shingles.

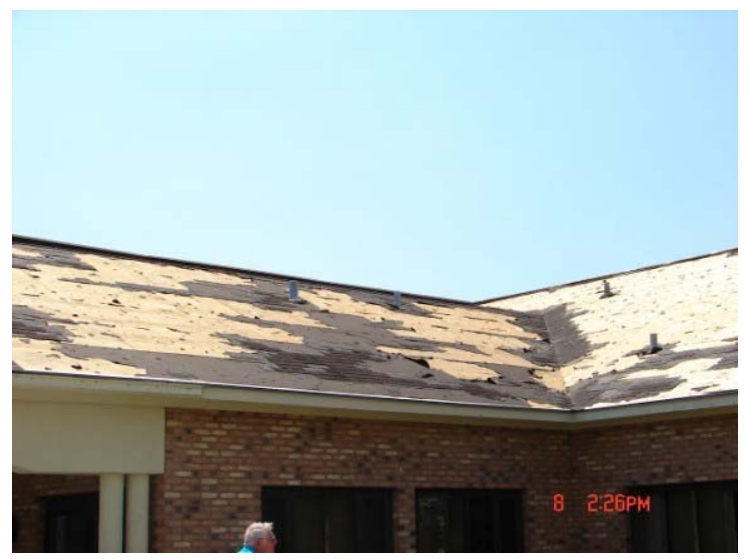

2.05-2. Fresenius Medical Kidney Center. Shingles and underlayment missing from windward side.

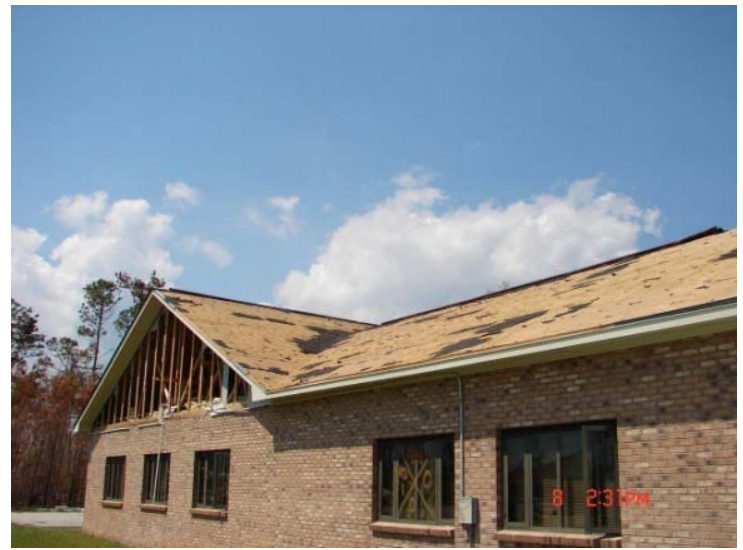

2.05-4. Fresenius Medical Kidney Center.

Cladding removed from gable end; however, deck remains in place. 


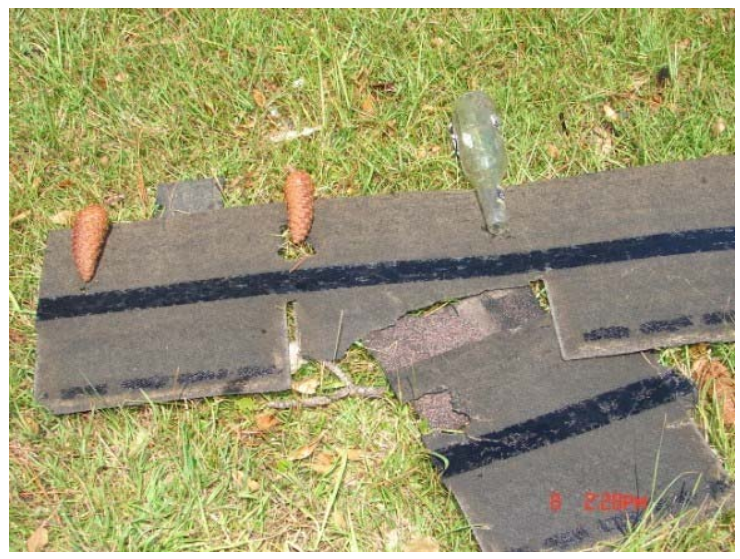

2.05-5. Fresenius Medical Kidney Center. Only three nails in shingles, high nailing.

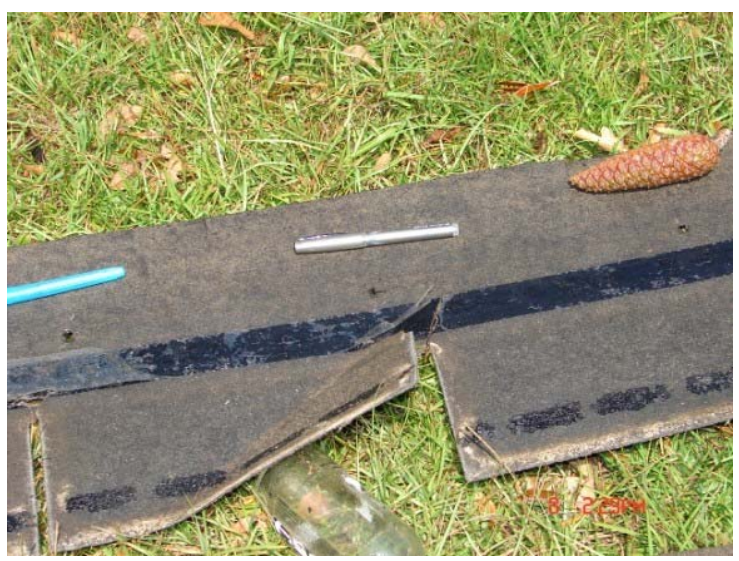

2.05-6. Fresenius Medical Kidney Center. Only three nails in shingles.

2.06(a) St. Stanislaus, 304 S. Beach Blvd., Bay St. Louis, MS

TYPE OF STRUCTURE-Educational facility

EXPOSURE-C

SITE COORDINATES-N30 $18^{\prime} 26^{\prime \prime}$ 'W89 $19^{\circ} 47^{\prime \prime}$

WALL CONSTRUCTION-Poured concrete with brick veneer

ROOF TYPE-BUR (smooth-surface), 3-ply (original roof was BUR with aggregate surfacing)

SLOPE- $-1 / 4: 12$

ROOF HEIGHT $-40 \mathrm{ft}$

ROOF WIDTH- $160 \mathrm{ft}$

ROOF LENGTH-160 ft

DECK - Cast-in-place concrete

WIND SPEED-120-130 mph

BUILDING CONSTRUCTION—Substantially institutional

METHOD OF ATTACHMENT-Hot-mopped BUR

NOTED DAMAGE-Several areas of complete blowoff (about $20 \%$ of roof). Other areas were undamaged.

DAMAGE INITIATION AND PROPAGATION_-Blowoff areas were due to roof edge failure. Typically, edge sections where blowoff occurred were not adequately fastened to roof deck.

ADDITIONAL COMMENTS-This facility was located in Bay St. Louis at the water's edge. It likely sustained the highest winds of Katrina in Mississippi, and it had storm surge well into the second story. The building was intact and sustained relatively minor roof damage compared with other structures in the area. 


\section{Photographs of Roof Damage}

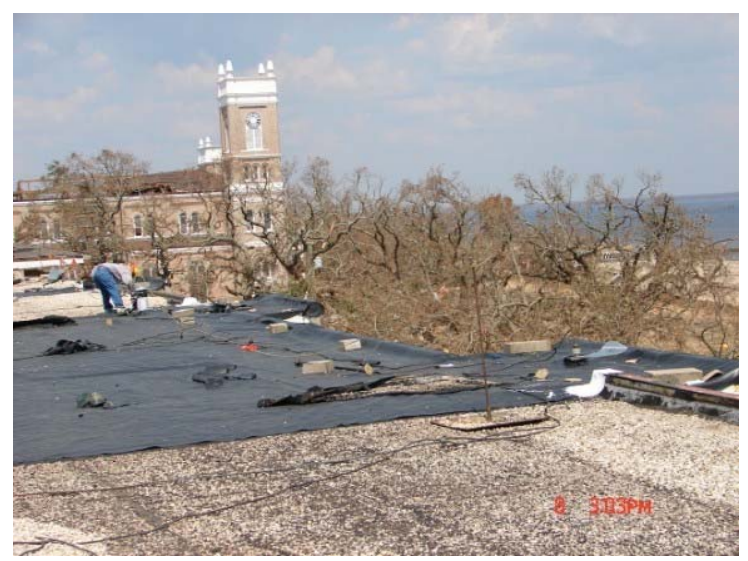

2.06(a)-1. St. Stanislaus. This membrane blowoff was located at the center of the windward wall.

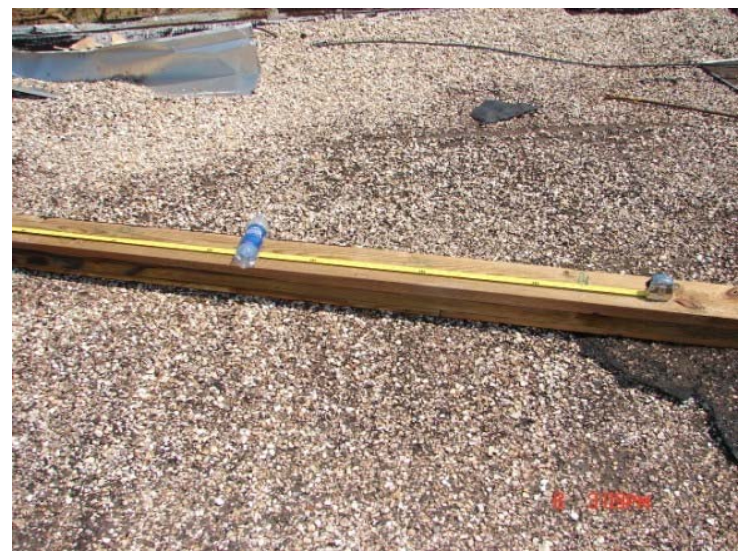

2-06(a)-3. St. Stanislaus. Wood blocking is shown here with fasteners spaced approximately 36 in. o.c.

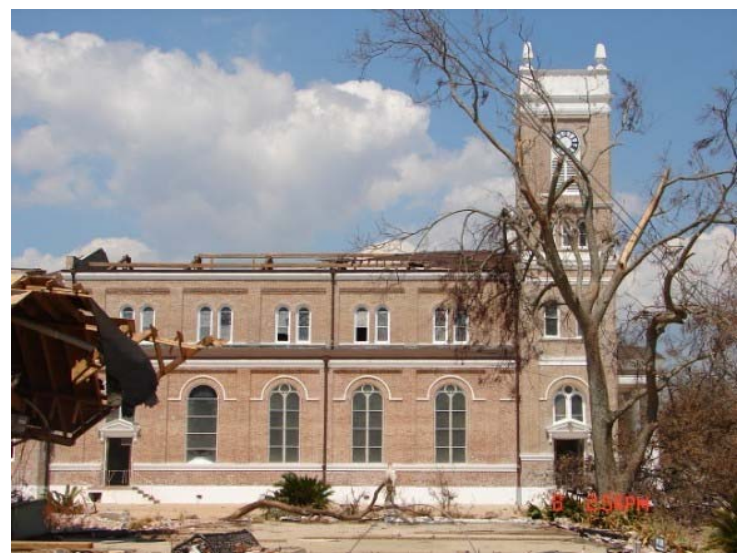

2.06(a)-5. St. Stanislaus. A nearby auditorium was missing its entire roof.

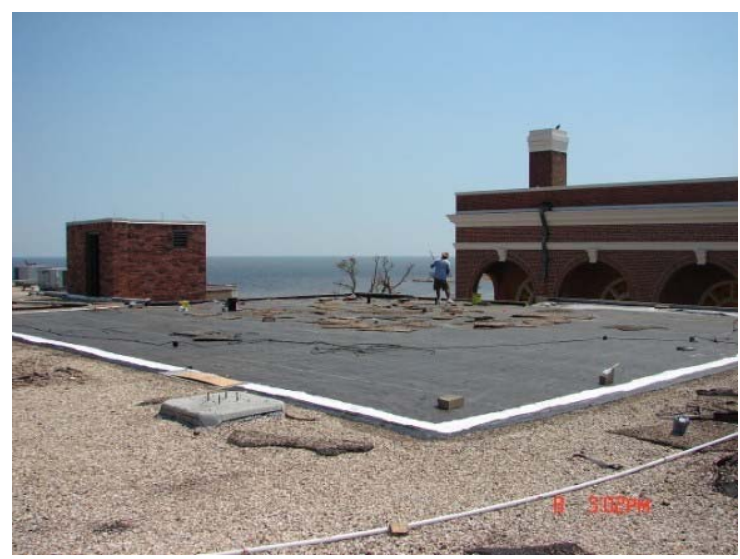

2.06(a)-2. St. Stanislaus. This large area is being temporarily repaired from the corner back. Note its proximity to the open ocean.

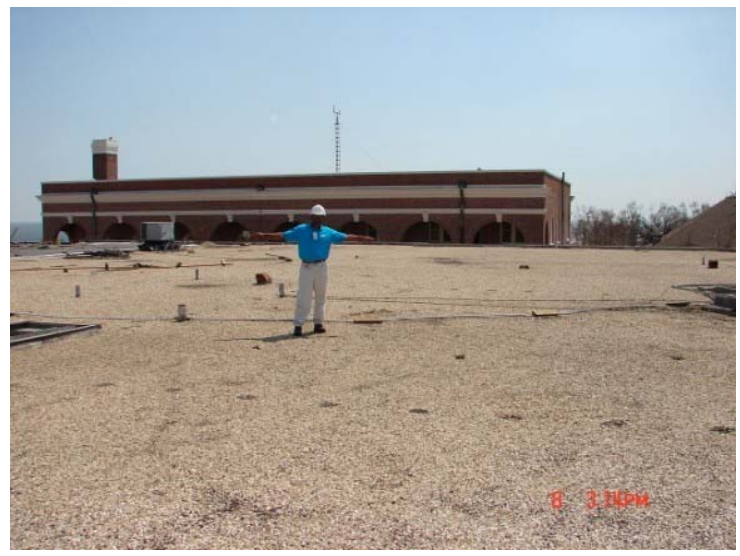

2.06(a)-4. St. Stanislaus. A large roof area appears undamaged, although an HVAC unit was displaced from attachment at left to spot at right.

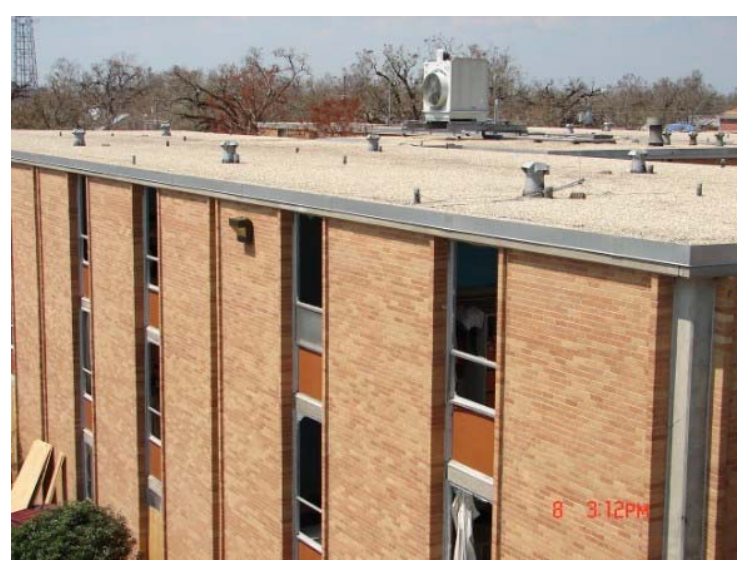

2.06(a)-6. St. Stanislaus. An adjacent building showed no apparent roof damage. 
2.06(b) St. Stanislaus, 304 S. Beach Blvd., Bay St. Louis, MS

TYPE OF STRUCTURE-School

EXPOSURE-C

SITE COORDINATES-N30 $18^{\prime} 26^{\prime \prime}$ W89 $19^{\prime} 47^{\prime \prime}$

WALL CONSTRUCTION-Concrete with brick façade

ROOF TYPE—PVC (single ply)

SLOPE- $0-1 / 4: 12$

ROOF HEIGHT-30 ft

ROOF WIDTH-80 ft

ROOF LENGTH-60 ft

DECK—Lightweight insulating concrete over steel

WIND SPEED-120-130 mph

BUILDING CONSTRUCTION—Substantially institutional

METHOD OF ATTACHMENT_-Mechanical screws and plates

NOTED DAMAGE-No storm-related damage noted

DAMAGE INITIATION AND PROPAGATION—No damage to membrane system

ADDITIONAL COMMENTS-This roof, somewhat protected, did not appear to have damage, although a few fasteners in the corner appear to have loosened.

\section{Photographs of Roof Damage}

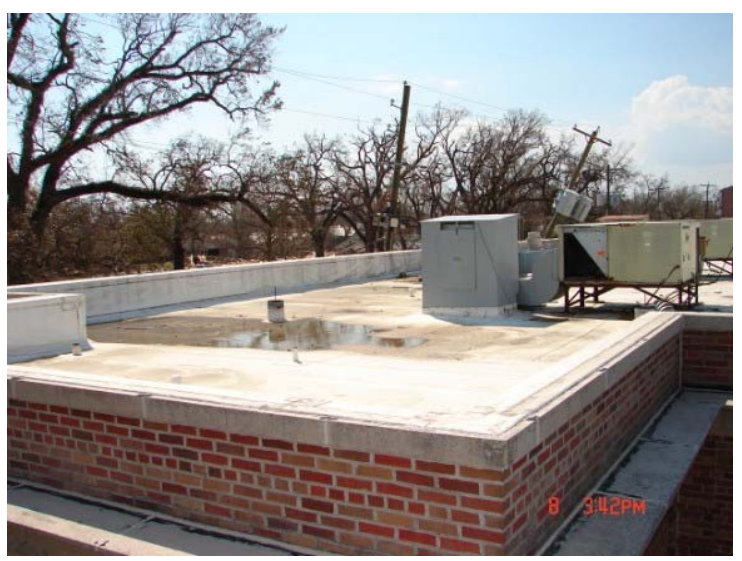

2.06(b)-1. St. Stanislaus. This mechanically fastened single ply membrane appeared undamaged.

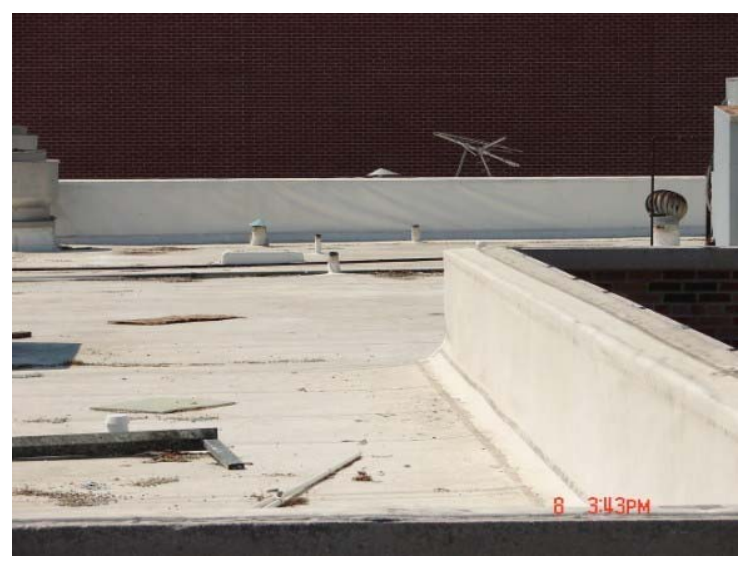

2.06(b)-2. St. Stanislaus. The debris shown here may have caused punctures to the roofing membrane. 


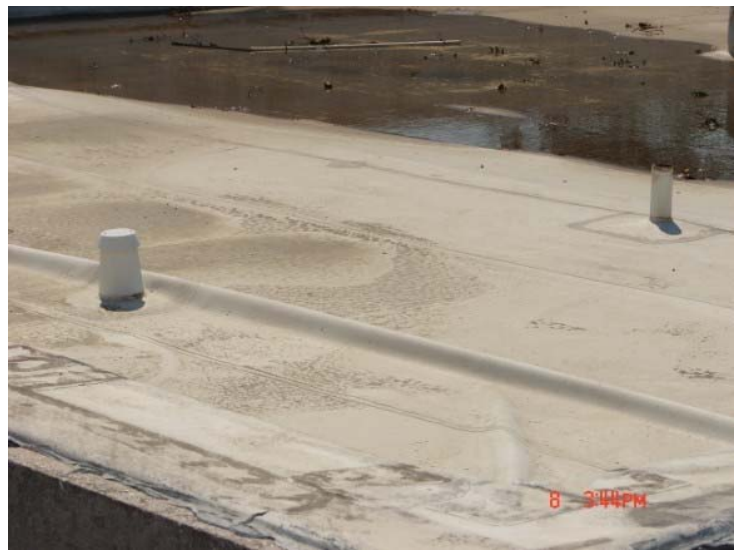

2.06(b)-3. St. Stanislaus. The membrane wrinkling visible here may be the result of loose fasteners.

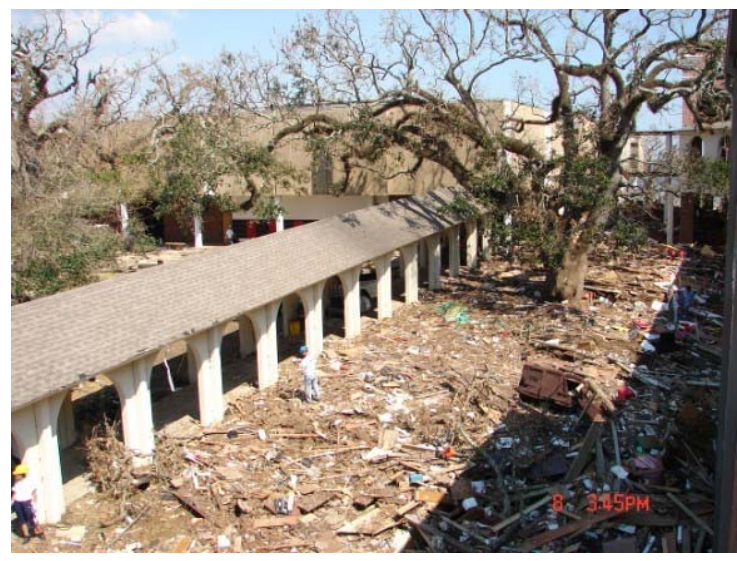

2.06(b)-4. St. Stanislaus. In the courtyard is storm debris, in contrast to an undamaged asphalt shingle roof over the relatively protected corridor.

\subsection{Robert W. MaGee Auditorium, Pine Street, Bay St. Louis, MS}

TYPE OF STRUCTURE-School

EXPOSURE-C

SITE COORDINATES-N30 18' $25^{\prime \prime}$ W89 $19^{\circ}$ '43”

WALL CONSTRUCTION — CMU with brick façade

ROOF TYPE-BUR (4-ply)

SLOPE- $-1 / 4: 12$

ROOF HEIGHT $-40 \mathrm{ft}$

ROOF WIDTH-120 ft

ROOF LENGTH-100 ft

DECK-Steel

WIND SPEED—120-130 mph

BUILDING CONSTRUCTION—Substantially steel frame

METHOD OF ATTACHMENT - Two layers of mechanically attached insulation, one layer of hotmopped insulation, and hot-mopped BUR

NOTED DAMAGE - The entire roof was damaged. In most areas, membrane and some insulation were blown completely off the roof. Coping was missing on entire upwind corner and one side.

DAMAGE INITIATION AND PROPAGATION - Garage door behind stage in auditorium was blown in, which pressurized the roof from the building interior. A drain directly above this area lifted and broke bonds in the system. The roof system failed primarily in the top perlite insulation layer as the weakest point. Fasteners were mostly intact, although the coping was blown off; it is unlikely that the latter initiated the roof damage.

ADDITIONAL COMMENTS - This facility was a storm shelter and was occupied at the time of the roof failure. An adjacent polyurethane foam roof was intact and appeared undamaged. We were able to access this high roof with the assistance of the National Guard. In this case and many others, they gave us courteous and helpful service. 


\section{Photographs of Roof Damage}

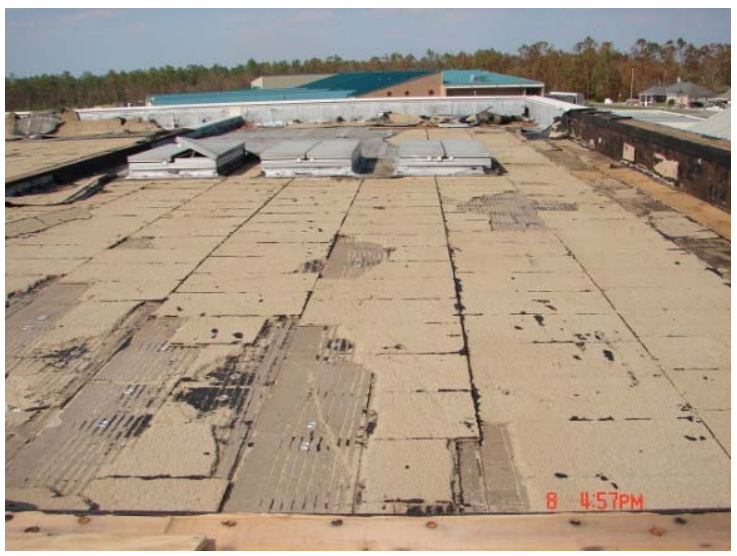

2.07-1. MaGee Auditorium. The membrane has blown off the insulation layer in this area.

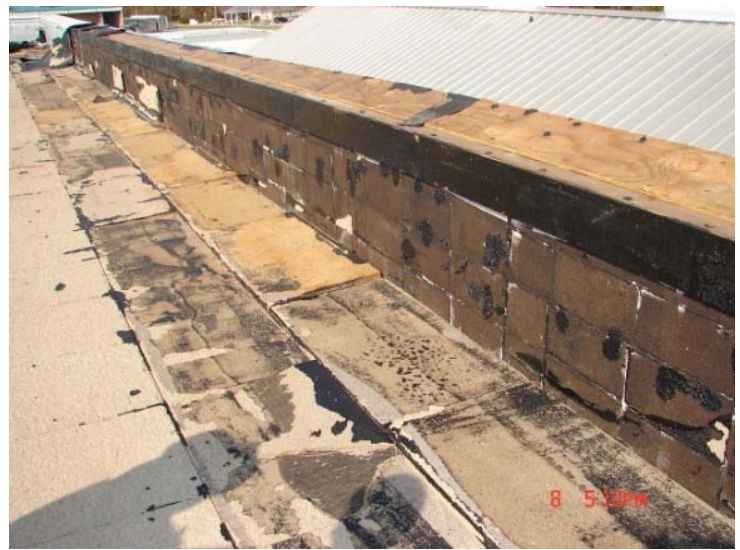

2.07-3. MaGee Auditorium. Coping and wall flashing are missing, likely blown off.

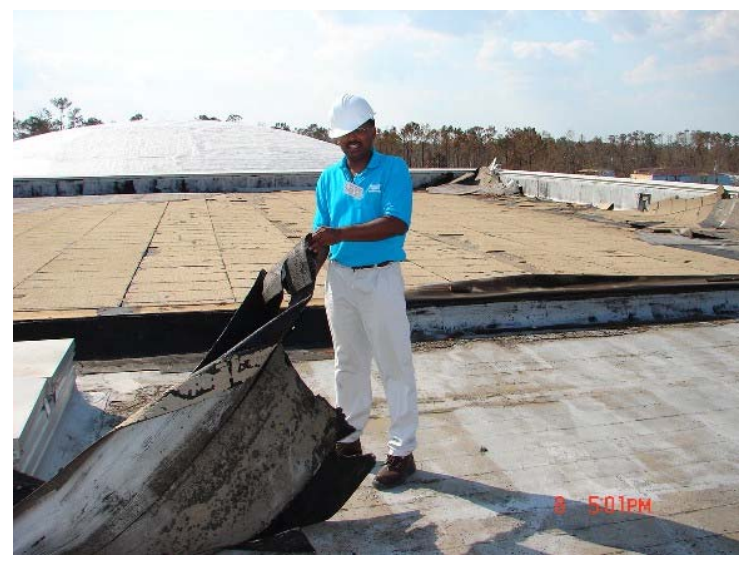

2.07-5. MaGee Auditorium. Some membrane remained on this roof. A polyurethane foam dome in background had no apparent damage.

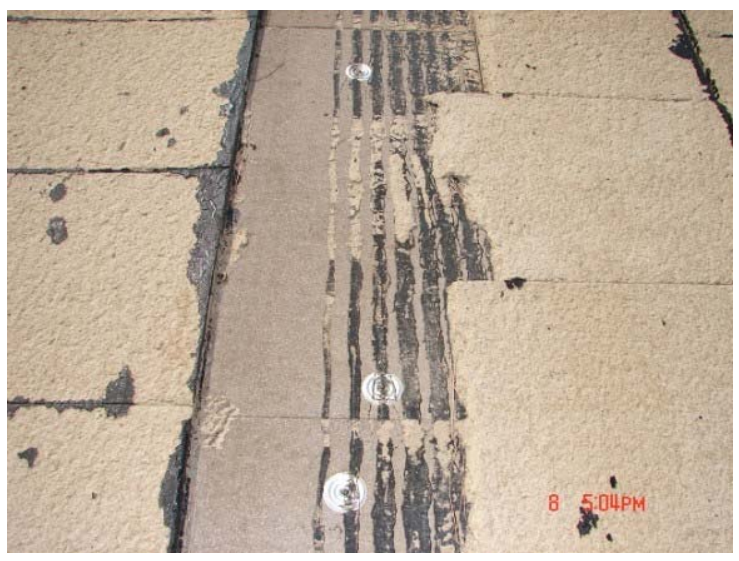

2.07-2. MaGee Auditorium. The bottom layer of perlite was screwed down; the top layer was stripmopped with asphalt. Excessive uplift force probably caused adhesive failure of the asphalt.

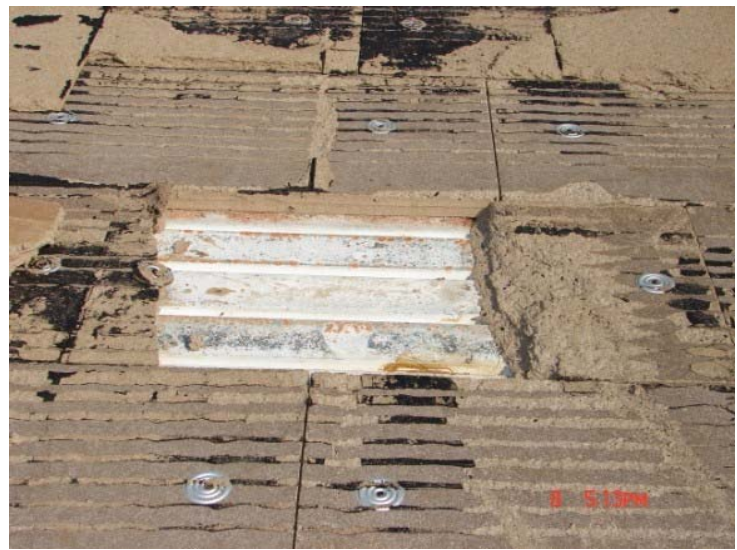

2.07-4. MaGee Auditorium. Only perlite insulation and decking remain on this roof; i.e., no membrane.

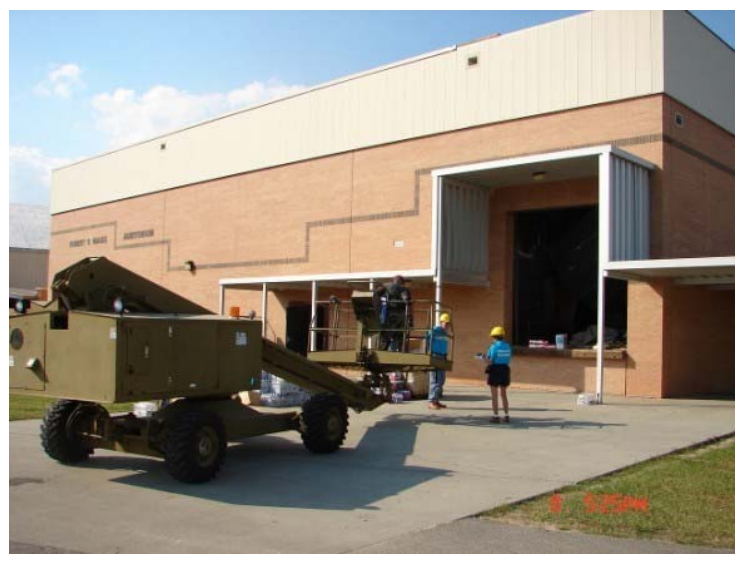

2.07-6. MaGee Auditorium. This garage door was blown in. 


\subsection{Winn Dixie Strip Mall, Route 90, Dunbar Avenue, Bay St. Louis, MS}

TYPE OF STRUCTURE—Shopping center

EXPOSURE-C

SITE COORDINATES-N30 $18^{\prime} 26^{\prime \prime}$ W89 $19^{\prime} 43^{\prime \prime}$

WALL CONSTRUCTION-Steel cladding on steel frame

ROOF TYPE—Standing seam: trapezoidal structural panel

SLOPE-0-1/4: 12

ROOF HEIGHT-20 ft

ROOF WIDTH-220 ft

ROOF LENGTH-100 ft

DECK—Standing seam steel

WIND SPEED-120-130 mph

BUILDING CONSTRUCTION—Metal building with some brick façade

METHOD OF ATTACHMENT-Clips

NOTED DAMAGE-A few punctures in the main roof and complete blowoff in localized areas where glass wall failed.

DAMAGE INITIATION AND PROPAGATION-Punctures through steel were caused by sharp debris. The section that blew off was pressurized when the glass wall failed, likely as a result of airborne debris. The metal clips were unable to withstand this additional load.

ADDITIONAL COMMENTS - A large amount of debris had accumulated in the corner of the building where the damage occurred.

\section{Photographs of Roof Damage}

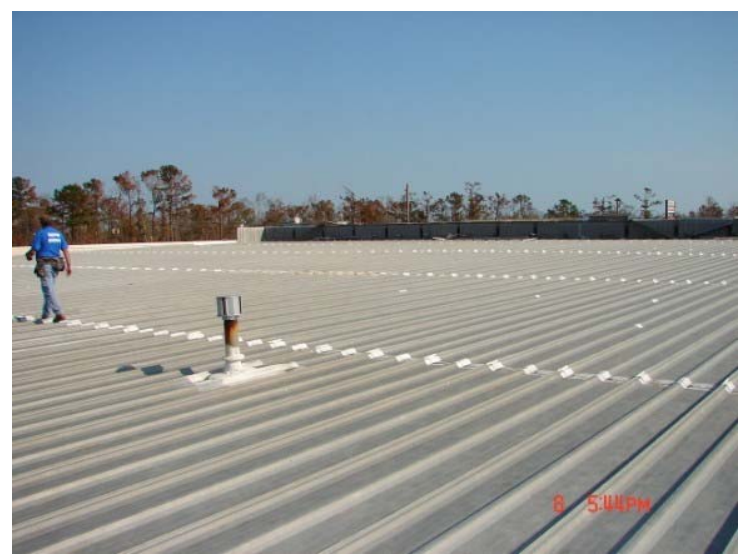

2.08-1. Winn Dixie Strip Mall. This is a wideangle view of the main roof.

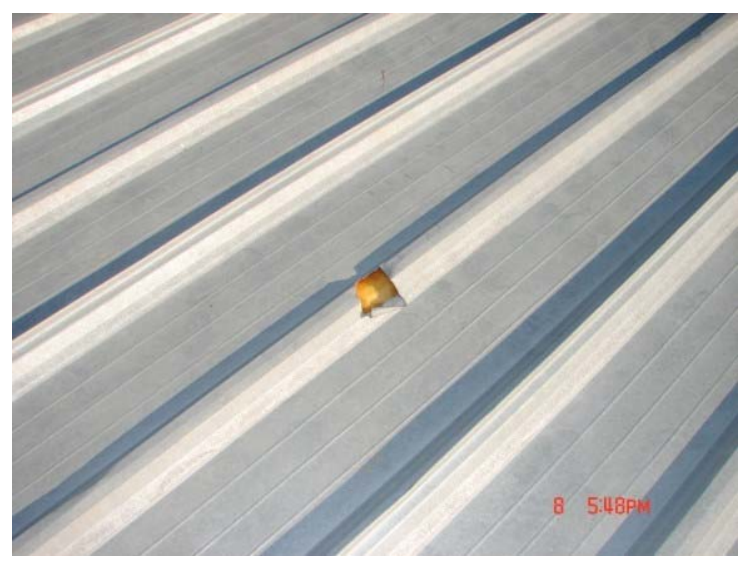

2.08-2. Winn Dixie Strip Mall. A torn metal rib can be seen. 


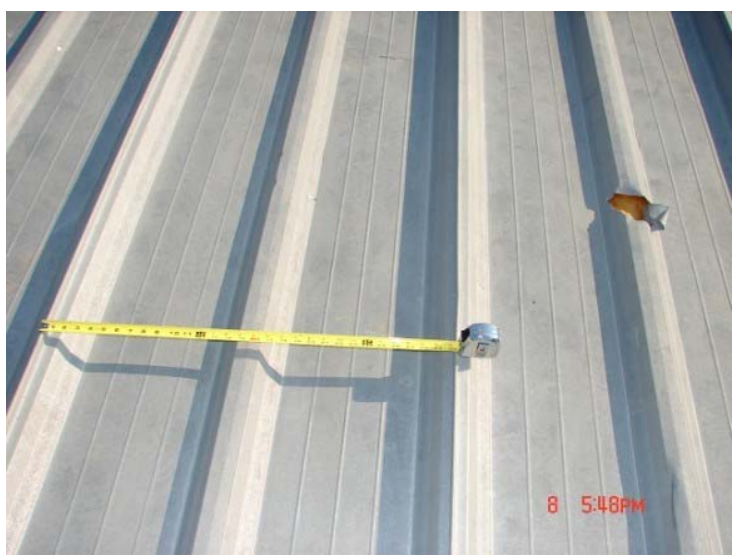

2.08-3. Winn Dixie Strip Mall. A tape measure shows rib spacing.

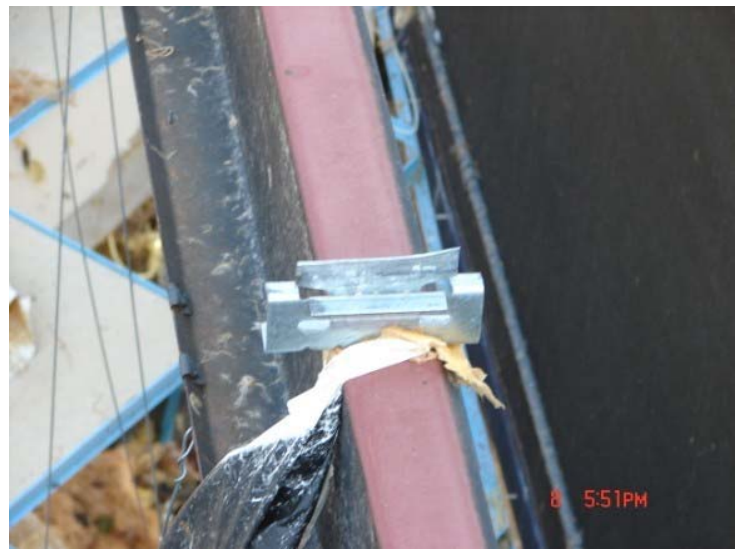

2.08-5. Winn Dixie Strip Mall. A clip is still attached to the purlin in this photo.

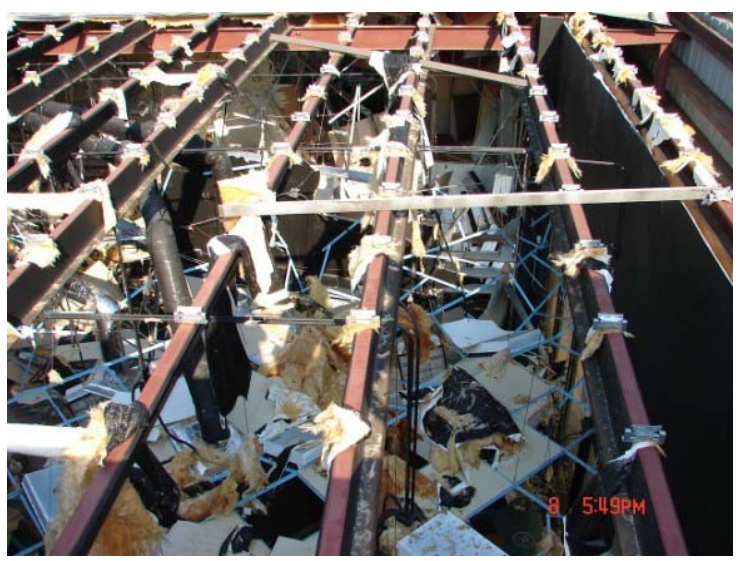

2.08-4. Winn Dixie Strip Mall. This is what a complete blowoff looks like in this corner area.

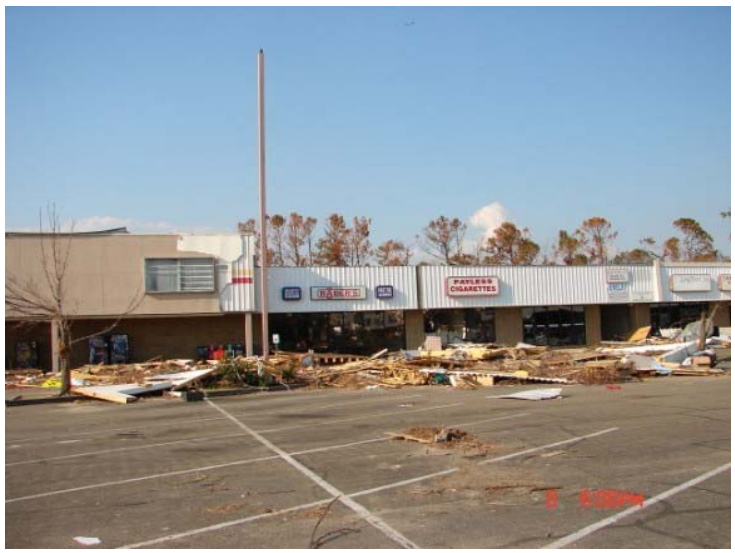

2.08-6. Winn Dixie Strip Mall. This is a corner area where the roof blew off.

\subsection{Sav-A-Center, Bay St. Louis, MS}

TYPE OF STRUCTURE-Shopping center

EXPOSURE-C

SITE COORDINATES-N30 $19^{\prime}$ 2" W89 20' 46"

WALL CONSTRUCTION-Brick and glass

ROOF TYPE-EPDM single ply membrane with stone ballast

SLOPE- $-1 / 4: 12$

ROOF HEIGHT-32 ft

ROOF WIDTH-225 ft

ROOF LENGTH-180 ft

DECK-Steel

WIND SPEED-120-130 mph

BUILDING CONSTRUCTION—Steel frame 


\section{METHOD OF ATTACHMENT—Stone ballast}

NOTED DAMAGE-Stone scour in some upwind areas and significant deck failure where there was a strike by a large object. Membrane and insulation were displaced in an upwind corner. An unusual scour pattern was noted near a parapet. Coping was missing on a large section of wall. Air handling units were displaced. A few stones were displaced from the roof, and small pavers near mechanical roof units were overturned and displaced.

DAMAGE INITIATION AND PROPAGATION-When stone scour occurred, some areas lost their ballast. This likely caused ballooning of the membrane, which tore the membrane and blew it back over the remaining stone. There was a large area of undamaged roof, but in the center of one section, a large hole through the deck was evident. It appears that a façade unit from over $100 \mathrm{ft}$ upwind was blown through the air and struck the deck. Several deck welds failed in upwind areas. The system was pressurized from openings in the parapet wall. Much of the coping and wall flashing were damaged.

ADDITIONAL COMMENTS-This building was in the storm surge area. The contents were ruined by the storm surge. Dozens of cars accumulated in the back of the building that had floated into the area. There was evidence that this roof had some unrepaired stone scour from a previous storm.

\section{Photographs of RoOF DAMAge}

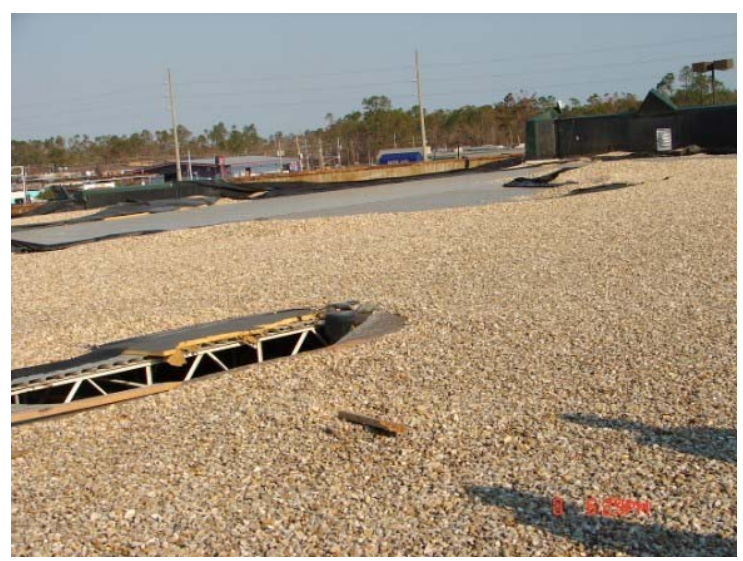

2.09-1. Sav-A-Center. Significant damage can be seen on this ballasted roof.

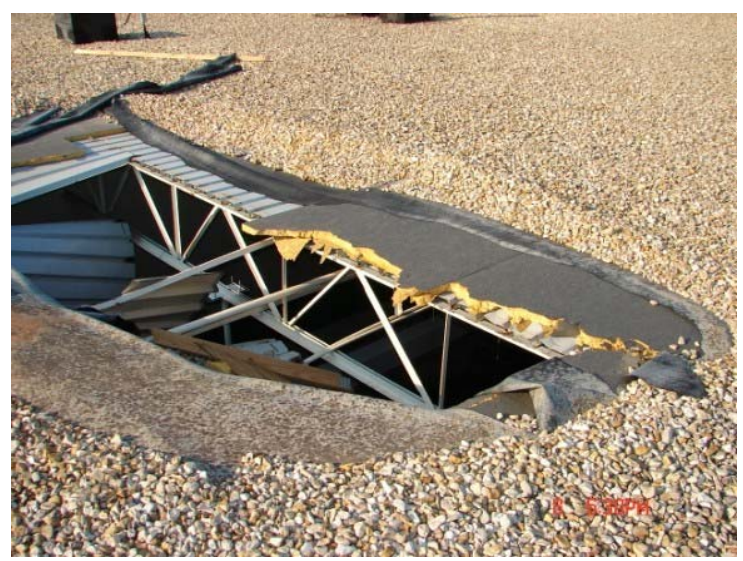

2.09-2. Sav-A-Center. The large hole was apparently caused by part of a mansard that traveled about100 ft. 


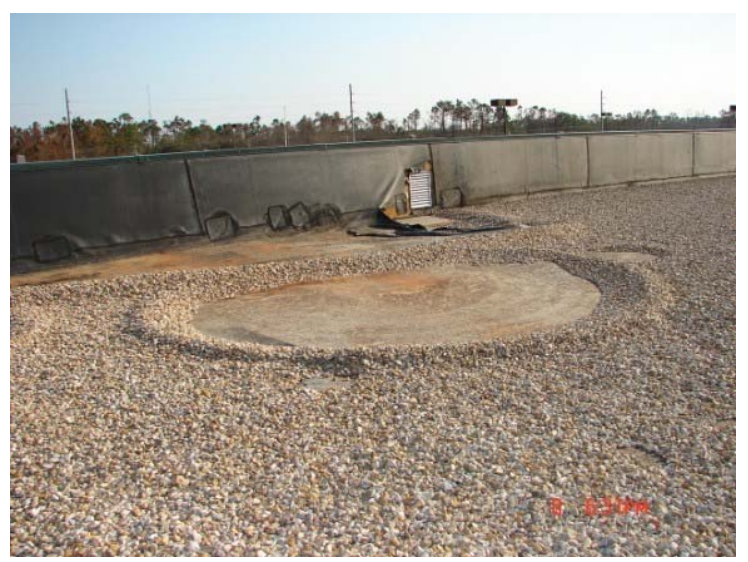

2.09-3. Sav-A-Center. The unusual scour pattern is likely from a vertical vortex (small tornado or unusual wind pattern due to the high parapet). The brown spots appear to be due to sun exposure prior to Katrina. Figure 2.09-5 also supports the vertical vortex theory.

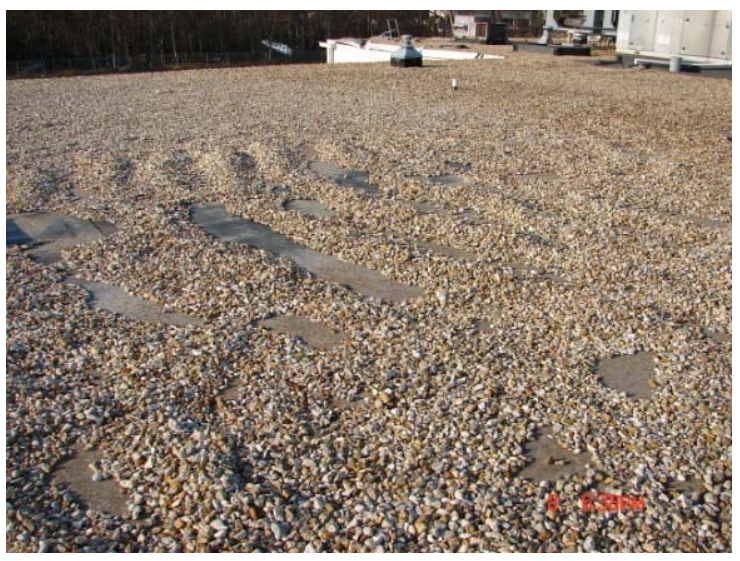

2.09-5. Sav-A-Center. Here is another unusual scour pattern. This pattern suggests a vertical vortex.

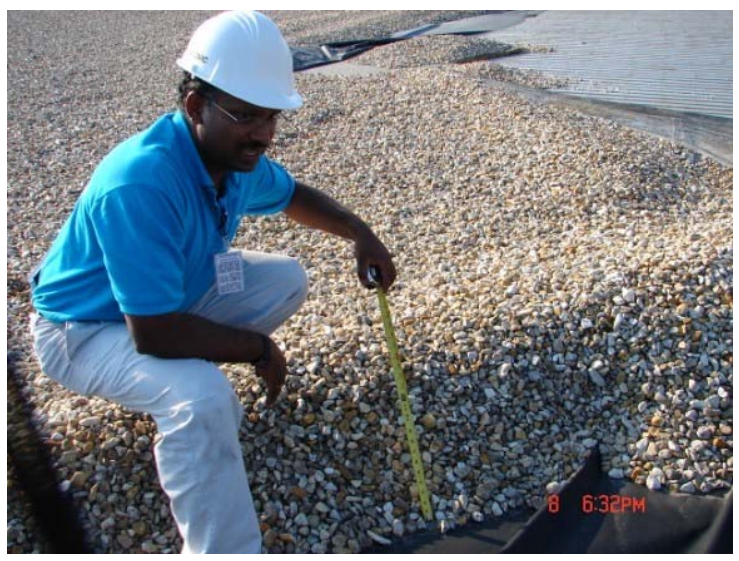

2.09-4. Sav-A-Center. This photo shows the way gravel accumulates near scoured areas. The gravel's weight helps limit the exposed damage area.

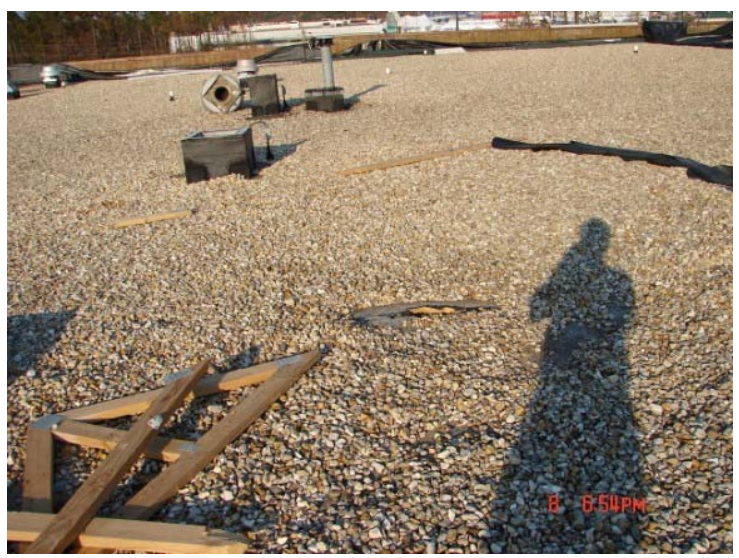

2.09-6. Sav-A-Center. Debris and related punctures were found in this area.

2.10 Industrial Manufacturing Facility, Pascagoula, MS

TYPE OF STRUCTURE-Manufacturing plant

EXPOSURE-C

SITE COORDINATES-N30 $19.027^{\prime}$ W89 $20.771^{\prime}$

WALL CONSTRUCTION-CMU

ROOF TYPE-EPDM (stone ballasted) with insulation

SLOPE- $-1 / 4: 12$

ROOF HEIGHT-28 ft

ROOF WIDTH-370 ft

ROOF LENGTH-220 ft 
DECK-Steel

WIND SPEED-120-130 mph

BUILDING CONSTRUCTION—Heavy steel framing

METHOD OF ATTACHMENT_-Stone ballast

NOTED DAMAGE-Wind scour at upwind corner; membrane blowoff damage noted on less than $5 \%$ of roof; coping metal damaged or missing in several areas; flashing material pulled from wall in several areas, suggesting membrane shrinkage; deck welds broken; some rusted decking.

DAMAGE INITIATION AND PROPAGATION-Wind scour of ballast and air entering through parapet wall ballooned membrane, leading to blowoff and other damage.

ADDITIONAL COMMENTS-This roof was being replaced during this inspection and all of the ballast had been removed. Membrane on the deck showed little or no damage outside the upwind corner.

\section{Photographs of Roof Damage}

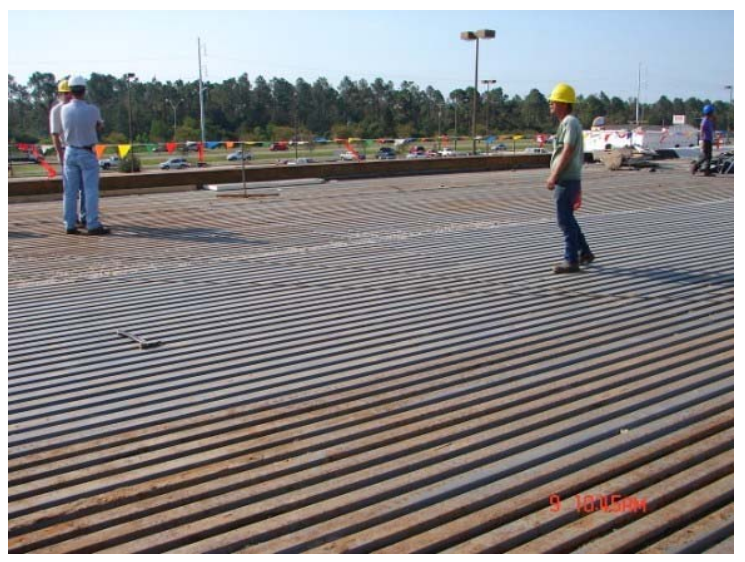

2.10-1. Manufacturing facility. This is an area where the membrane has been removed.

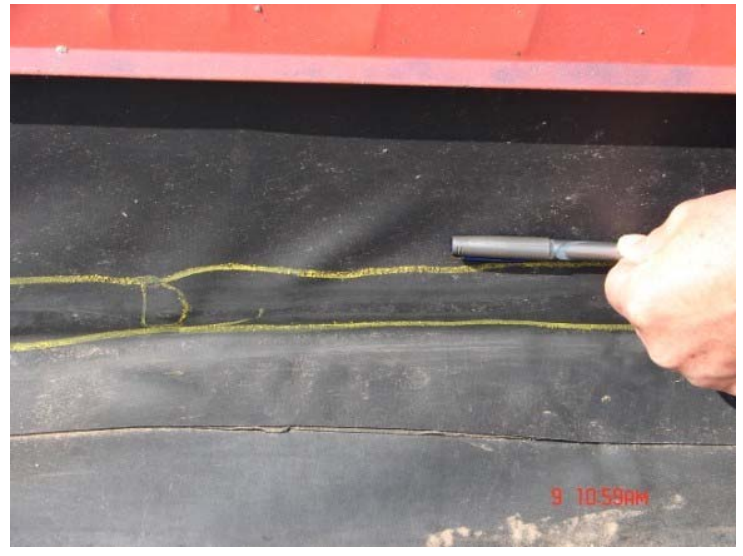

2.10-3. Manufacturing facility. Perimeter securement high on this wall allowed air pressurization at the wall/roof interface.

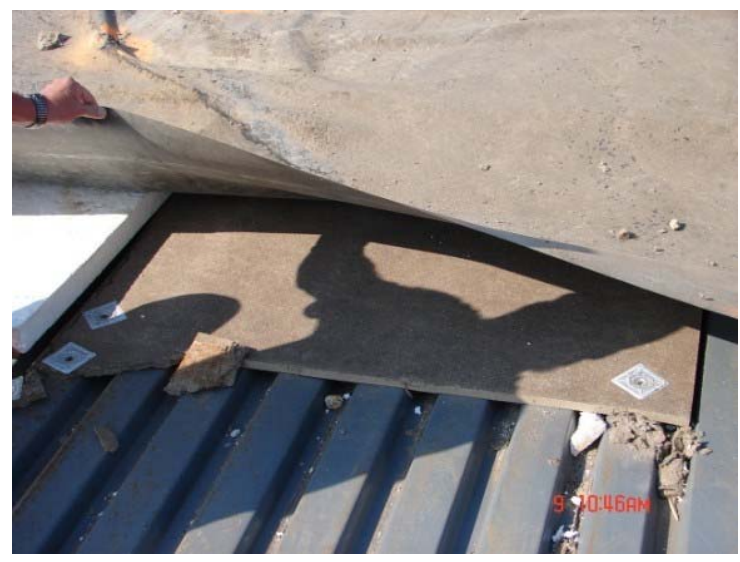

2.10-2. Manufacturing facility. An underlying tapered insulation system is visible here.

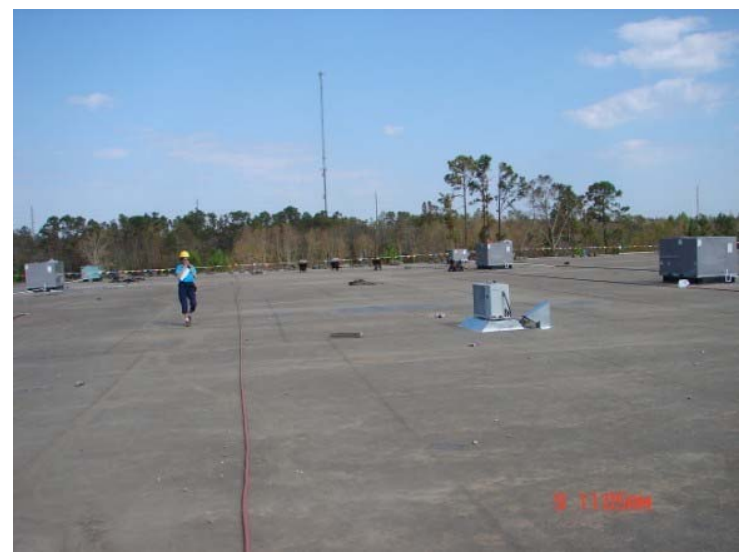

2.10-4. Manufacturing facility. This is a large area of undamaged roof. 


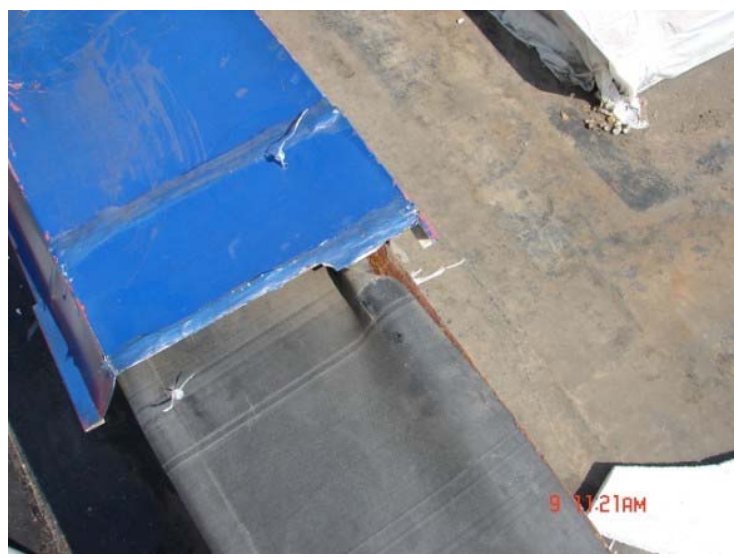

2.10-5. Manufacturing facility. Coping was displaced from this parapet.

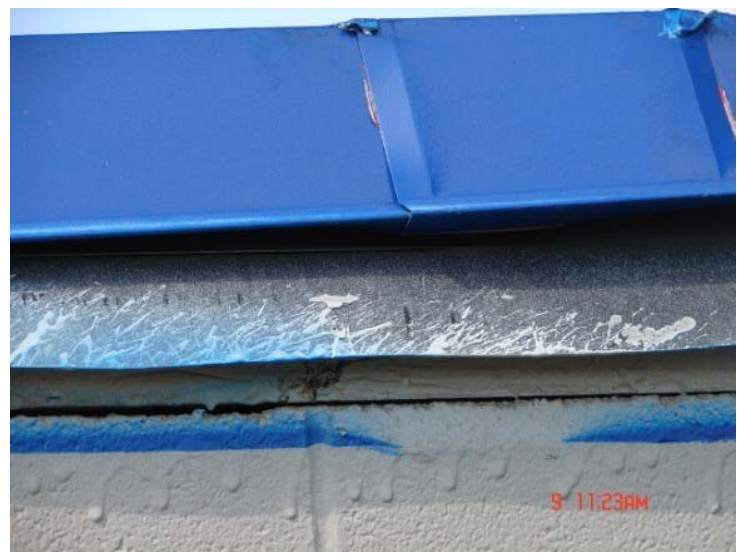

2.10-6. Manufacturing facility. Coping pulled loose from the cleat in this photo.

\subsection{Harper McCoughan Elementary School, Long Beach, MS}

TYPE OF STRUCTURE—School

EXPOSURE-B

SITE COORDINATES-Unknown

WALL CONSTRUCTION-Brick

ROOF TYPE-Structural metal

SLOPE- $-1 / 4: 12$

ROOF HEIGHT-14 ft

ROOF WIDTH—40 ft

ROOF LENGTH—750 ft (three sections are similar)

DECK - Standing seam metal deck

WIND SPEED-120-130 mph

BUILDING CONSTRUCTION—Brick and concrete block

METHOD OF ATTACHMENT - Clips

NOTED DAMAGE-Limited damage occurred where gable end failed and in another area where a tree fell on the roof.

DAMAGE INITIATION AND PROPAGATION-The gable end was blown out and the roof pressurized, causing limited damage in the immediate area.

ADDITIONAL COMMENTS-This building was seriously damaged by the storm surge, which broke walls and windows, but the roof survived in good condition in most areas. 


\section{Photographs of RoOF DAmage}

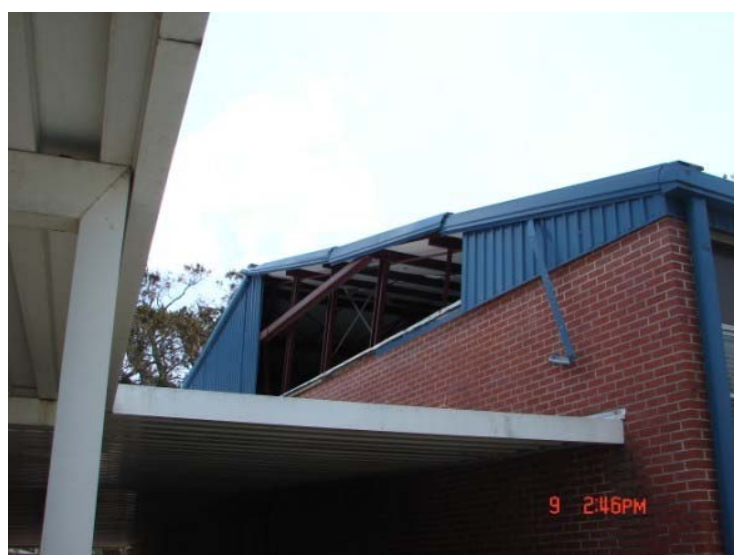

2.11-1. H. McCoughan Elementary. Wall and roof damage is visible on this building.

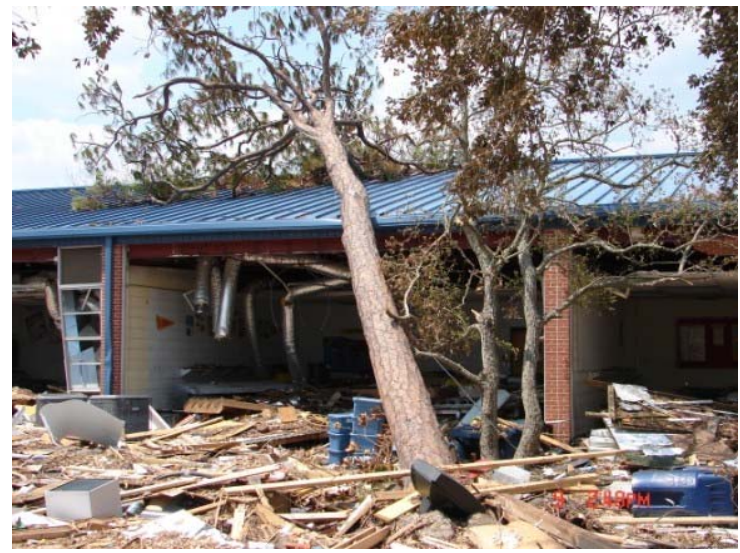

2.11-3. H. McCoughan Elementary. Trees were damaged by both high winds and storm surge.

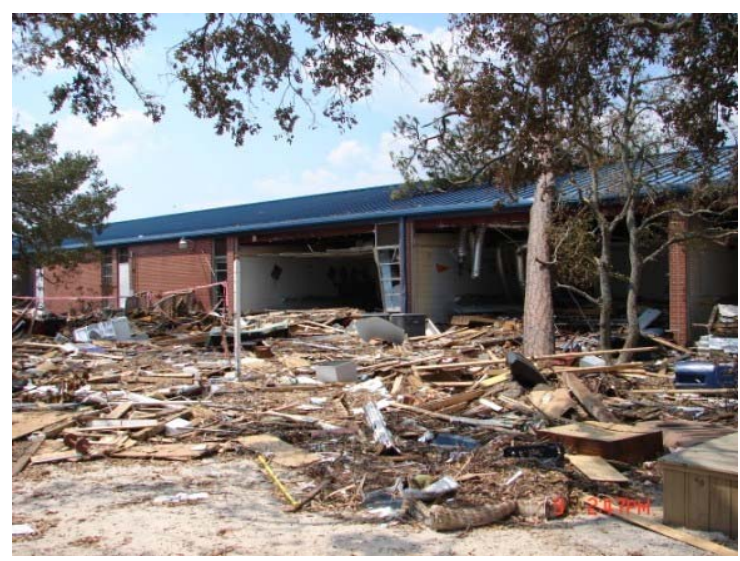

2.11-2 H. McCoughan Elementary. Storm surge debris covered the grounds around this building.

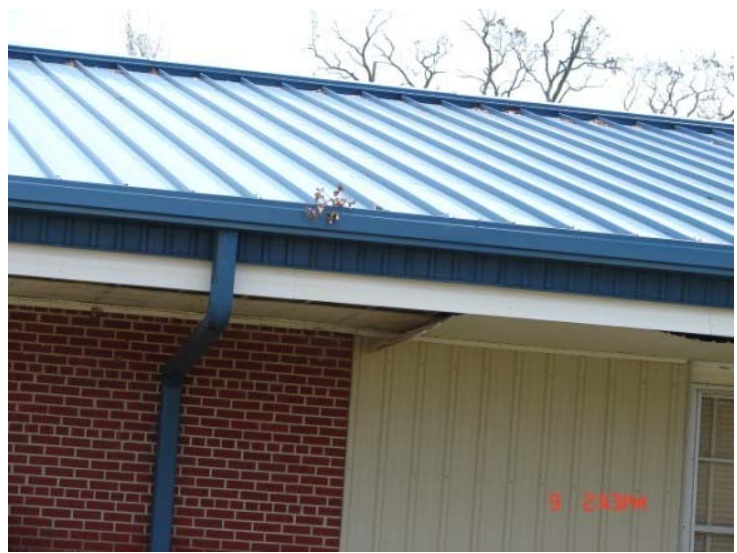

2.11-4. H. McCoughan Elementary. This was a typical roof condition at this site.

\subsection{American Commercial Exchange, Pass Christian, MS}

TYPE OF STRUCTURE-Commercial storage facility

EXPOSURE-B

SITE COORDINATES-Unknown

WALL CONSTRUCTION-Metal

ROOF TYPE-Through-fastened metal roof

SLOPE-2-3 : 12

ROOF HEIGHT $-14 \mathrm{ft}$

ROOF WIDTH-230 ft

ROOF LENGTH-220 ft

DECK-Steel

WIND SPEED-120-130 mph 
BUILDING CONSTRUCTION-Typical metal building

METHOD OF ATTACHMENT-Screws

NOTED DAMAGE—This building collapsed, and the roof blew off in many areas.

DAMAGE INITIATION AND PROPAGATION-Apparent wall failure led to building pressurization and final destruction.

ADDITIONAL COMMENTS - This was a warehouse filled with merchandise, which was ruined by the wind damage.

\section{Photographs of RoOF DAMAge}

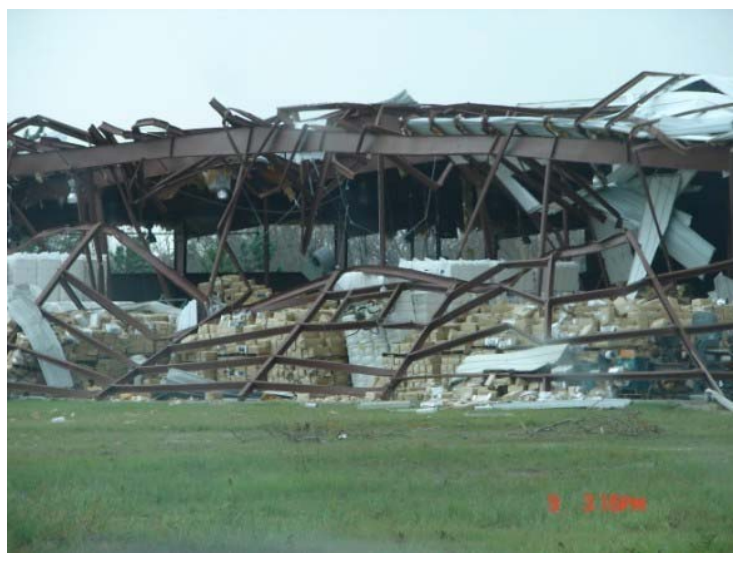

2.12-1. Commercial Exchange. This photo shows the total collapse of a storage building.

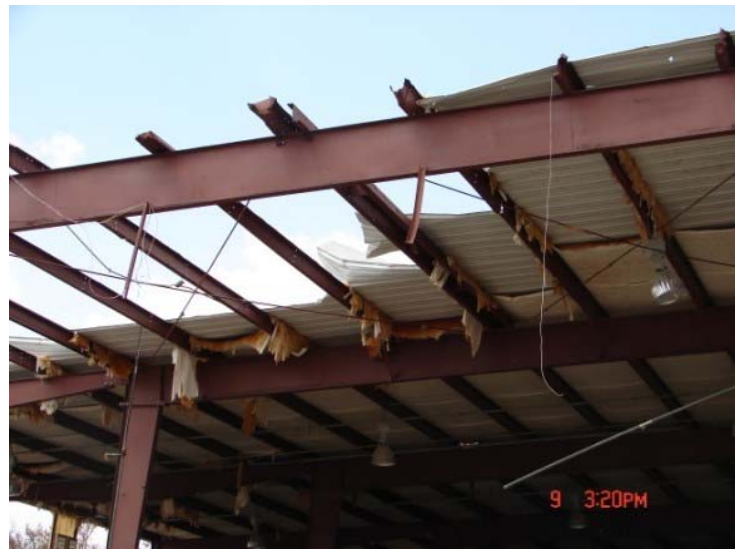

2.12-3. Commercial Exchange. Structural damage is visible in this photo.

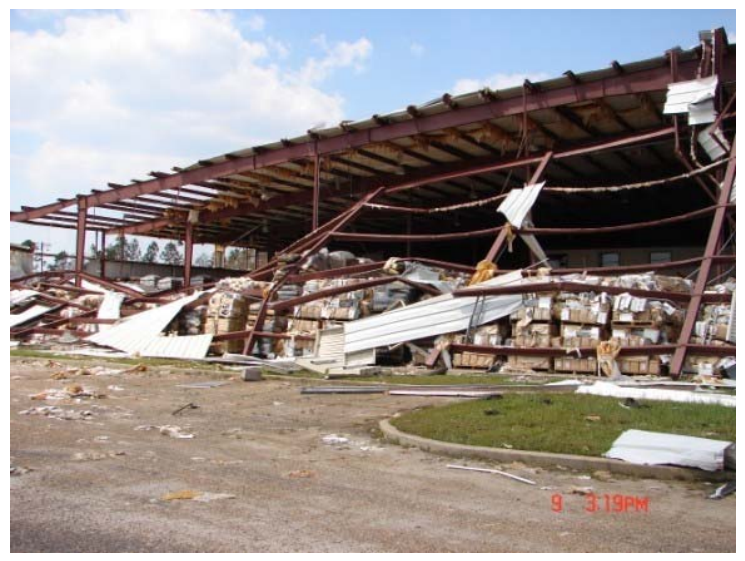

2.12-2. Commercial Exchange. Missing roof and wall sections are conspicuous here.

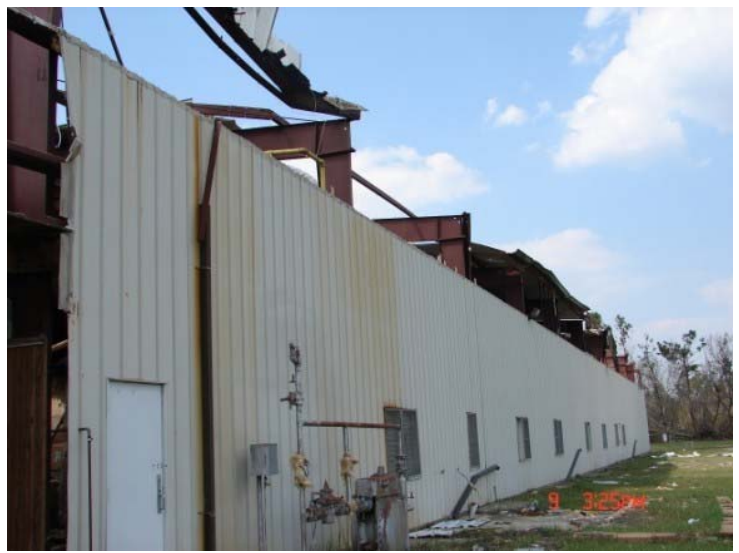

2.12-4. Commercial Exchange. Portions of the sidewall and roof are missing from this building. 


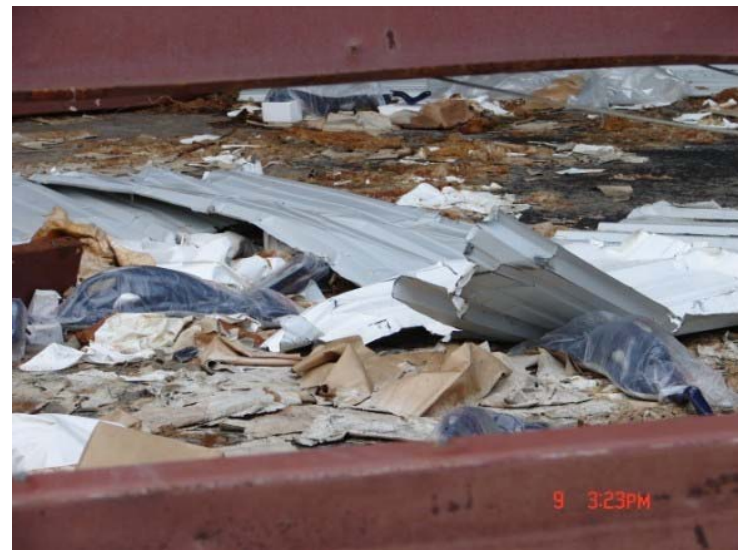

2.12-5. Commercial Exchange. This is what's left of a metal roof, with fasteners showing.

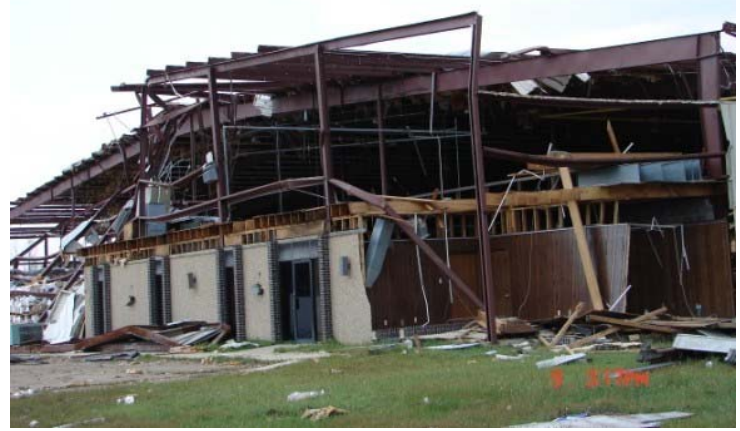

2.12-6. Commercial Exchange. Only the doors remain in place on this building.

\subsection{Sav-A-Center, Route 605 and Pass Road, Mississippi City, MS}

TYPE OF STRUCTURE-Commercial

EXPOSURE-C

SITE COORDINATES-Unknown

WALL CONSTRUCTION-CMU

ROOF TYPE-EPDM single ply with stone ballast

SLOPE- $-1 / 4: 12$

ROOF HEIGHT-21 ft

ROOF WIDTH-200 ft

ROOF LENGTH-210 ft

DECK-Steel

WIND SPEED-120-130 mph

BUILDING CONSTRUCTION—Steel frame

METHOD OF ATTACHMENT—Stone ballast

NOTED DAMAGE-Limited stone scour (less than $2 \%$ of roof) at upwind corners, around projections, and directly over a building expansion joint; membrane detached from parapet; a few punctures from airborne debris.

DAMAGE INITIATION AND PROPAGATION_-Air gaps at the roof perimeter pressurized a space under the membrane. This led to detachment of wall flashing from the parapet in several areas, primarily in the downwind parapet/façade area.

ADDITIONAL COMMENTS-A truck trailer was overturned near the back of the building in a protected area. The store was open for business on September 9 following the hurricane, with fresh stocks of produce and other basics. The roof membrane was mostly intact except for a few punctures. 


\section{Photographs of Roof Damage}

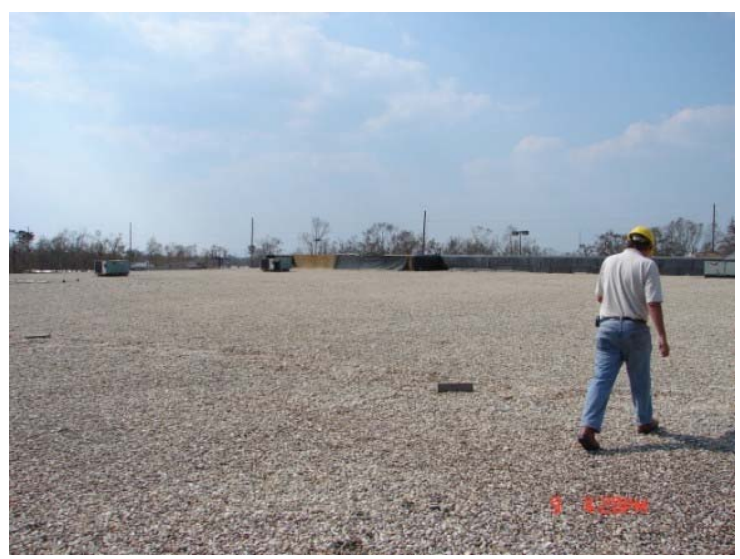

2.13-1. Sav-A-Center. This photo is typical of the roof areas at this site.

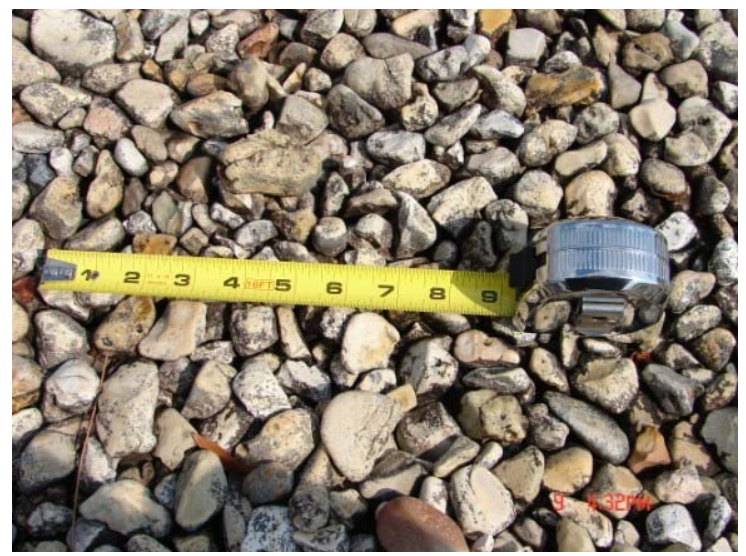

2.13-3. Sav-A-Center. This tape shows the typical stone size found here (ASTM D448\#3).

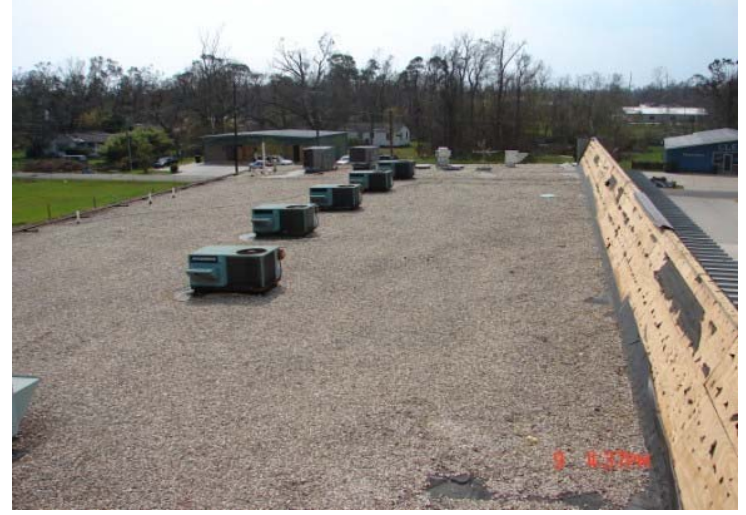

2.13-5. Sav-A-Center. More damaged wall flashing was noted here, although the membrane was intact.

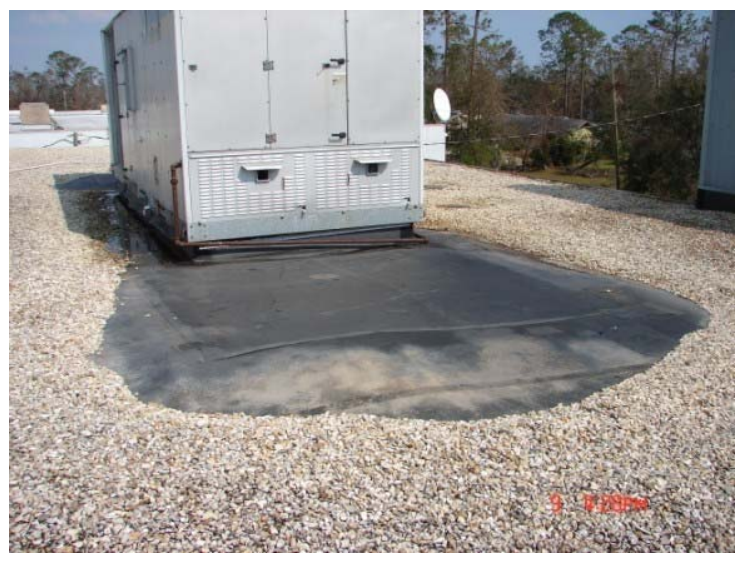

2.13-2. Sav-A-Center. This scour pattern was typical of what was found here. Wind blowing from the far side united to displace gravel on the near side.

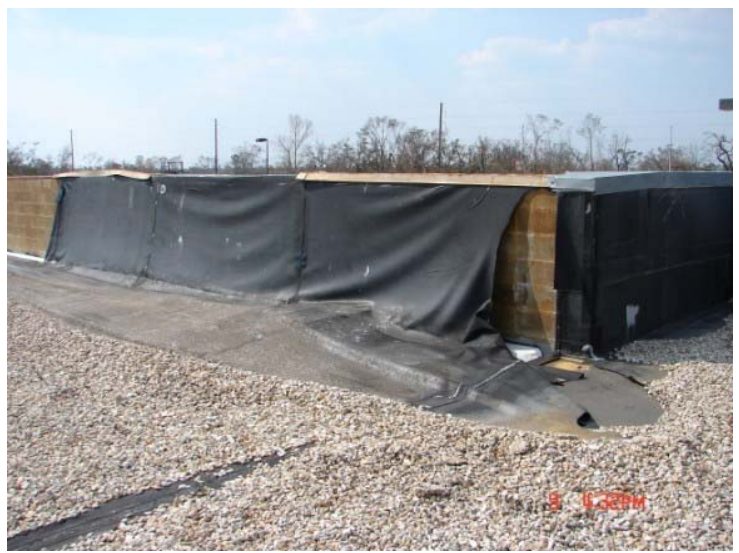

2.13-4. Sav-A-Center. Damaged wall flashing and coping are visible here.

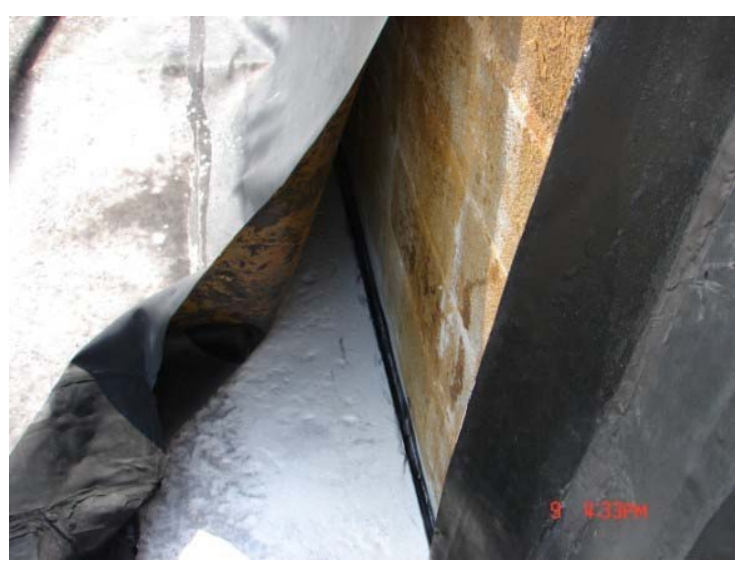

2.13-6. Sav-A-Center. The air gap at this wall can result in internal pressure blowing off the roof. 


\subsection{K-Mart, Tr. 605 and Pass Road, Mississippi City, MS}

TYPE OF STRUCTURE-Commercial

EXPOSURE-C

SITE COORDINATES-Unknown

WALL CONSTRUCTION-CMU

ROOF TYPE-Thermoplastic polyolefin single ply

SLOPE-0-1/4:12

ROOF HEIGHT-20 ft

ROOF WIDTH- $360 \mathrm{ft}$

ROOF LENGTH-245 ft

DECK-Steel

WIND SPEED-120-130 mph

BUILDING CONSTRUCTION-Steel frame

METHOD OF ATTACHMENT-Mechanically fastened

NOTED DAMAGE-A few punctures

DAMAGE INITIATION AND PROPAGATION—Debris hitting roof

ADDITIONAL COMMENTS - This roof was in very good shape. All debris damage was localized at the point of impact. The system appeared to be installed according to manufacturer's specifications and performed as expected.

\section{Photographs of Roof Damage}

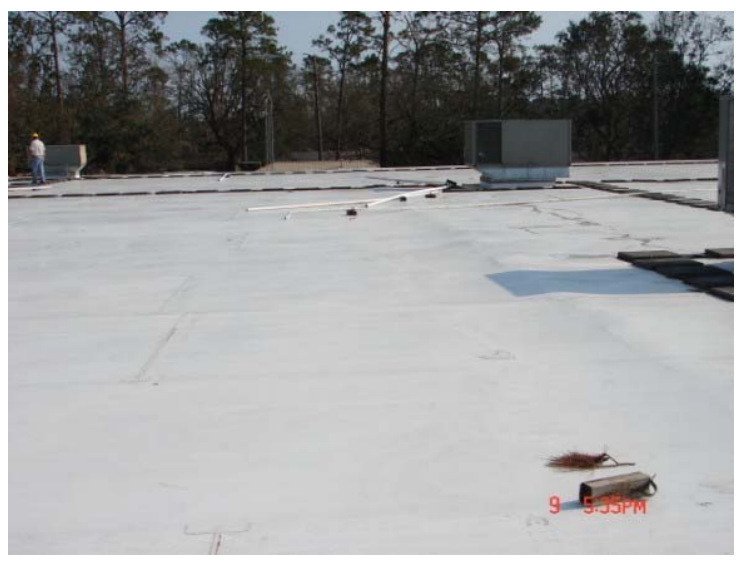

2.14-1 K-Mart. This roof exhibited no apparent damage.

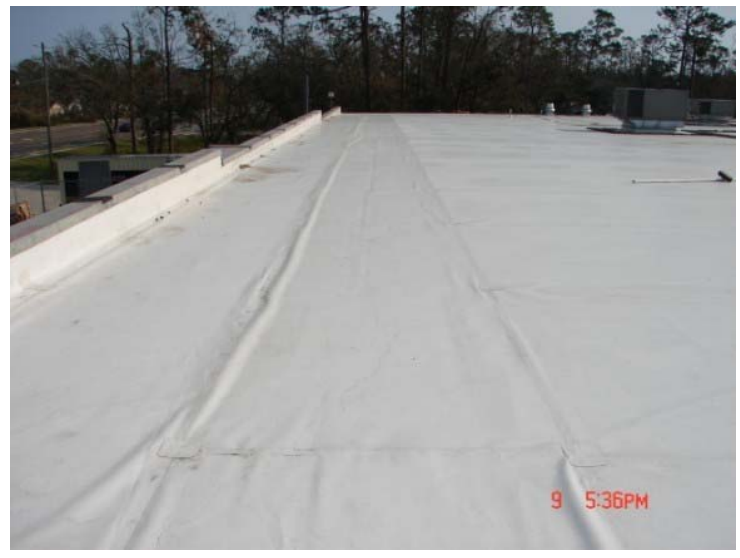

2.14-2. K-Mart. Slight wrinkling was found here. 


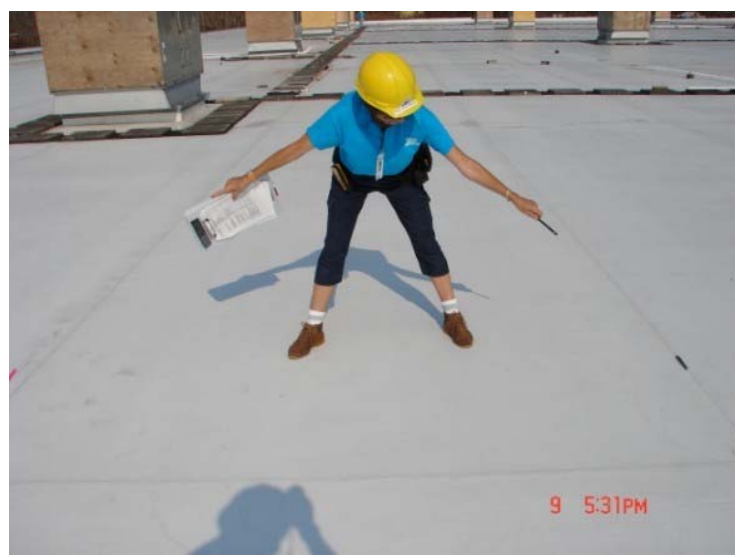

2.14-3. K-Mart. Batten bars in the field of this roof were $6 \mathrm{ft}$ o.c.

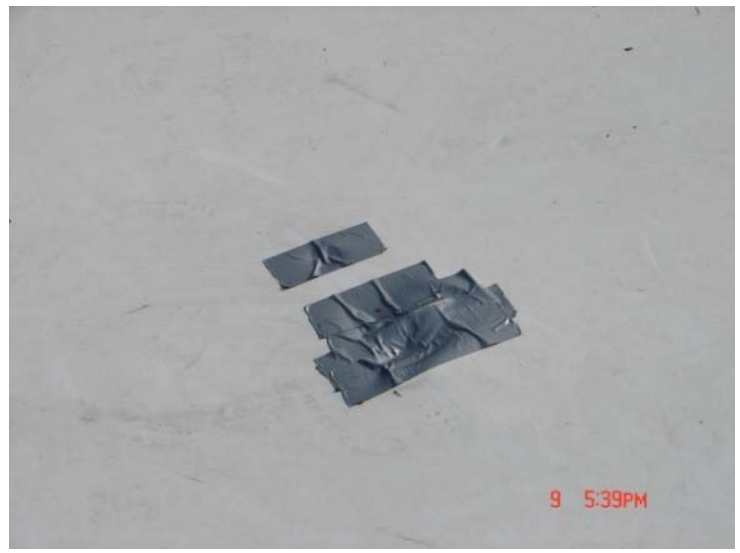

2.14-5. K-Mart. This is a temporarily patched puncture.

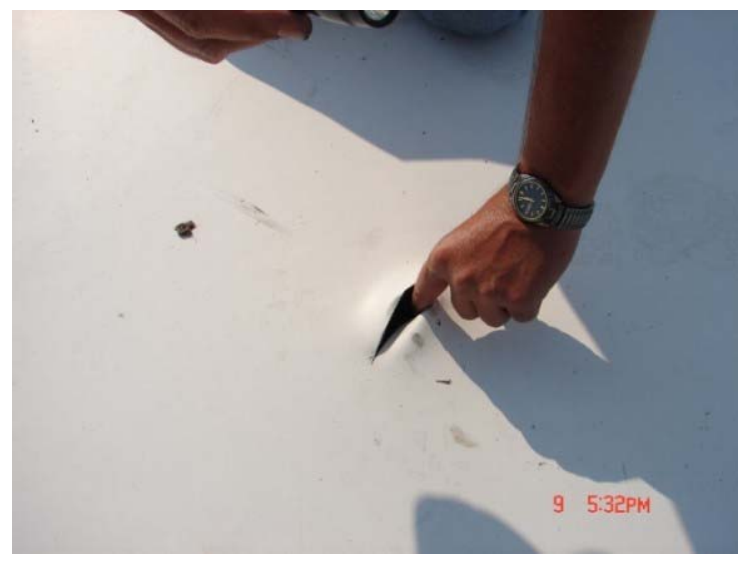

2.14-4. K-Mart. This photo shows a punctured single ply membrane.

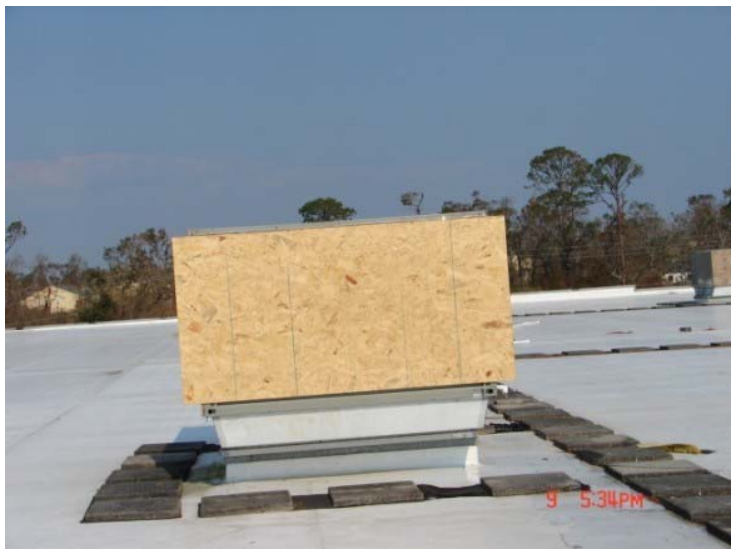

2.14-6. K-Mart. Plywood protects this HVAC unit encircled by pavers that were still in place.

\subsection{Quarles Elementary School, Long Beach, MS}

TYPE OF STRUCTURE-School

EXPOSURE-B

SITE COORDINATES-Unknown

WALL CONSTRUCTION-Poured concrete

ROOF TYPE-Structural metal

SLOPE- $-1 / 4: 12$

ROOF HEIGHT_Unknown

ROOF WIDTH-Unknown

ROOF LENGTH—Unknown

DECK - Cast-in-place concrete

WIND SPEED-120-130 mph.

BUILDING CONSTRUCTION—Concrete 
METHOD OF ATTACHMENT—Clips

NOTED DAMAGE—Limited damage in a few areas.

DAMAGE INITIATION AND PROPAGATION-Wall damage led to internal pressurization of building directly beneath damaged roof areas.

ADDITIONAL COMMENTS-This was a drive-by inspection, with no photos. 


\section{HURRICANE KATRINA: TEAM 4}

\section{OVERVIEW}

Team 4 members investigated a variety of low slope roofs. The team visited commercial areas in Biloxi, D'Iberville, and Gulfport, Mississippi, that were affected by Hurricane Katrina. The focus was primarily on areas hit by the highest wind speeds and on selecting a variety of roof system types. The team surveyed a total of eight roofs, consisting of metal, spray polyurethane foam (SPF), single ply, modified bitumen (styrene butadiene styrene, or SBS), and built-up roofing (BUR).

\section{Team 4 Members}

The following team members participated for at least one of the four investigation days:

André Desjarlais, assistant report writer

Paul Fogarty, sample collector

Sean Foley, sample collector

Mike Hamilton, photographer

Cheri Panasik, report writer and data recorder

\section{Summary Observations}

In some cases, damage was initiated where prescribed fastening patterns were not followed. In other cases, heating, ventilation, and air-conditioning (HVAC) equipment was not secured adequately to withstand strong winds. A high percentage of roof systems in the study area were ethylene propylene diene monomer (EPDM) and BUR and did not appear damaged. Team 4 continued to search, however, until a variety of roof systems were located.

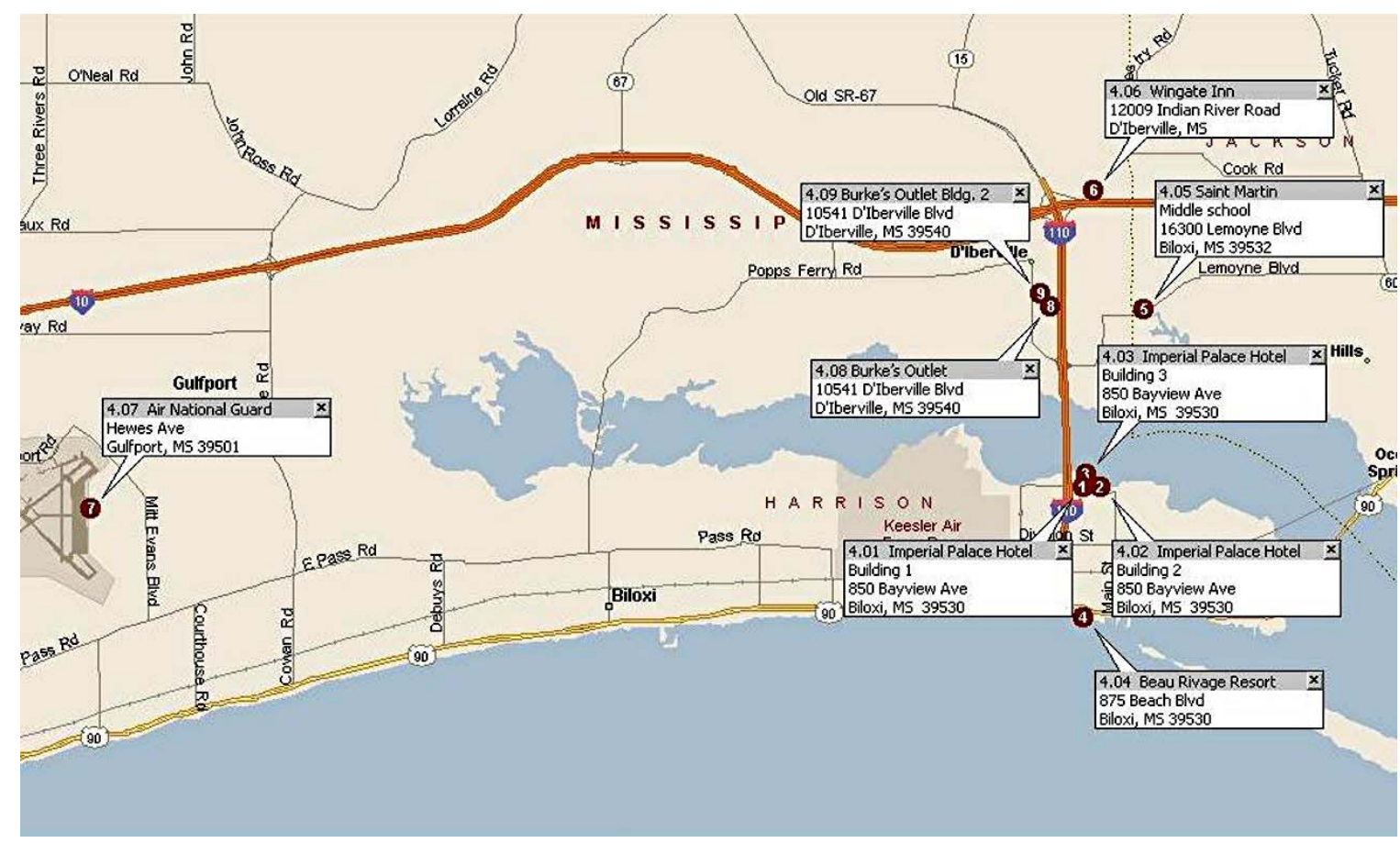

Map 1. Biloxi, D'Iberville, and Gulfport, MS, area. 


\section{INDIVIDUAL ROOF REPORTS}

\subsection{Imperial Palace Hotel-Building 1, 850 Bayview Drive, Biloxi, MS}

TYPE OF STRUCTURE-Hotel

EXPOSURE-C

SITE COORDINATES-N30 $27^{\prime}$ W88 53'

WALL CONSTRUCTION-Exterior wall was covered with exterior insulated finished system (EIFS); 40-60\% of the exterior walls had windows and/or other openings.

ROOF TYPE—From the top down, materials consisted of acrylic coating (15 mil), SPF (1-2 1/2 in.), polyisocyanurate insulation board (11/2 in.), expanded polystyrene (EPS) board.

SLOPE— $1 / 2-1: 12$

DECK—Cast-in-place concrete

WIND SPEED-120-130 mph

BUILDING CONSTRUCTION-Structural concrete high-rise (33 stories). The base of the building was $30 \mathrm{ft}$ above sea level. The roof deck was about $385 \mathrm{ft}$ high. The building was constructed in 1993.

METHOD OF ATTACHMENT - Insulation boards (polyisocyanurate over EPS-staggered) were installed using screws and plastic plates. Three screws per plate were installed through the centerline of each $4 \times 8 \mathrm{ft}$ sheet. Other screws/plates were improperly installed between adjacent boards (three per short side and four per long side) rather than penetrating either board.

NOTED DAMAGE-Over $50 \%$ of the roof surface was completely stripped off the roof assembly with only plates, screws, and concrete deck remaining. Sheet metal exhaust units were also displaced by winds.

DAMAGE INITIATION AND PROPAGATION-Inadequate fastener quantity and improper fastening methods caused facer delamination, which resulted in total loss of roof assembly over much of the roof surface.

ADDITIONAL COMMENTS-The hotel building was much taller than its surroundings (except neighboring Imperial Buildings 2 and 3) and in an open water hurricane zone. The parapet height was 39 in. 


\section{Photographs of Roof Damage}

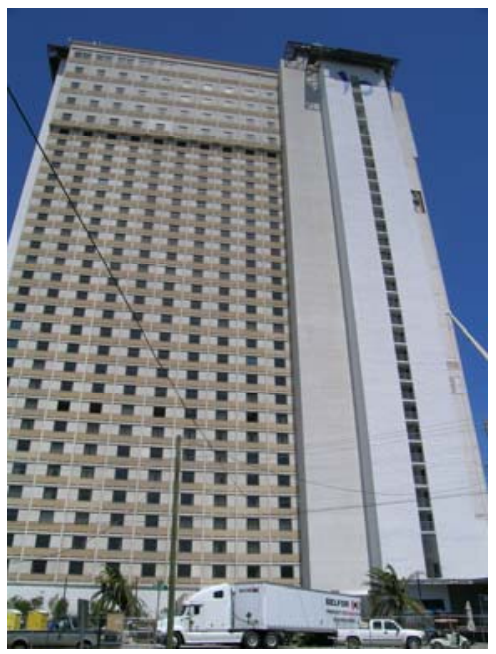

4.01-1. Imperial Palace Hotel Building 1. Southern exposure. Note the penthouse and the missing wall panels in the upper right.

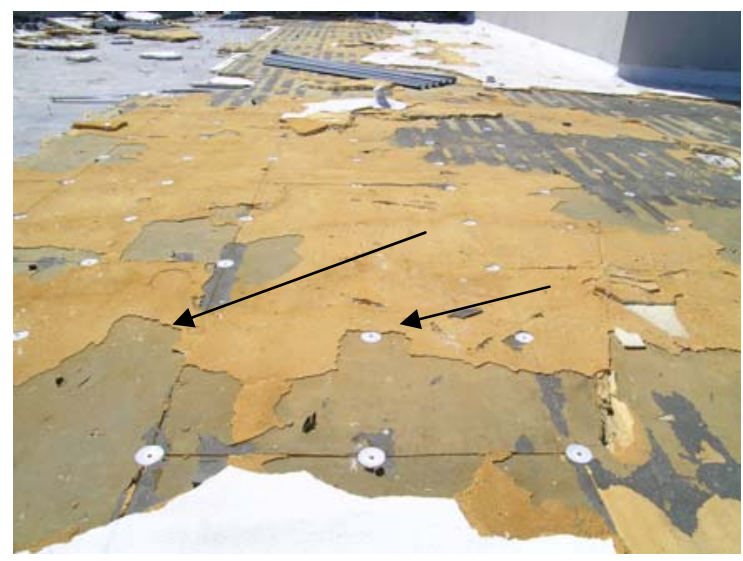

4.01-2. Imperial Palace Hotel Building 1. Plates are positioned between the $4 \times 8 \mathrm{ft}$ sheets of insulation, rather than through each board. This is an example of poor workmanship.

\subsection{Imperial Palace Hotel, Building 2, 850 Bayview Drive, Biloxi, MS}

TYPE OF STRUCTURE-Hotel

EXPOSURE-C

\section{SITE COORDINATES-N30 $27^{\prime}$ W8 $88^{\circ} 53^{\prime}$}

WALL CONSTRUCTION-Exterior wall was covered with EIFS; 40-60\% of the exterior walls had windows and/or other openings.

ROOF TYPE-From the top down, materials consisted of acrylic coating (15 mil), SPF (1- 21/2 in.), polyisocyanurate insulation board ( $1 \frac{1}{2}$ in.), EPS ( 2 in. board).

SLOPE- $1 / 2-1: 12$

DECK - Cast-in-place concrete

WIND SPEED—120-130 mph

BUILDING CONSTRUCTION-Structural concrete high-rise. The base of the building was at $3 \mathrm{ft}$ above sea level. The roof deck was about $410 \mathrm{ft}$ high. The building was constructed in 1993.

METHOD OF ATTACHMENT-Mechanically fastened at the seams

NOTED DAMAGE-Over $50 \%$ of the roof surface was completely stripped off the roof assembly with only plates, screws, and concrete deck remaining. Sheet metal exhaust units were also displaced by winds.

DAMAGE INITIATION AND PROPAGATION-Inadequate fastener quantity and improper fastening methods caused facer delamination, which resulted in total loss of roof assembly over much of the roof surface.

ADDITIONAL COMMENTS-The building is one of the tallest buildings in the state of Mississippi. It is much taller than its surroundings and in an open water hurricane zone. Parapet height was 39 in. 


\subsection{Imperial Palace Hotel-Building 3, 850 Bayview Drive, Biloxi, MS}

TYPE OF STRUCTURE-Hotel

EXPOSURE-C

SITE COORDINATES-N30 $27^{\prime}$ W88 $53^{\prime}$

WALL CONSTRUCTION-Exterior walls were constructed using concrete masonry units (CMU); $0-5 \%$ of exterior walls had windows and/or openings.

ROOF TYPE—Steel panel welded to the purlins; roof panels mechanically fastened to the steel deck

SLOPE-12:12

DECK-Steel

WIND SPEED-120-130 mph

BUILDING CONSTRUCTION_-The base of the building was at $30 \mathrm{ft}$ above sea level. The roof deck was about $420 \mathrm{ft}$ high. The building was constructed in 1993.

METHOD OF ATTACHMENT-Steel decking was puddle-welded at $4 \mathrm{ft}$ o. c. to secondary support "I" purlins; $3 \times 8 \mathrm{ft}$ roof panels were mechanically fastened to the steel decking using $3 / 4 \mathrm{in}$. exposed through-fasteners spaced $3 \mathrm{ft}$ o.c.. Roof panels were connected to every support; no roof insulation was used; roof overhang was $7 \mathrm{ft}$.

NOTED DAMAGE-There was approximately 50\% damage to the low slope roof. Decking damage was present in $25 \%$ of the steep slope metal roofing on small buildings on top of the large Imperial Palace building. The small building had $25 \%$ of its entire roof deck damaged.

DAMAGE INITIATION AND PROPOGATION_Corroded puddle welds and weld burn-through appear to have led to failure of the connection of steel decking to purlin. Metal panels were blown off as their structural supports were compromised by wind uplift forces. As steel decking lost its attachment to purlins, the entire roof assembly blew off.

ADDITIONAL COMMENTS-The hotel building was much taller than the surroundings and in an open water hurricane zone. There were two structures on this building that had the same metal roof construction. Both of these roofs were blown off.

\section{Photographs of Roof Damage}

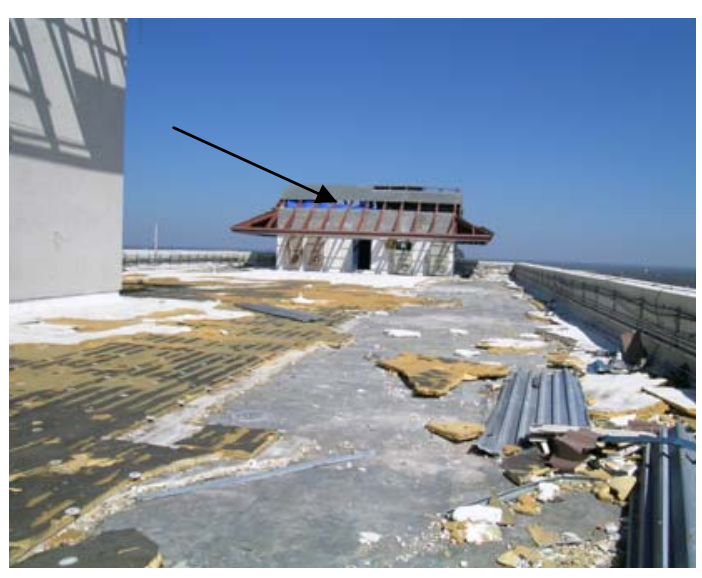

4.03-1. Imperial Palace Hotel Building 3.

Damage on main roof and small building atop main roof.

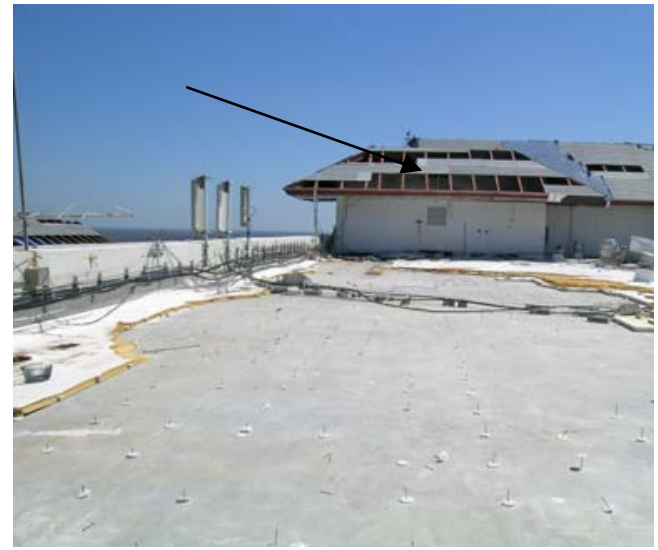

4.03-2. Imperial Palace Hotel Building 3. Damage on main roof and small building atop main roof. 


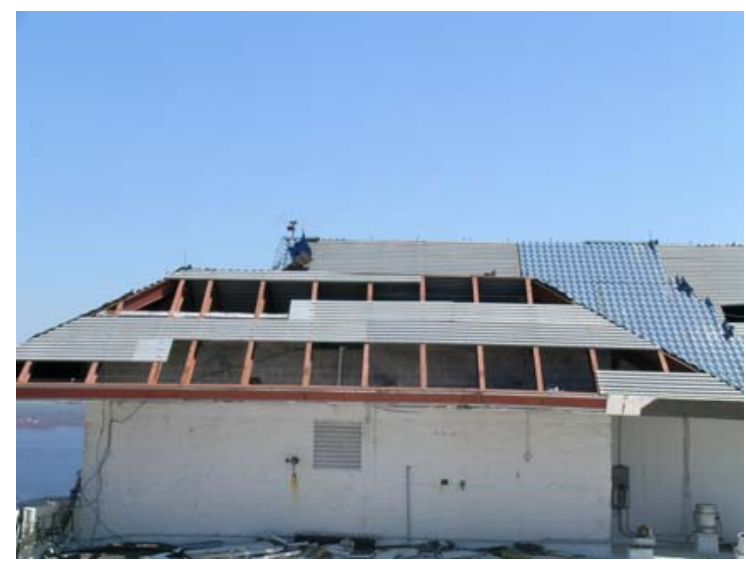

4.03-3. Imperial Palace Hotel Building 3. Steel decking and roof panel blew off. Welds failed, and steel decking and the mechanical fasteners failed at the roof panels.

\title{
4.04 Beau Rivage Hotel and Casino, Biloxi, MS
}

TYPE OF STRUCTURE-Hotel

\author{
EXPOSURE-C
}

SITE COORDINATES-N30 $39^{\prime}$ W88 $89^{\prime}$

WALL CONSTRUCTION_Exterior wall was covered with EIFS; 40-60\% of the exterior walls had windows and/or other openings.

ROOF TYPE—Modified bitumen (SBS) membrane with mineral surfacing

SLOPE- $-1 / 4: 12$

DECK—Lightweight structural concrete

WIND SPEED-120-130 mph

BUILDING CONSTRUCTION_-The base of the building was $3 \mathrm{ft}$ above sea level. The hotel building was much taller than the surroundings and in an open water hurricane zone. The roof was approximately $36 \mathrm{ft}$ high. The building was constructed in 1999.

METHOD OF ATTACHMENT — Lightweight insulated concrete plates, $23 / 4$ in. diameter, attached with split-shank fasteners through the base sheet, spaced $10 \mathrm{in}$. apart; 2-ply modified bitumen membrane fully adhered on the mechanically fastened base sheet.

NOTED DAMAGE-Approximately $5 \%$ of the roofing membrane was damaged (torn), and 30\% of the perimeter wood blocking (edge nailer) was detached. An expansion joint was exposed as a result of the cover's becoming detached. Lightweight concrete plates were detached from the lightweight concrete. Exhaust equipment was ripped out of place and lay dislodged on the roof.

DAMAGE INITIATION AND PROPAGATION-Exhaust equipment apparently was blown the length of the roof, damaging the membrane as it dragged along the rooftop.

ADDITIONAL COMMENTS—Roof damage seemed to be solely due to exhaust equipment cutting and tearing the membrane. The parapet was $8 \mathrm{ft}$ high. 


\section{Photograph OF Roof Damage}

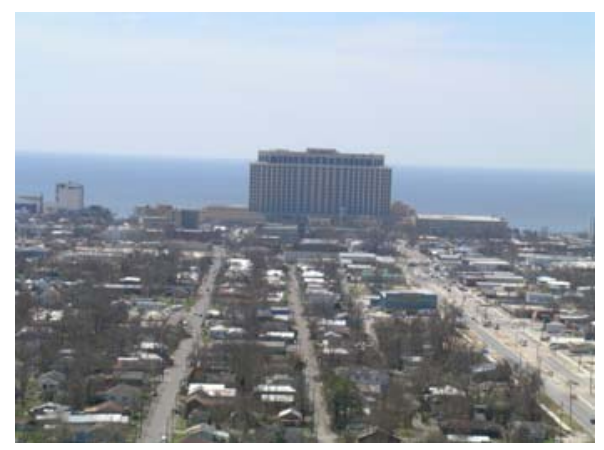

4.04-1. Beau Rivage Hotel. Overview.

\subsection{Saint Martin Middle School, Lemoryre Blvd., D’Iberville, MS}

TYPE OF STRUCTURE—School

EXPOSURE-C

SITE COORDINATES-Not available

WALL CONSTRUCTION-Brick. Approximately half of the exterior walls had windows and/or other openings.

ROOF TYPE-Membrane was a "base and 4-ply" BUR with aggregate surfacing.

SLOPE— $1 / 4: 12$

DECK-Cementitious wood fiber (CWF)

WIND SPEED—120-130 mph

BUILDING CONSTRUCTION_-The building was constructed in 1959. The roof was $15 \mathrm{ft}$ high.

METHOD OF ATTACHMENT_-Base sheet was mechanically attached using steel ring shank nails and tin caps with one per square foot and sporadically at the lap. The perimeter had three fasteners per lineal foot. Perimeter zone 2 and perimeter zone 3 cornering area had $1 / 3 \mathrm{ft}^{2}$ per fastener. CWF decking was secured to metal bar joists with H-clips spaced $8 \mathrm{ft}$ o. c.

NOTED DAMAGE-Approximately $98 \%$ of the roof and $90 \%$ of perimeter metal were damaged. Approximately $25 \%$ of the edge blocking (wood nailer) was detached. Approximately $90 \%$ of substrate attachment was damaged. Deck detachment was in the southeast corner. Deck was detached from bulb Ts. The sheet metal H-clips were rusted and pulled free from the bar joists.

DAMAGE INITIATION AND PROPAGATION-The building was internally pressurized because the windows had blown in. This resulted in failure of the base sheet, membrane, and deck panels to remain attached to the structure. Wind pressure forced $\mathrm{H}$-clips to pull free of the bar joints. Close inspection confirmed that remaining $\mathrm{H}$-clips were not secure and were easily removed from the bar joint. Base sheet fasteners were inadequate to hold the base sheet in place.

ADDITIONAL COMMENTS-Windows and doors were missing, and numerous roof deck panels were displaced. The inside of the building and its contents were destroyed. 


\section{PhOtographs of RoOF DAMAge}

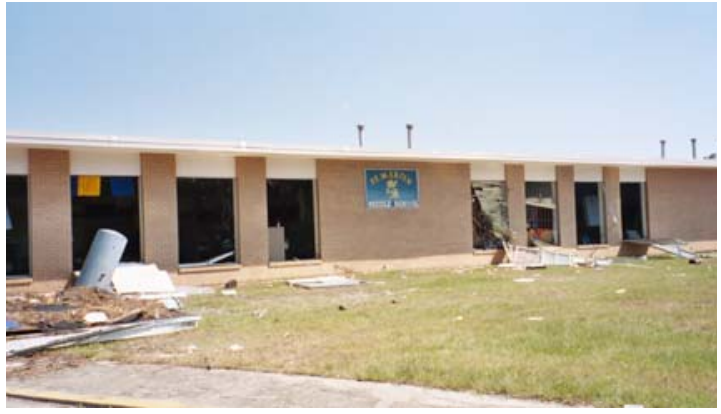

4.05-1. Saint Martin Middle School. Windows blown inward at south elevation caused interior to be pressurized.

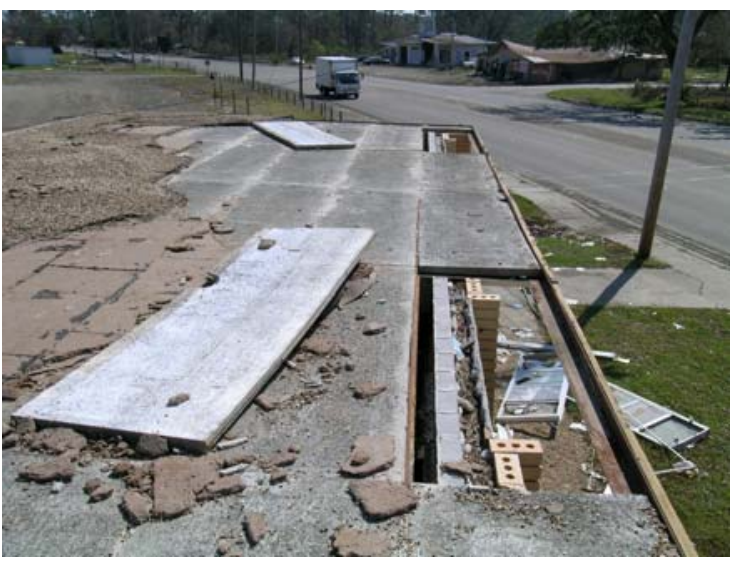

4.05-2. Saint Martin Middle School. Roof blew off along southern exposure toward the Gulf. CWF deck panel was blown off with the sheet metal at the perimeter.

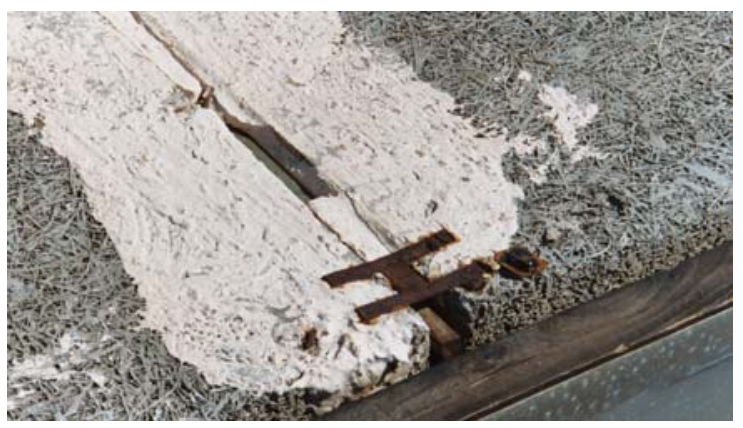

4.05-3. Saint Martin Middle School. Rusted " $H$ " clip. Age, corrosion, and inadequate spacing, along with the internal pressurization, possibly caused the deck losses.

\subsection{Wingate Hotel, 12009 Indian River Road, D'Iberville, MS}

TYPE OF STRUCTURE-Hotel

EXPOSURE-B

SITE COORDINATES-N30 27' 27" W88 53' 48"

WALL CONSTRUCTION-Exterior wall covered with EIFS

ROOF TYPE—Single ply EPDM installed over polyisocyanurate insulation boards

SLOPE— $1 / 4: 12$

DECK-Steel

WIND SPEED-120-130 mph

BUILDING CONSTRUCTION-The base of the building was at a $3 \mathrm{ft}$ elevation. The roof was $34 \mathrm{ft}$ high. The building was constructed in 1999. 
METHOD OF ATTACHMENT - Membrane was mechanically fastened through the insulation layer to the deck with screws and plates. Corner membrane fastening consisted of battens and glued seams. Insulation boards were fastened using five screws and plates per $32 \mathrm{ft}^{2}$ board.

NOTED DAMAGE—Damage was limited to one corner and eave-approximately $3 \%$ of the roof area. There was no original metal flashing on the parapet.

DAMAGE INITIATION AND PROPAGATION_-The membrane had been fully adhered at the parapet, but a witness said it lifted and billowed up, pulling loose from the corner and parapet. The exterior EIFS wall at rooftop and parapet was blown out from internal building pressurization. Blowout damage occurred at the southwest corner, beginning at the exterior wall and eave.

ADDITIONAL COMMENTS-Temporary repairs were done using an asphalt-based product that specifically states it should not be used on EPDM surfaces. Plastic tarpaulins were in use to temporarily cover and protect damaged spots. The parapet was $4 \mathrm{ft}$ high.

\section{Photographs of Roof Damage}

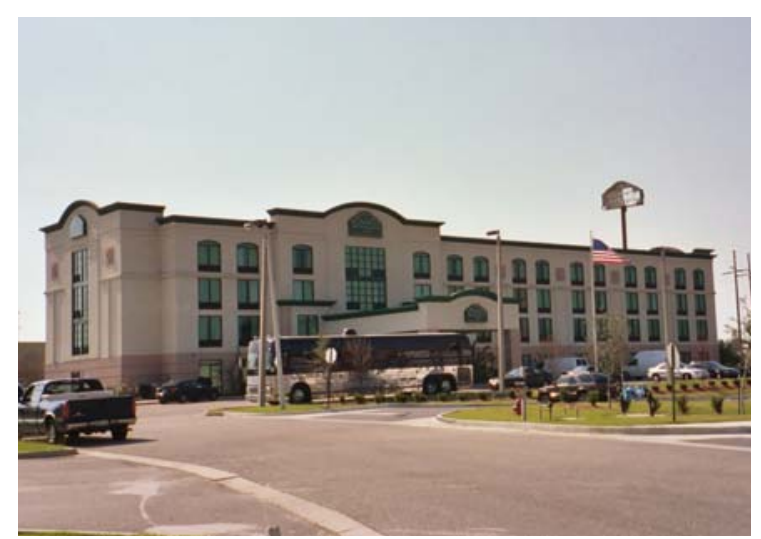

4.06-1. Wingate Hotel. North elevation.

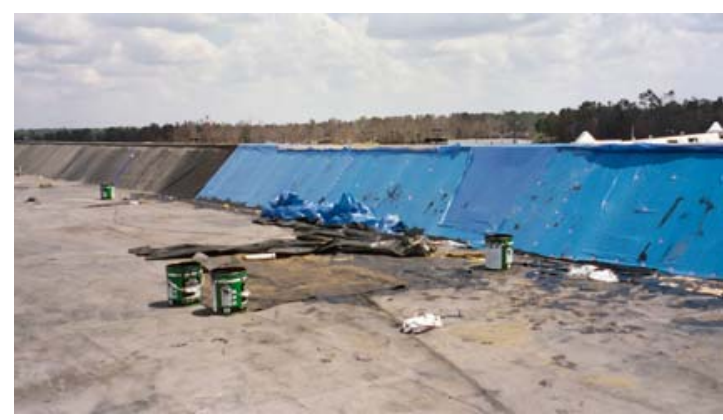

4.06-3. Wingate Hotel. Temporary repairs.

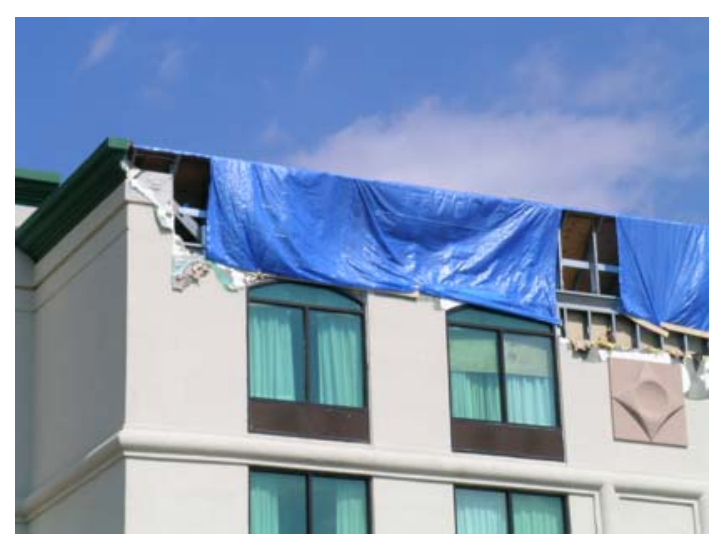

4.06-2. Wingate Hotel. Southern elevation parapet façade made of EFIS on metal studs failed from internal pressurization (inside the façade) from the roof side of the parapet.

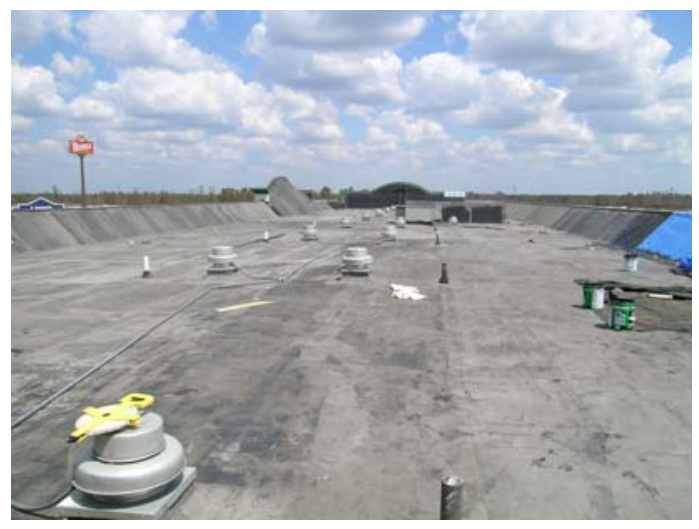

4.06-4. Wingate Hotel. Most of the roof had no damage. 


\subsection{National Guard Airport, Hawes Ave, Gulfport, MS}

TYPE OF STRUCTURE-Airport

EXPOSURE-B

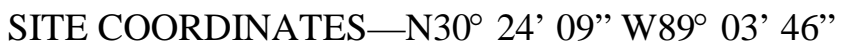

WALL CONSTRUCTION-Exterior wall construction was concrete tilt-wall; 0-5\% of the exterior walls had windows and/or other openings.

ROOF TYPE-Steel standing seam with ribs 16 in. o.c. Steel decking was secured to metal bar joists by puddle welds; insulation was polyisocyanurate board.

SLOPE-1-2: 12

DECK-Steel

WIND SPEED-120-130 mph

BUILDING CONSTRUCTION-The exterior wall construction was tilt-up concrete. The base of the building was at a $20 \mathrm{ft}$ elevation. The roof was $35 \mathrm{ft}$ high.

METHOD OF ATTACHMENT_-Metal standing seam roof was attached with clips, which were mechanically fastened to the steel purlins.

NOTED DAMAGE-One percent of the roof was damaged. Metal roof panels were damaged in two areas, and the underlying insulation was visible. Some edge details and gutters were detached and missing. Dents and scrapes were noted in several areas. Exhaust equipment was detached from its supports in three areas. Some building contents were damaged.

DAMAGE INITIATION AND PROPAGATION-Exhaust equipment in three areas blew off its supports and dragged across the roof, causing dents and scrapes. The exhaust unit housing was secured with only six screws, and they either tore through the sheet metal or sheared off. The exhaust equipment was found on the ground.

ADDITIONAL COMMENTS - Some temporary repairs had been started. Roof openings had been covered with plywood and caulked. The parapet was $21 \mathrm{in}$. high. The $35 \mathrm{ft}$ high building was much taller than its surroundings and was in a grassy open area. If the exhaust equipment had held in place, there would likely have been no damage to the roof.

\section{Photographs of Roof Damage}

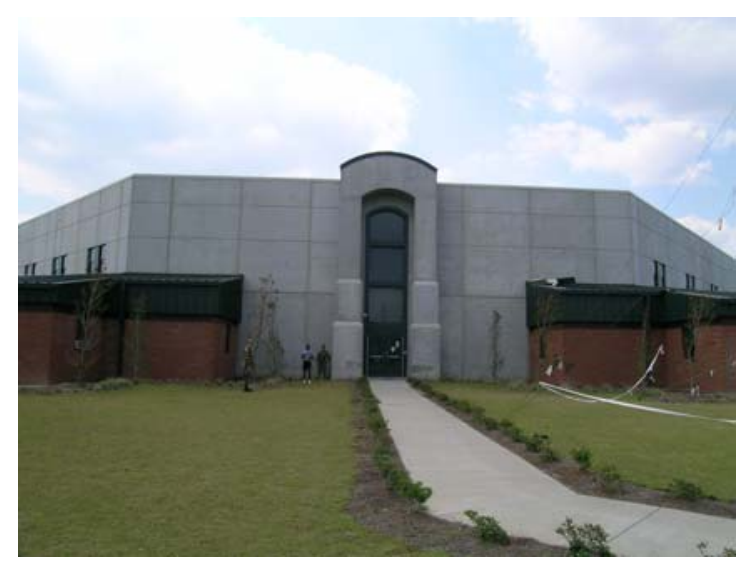

4.07-1. National Guard Airport. East elevation.

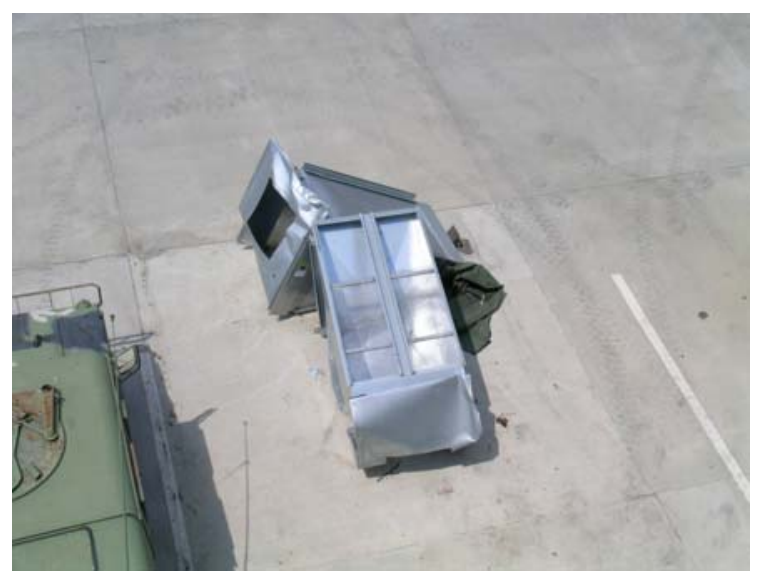

4.07-2. National Guard Airport. Large HVAC unit, curb, and duct blown off the roof. 


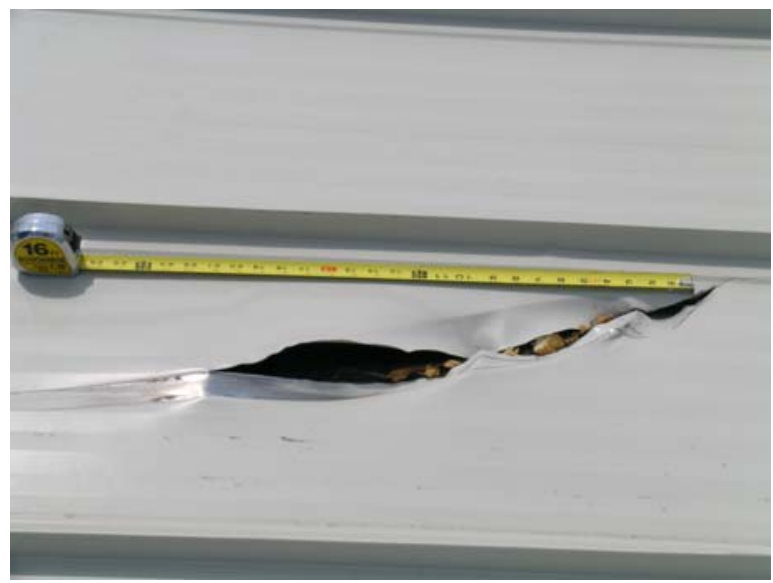

4.07-3. National Guard Airport. Large gash in the standing seam metal roof panel from the HVAC unit depicted in 4.07-2.

\subsection{Burke's Outlet Building 1, 10541-D Auto Mall Parkway, D'Iberville, MS TYPE OF STRUCTURE—Strip mall}

EXPOSURE-B

SITE COORDINATES-N30 36'24" W38 53' $10^{\circ}$ ”

WALL CONSTRUCTION-Exterior wall was covered with EIFS; 0-5\% of the exterior walls had windows and/or other openings.

ROOF TYPE-Single ply thermoplastic polyolefin (TPO) with polyisocyanurate insulation board mechanically attached to steel deck

SLOPE- $-1 / 4: 12$

DECK - Steel deck (no exposed deck on top of the roof, but investigators could see inside it)

WIND SPEED-120-130 mph

BUILDING CONSTRUCTION-The base of the building was at a $10 \mathrm{ft}$ elevation. The building height was similar to that of adjacent structures, and there were other buildings in the area. The roof was $15 \mathrm{ft}$ high.

METHOD OF ATTACHMENT - Seam fasteners were spaced every 12 in. Field (zone 1) had one fastener per $10 \mathrm{ft}^{2}$ with rows spaced every 10 lineal foot. Perimeters (zone 2) were fastened with screws and plates spaced at 1 per $\mathrm{ft}^{2}$. The corner area (zone 3) was fastened with screws and plates spaced at 1 per $\mathrm{ft}^{2}$. Seams were heat-welded. Insulation board was mechanically fastened to the deck. We could not see under the membrane because it did not fail.

NOTED DAMAGE-Minor (1\%) damage to membrane at eave edge. There was a 10 in. tear in the perimeter of the TPO membrane. The eave had minor damage, and some ponding was observed.

DAMAGE INITIATION AND PROPAGATION-Sheet metal was blown around on the roof and wedged into the satellite dish. The sheet metal cut the membrane as it was blown across the roof.

ADDITIONAL COMMENTS-The roof would likely have had no damage if the sheet metal debris had not blown across it. The parapet was 21 in. high. 


\section{Photographs of RoOf DAMAge}

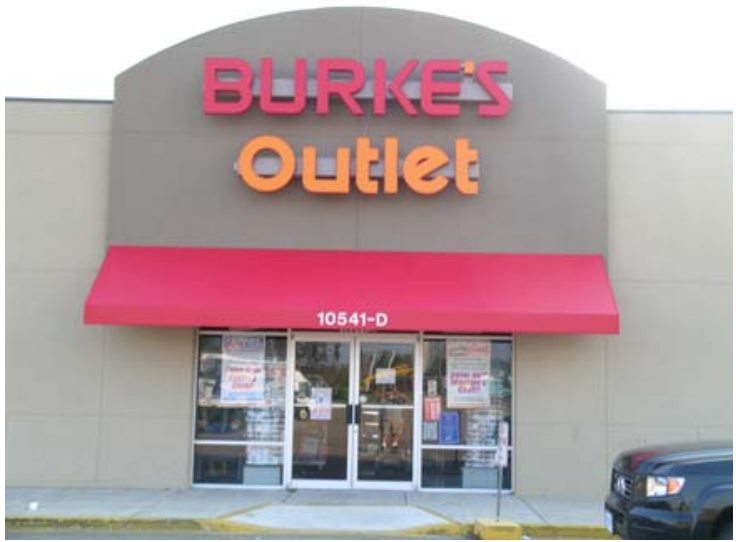

4.08-1. Burke's Outlet Building 1. North elevation.

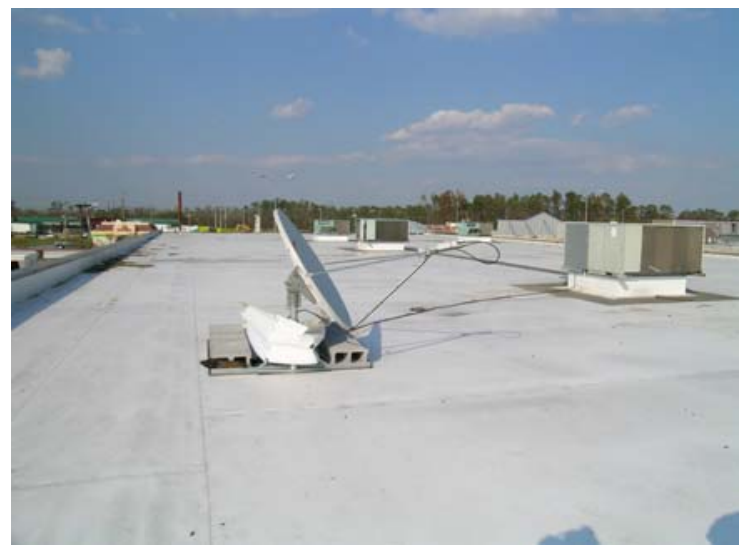

4.08-2. Burke's Outlet Building 1. Field of the roof shows small amount of sheet metal debris lodged in the satellite dish.

\subsection{Burke's Outlet Building 2, 10541-D Auto Mall Parkway, D'Iberville, MS}

TYPE OF STRUCTURE-Store in strip mall

EXPOSURE-B

SITE COORDINATES-N30 36' 24 " W38 $53^{\circ}$ ' 10"

WALL CONSTRUCTION-Exterior wall was covered with EIFS; 0-5\% of the exterior walls had windows/openings.

ROOF TYPE—Single ply EPDM with ASTM Type 4 ballast and solvent-glued seams

SLOPE- $-1 / 4: 12$

DECK-Unknown

WIND SPEED-120-130 mph

BUILDING CONSTRUCTION-The base of the building was at a $10 \mathrm{ft}$ elevation. The building height was similar to that of adjacent structures, and there were other buildings in the area. The roof was approximately $13 \mathrm{ft}$ high.

\section{NOTED DAMAGE-None}

DAMAGE INITATION AND PROPAGATION-None

ADDITIONAL COMMENTS-This roof was the lowest one of the strip mall's connected roofs and stores. The membrane was entirely intact with little gravel remaining. However, the pea gravel was scoured in one corner. The system was $100 \%$ watertight. 


\section{Photographs of Roof Damage}

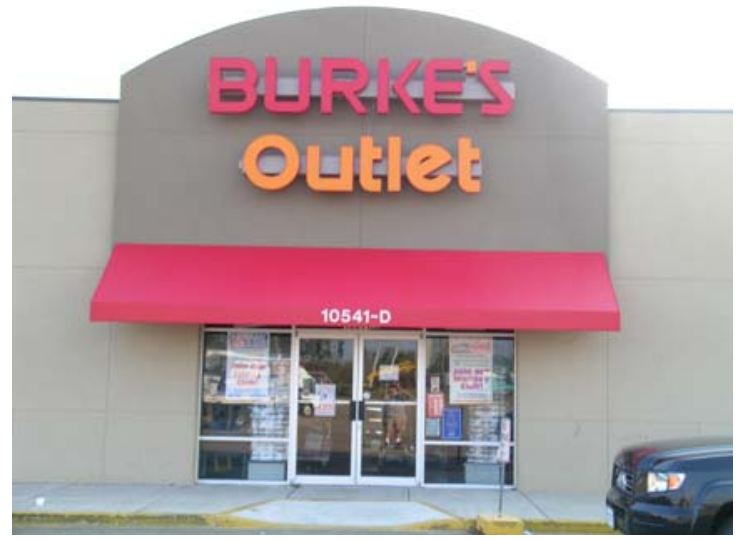

4.09-1. Burke's Outlet Building 2. North elevation.

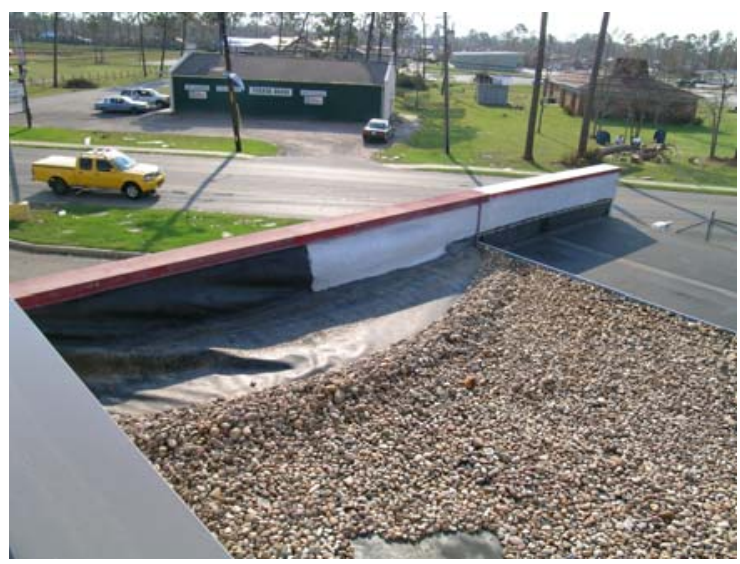

4.09-2. Burke's Outlet Building 2. Wind scour in the southwest corner of the building.

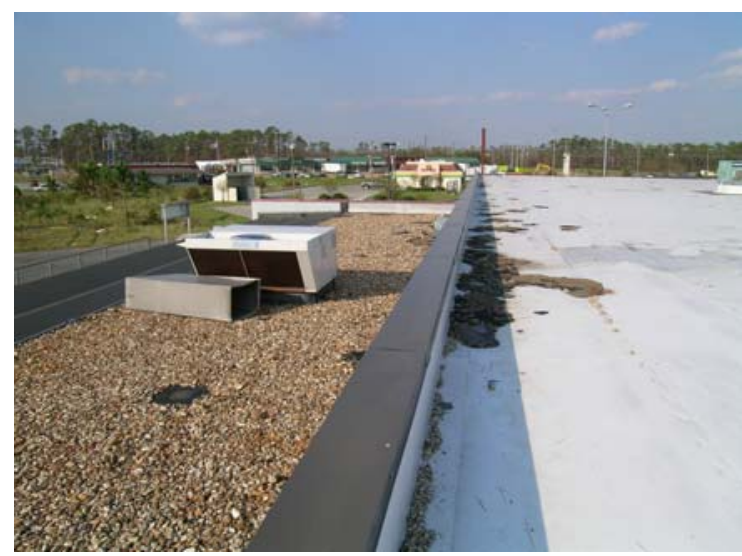

4.09-3. Burke's Outlet Building 2. Debris from the adjacent roof. 


\section{HURRICANE KATRINA: TEAM 5}

\section{OVERVIEW}

RICOWI's Team 5 for Hurricane Katrina investigations was composed of two representatives from the Metal Building Manufacturers Association (MBMA) and four other participants. Individuals and their respective affiliations are as follows:

\section{Jim Bush, ATAS}

Bruce Hackmeyer, Alsan Group

Eric Haefli, State Farm

Jerry Hatch, Ceco Buildings

Lee Shoemaker, MBMA

Dan Walker, MBMA

The daily makeup of Team 5 was as follows:

- September 7-Lee Shoemaker, Eric Haefli, Jim Bush, and Jerry Hatch

- September 8-Lee Shoemaker, Dan Walker, Jerry Hatch, and Bruce Hackmeyer

- September 9-Lee Shoemaker, Jim Bush, Jerry Hatch, and Bruce Hackmeyer.

The team deployed primarily to the Mississippi Gulf coast area and focused on the performance of metal roofing. Inspections included metal buildings as well as metal roofing on other construction types. The observations summarized in this report are based on several extended site visits and on drive-by observations. Map 1 shows the general investigation area and the locations of the extended site visits. It is marked with numbers that correspond to the inspection report numbers.

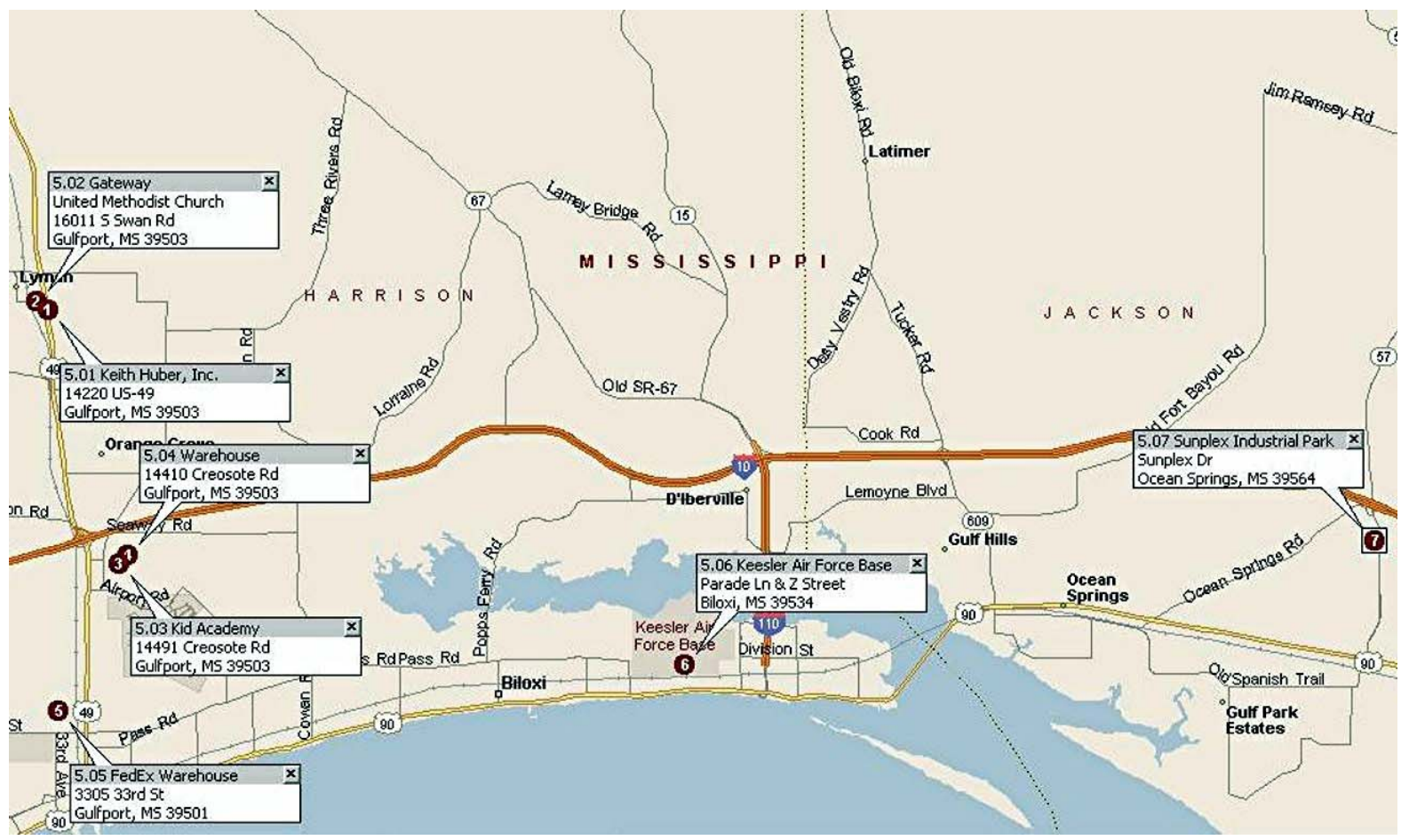

Map 1. Team 5 investigation sites. 


\section{Summary Observations}

The following general observations about Katrina are similar to those made by the RICOWI inspection teams for Hurricanes Charley and Ivan.

- Metal roofs designed and installed during the past five or six years using newer code standards performed very well. Exceptions were few, and roof damage was confined to installation lapses and/or internal pressurization from openings typically created by failed accessories, rather than metal roofing component/design problems.

- Overhead doors had a high occurrence of failure, especially in older structures. These failures contributed to rapid internal pressurization and roof blowoffs. Although newer doors performed much better, there is still a need to improve the door/building interface and to ensure that tested door assemblies accurately reflect real-world conditions.

- Standing seam roofs appeared to be more vulnerable to blowoff caused by rapid internal pressurization (such as from failed overhead doors) than were through-fastened metal roofs.

- When metal roofs over ten years old are compared, through-fastened roofs generally seemed to perform better than standing seam roofs. Improved testing methods coupled with higher roof load requirements have contributed significantly to improving the performance of standing seam roofs on newer structures.

- When standing seam roofs on metal supports failed, the failure mode was almost always clip separation from the panel seam. This emphasizes the importance of the type of seam and the seaming operation.

- Most observed metal roof failures not associated with door failure or internal pressurization started at eaves or rake edges and progressed up toward the ridges. In many cases, poor eave or rake details, such as gutter attachments and flashing, were found to be the weak points where roof failures likely originated.

\section{INDIVIDUAL ROOF REPORTS}

The following data were logged at various sites representative of the overall observations, as well as unusual situations.

\subsection{Keith Huber, Inc., 14220 Highway 49, Gulfport, MS}

TYPE OF STRUCTURE-Commercial

EXPOSURE-C

SITE COORDINATES-Unknown

WALL CONSTRUCTION-Metal panel, typical assembly

ROOF TYPE—Metal panels; 24 in. trapezoidal through-fastened roof supported on Z-purlins

SLOPE-1 : 12 (approximate)

ROOF HEIGHT - $30 \mathrm{ft}$ south side; $20 \mathrm{ft}$ north side

ROOF WIDTH- $120 \mathrm{ft}$

ROOF LENGTH-525 ft

DECK - None (structural roof panel)

WIND SPEED-120-130 mph

BUILDING CONSTRUCTION_-Typical metal building, constructed in 1997 (photo 5.01-1)

METHOD OF ATTACHMENT_Attached by screws to Z-purlins spaced $5 \mathrm{ft}$ o.c. 
NOTED DAMAGE-All 14 overhead rolling doors $(14 \times 16 \mathrm{ft})$ blew in on the south wall of the building. (photo 5.01-2) Edge flashing was damaged in several locations (photo 5.01-3). Flashing fastener spacing was $3 \mathrm{ft}$ o.c.

DAMAGE INITIATION AND PROPAGATION-It appeared that damage to the overhead rolling doors occurred initially. Next, an upper section of the east wall and some wall light-transmitting panels (LTPs) blew out (photo 5.01-1). This likely prevented roof blowoff despite internal pressurization because pressure was significantly reduced when the wall and LTPs blew out.

ADDITIONAL COMMENTS - The single slope roof had an eave height at the south side of approximately $30 \mathrm{ft}$ and an eave height at the north side of approximately $20 \mathrm{ft}$; Z-purlins were spaced at $5 \mathrm{ft}$ o.c.

\section{Photographs of Roof Damage}

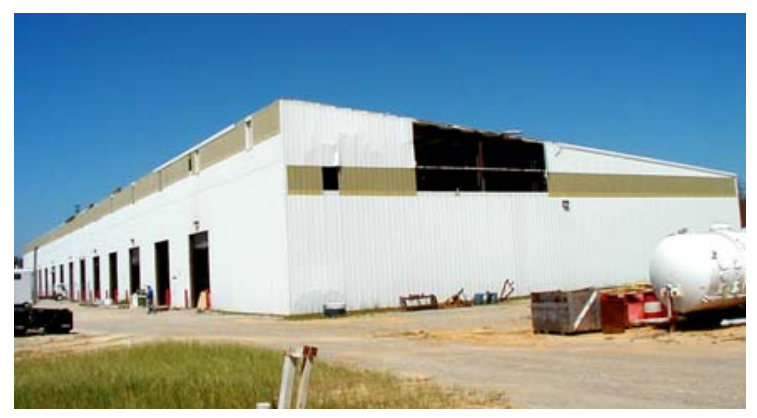

5.01-1. Keith Huber, Inc. This photo shows the southeast corner, which was in the face of the approaching wind.

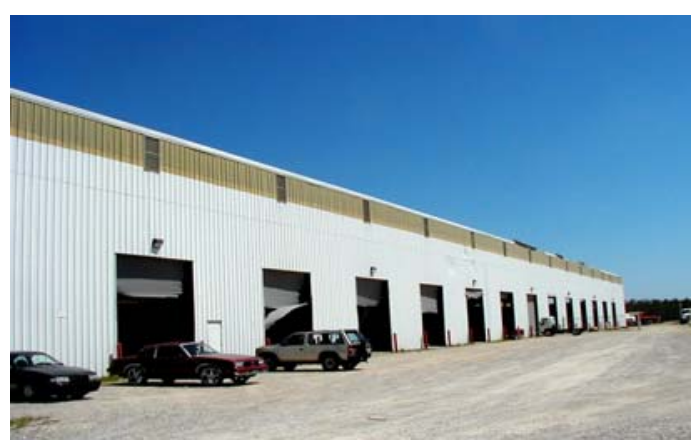

5.01-2. Keith Huber, Inc. All 14 of these overhead rolling doors on the south wall blew in.

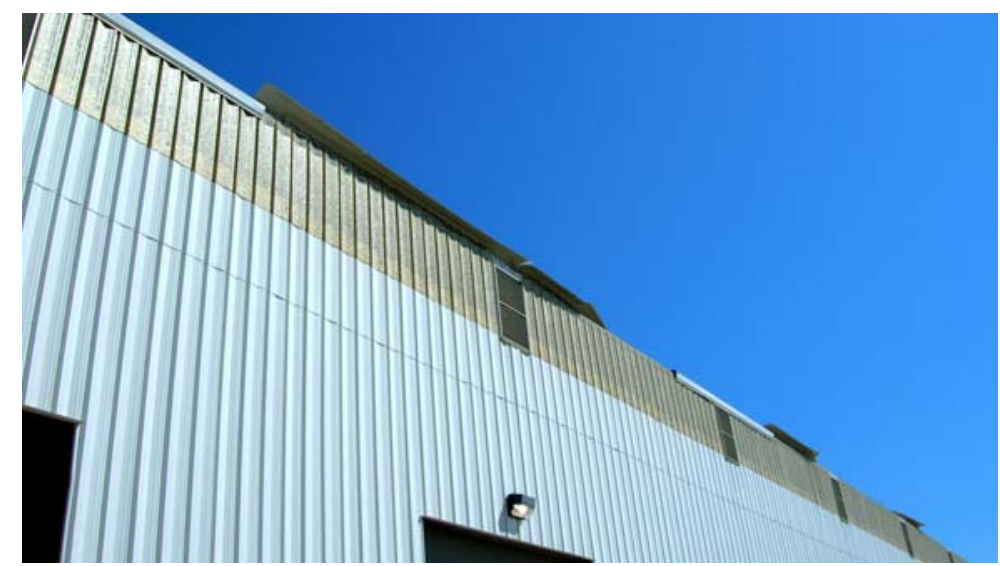

5.01-3. Keith Huber, Inc. Edge flashing failures (south wall) are visible here, but there was no damage to through-fastened roof.

\subsection{Gateway United Methodist Church, 16011 S. Swan Road, Gulfport, MS}

TYPE OF STRUCTURE-Church

EXPOSURE-C

SITE COORDINATES-Unknown

WALL CONSTRUCTION-Metal panel; brick veneer in front (south wall) 
ROOF TYPE—Through-fastened metal panel (photo 5.02-2)

SLOPE-3 : 12

ROOF HEIGHT-25 ft

ROOF WIDTH-90 ft

ROOF LENGTH-180 ft

DECK-Unknown

WIND SPEED-120-130 mph

BUILDING CONSTRUCTION-Metal building, constructed in late 1990s (photo 5.02-1)

METHOD OF ATTACHMENT_Fastened with two screws every 12 in. (one each side of rib). Purlins were more closely spaced at eaves.

NOTED DAMAGE-The only observed roofing damage was to the rake flashing at the interface with the brick veneer front (photo 5.02-3).

DAMAGE INITIATION AND PROPAGATION-There did not appear to be any attachment of the rake flashing to the brick veneer. Consequently, the flashing detached because of the high winds.

ADDITIONAL COMMENTS-None

\section{Photographs of RoOF DAMAge}

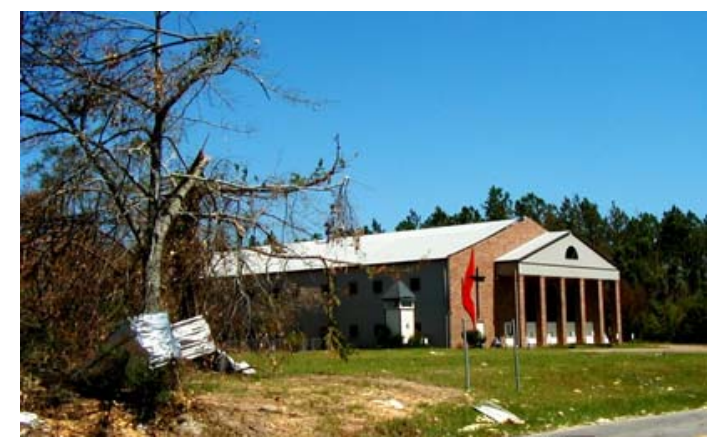

5.02-1. Gateway United Methodist Church. This is a view of the southwest corner.

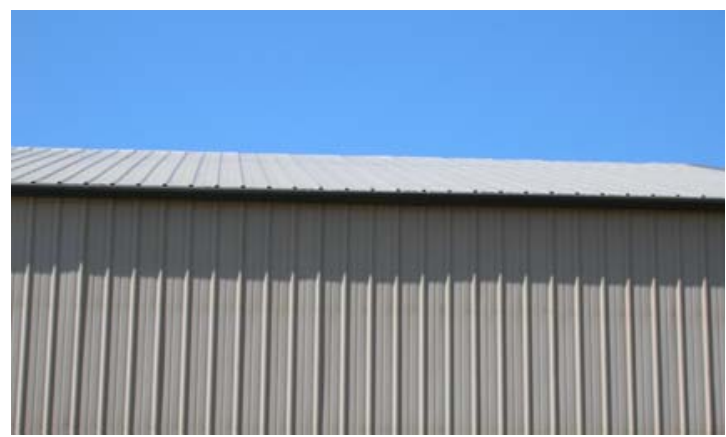

5.02-2. Gateway United Methodist Church. This through-fastened roof had no visible damage.

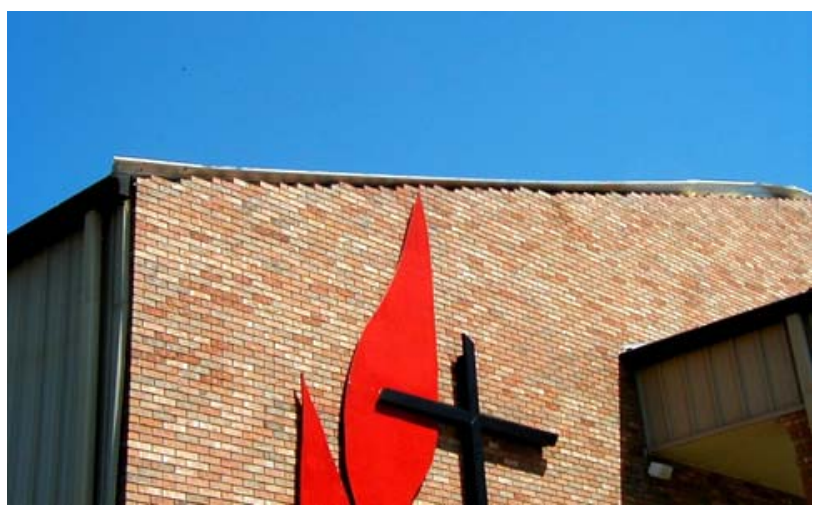

5.02-3. Gateway United Methodist Church. Rake flashing damage is visible at the brick veneer front. 


\subsection{Kid Academy, 14491 Creosote Road, Gulfport, MS}

TYPE OF STRUCTURE-School

EXPOSURE-B

SITE COORDINATES-Unknown

WALL CONSTRUCTION-Metal panel; brick veneer on north and west walls. East and south walls were covered with through-fastened metal panels.

ROOF TYPE—Steel standing seam panels with trapezoidal ribs and double-lock seams

SLOPE—1: 12 single slope (one direction)

ROOF HEIGHT - $10 \mathrm{ft}$ low eave and $15 \mathrm{ft}$ high eave on single slope roof

ROOF WIDTH-60 ft

ROOF LENGTH-120 ft

DECK-None (structural roof panel)

WIND SPEED-120-130 mph

BUILDING CONSTRUCTION-Metal building with the entrance in the west end wall (photo 5.03-1). There was a $5 \mathrm{ft}$ façade on the west end wall.

METHOD OF ATTACHMENT—Attached by screws to purlins spaced $5 \mathrm{ft}$ o.c.

NOTED DAMAGE - No wall panel damage or roof panel damage was noted. There was a crimp in the cap flashing along the north wall (photo 5.03-3). This may have been damage from an impact by airborne debris or damage from a source other than the storm.

DAMAGE INITIATION AND PROPAGATION-There did not appear to be any wind-related damage to the roof except for possible airborne debris damage to the cap flashing along the north wall.

ADDITIONAL COMMENTS-None

\section{Photographs of Roof Damage}

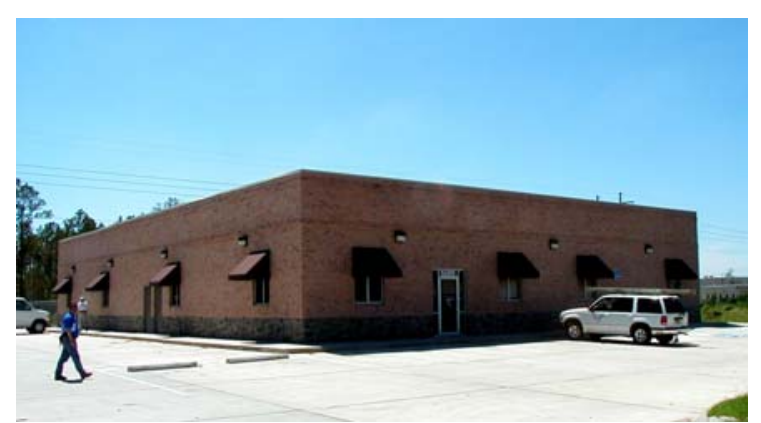

5.03-1. Kid Academy. Front (north) and side (east) walls shown here are brick veneer with parapets.

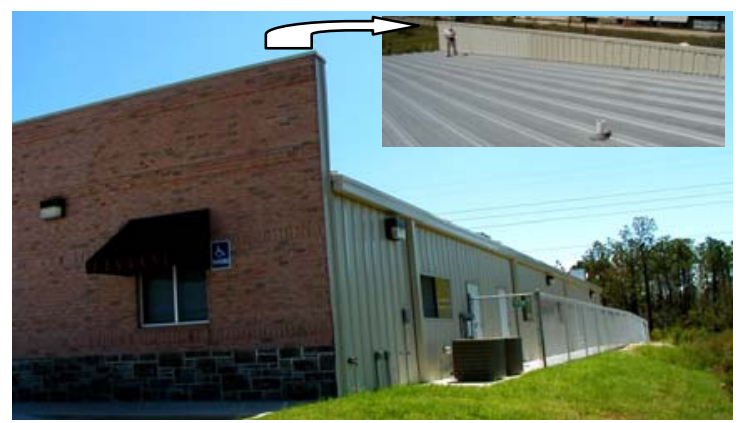

5.03-2. Kid Academy. At left is the west wall with parapet (inset is back of parapet showing roof slope from east to west side). 


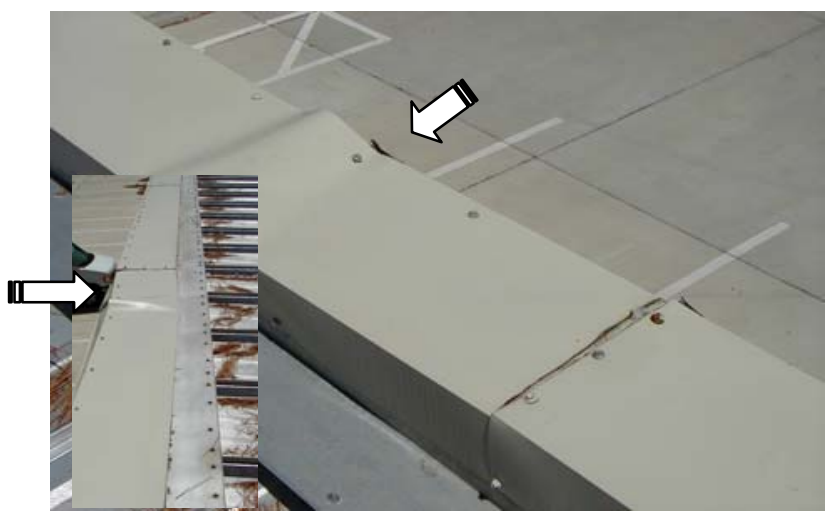

5.03-3. Kid Academy. East parapet cap flashing damage-perhaps from impact.

\subsection{Warehouse, 14410 Creosote Road, Gulfport, MS}

TYPE OF STRUCTURE-Commercial warehouse

EXPOSURE-B

SITE COORDINATES-Unknown

WALL CONSTRUCTION-Metal through-fastened panels

ROOF TYPE-Metal through-fastened panels

SLOPE-1 : 12

ROOF HEIGHT - $14 \mathrm{ft}$

ROOF WIDTH- $120 \mathrm{ft}$

ROOF LENGTH-180 ft

DECK-None (structural roof panel)

WIND SPEED-120-130 mph

BUILDING CONSTRUCTION-This metal building had six $30 \mathrm{ft}$ bays and six $20 \mathrm{ft}$ end wall bays. The frames are made of hot-rolled prismatic sections. Purlins and girts had many holes in the web and none in the flanges. Purlins were attached to the rafter with knife-plates to which purlins were bolted. Purlins were bolted to end wall rafters. The holes for the bolts were torch-cut. It appeared that the building frame was fabricated by a conventional steel manufacturer, and the girts, purlins, and sheets were from a components supplier.

METHOD OF ATTACHMENT—Attached by screws to purlins spaced $5 \mathrm{ft}$ o.c.

NOTED DAMAGE - The end bay roof structure was lifted up and folded back onto the roof. The end wall then blew into the building. The end wall that was damaged was facing east. The rest of the building had no damage. The building was well constructed except for the connection of purlins to end wall rafters.

DAMAGE INITIATION AND PROPAGATION_-The end bay roof structure was lifted up by the storm and then folded back onto the roof. The torch-cut holes in purlins were too large for the bolt heads. Some of the torch-cut holes showed no sign of deformation due to pulling over the bolt heads, indicating that the hole size was too large and washers were not used. Bolts were still attached to the end wall rafter. 
ADDITIONAL COMMENTS-Incompatible components (possibly from more than one source) may have been the underlying cause of this sequence of damage.

\section{Photographs of Roof Damage}

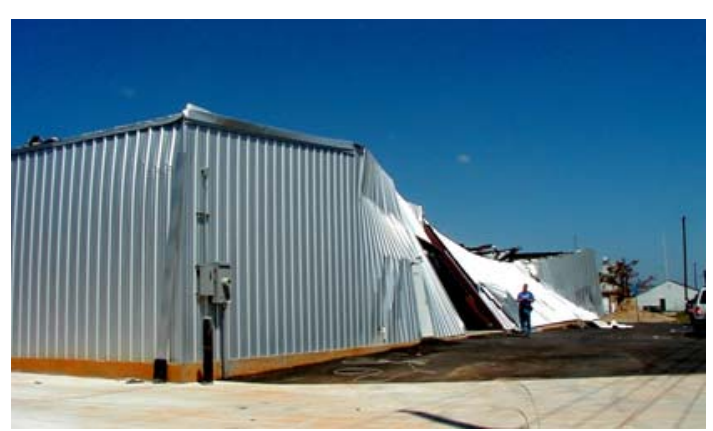

5.04-1. Warehouse on Creosote Rd. Front (south) wall that failed inward.

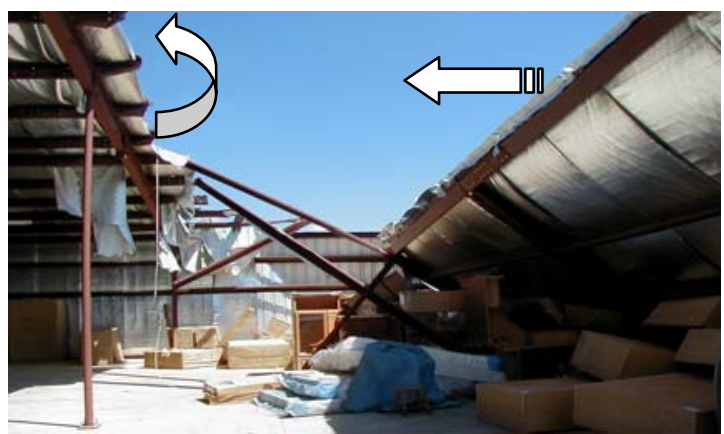

5.04-2. Warehouse on Creosote Rd. This front wall collapsed inward, then the roof purlins rolled back over the next frame.

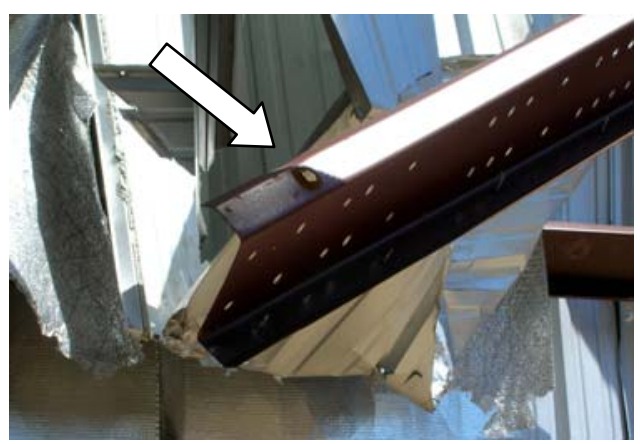

5.04-3. Warehouse on Creosote Rd. A torchcut hole in this purlin is where failure occurred at an end wall connection.

\subsection{FedEx Warehouse, $33053^{\text {rd }}$ Street, Gulfport, MS}

TYPE OF STRUCTURE-Commercial warehouse

\section{EXPOSURE-C}

SITE COORDINATES-Unknown

WALL CONSTRUCTION-Through-fastened metal panels

ROOF TYPE—Through-fastened metal panels

SLOPE-less than $1: 12$

ROOF HEIGHT-20 ft

ROOF WIDTH-160 ft

ROOF LENGTH-600 ft

DECK - None (structural roof panel)

WIND SPEED—120-130 mph 
BUILDING CONSTRUCTION_-There were two adjacent buildings at this site, of approximately the same size. The buildings were approximately 10 years old and were conventional metal building construction.

METHOD OF ATTACHMENT-Attached by screws to purlins spaced $5 \mathrm{ft}$ o.c.

NOTED DAMAGE-Building 1 had two damaged end bays. Roof sheets were missing in the end bay and in one-half of the next bay. Building 2 had some wall sheets blown off the building at the south end and the southeast corner.

DAMAGE INITIATION AND PROPAGATION-It was difficult to determine how the damage initiated in Building 1. It is possible that the strut purlins in the end bay failed from combined axial and bending loads.

ADDITIONAL COMMENTS - Construction crews had cut away the end wall to remove vehicles; consequently, it was difficult to determine the nature of the failure. The end wall was facing south and there was a large clear-cut field for about $1000 \mathrm{ft}$ at the south end of the building.

\section{Photographs of RoOF DAMAGE}

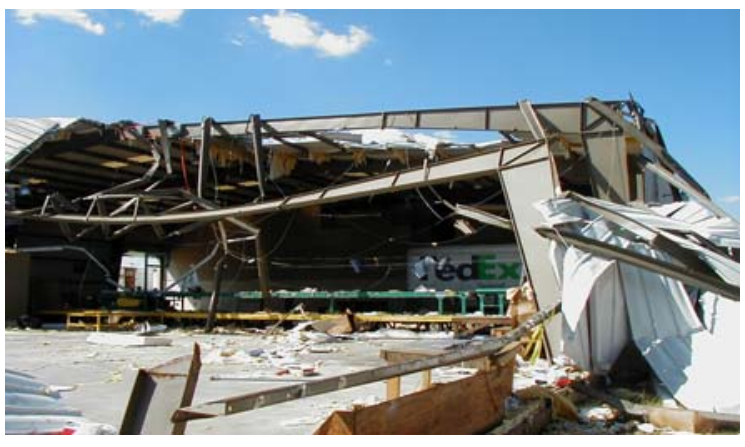

5.05-1. FedEx Warehouse. Building 1 with severe damage to the end wall.

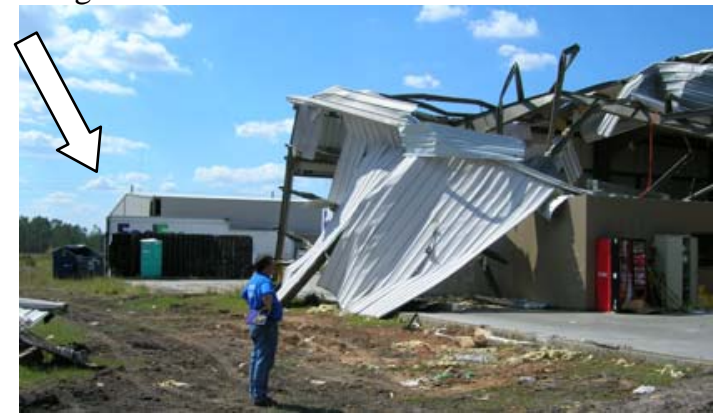

5.05-3. FedEx Warehouse. An adjacent building, which was similar to Building No. 1, can be seen in the background and with only minor damage.

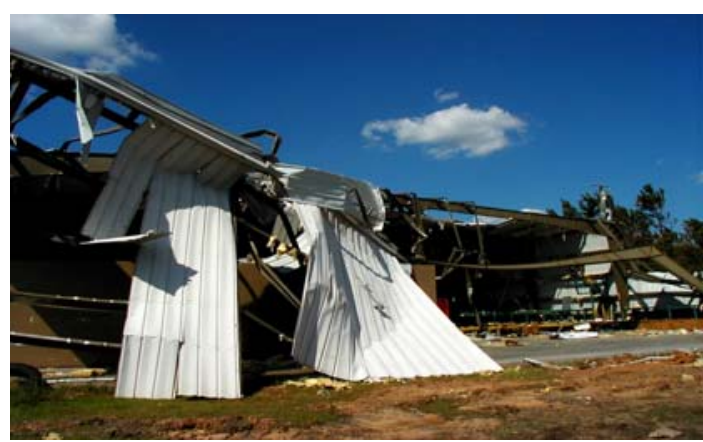

5.05-2. FedEx Warehouse. Another view of wall damage.

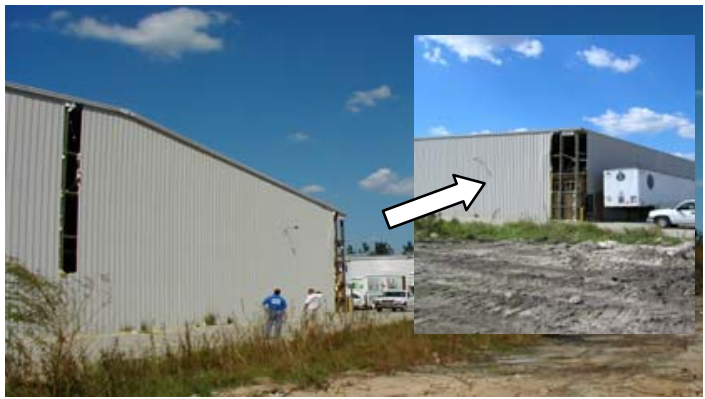

5.05-4. FedEx Warehouse. Building 2 with minor end wall and corner wall damage.

\subsection{Keesler Air Force Base, Biloxi, MS}

Team 5 gained access to Keesler Air Force Base on September 8 to document damage to two metal buildings and to do a drive-by inspection of several other buildings with metal roofs. Following are individual reports (5.06a and 5.06b), as well as an overview based on drive-by observations (5.06c). 


\subsection{6(a) Warehouse (Building 4422) between Parade and Z Street}

TYPE OF STRUCTURE-Commercial warehouse

EXPOSURE-B

SITE COORDINATES-Unknown

WALL CONSTRUCTION-Through-fastened metal panel

ROOF TYPE—Standing seam metal panel

SLOPE-1 : 12

ROOF HEIGHT- $17 \mathrm{ft}$

ROOF WIDTH- $100 \mathrm{ft}$

ROOF LENGTH-270 ft

DECK-None (structural roof panel)

WIND SPEED-120-130 mph

BUILDING CONSTRUCTION-Metal building appeared to be at least 20 years old.

METHOD OF ATTACHMENT - A thermal block and flashing were through-fastened to the eave strut. The roof panel was then through-fastened to the flashing. This is a poor eave detail. There were no clips on the eave strut; therefore, the nearest clips were $5 \mathrm{ft}$ from the edge of the building on the first purlin.

NOTED DAMAGE-The roof at the southeast corner peeled back about halfway to the peak. This damage appears to be due to failure of the eave detail.

DAMAGE INITIATION AND PROPAGATION-Roll-up overhead doors on the south side of the building blew in, causing internal pressurization that likely initialized peeling back of roof panels.

ADDITIONAL COMMENTS-None

\section{Photographs of Roof Damage}

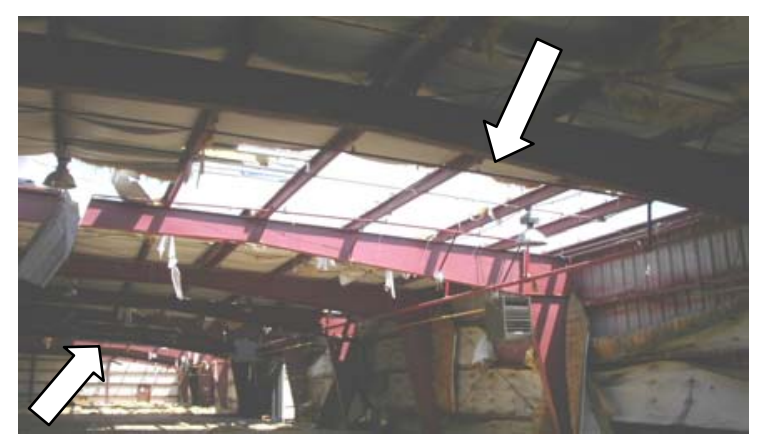

5.06(a)-1. Keesler Warehouse Bldg. 4422. This view from below shows two areas of missing roof at the corner (left) and middle of the building.

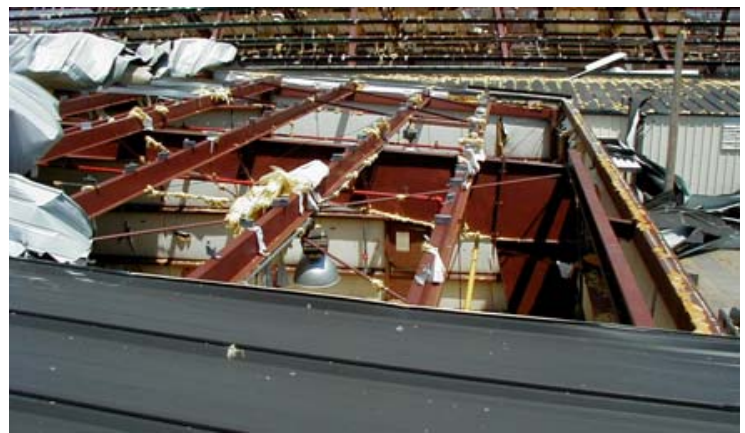

5.06(a)-2. Keesler Warehouse Bldg. 4422. The windward corner of the building is shown with the standing seam roof peeled back. 


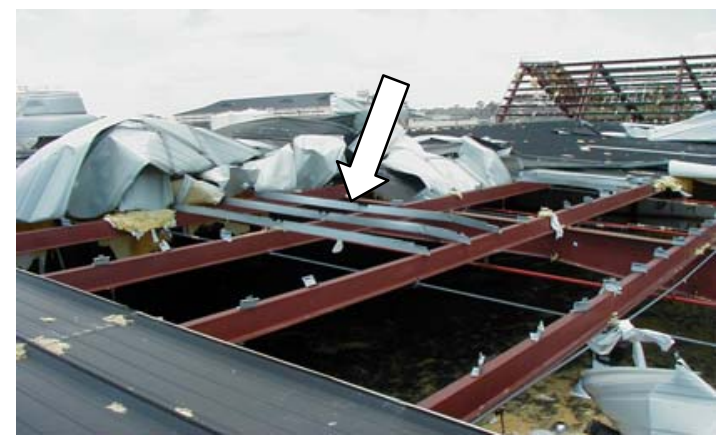

5.06(a)-3. Keesler Warehouse Bldg. 4422. This blowoff included some unusual metal panel failure along the rib. The arrow indicates where the vertical leg of the rib is still attached after the rest of the panel was torn off.

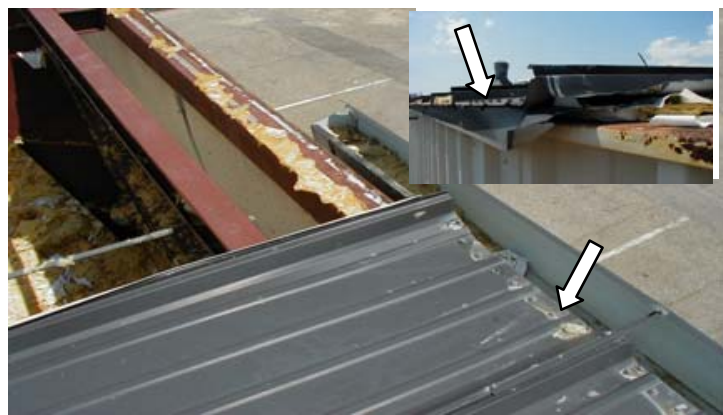

5.06(a)-4. Keesler Warehouse Bldg. 4422. These two views of poor eave detailing show that fasteners did not penetrate the eave strut.

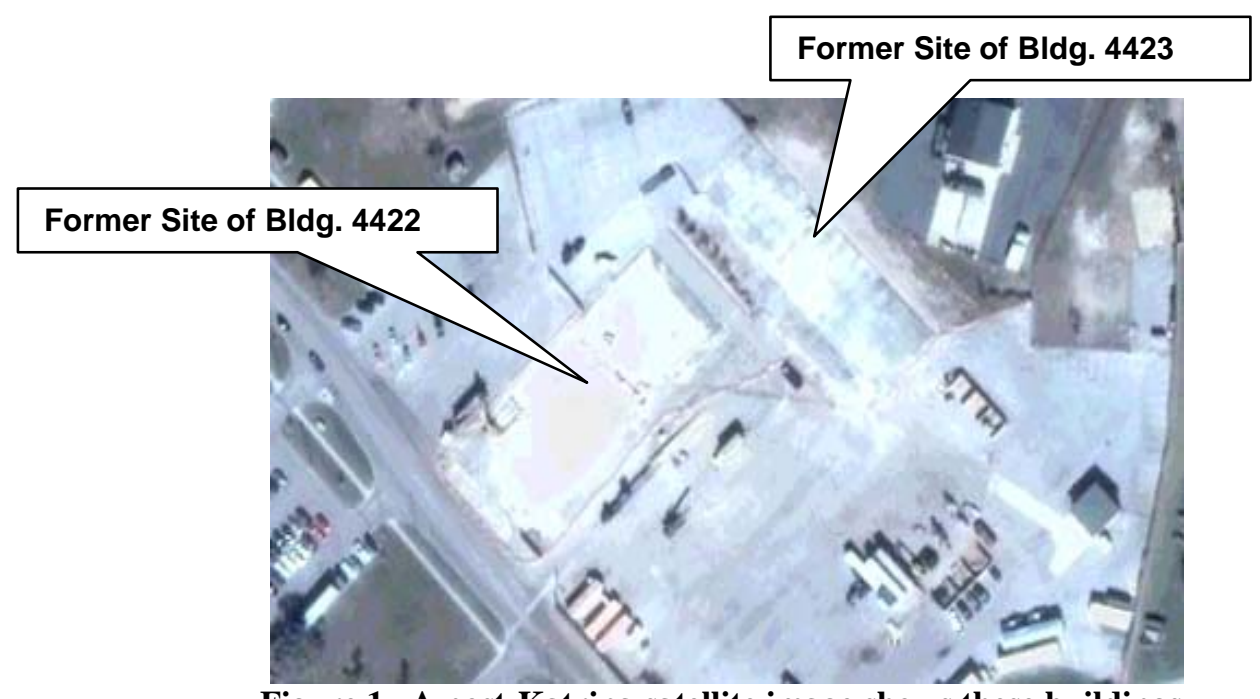

Figure 1. A post-Katrina satellite image shows these buildings have been demolished. (Photo courtesy of GoogleEarth)

\subsection{6(b) Maintenance (Building 4423) Between Parade and Z Street}

TYPE OF STRUCTURE-Commercial building

EXPOSURE-B

SITE COORDINATES-None

WALL CONSTRUCTION-Through-fastened metal panel

ROOF TYPE-Metal panel

SLOPE-5 : 12

ROOF HEIGHT-Not recorded

ROOF WIDTH-Not recorded

ROOF LENGTH-Not recorded

DECK - None (structural roof panel) 
WIND SPEED-120-130 mph

BUILDING CONSTRUCTION—Metal building

METHOD OF ATTACHMENT_-Unknown

NOTED DAMAGE-Most roof panels were missing and the building was leaning toward the north end wall. The north end wall had detached from the rest of the building and was on the ground.

DAMAGE INITIATION AND PROPAGATION-Connection of the end wall column to the roof system was through one 3 in. long fillet weld, which was of poor quality. This is likely the reason the end wall detached from the building.

ADDITIONAL COMMENTS—This building was subsequently demolished, as shown in Figure 1.

\section{Photographs of Roof Damage}

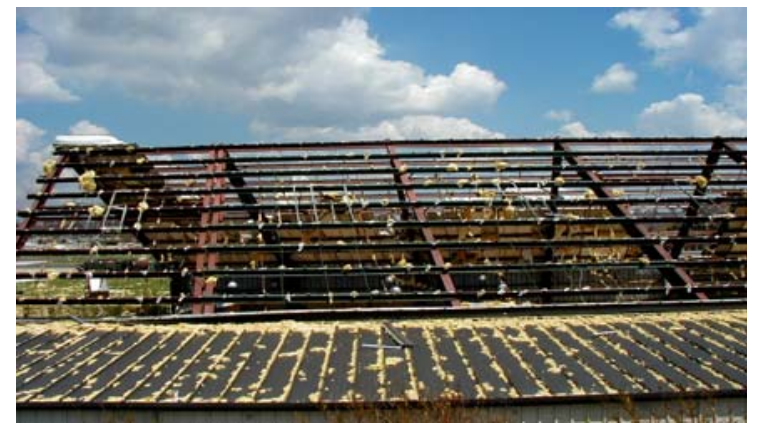

5.06(b)-1. Keesler Maintenance Bldg. 4423. This standing seam roof was totally blown away. This older building suffered severe damage.

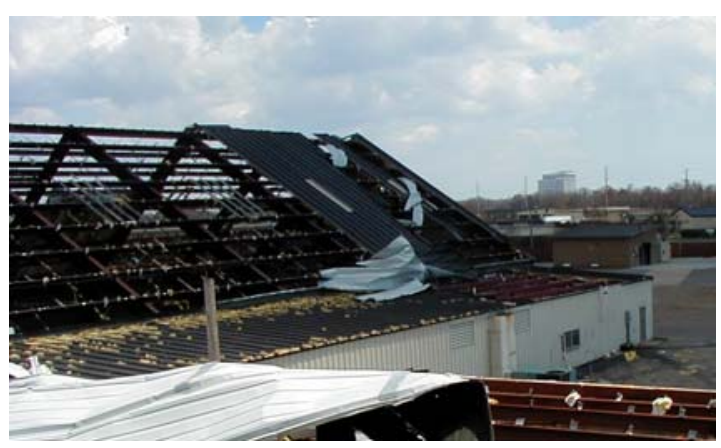

5.06(b)-2. Keesler Maintenance Bldg. 4423.

Another view of standing seam roof failure on an older building.

\subsection{6(c) Drive-by Observations}

Several buildings on Keesler Air Force Base were covered with architectural metal roofing. These include Thomson Hall, Building 4214, Lott Hall, Vosler Hall, Student Dormitory, and Building 2505. They are documented in photos 5.06(c) through 5.06(f). All of these standing seam roofs were on a slope of approximately $3: 12$. The only failures noted were of soffits, gutters, and flashings. Examples are illustrated in the photographs.

\section{Photographs of Roof Damage}

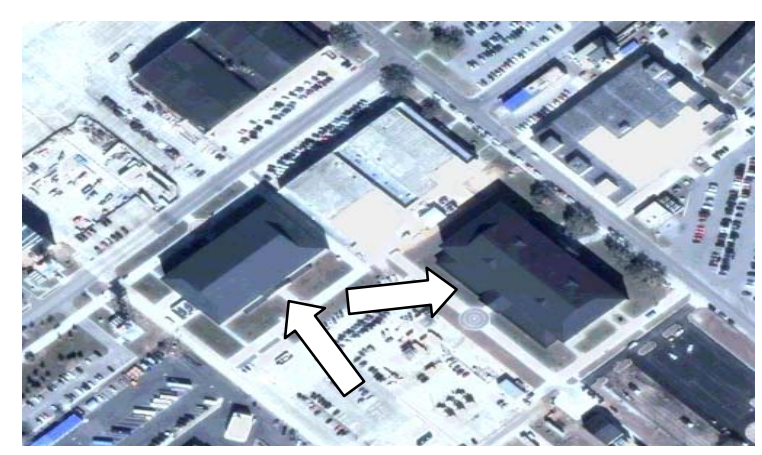

5.06(c)-1. Post-Katrina satellite photo. Keesler Thomson Hall is at left, with Bldg. 4214 at right. Arrows show next two photo orientations.

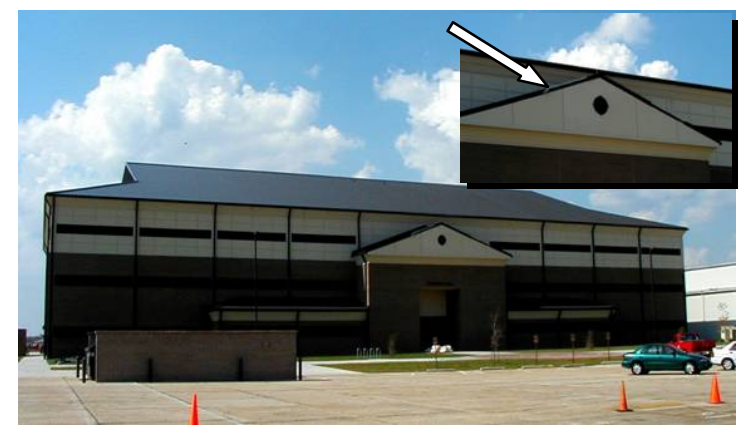

5.06(c)-2. Keesler Thomson Hall (Bldg. 4213). The only damage noted was to the trim on this roof (see inset). 


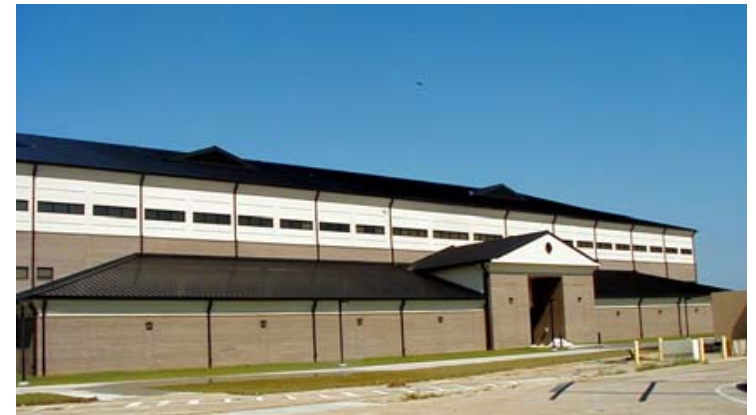

5.06(c)-3. Keesler Bldg. 4214. No damage was noted on this architectural standing seam roof.

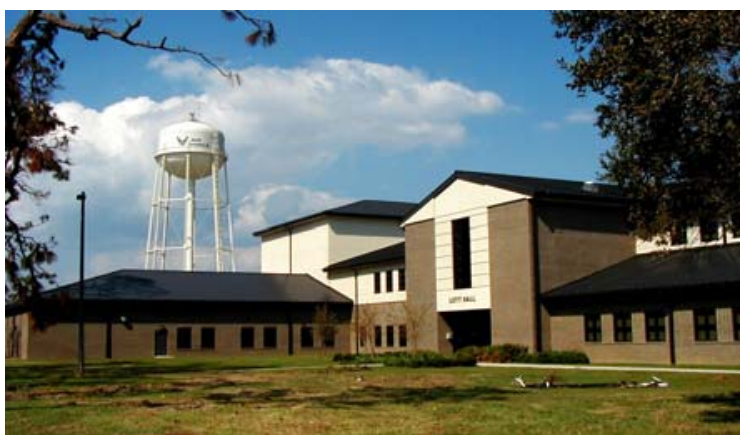

5.06(d)-2. Lott Hall. The only damage noted on this architectural standing seam roof was to the soffit area shown in photo 5.06(d)-3.

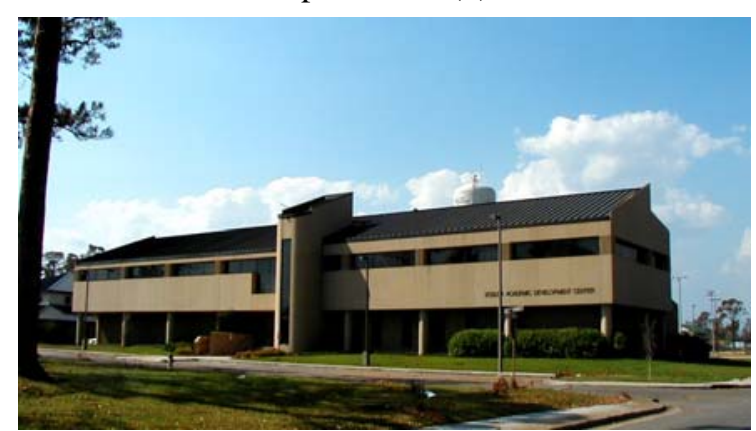

5.06(d)-4. Vosler Hall. The only damage noted on this architectural standing seam roof was to the trim, as shown in photo $5.06(\mathrm{~d})-5$.

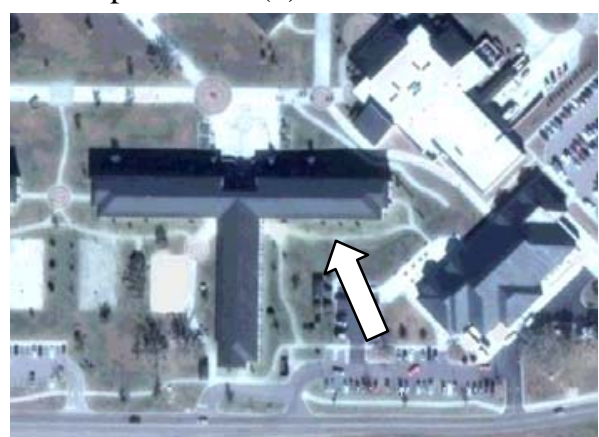

5.06(e)-1. Post-Katrina satellite photo. Keesler Student Dormitory (Bldg. 6965) is shown.

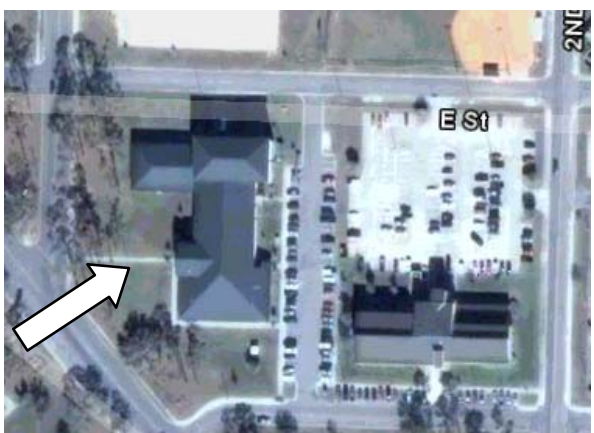

5.06(d)-1. Post-Katrina satellite photo. This photo shows Keesler's Lott Hall, at left, and Vosler Hall, at right.

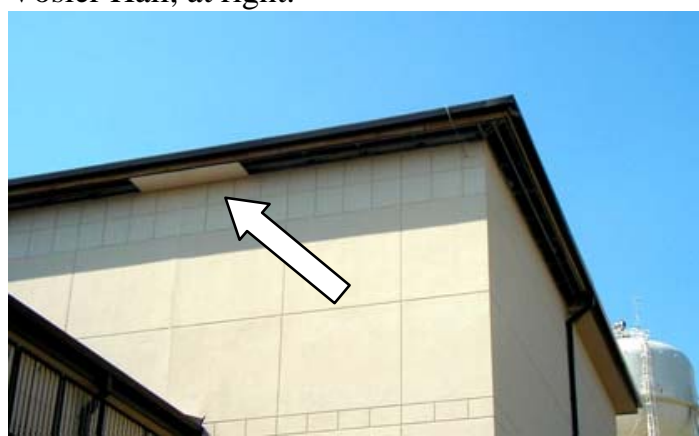

5.06(d)-3. Lott Hall. Soffit damage can be seen.

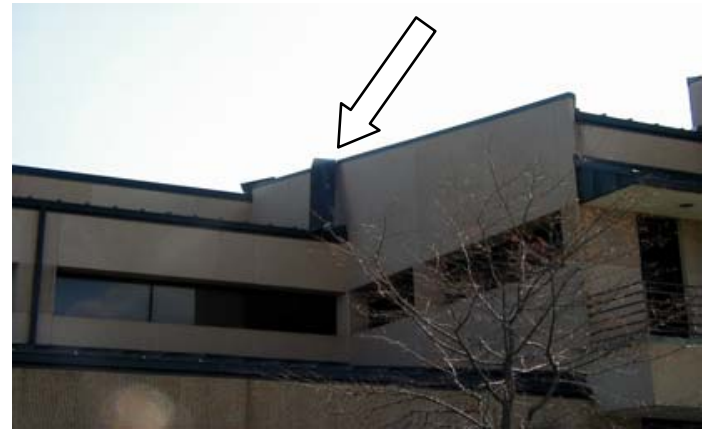

5.06(d)-5. Vosler Hall. Trim damage is shown.

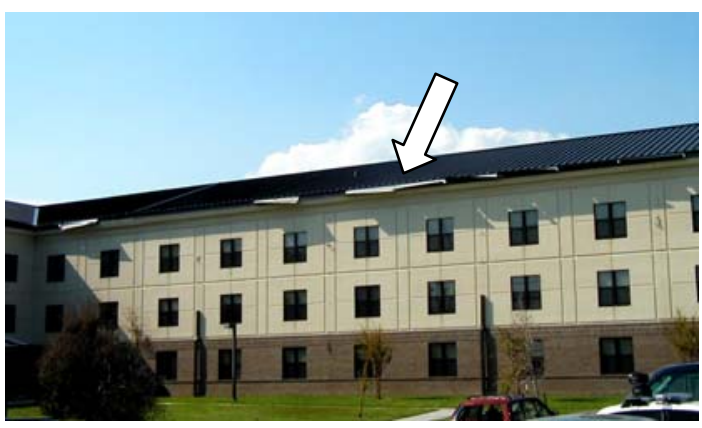

5.06(e)-2. Student Dormitory. Gutter damage is visible (at arrow). 


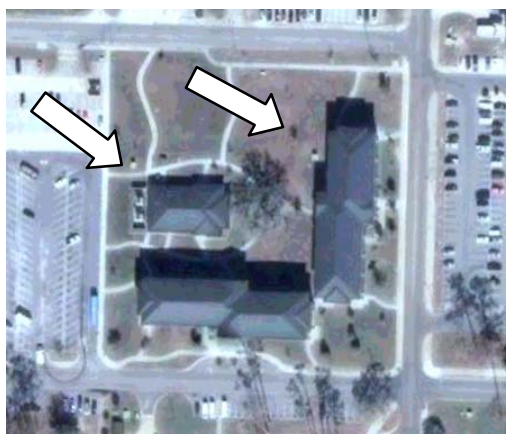

5.06(f)-1. Post-Katrina satellite photo. This is an aerial view of Keesler Building 2505, at right, and nearby buildings.

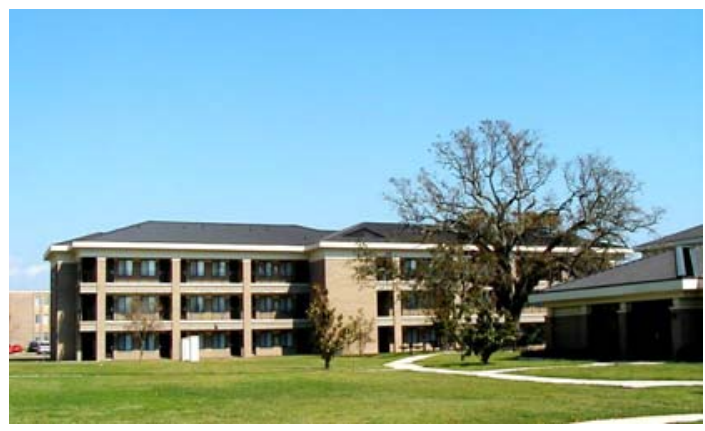

5.06(f)-2. Keesler Building 2505. No roof damage was observed on this architectural standing seam roof.

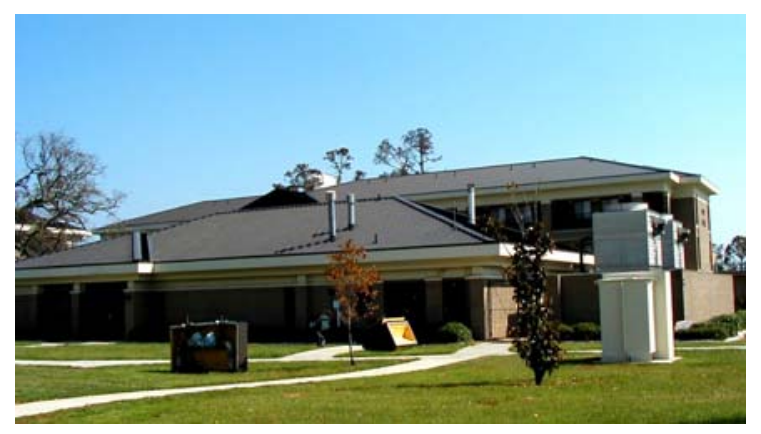

5.06(f)-3. Keesler buildings near 2505. No roof damage was observed on these architectural standing seam roofs.

\subsection{Sunplex Industrial Park, Ocean Springs, MS}

Seventeen metal buildings were inspected in this industrial park. The satellite photo in Figure 2 shows the 13 businesses and the addresses of the sites inspected. (Note that two of the businesses had three buildings each.) The total roofing area of the 17 buildings was approximately 103,000 $\mathrm{ft}^{2}$. Most buildings were covered with through-fastened metal roofing. Only two buildings had standing seam roofs (Liqui-Chem and Superior Optical), totaling approximately $8200 \mathrm{ft}^{2}$.

These buildings ranged in age from 2 to 12 years, with an average age of 6 years. Overall, the roofs performed very well, and only one had serious damage (Superior Optical). Of the 17 metal buildings inspected, 8 lost at least one overhead door, resulting in internal pressurization of the buildings. Only two of these eight buildings, however, suffered roof damage that seemed related to the internal pressurization. It is interesting that these two were both standing seam roofs. The six buildings that experienced internal pressurization (due to loss of overhead doors) but did not experience roof problems were all through-fastened roof systems.

Conclusion: It appears that through-fastened roofs may be more resistant to the sudden pressurization of a building than are standing seam roofs. 


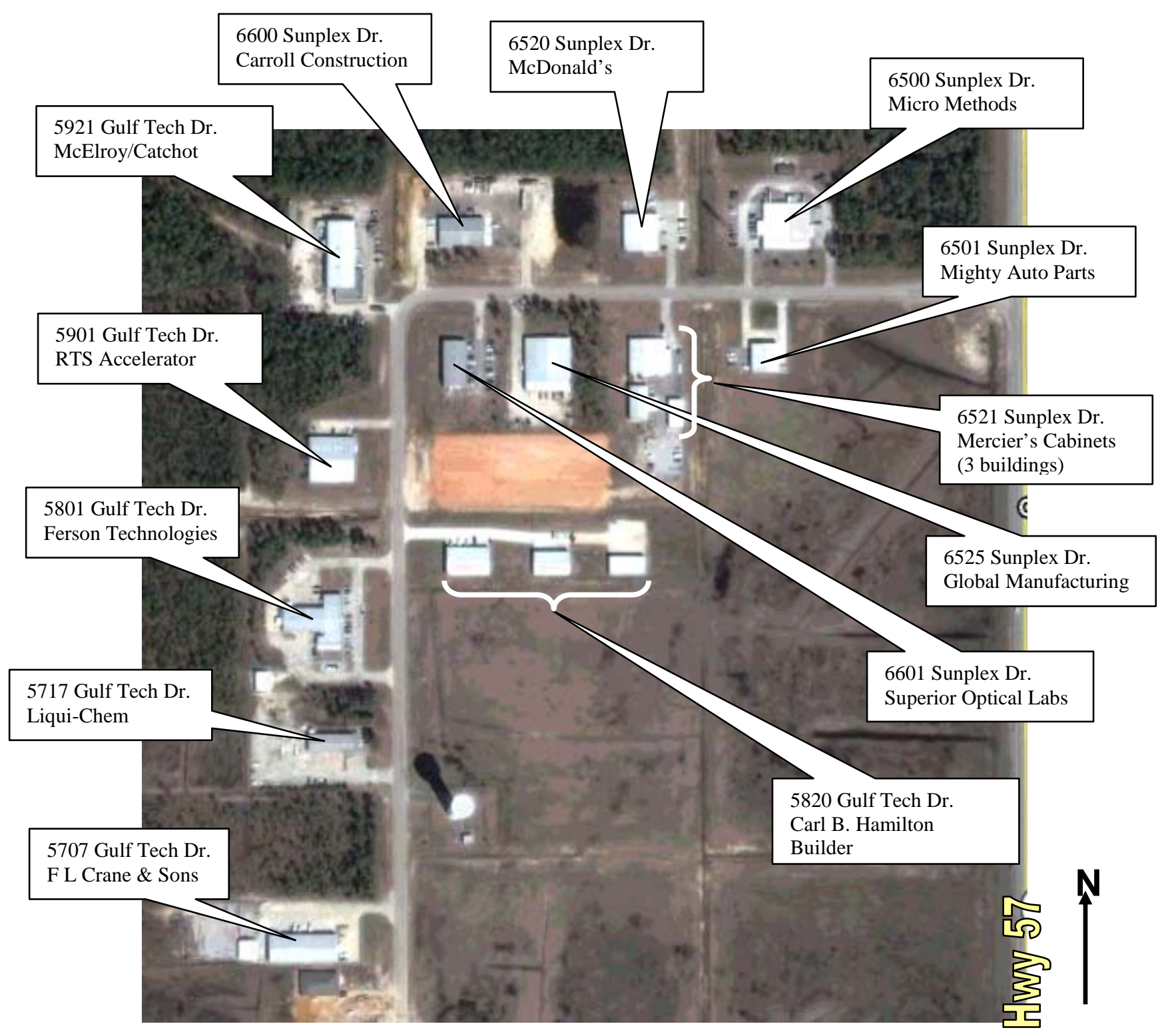

Figure 2. An aerial view of Sunplex Industrial Park, Ocean Springs, MS. 


\section{Photographs of Roof Damage}

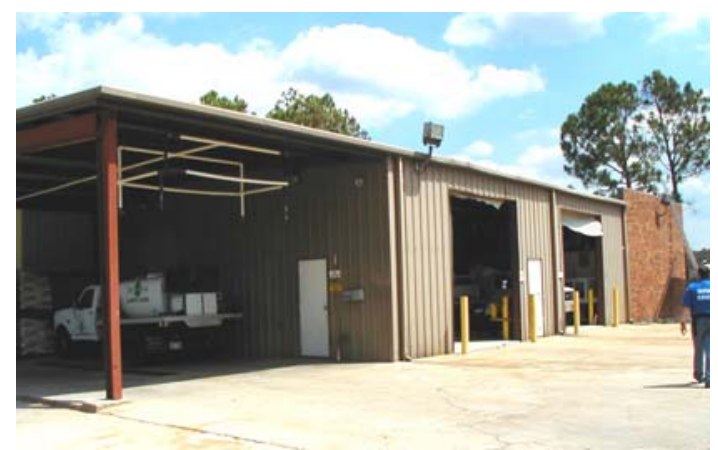

5.07-1. Sunplex Industrial Park. The overhead doors at this Liqui-Chem building failed as a result of high winds.

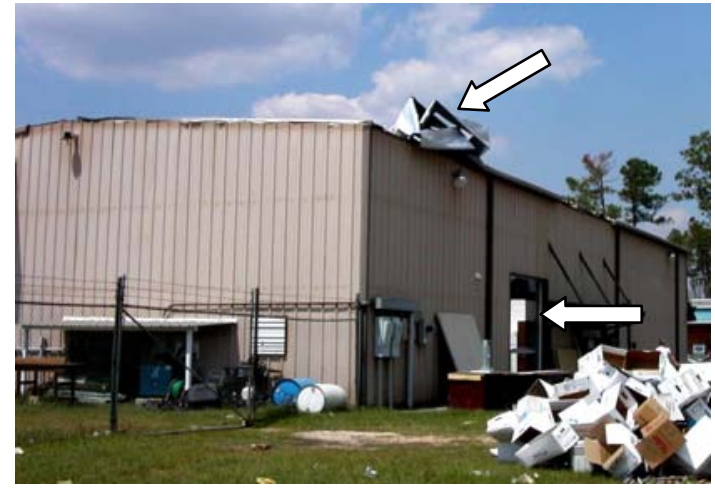

5.07-3. Sunplex Industrial Park. Superior

Optical experienced substantial standing seam roof blowoff (upper arrow). The lower arrow shows a failed overhead door.

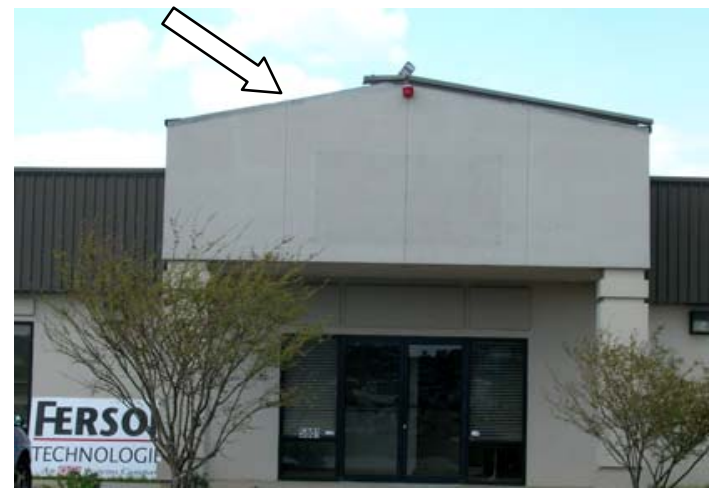

5.07-5. Sunplex Industrial Park. At the Ferson Building, failed flashings can be seen.

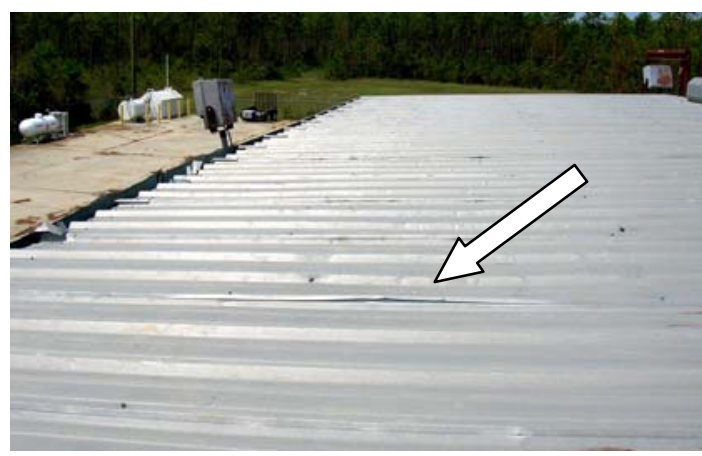

5.07-2. Sunplex Industrial Park. On this LiquiChem building, several standing seams blew open as a result of high internal pressure.

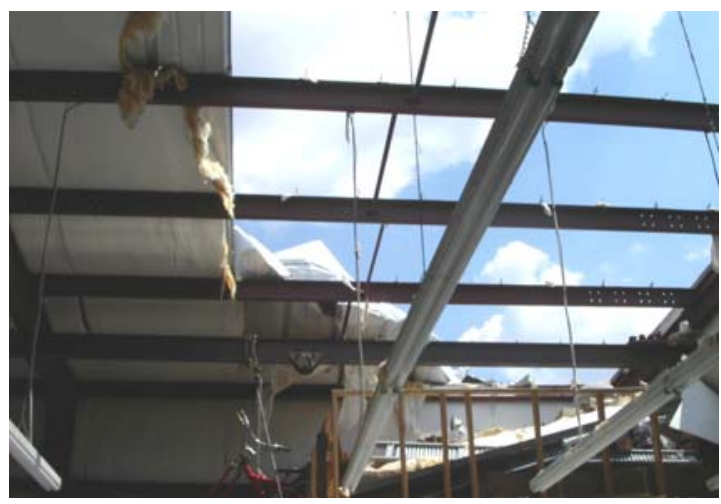

5.07-4. Sunplex Industrial Park. This photo shows a standing seam roof failure at Superior Optical. Clips remain attached to purlins.

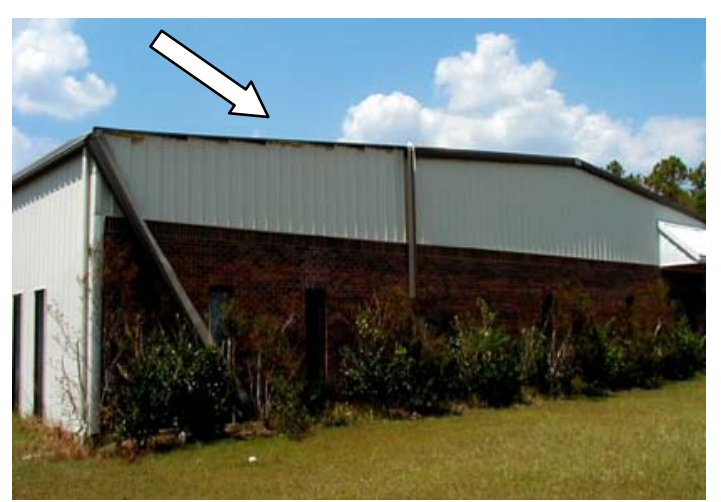

5.07-6. Sunplex Industrial Park. The RTS

Building gutter and flashing failure occurred at the front of the building. 


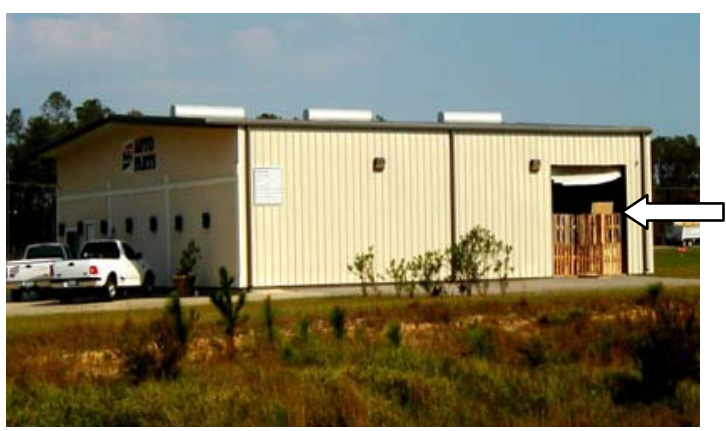

5.07-7. Sunplex Industrial Park. Mighty Auto Parts had a failed overhead door, but the throughfastened roof survived intact. 


\section{HURRICANE KATRINA: TEAM 3}

\section{OVERVIEW}

Team 3 members investigated steep slope roofs. The team visited the following cities in Mississippi: Gautier, Ocean Springs, Biloxi, and Diamond Head. Because of damaged bridges linking major highway arteries, combined with heavy traffic, travel within and around the inspection area was difficult. With three days allocated for roof inspections, locations were chosen with an emphasis on finding a variety of roofs within an area that was accessible from our mobile base. Inspections conducted by Team 3 are depicted in maps 1, 2 and 3 .

Much of the building damage from Hurricane Katrina resulted from the intensity of the storm surge. Sites selected by Team 3 were limited to those with the most severe wind damage. Efforts were made to include a diversity of roofing materials in areas of wind damage. Particular focus was given to areas where damaged roofs were in close proximity to undamaged roofs.

The team surveyed a total of 21 steep slope roofs, consisting of 5 long-run metal, 11 asphalt composition shingle, 1 concrete tile, 2 metal shingle, 1 copper, and 1 wood shake.

\section{Team Members}

The following members participated on Team 3 for at least 1 of the 3 investigation days:

Jim Bush, photographer

Rose Grant, data recorder

Bruce Hackmeyer, data recorder

Dave Hunt, sample collector

Jon Kurtz, photographer

Joe Russo, photographer

Dan Walker, observer

Joe Wilson, report writer

\section{Summary Observations}

In survey areas, it was observed that building envelopes for non-engineered buildings did not resist wind loads that should have been anticipated, given the uplift pressures listed on the ASCE 7 table. Construction weaknesses were observed, and it was apparent that failures were compounded, throughout the building envelope. For example, problems in roof sheathing attachment and/or truss attachment created additional problems in the performance of roofing. Little evidence was found that necessary care was taken at perimeter edges of the buildings investigated, yet these were the areas exposed to the highest wind uplift forces.

In many cases of roof damage, the frequency of fastener attachment was not adequate to resist Katrina's winds. For example, it was observed that asphalt shingles applied in vertical rows, where only every other course of shingles was nailed at the edge, did not resist the wind's force.

More damage was found in roofing areas close to large projections or walls, i.e., dormers, chimneys, etc. This would suggest that additional steps are required to resist the higher uplift forces found around projections in the roof plane. Many Team 3 investigations were performed on older buildings that have been altered over time. There were cases where building alterations created construction anomalies. It is evident that such anomalies require special detailing to provide better protection against high winds, especially in retrofit applications. 
Although many roofs were undamaged, it is apparent that significant roofing damage could have been eliminated or reduced if the construction methods used had been consistent with those outlined in the latest codes. Previous RICOWI investigations have demonstrated that the roof damage from Katrina was similar to that from hurricanes Charley and Ivan. One difference, however, is that the Katrina damage observed by Team 3 occurred during lower wind speeds. The team consistently observed one or two fewer fasteners per shingle/panel than were observed by the teams in the Florida investigations. Hurricane Katrina damage to roofs would have been less had the roofs been installed with the same fastening patterns used in the Florida applications.

Maps of the areas visited by Team 3 are marked with numbers that coincide with the inspection report numbers.

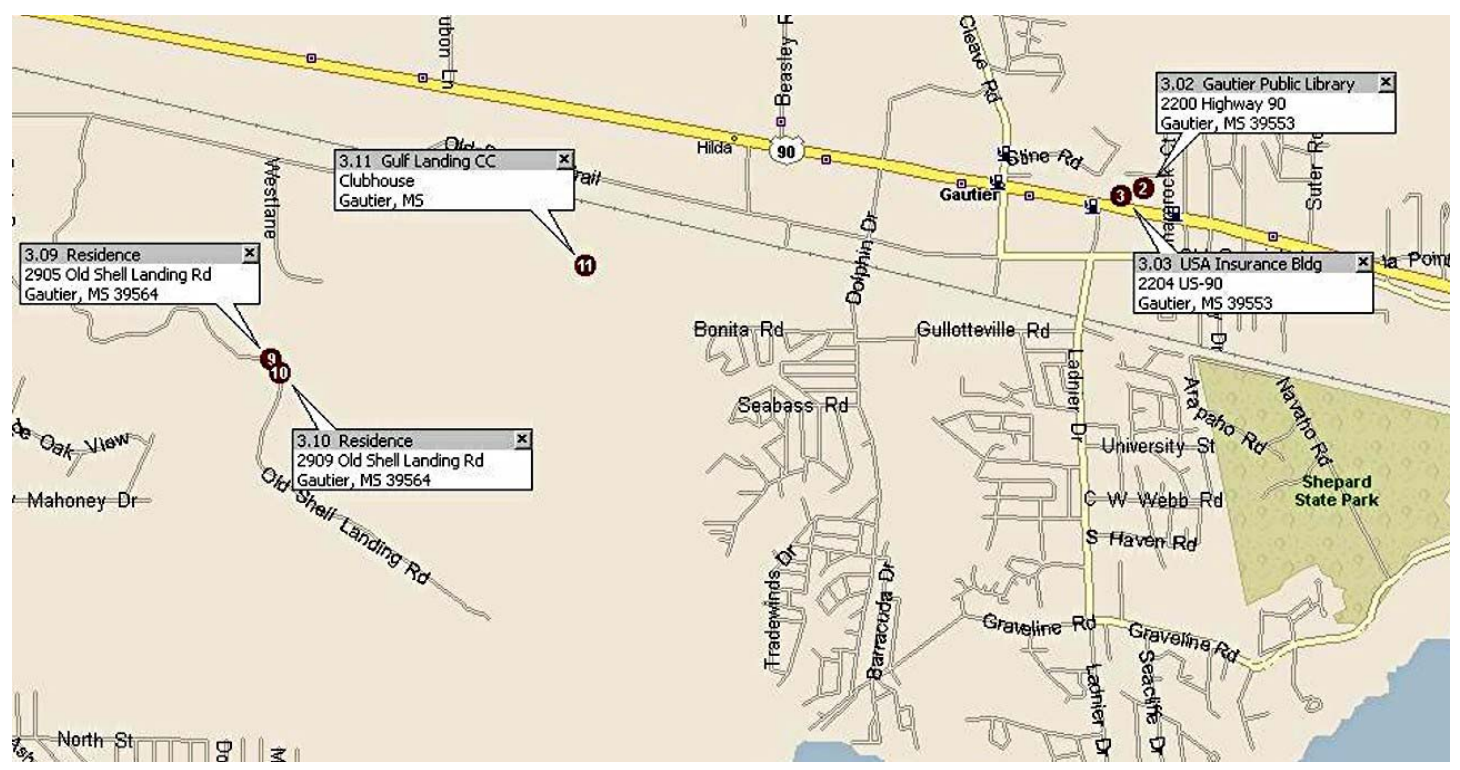

Map 1. Gautier, MS, area.

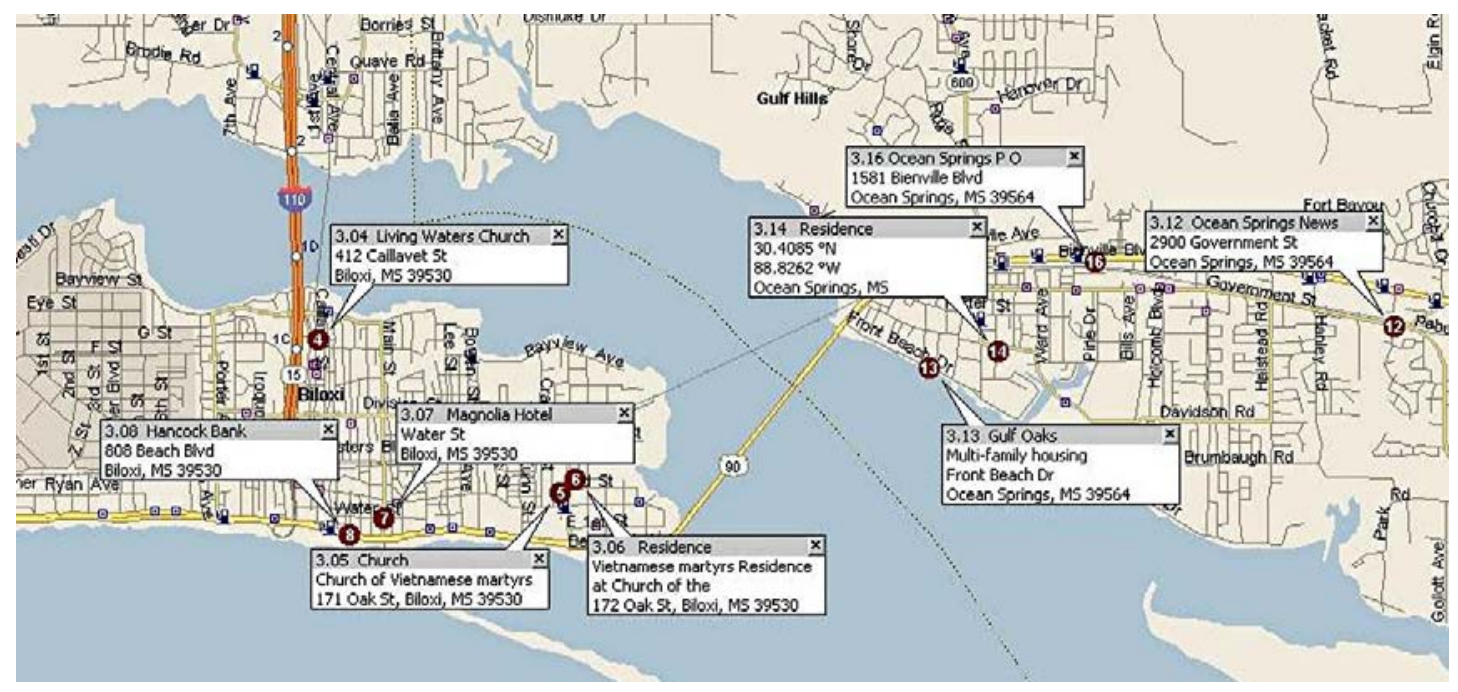

Map 2. Biloxi/Ocean Springs, MS, area. 


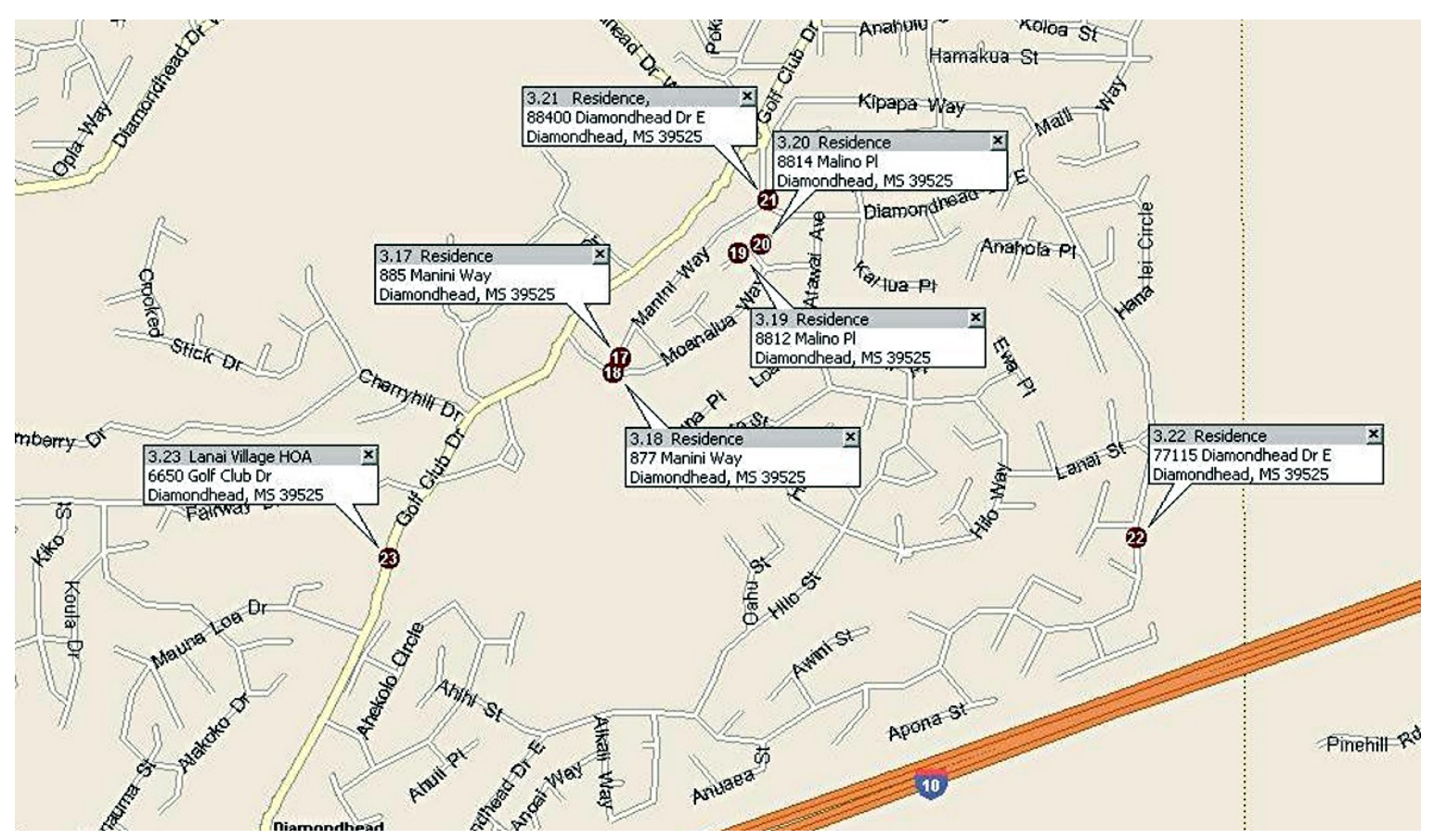

Map 3. Diamondhead, MS, area.

\section{INDIVIDUAL ROOF REPORTS}

\subsection{Gautier Public Library, 2200 Highway 90, Gautier, MS}

TYPE OF STRUCTURE-Library

EXPOSURE-C

SITE COORDINATES-N30 39' $15^{\prime \prime} \mathrm{W} 88^{\circ} 64^{\prime} 24{ }^{\prime \prime}$

WALL CONSTRUCTION-Brick

ROOF TYPE-Asphalt shingle, 3-tab

SLOPE-3-4: 12

DECK-Plywood

WIND SPEED-110-120 mph

BUILDING CONSTRUCTION-One story building with wood rafters

METHOD OF ATTACHMENT - Three or four nails per shingle on alternating courses

NOTED DAMAGE-Shingle tabs were torn loose on courses where shingles were attached with only three nails.

DAMAGE INITIATION AND PROPAGATION-Un-nailed ends of shingles lifted and tore loose. ADDITIONAL COMMENTS—Newer library roof was undamaged, whereas older roof had torn shingle tabs. 


\section{Photographs of Roof Damage}

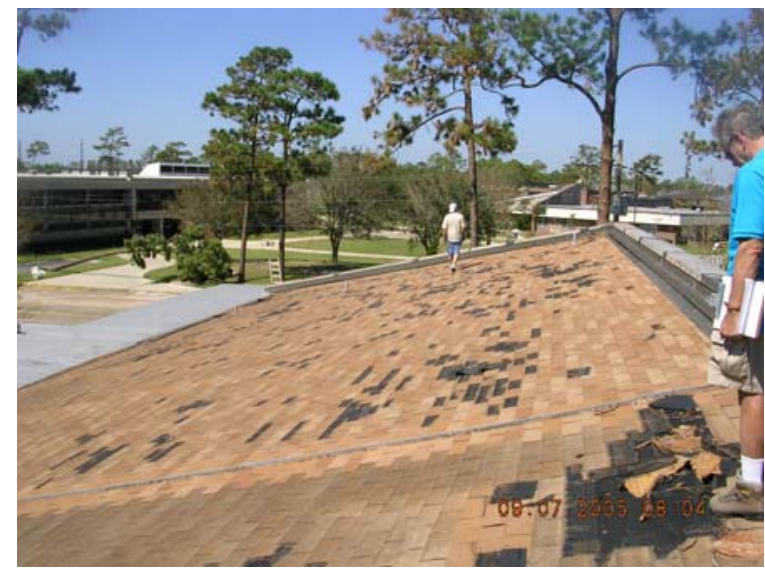

3.01-1. Gautier Library. This view of the older library roof shows damage to alternate courses. "Racking" method of installation was used; i.e., alternating courses of shingles attached with three, then four nails.

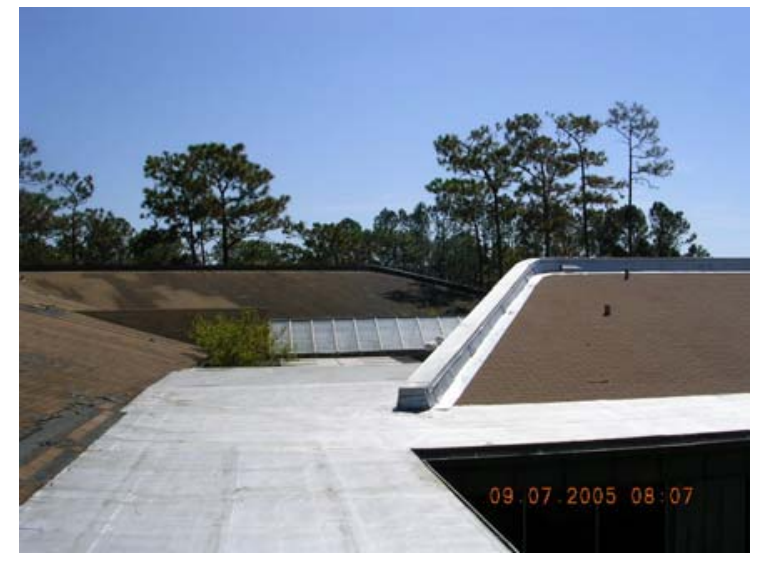

3.01-2. Gautier Library. This is the newer, undamaged library roof next to the older (damaged) roof.

\subsection{USA Insurance Building, 2204 Highway 90, Gautier, MS}

TYPE OF STRUCTURE-Commercial

EXPOSURE-C

SITE COORDINATES-N30 39'15" W88 64'24”

WALL CONSTRUCTION-Stucco finish

ROOF TYPE-Copper raised seam over wood trusses spaced $2 \mathrm{ft}$ o.c.

SLOPE-4-6: 12

DECK-Plywood

WIND SPEED-110-120 mph

BUILDING CONSTRUCTION-Wood rafters

METHOD OF ATTACHMENT-Unknown

NOTED DAMAGE-None

DAMAGE INITIATION AND PROPAGATION-No damage

ADDITIONAL COMMENTS-Building is located in proximity to other roofs that sustained damage. 


\section{Photographs of RoOf Damage}

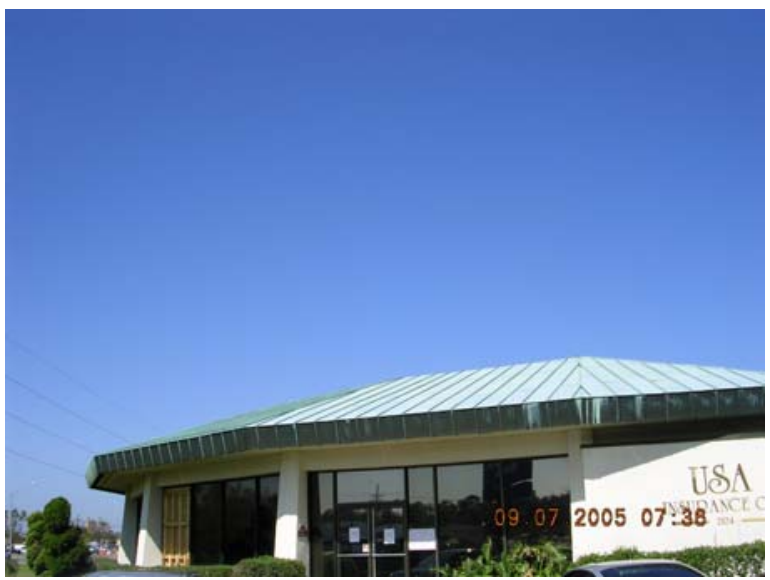

3.02-1. USA Insurance Building. An undamaged raised-seam copper roof. Neighboring roofs did sustain damage.

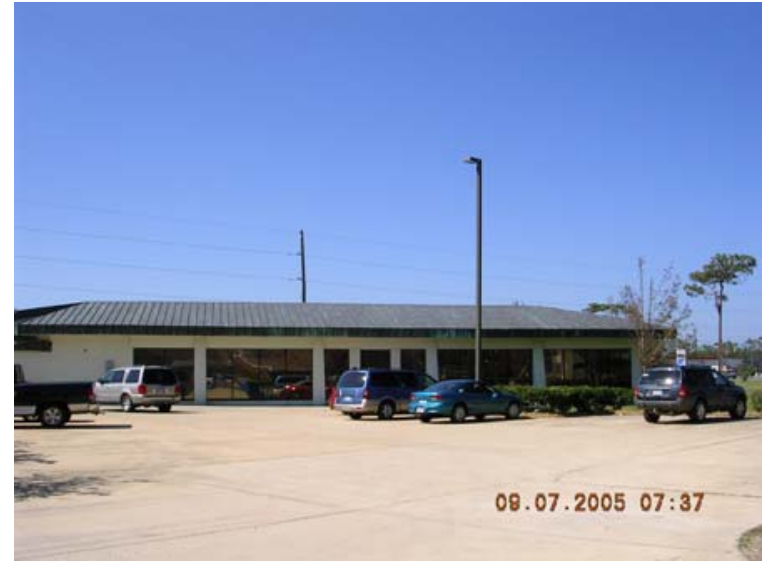

3.02-2. USA Insurance Building. This is another view of the undamaged copper roof.

\subsection{Living Waters Church, 412 Cailavet, Biloxi, MS}

TYPE OF STRUCTURE—Church

EXPOSURE-C

SITE COORDINATES-N3040'57" W88 89' 12"

WALL CONSTRUCTION-Brick

ROOF TYPE-Asphalt shingle, 3-tab, over wood beams spaced $6 \mathrm{ft}$ o.c.

SLOPE-6 : 12 or greater

DECK-Plywood

WIND SPEED-120-130 mph

BUILDING CONSTRUCTION—Wood rafters

METHOD OF ATTACHMENT - Three, then four nails per shingle on alternating courses NOTED DAMAGE-Shingles torn off in vertical patterns

DAMAGE INITIATION AND PROPAGATION—Shingles fastened with three nails were loose at one end and tore off.

ADDITIONAL COMMENTS - Alternating course vertical installation pattern ("racking method") 


\section{Photographs of Roof Damage}

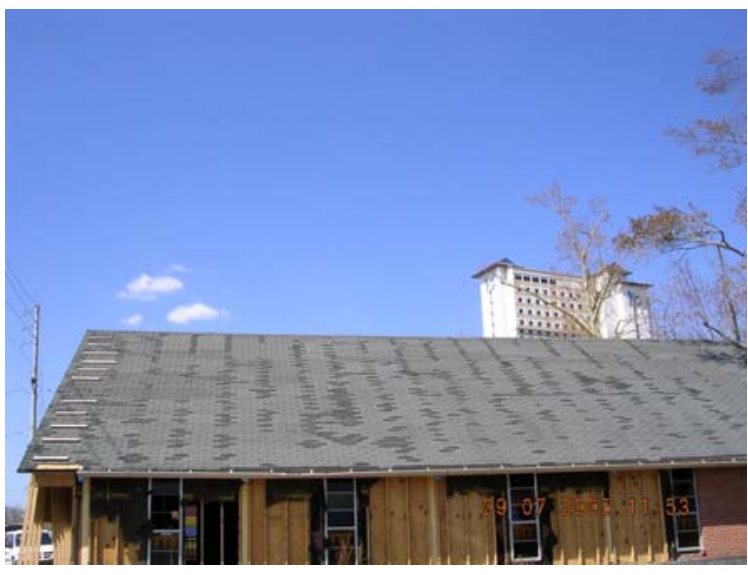

3.03-1. Living Waters Church. Torn tabs at unattached ends of shingles follow a vertical pattern.

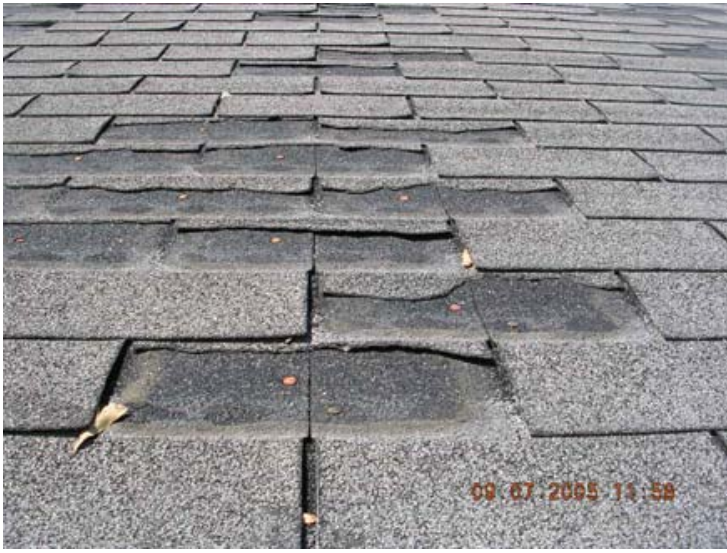

3.03-2. Living Waters Church. A closer view of torn shingles shows missing nails in alternating courses.

\subsection{Church of the Vietnamese Martyrs, 171 Oak Place, Biloxi, MS}

TYPE OF STRUCTURE-Church

EXPOSURE-C

SITE COORDINATES-N30 39' 39”'W88 86' 47”

WALL CONSTRUCTION-Concrete masonry units (CMU)

ROOF TYPE—Roll-formed "simulated tile" steel roof

SLOPE-4-6: 12

DECK-Wood

WIND SPEED-120-130 mph

BUILDING CONSTRUCTION—CMU with solid wood beams and tongue-and-groove sheathing METHOD OF ATTACHMENT_-Screws placed along each 12 in. course and at panel ends NOTED DAMAGE-A metal coping flashing piece was lost on an otherwise undamaged roof. DAMAGE INITIATION AND PROPAGATION_A flashing piece was lost as a result of an attachment issue.

ADDITIONAL COMMENTS—Roof was undamaged except for the flashing piece. 


\section{Photographs of RoOf Damage}

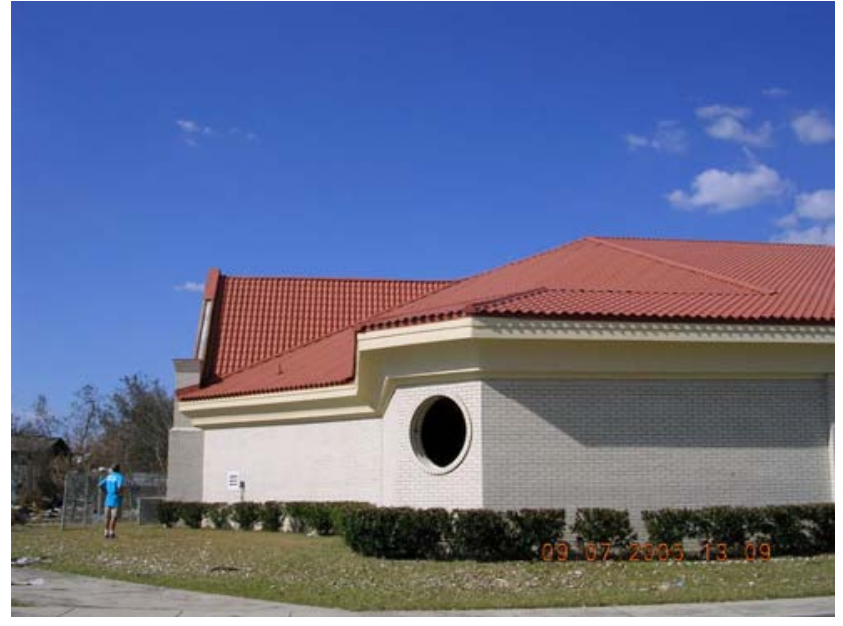

3.04-1. Church of the Vietnamese Martyrs. A steel "simulated tile" roof was installed on this church. Damage was limited to a missing coping flashing.

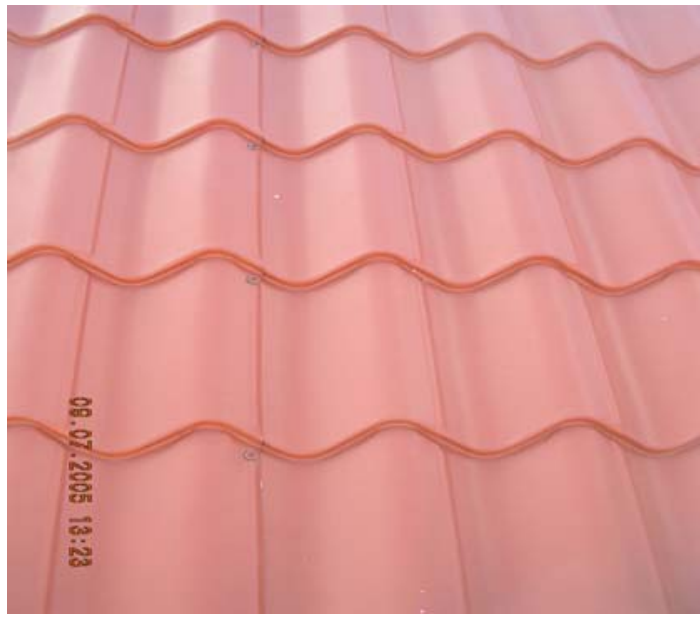

3.04-2 Church of the Vietnamese Martyrs. This is a closer view of field panel attachment.

\subsection{Residence at Church of the Vietnamese Martyrs, 172 Oak Place, Biloxi, MS}

TYPE OF STRUCTURE-Residential

\section{EXPOSURE-C}

SITE COORDINATES-N3039'40" W88 86' 49"

WALL CONSTRUCTION-Wood stud framing and siding

ROOF TYPE-Metal roll-formed agricultural style ("R") panel

SLOPE—6 : 12 or greater

DECK—Wood sheathing boards (spaced, not solid)

WIND SPEED—120-130 mph

BUILDING CONSTRUCTION—Wood stud framing and siding

METHOD OF ATTACHMENT—Screws spaced 12 in. o.c. across sheathing boards and 24 in. o.c. vertically on every other board

NOTED DAMAGE-Approximately half of the vertical panels were blown off the roof.

DAMAGE INITIATION AND PROPAGATION_-Damage initiated from the perimeter edge and was aided by internal pressurization through spaced board sheathing.

ADDITIONAL COMMENTS-None 


\section{Photographs of RoOf DAMAge}

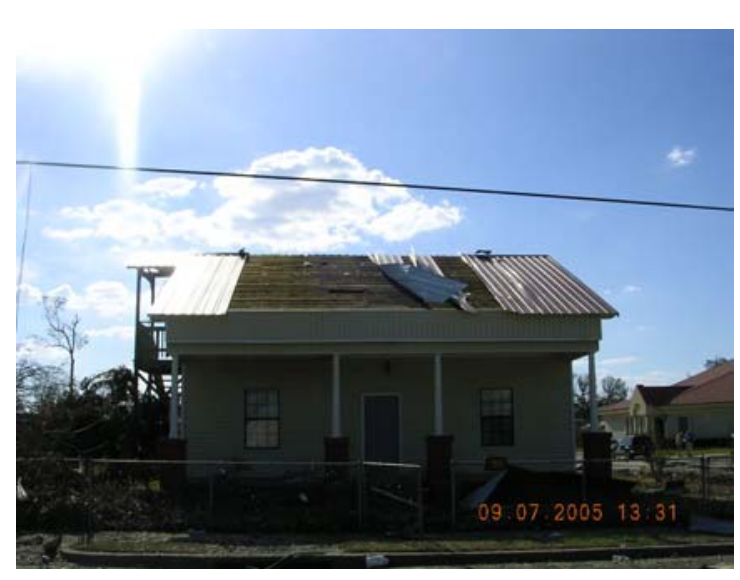

3.05-1. Church of the Vietnamese Martyrs. This photo shows steel "R" panels pulled loose from spaced sheathing boards.

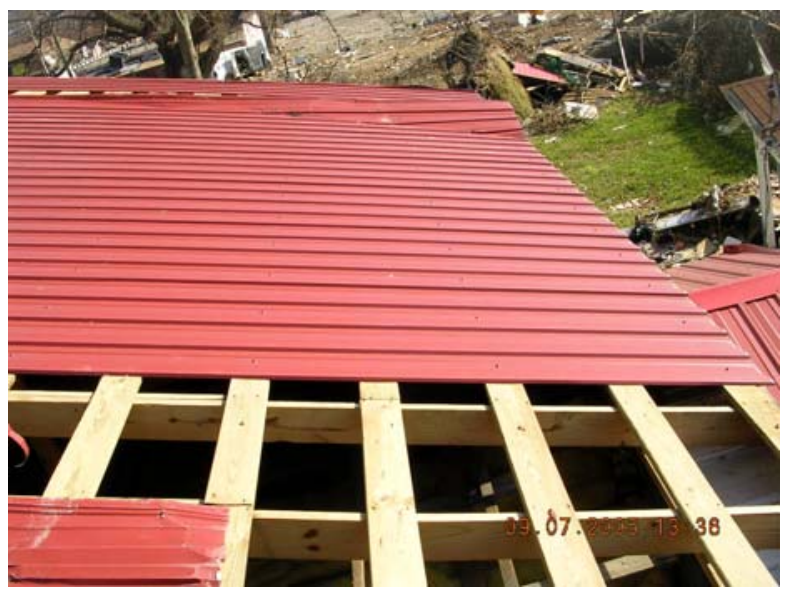

3.05-2. Church of the Vietnamese Martyrs. Three screws per panel spaced on every other board was inadequate attachment and did not resist the internal and external wind pressures of hurricane Katrina.

\subsection{Magnolia Hotel, 119 Water Street, Biloxi, MS}

TYPE OF STRUCTURE-Hotel

EXPOSURE-C

SITE COORDINATES-N30 39' 28" W88 88' 57"

WALL CONSTRUCTION-Wood framing

ROOF TYPE—Wood shakes

SLOPE—6 : 12 or greater

DECK—Wood sheathing boards

WIND SPEED—120-130 mph

BUILDING CONSTRUCTION—Wood framing and siding (two story)

METHOD OF ATTACHMENT_Nails (two per wood shake)

NOTED DAMAGE—Sporadic loss of wood shakes

DAMAGE INITIATION AND PROPAGATION_-Poorly installed shakes offered little resistance to strong winds and tore loose.

ADDITIONAL COMMENTS-It appears that the installer paid more attention to aesthetics than structural resistance to uplift forces, with shake exposures of 10 in. or greater. 


\section{Photographs of Roof Damage}

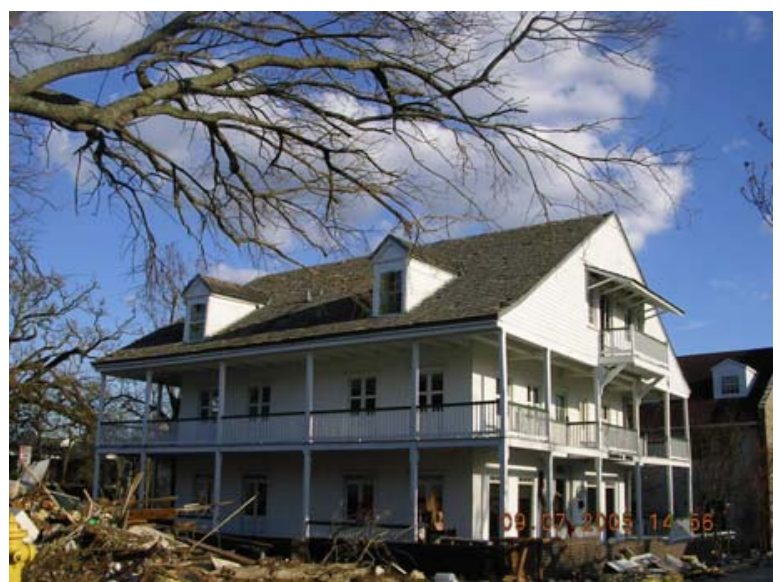

3.06-1. Magnolia Hotel. Sporadic wood shake loss was noted on this historic hotel.

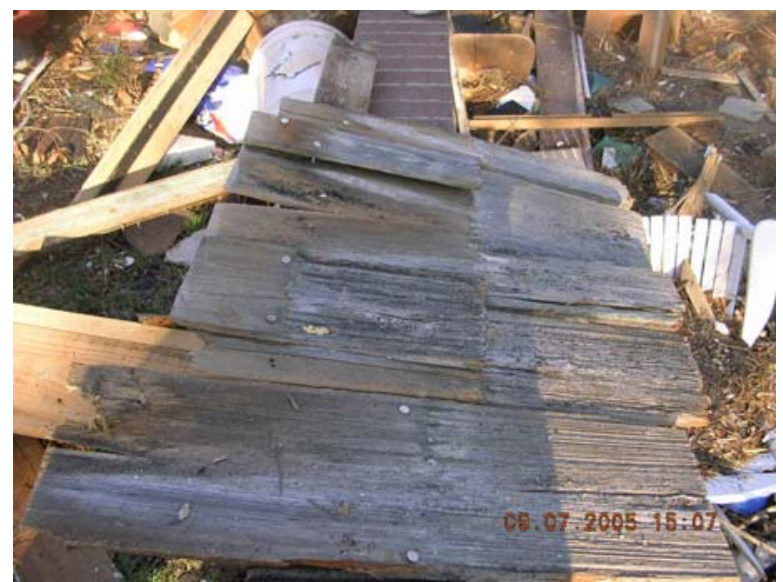

3.06-2. Magnolia Hotel. These wood shakes were installed in a way that appears to be a compromise in favor of aesthetics, rather than in a structurally sound manner.

3.07 Hancock Bank, 808 Beach, Biloxi, MS

TYPE OF STRUCTURE-Commercial

EXPOSURE-C

SITE COORDINATES-N30 39' 21" W88 88' 55"

WALL CONSTRUCTION-Brick

ROOF TYPE—Asphalt shingle, laminated

SLOPE—6 : 12 or greater

DECK-Plywood

WIND SPEED-120-130 mph

BUILDING CONSTRUCTION—Brick and wood rafter (two story)

METHOD OF ATTACHMENT_-Nails (four per shingle)

NOTED DAMAGE—Roof damage at leading edges to wind direction. Damage around dormers suggested that wind turbulence elevated pressures. Some hip and ridge pieces were missing.

DAMAGE INITIATION AND PROPAGATION—Shingle ends lifted free.

ADDITIONAL COMMENTS-None 


\section{Photographs of Roof Damage}

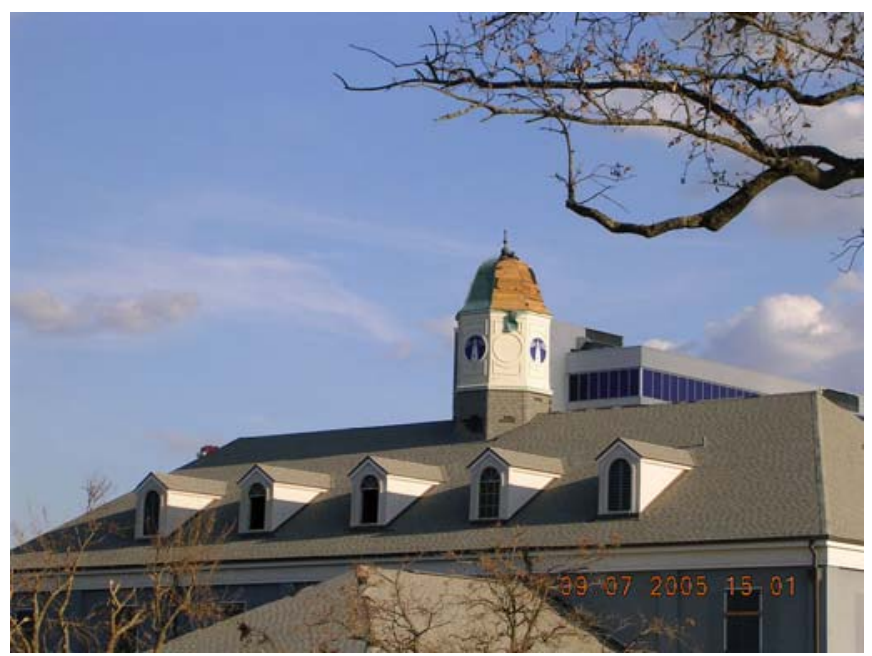

3.07-1. Hancock Bank. Damage at hips, ridges, dormers, and leading edges was noted on this shingle roof.

\subsection{Residence, 2905 Shell Landing, Gautier, MS}

TYPE OF STRUCTURE—Residential, single family

EXPOSURE-C

SITE COORDINATES-N30 23' 52" W88 38' 7"

WALL CONSTRUCTION-Brick and stucco

ROOF TYPE-Concrete tile

SLOPE-6 : 12 or greater

DECK—Oriented strand board (OSB)

WIND SPEED-110-120 mph

CONSTRUCTION-Wood truss and framing (single story)

METHOD OF ATTACHMENT_-Nails

NOTED DAMAGE-None

DAMAGE INITIATION AND PROPAGATION—Not applicable

ADDITIONAL COMMENTS—Pool screen at rear of house and an adjacent shingle roof were damaged. 


\section{Photographs of RoOF Damage}

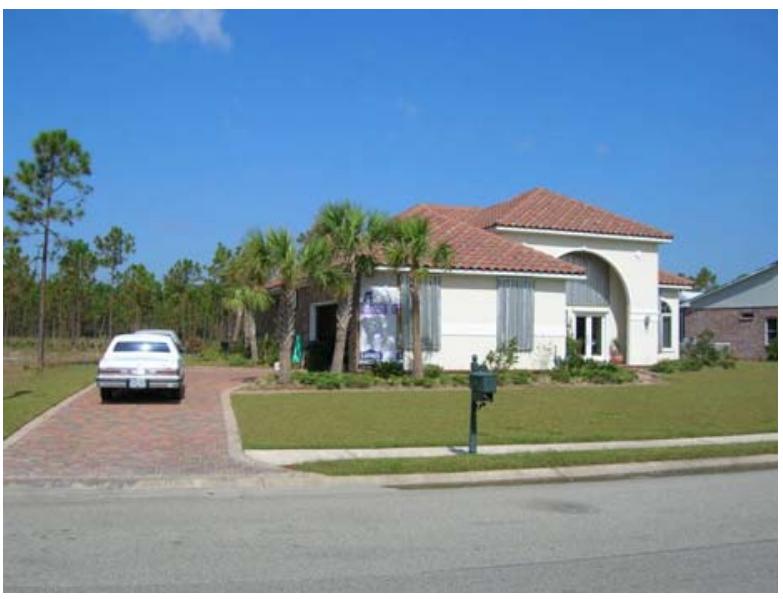

3.08-1. Residence. A surviving concrete tile roof is shown here.

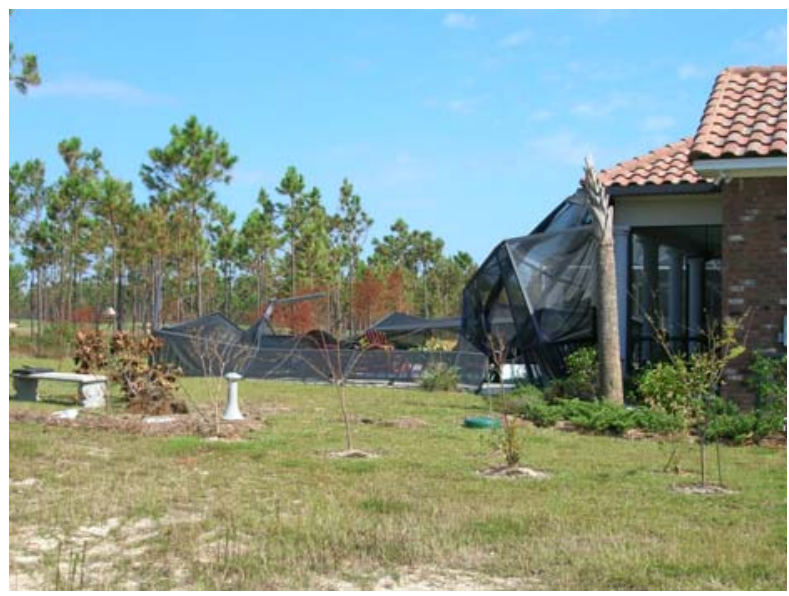

3.08-2. Residence. This photo shows a destroyed pool screen formerly connected to this undamaged concrete tile roof.

\subsection{Residence, 2909 Shell Landing, Gautier, MS}

TYPE OF STRUCTURE—Residential, single family

EXPOSURE-C

SITE COORDINATES-N30 22' 57' W88 40' 31"

WALL CONSTRUCTION-Brick and stucco

ROOF TYPE-Asphalt shingle (laminated)

SLOPE—6 : 12 or greater

$\mathrm{DECK}-\mathrm{OSB}$

WIND SPEED-110-120 mph

BUILDING CONSTRUCTION-Wood truss and framing (single story)

METHOD OF ATTACHMENT — Nails (three to five per shingle)

NOTED DAMAGE - Shingle loss in field and ridges

DAMAGE INITIATION AND PROPAGATION—Nails were consistently overdriven, often through the shingle and cutting the shingle below. Shingles were straight-laid in a vertical pattern in some areas, rather than staggered. Edge metal was nailed 30 inches o.c.- too few fasteners. Shingles were very loose at rake edges. Some ridge venting was missing.

ADDITIONAL COMMENTS-None 


\section{Photographs of Roof Damage}

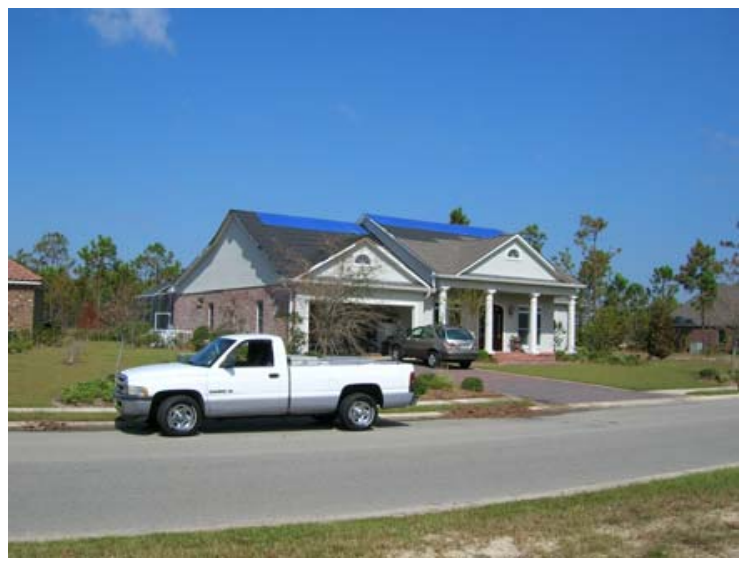

3.09-1. Residence. This is a residence with missing laminated asphalt shingles.

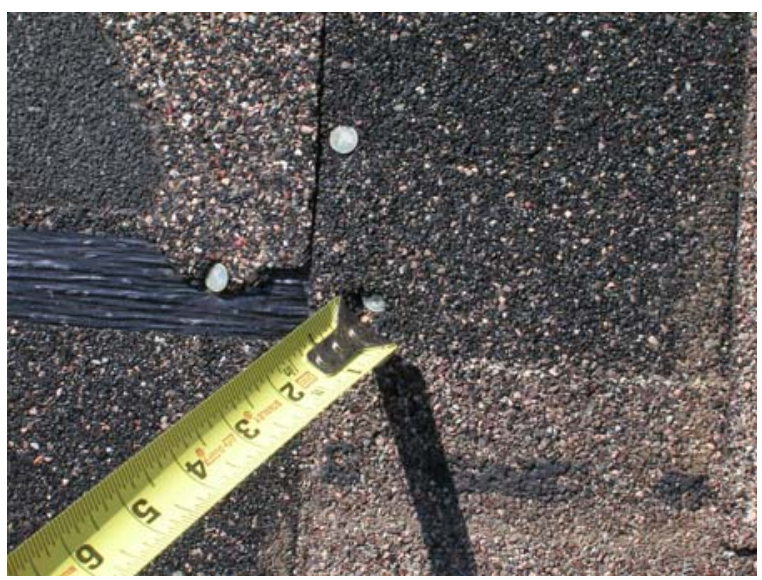

3.09-2. Residence. This is an example of inconsistent fastener placement and overdriven nails.

\subsection{Gulf Landing Country Club Clubhouse, Gautier, MS}

TYPE OF STRUCTURE—Country club

EXPOSURE-C

SITE COORDINATES-N30'23' $15^{\prime \prime} " \mathrm{~W} 88^{\circ} 40^{\prime} 38^{\prime \prime}$

WALL CONSTRUCTION-Brick and stucco

ROOF TYPE-Asphalt shingles, laminated

SLOPE—6 : 12 or greater

$\mathrm{DECK}-\mathrm{OSB}$

WIND SPEED—110-120 mph

BUILDING CONSTRUCTION_-Wood truss and framing (single story)

METHOD OF ATTACHMENT - Nails (four to five per shingle)

NOTED DAMAGE—-Shingles missing from eave edge and field; hip shingles folded over and detached.

DAMAGE INITIATION AND PROPAGATION-Nails missing from one end of shingles resulted in loose attachment and subsequent deformation and/or detachment resulting from high winds.

ADDITIONAL COMMENTS-Missing nails resulted in shingle losses. 


\section{Photographs of RoOf Damage}

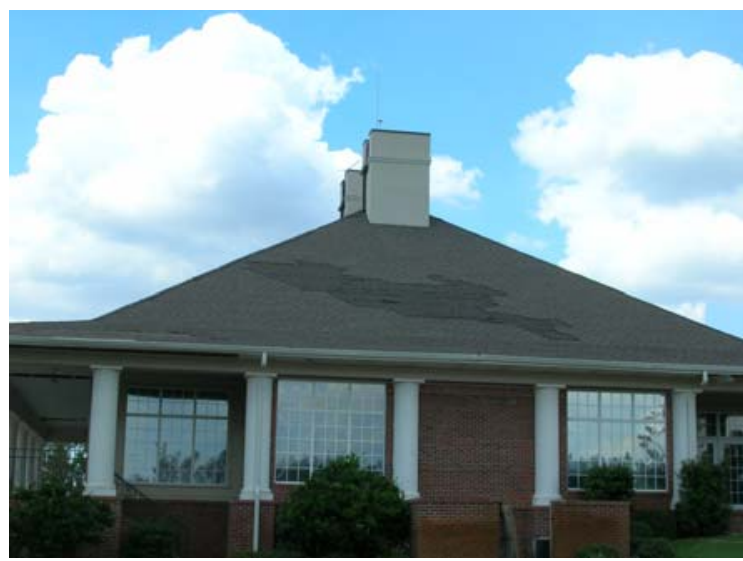

3.10-1. Gulf Landing CC Clubhouse. This clubhouse roof lost shingles between the eave and the chimney.

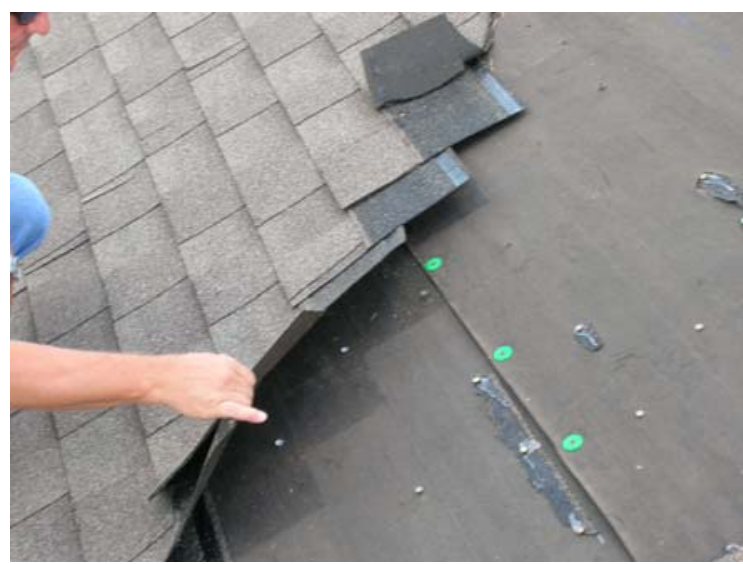

3.10-2. Gulf Landing CC Clubhouse. Shingles in the field of this roof were loose because of missing nails.

\subsection{Ocean Springs News Office Building, 2900 Government Street, Ocean Springs, MS}

TYPE OF STRUCTURE-Commercial

EXPOSURE-C

SITE COORDINATES-N30 $24{ }^{\prime} 37^{\prime \prime}$ W88 $48^{\circ}$ ' $11^{\prime \prime}$

WALL CONSTRUCTION-Brick and stucco

ROOF TYPE—Standing seam using snap-lock steel panels with ribs 16 in. o.c.

SLOPE-6 : 12 or greater

DECK—Plywood

WIND SPEED-120-130 mph

BUILDING CONSTRUCTION—Wood truss (single story)

METHOD OF ATTACHMENT—Screws spaced 30 in. o.c. vertically

NOTED DAMAGE - Two hip panels were missing.

DAMAGE INITIATION AND PROPAGATION_-The hip pieces came loose from Z-members that were not spaced sufficiently apart to engage hip pieces.

ADDITIONAL COMMENTS-16 in. standing seam 


\section{Photographs of RoOF DAMAge}

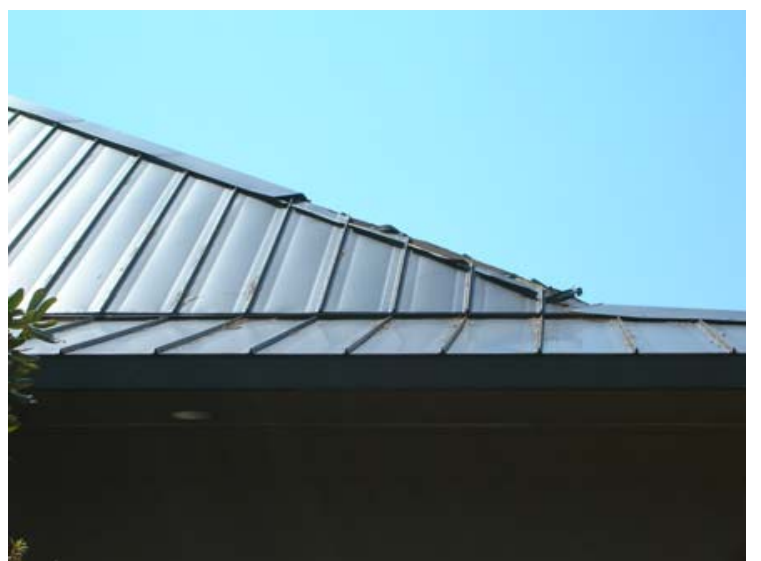

3.11-1. News Office Building. This "snap-lock" standing seam roof survived mostly intact, other than losing two hip panels.

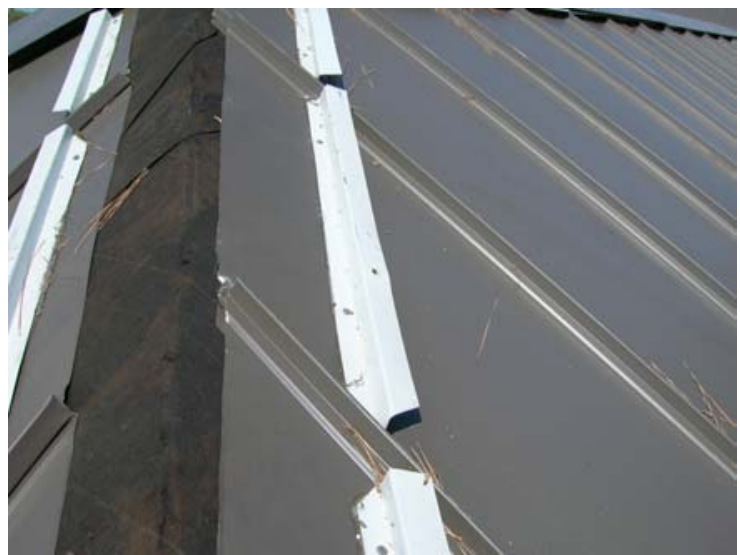

3.11-2. News Office Building. These " $Z$ " supports were spaced too closely to adequately secure trim pieces.

\subsection{Gulf Oaks Multi-Family Housing, Front Beach Drive, Ocean Springs, MS}

TYPE OF STRUCTURE—Residential, multi-family (condominium)

EXPOSURE-C

SITE COORDINATES-N30 $24^{\prime} 31^{\prime \prime} \mathrm{W} 88^{\circ} 49^{\prime} 34^{\prime \prime}$

WALL CONSTRUCTION-Brick

ROOF TYPE-Aluminum shingle panels forming a mansard-style roof

SLOPE-12: 12 or greater

DECK-Wood

WIND SPEED-120-130 mph

BUILDING CONSTRUCTION_-Mansard style roofing used as siding with flat roofing on top METHOD OF ATTACHMENT_Nails (four per aluminum panel)

NOTED DAMAGE—Roofing panels were either missing or left disengaged/displaced.

DAMAGE INITIATION AND PROPAGATION-Perimeter edge metal deformed and released front lip of panels, which were then folded back by the wind. Deformed panels then disengaged from adjacent panels.

ADDITIONAL COMMENTS-None 


\section{Photographs of Roof Damage}

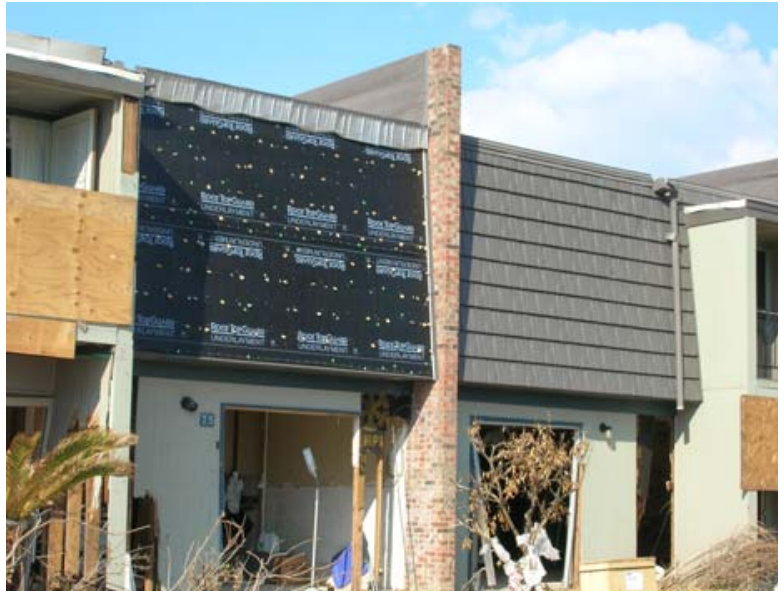

3.12-1. Gulf Oaks Multi-family Housing.

Aluminum formed shake panels were missing from the mansard roof on this condominium.

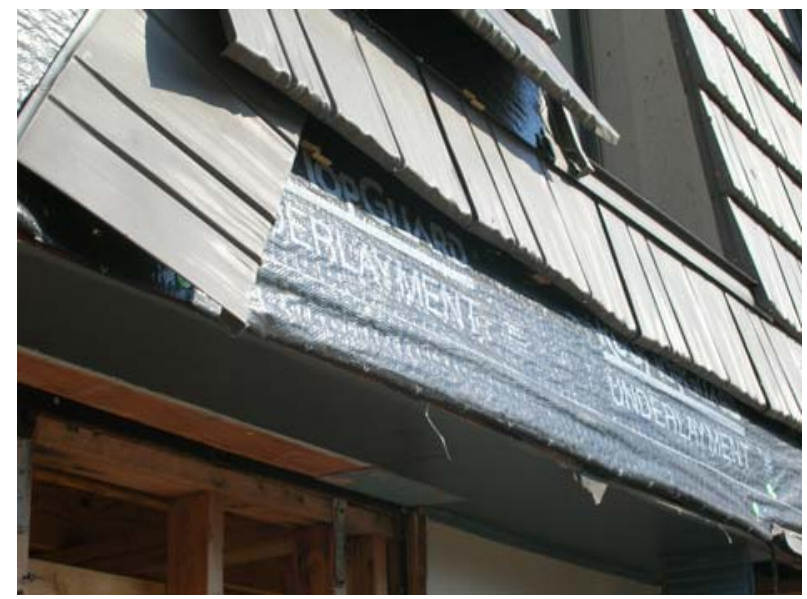

3.12-2. Gulf Oaks Multi-family Housing. Shingles disengaged at the front lip from edge metal and the rear of lapped panels.

\subsection{Residence, 172 Oak Place, Biloxi, MS}

TYPE OF STRUCTURE—Residential, single family

EXPOSURE-C

SITE COORDINATES-N30 24' 31' W88 49' 34"

WALL CONSTRUCTION-Brick

ROOF TYPE-Asphalt shingles, laminated

SLOPE-4-6 : 12

DECK-Plywood

WIND SPEED-120-130 mph

BUILDING CONSTRUCTION_-Wood framing and truss (single story)

METHOD OF ATTACHMENT_Nails (four per shingle)

NOTED DAMAGE_-Missing shingles from field, hip, and edge, including edge metal

DAMAGE INITIATION AND PROPAGATION_-Damage originated at perimeter edge. Once the edge released, field and hip shingles also became detached.

ADDITIONAL COMMENTS-Additional care with method of attachment would likely have prevented damage. 


\section{Photographs of RoOF DAMAge}

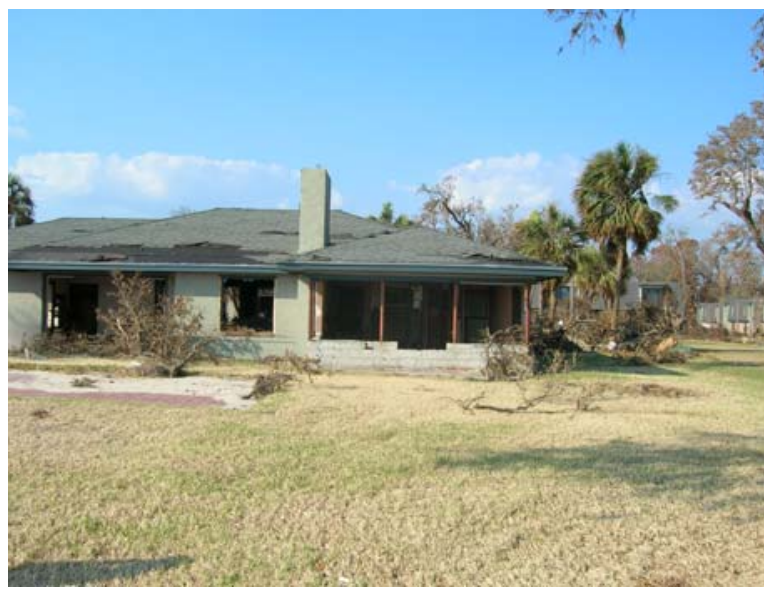

3.13-1. Residence. Ocean-front building with some shingles lost on windward side.

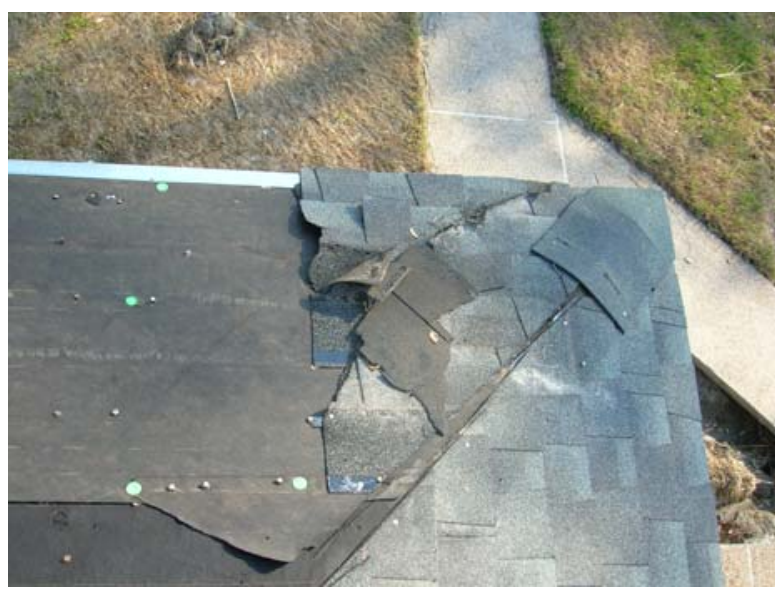

3.13-2. Residence. On this roof, shingles were torn loose from metal edge on the windward side.

\subsection{Ocean Springs Post Office, 1581 Bienville, Ocean Springs, MS}

TYPE OF STRUCTURE-Commercial

EXPOSURE-C

SITE COORDINATES-N30 $41^{\prime} 41^{\prime \prime} \mathrm{W} 88^{\circ} 81^{\prime} 35^{\prime \prime}$

WALL CONSTRUCTION-Brick

ROOF TYPE-Standing seam steel roof with $1 \frac{1}{2} 2$ in. high ribs; ribs were 16 in. o.c.

SLOPE-4-6: 12

DECK—Retrofitted steel purlin system

WIND SPEED-120-130 mph

BUILDING CONSTRUCTION_Brick walls (single story) with tall parapet gable ends

METHOD OF ATTACHMENT_-Panels were attached with clips spaced 48 in. o.c.; joints were mechanically seamed.

NOTED DAMAGE-Three panels were lost. Panel clips were attached to steel studs running horizontally across the old metal roof. New metal roof was installed over the old one.

DAMAGE INITIATION AND PROPAGATION-Mechanical seaming stopped 18 in. from the eave; i.e., seaming was incomplete.

ADDITIONAL COMMENTS-The failure occurred in close proximity (within $9 \mathrm{ft}$ ) to the end wall that extended $5 \mathrm{ft}$ above the roof surface. This type of roof and others with similar characteristics often incur significant damage in close proximity to dormers, parapets, or other disconformities. 


\section{Photographs of Roof Damage}

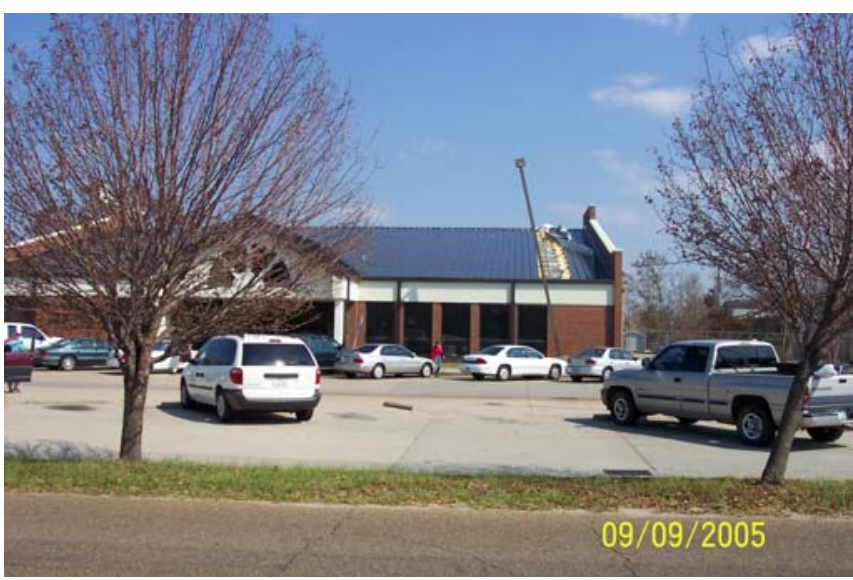

3.14-1. Post Office. This standing seam roof was missing three panels near the raised gable end wall.

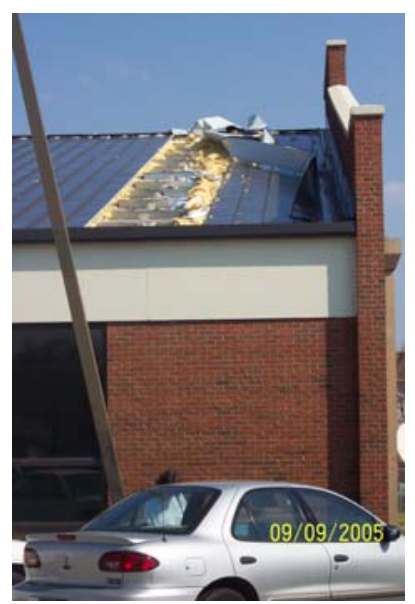

3.14-2. Post Office. A closer view of the panel seam delamination shown in previous photo.

\subsection{Residence, 885 Manini, Diamond Head, MS}

TYPE OF STRUCTURE—Residential, single family

EXPOSURE-B

SITE COORDINATES-Unknown

WALL CONSTRUCTION-Brick

ROOF TYPE-Asphalt shingle, 3-tab

SLOPE—6 : 12 or greater

DECK-Plywood

WIND SPEED—120-130 mph

BUILDING CONSTRUCTION—Brick and wood rafter (single story)

METHOD OF ATTACHMENT_Nails (three to four per shingle)

NOTED DAMAGE — Shingle edges of every other course were not fastened and ripped loose.

DAMAGE INITIATION AND PROPAGATION_Un-nailed shingle edges ripped tabs loose.

ADDITIONAL COMMENTS-The typical "racking" installation method was used here. 


\section{Photographs of Roof Damage}

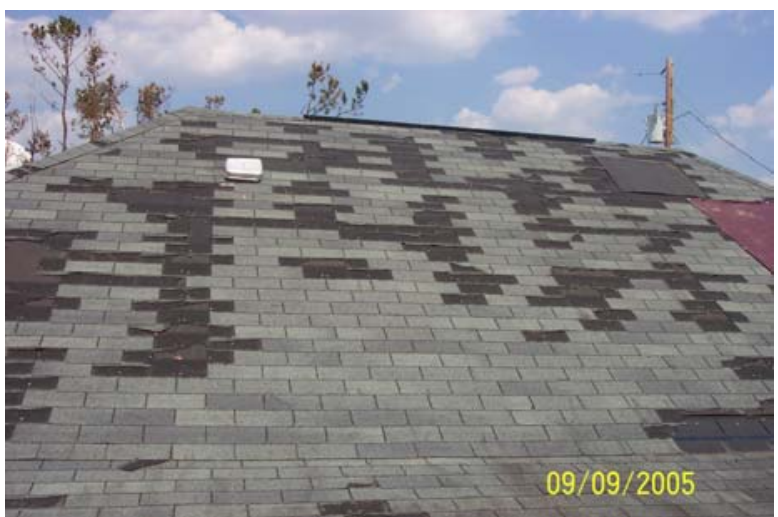

3.15-1. Residence. This roof was installed using a vertical "racking" installation method, which resulted in significant damage to many of the 3-tab shingles.

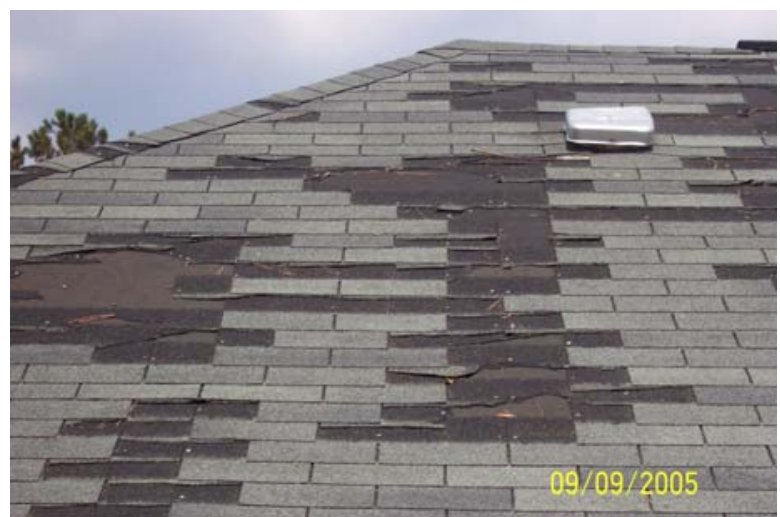

3.15-2. Residence. Fasteners were missing on alternating courses of shingles.

\subsection{Residence, 877 Manini, Diamond Head, MS}

TYPE OF STRUCTURE—Residential, single family

EXPOSURE-C

SITE COORDINATES-Unknown

WALL CONSTRUCTION-Brick

ROOF TYPE-Asphalt shingles, 3-tab

SLOPE-6 : 12 or greater

DECK-Plywood

WIND SPEED-120-130 mph

BUILDING CONSTRUCTION-Wood truss and framing (single story)

METHOD OF ATTACHMENT —Nails (four per shingle)

NOTED DAMAGE—-Some shingles were missing around perimeter and hips.

DAMAGE INITIATION AND PROPAGATION—Shingles tore loose from leading edge.

ADDITIONAL COMMENTS-The 1/1/4 in. long nails were not long enough to secure hip pieces. 


\section{Photographs of RoOF Damage}

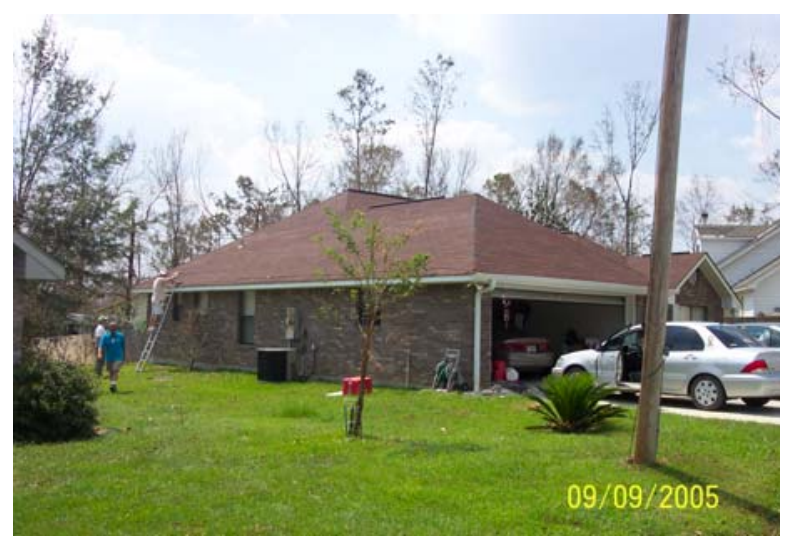

3.16-1. Residence. This overlay shingled roof lost shingles from leading edges and hips.

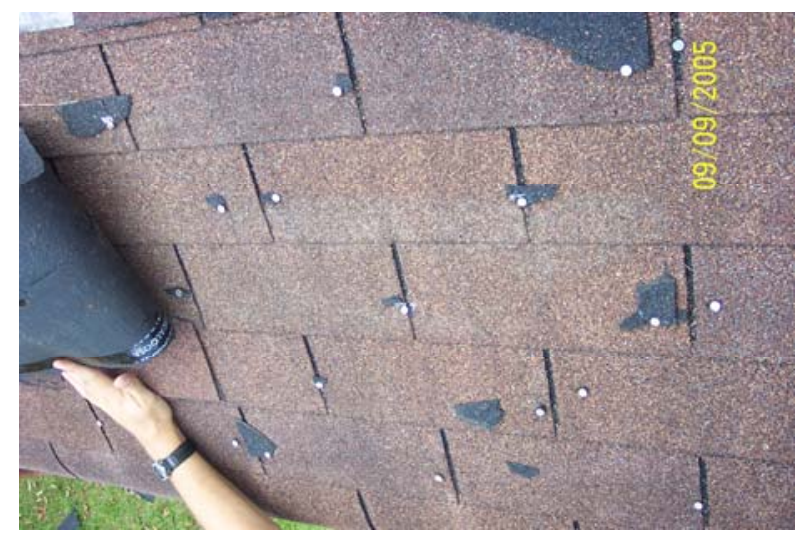

3.16-2. Residence. Shingles on this section and others tore from nails at leading edge.

\subsection{Residence, 8812 Malino Way, Diamond Head, MS}

TYPE OF STRUCTURE—Residential, single family

EXPOSURE-B

SITE COORDINATES-Unknown

WALL CONSTRUCTION-Brick

ROOF TYPE—Asphalt shingles, 3-tab (approximately 4 years old)

SLOPE—6 : 12 or greater

DECK-Plywood

WIND SPEED-120-130 mph

BUILDING CONSTRUCTION_-Wood truss and framing (single story)

METHOD OF ATTACHMENT — Nails (four per shingle)

NOTED DAMAGE-A few missing shingles

DAMAGE INITIATION AND PROPAGATION—Damage was limited to a few tabs lifting and tearing loose.

ADDITIONAL COMMENTS—Wind knocked down fencing and damaged adjacent roofs. 


\section{Photographs of Roof Damage}
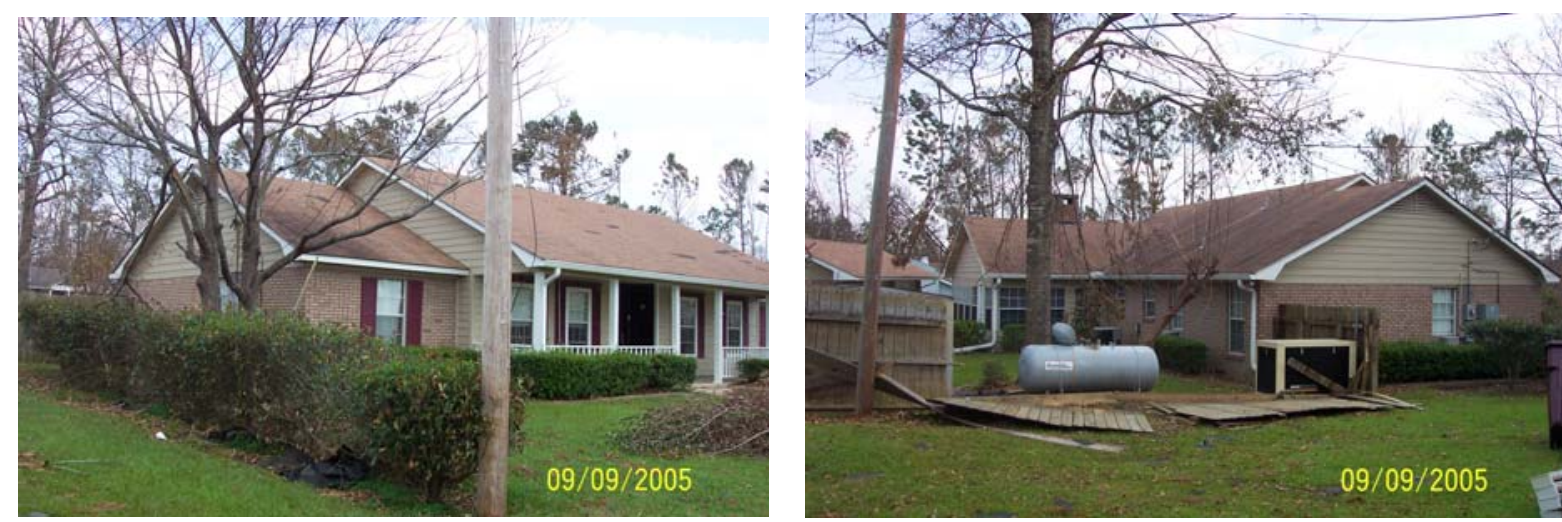

3.17-1. Residence. A few shingles were missing from this 4-year-old roof.

3.17-2. Residence. Fence damage at this residence.

\subsection{Residence, 8814 Malino, Diamond Head, MS}

TYPE OF STRUCTURE—Residential, single family

EXPOSURE-B

SITE COORDINATES-Unknown

WALL CONSTRUCTION-Brick

ROOF TYPE-Asphalt shingle, 3-tab

SLOPE-6 : 12 or greater

DECK-Plywood

WIND SPEED—120-130 mph

BUILDING CONSTRUCTION—Wood truss (single story)

METHOD OF ATTACHMENT - Nails (three or four nails on alternating courses installed vertically) NOTED DAMAGE—-Detached shingles

DAMAGE INITIATION AND PROPAGATION-The edges of every other course of shingles were not fastened, which caused shingles to rip loose.

ADDITIONAL COMMENTS_-"Racking" (vertical) installation method resulted in too few nails at edges of every other course of shingles. 


\section{PhOtOGRAPH OF ROOF DAMAGE}

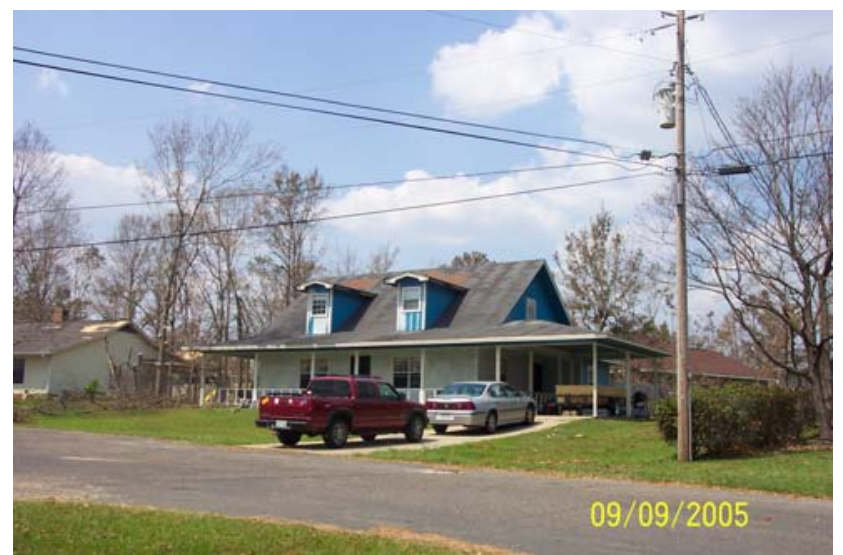

3.18-1. Residence. The vertical ("racking") method of installation caused tearing of shingles at alternating courses.

\subsection{Residence, 88400 Diamond Drive East, Diamond Head, MS}

TYPE OF STRUCTURE-Residential

EXPOSURE-B

SITE COORDINATES-N3039'30" W89 35' 16"

WALL CONSTRUCTION-Stucco finish

ROOF TYPE-Metal shingles

SLOPE—6 : 12 or greater

DECK-Plywood

WIND SPEED—120-130 mph

BUILDING CONSTRUCTION—Wood truss and framing (single story)

METHOD OF ATTACHMENT_Metal clips (three per shingle)

NOTED DAMAGE — Three or four shingle courses were missing, beginning from perimeter edge metal.

DAMAGE INITIATION AND PROPAGATION—Shingles disengaged from deformed perimeter metal edging. Subsequent courses of shingles came loose from clips.

ADDITIONAL COMMENTS-None 


\section{Photograph of Roof Damage}

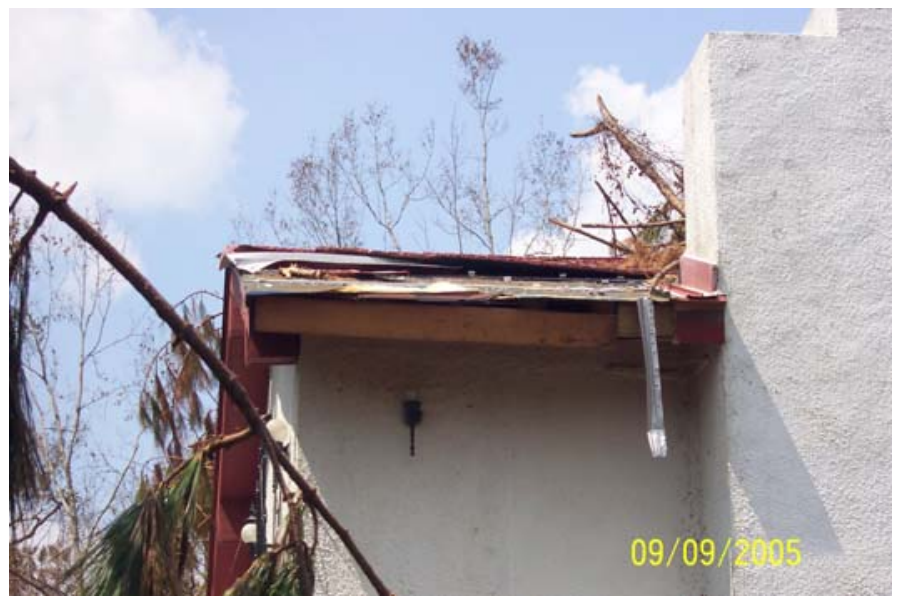

3.19-1. Residence. Metal shingles came loose when this metal edging was deformed by strong winds.

\subsection{Residence, 77115 Diamond Drive, Diamond Head, MS}

TYPE OF STRUCTURE-Residential, single family

EXPOSURE-B

SITE COORDINATES-N30 39' $15^{\prime \prime}$ W89 35' 48”

WALL CONSTRUCTION-Stucco finish

ROOF TYPE-Through-fastened steel "R" panel

SLOPE—6 : 12 or greater

DECK-Plywood

WIND SPEED-120-130 mph

BUILDING CONSTRUCTION_-Wood truss and framing (single story)

METHOD OF ATTACHMENT_Panels were attached 9 in. o.c. horizontally and 24 in. o.c. vertically.

NOTED DAMAGE — A few loose screws and a missing rake (siding) cover piece

DAMAGE INITIATION AND PROPAGATION-Panel vibration probably loosened some screws.

ADDITIONAL COMMENTS-Essentially roof performed well because of adequate fastener spacing. Some fasteners need replacement. 


\section{Photographs of Roof Damage}

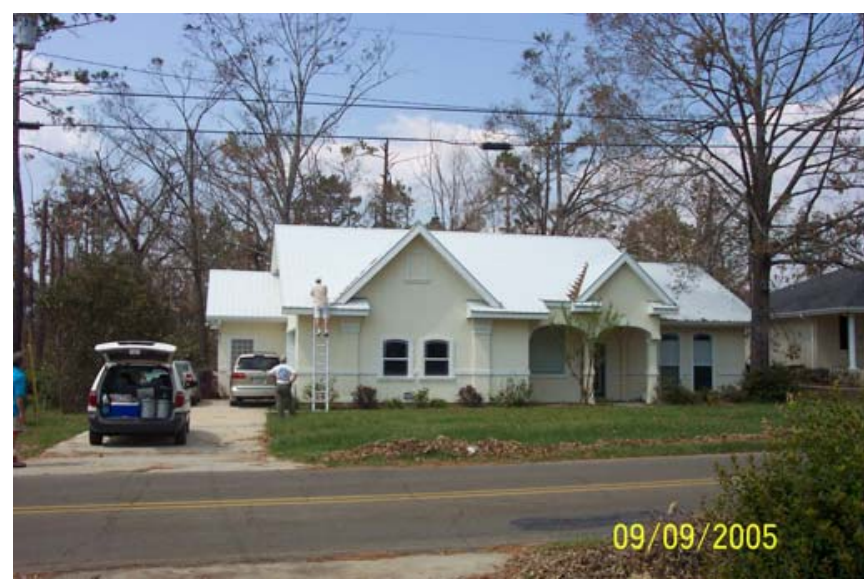

3.20-1. Residence. This steel panel roof appears to be undamaged.

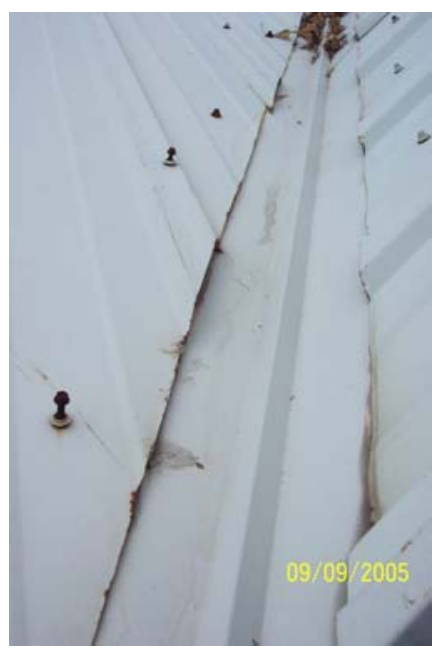

3.20-2. Residence. The loose fasteners are the result of the cyclic nature of the loading in the hurricane winds.

\subsection{Lanai Village Homeowners Association, 6650 Golf Club Drive, Diamond Head, MS}

TYPE OF STRUCTURE—Residential, multi-family (two story condominiums)

EXPOSURE-B

SITE COORDINATES-N30 38' 38" W89 36' 11"

WALL CONSTRUCTION-Wood framing and siding

ROOF TYPE—Asphalt shingles, 3-tab

SLOPE—6 : 12 or greater

DECK-Plywood

WIND SPEED-120-130 mph

BUILDING CONSTRUCTION_-Wood truss and framing (two story)

METHOD OF ATTACHMENT - Nails (three per shingle); un-nailed at one end

NOTED DAMAGE-Major roofing and structural damage

DAMAGE INITIATION AND PROPAGATION—Damage initiated from wind pressurization through gable ends.

ADDITIONAL COMMENTS-Pitched roof section was prefabricated and was shipped to area by barge and then set in place via crane. This entire roof section was blown off as a result of inadequate attachment; i.e., the pitched roof was attached to the top plate with $16 \mathrm{~d}$ nails. The gable end of this roof section was directly exposed to the wind. The truss section pressurized from the gable end and lifted off. The roof section opposite the gable end was a hip design. Shingles were also noted to have been nailed irregularly; i.e., high nailing, insufficient fastener quantity, overdriven nails, and shingle ends left loose. Plywood was nailed to rafters with $6 \mathrm{~d}$ nails spaced 6 in. o.c. at ends and 12 in. o.c. in the field. In summary, shingles, plywood, and framing became detached both separately and as an 
assembly. Other roofs on nearby buildings that were not part of the homeowners association (HOA) building were either undamaged or in need of minor repair.

\section{Photographs of RoOF DAMAgE}

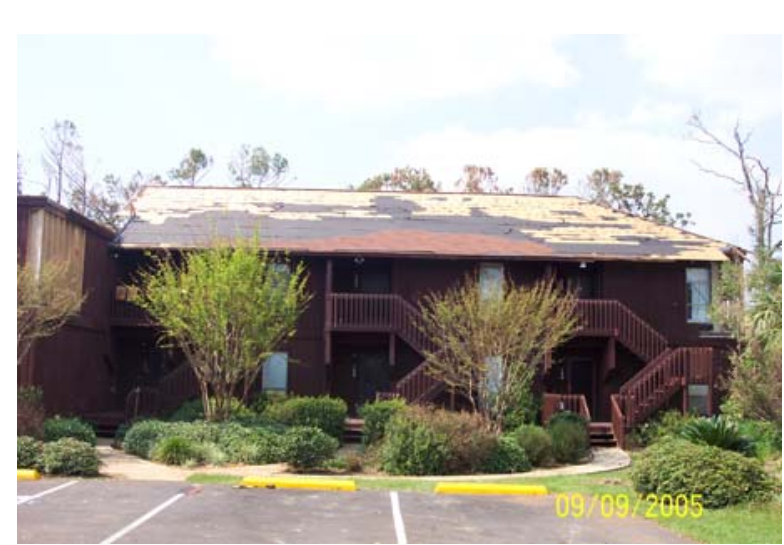

3.21-1. Lanai Village HOA. Major roofing damage is visible on this two story homeowner's association building.

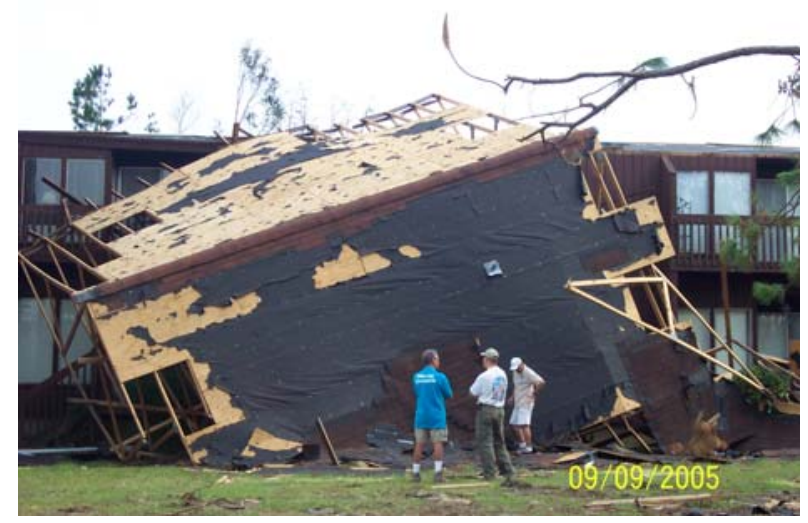

3.21-3. Lanai Village HOA. This entire retrofitted gabled roof section, originally installed as a unit, by crane, was displaced by winds.

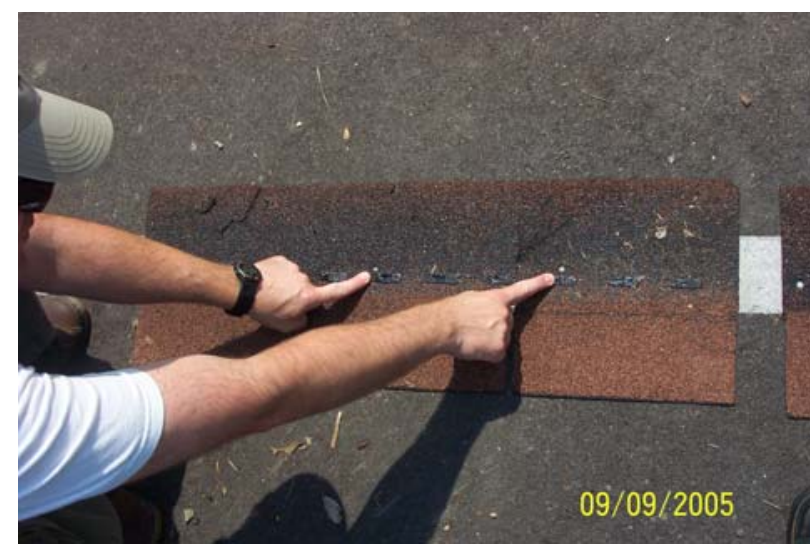

3.21-2. Lanai Village HOA. Shingles were not fastened at one end. Overdriven nails were noted in other places. Both anomalies contributed to blowoff and other damage.

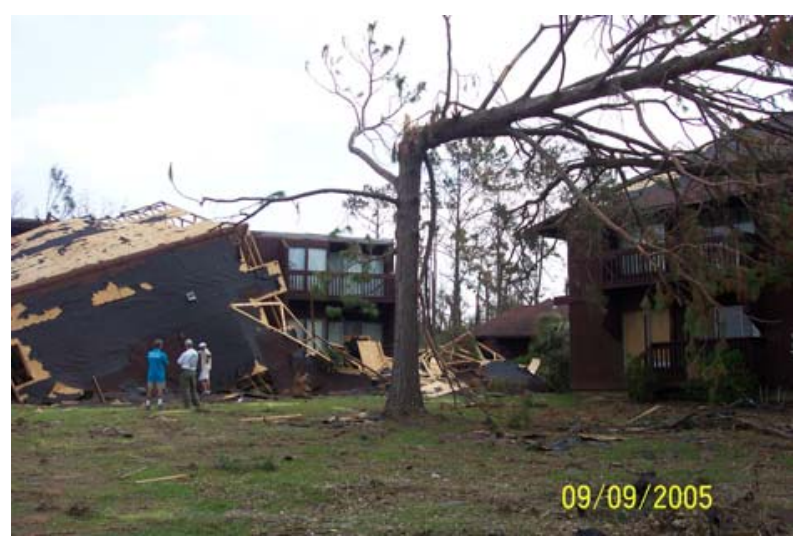

3.21-4. Lanai Village HOA. This is a wider view of the same roof section (at left). An adjacent hip roof, at right, remained in place despite the strong winds. 


\section{HURRICANE KATRINA: TEAM 6}

\section{OVERVIEW}

\section{Team 6 Members}

The following members participated on RICOWI's Hurricane Katrina Team 6 for at least 1 of the 3 days of investigations (September 7-9, 2005):

Tom Kelly, report writer Paul Fogarty, sample collector

Rose Grant, data recorder Eric Haefli, photographer John Kurtz, data recorder Joe Russo, photographer

\section{SUMMARY OBSERVATIONS}

The low slope roof damage viewed was a result of the products not being applied according to code or prescribed manufacturer standards for perimeter and membrane attachment. Metal roof damage observed was also a result of failure to follow attachment methods recommended by manufacturers. Shingle roof damage observed was primarily due to the lack or misplacement of fasteners. The overlap under the nails was missing, which caused delamination of the shingles vertically in the lap areas.

The following map depicts the areas visited by Team 6 .

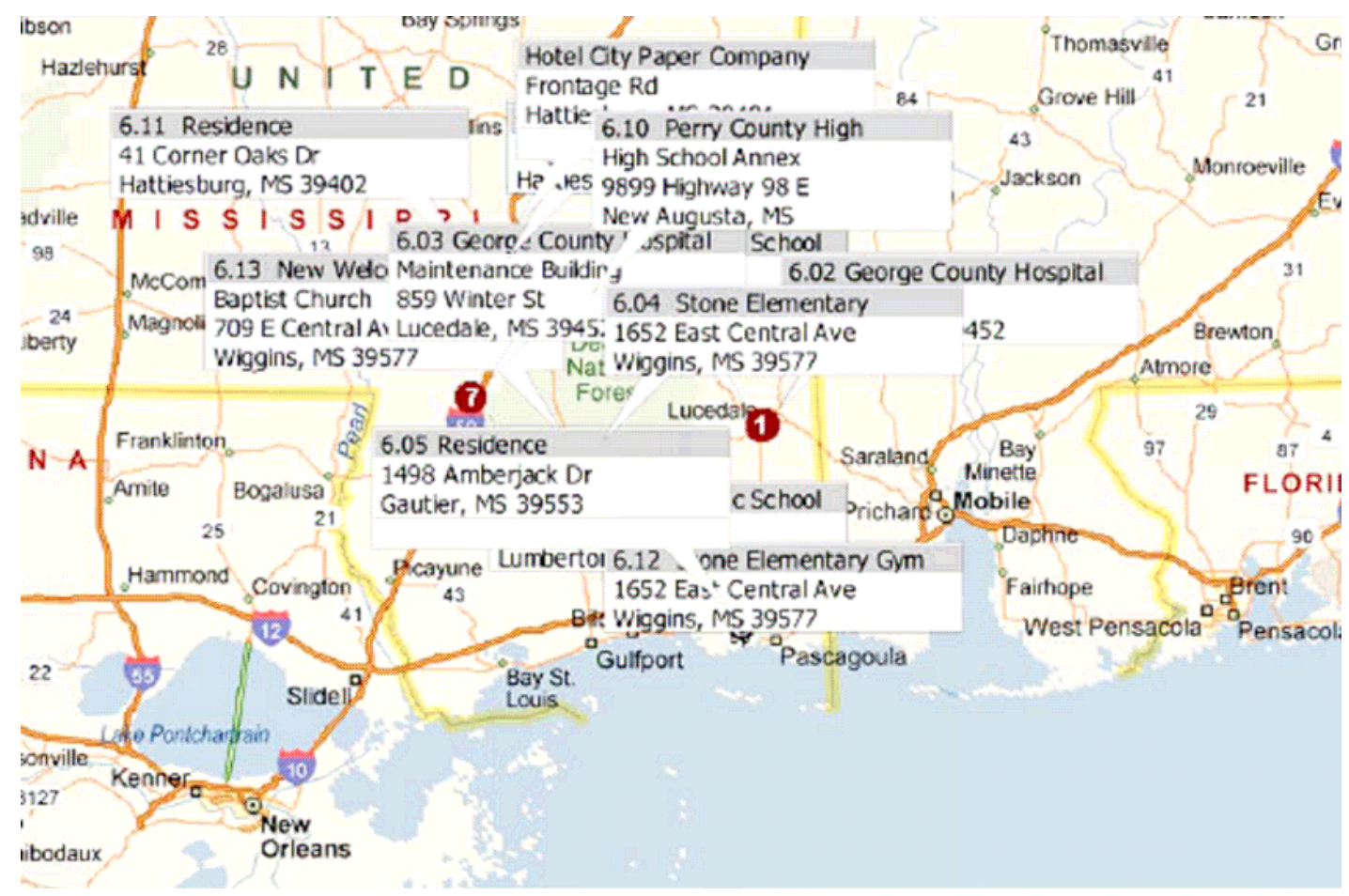




\section{INDIVIDUAL ROOF REPORTS}

\subsection{Community Medical Center, 92 West Ratliff Street, Lucedale, MS}

TYPE OF STRUCTURE-Hospital

EXPOSURE-B

SITE COORDINATES-N30 $55^{\prime}$ W89 $35^{\prime}$

WALL CONSTRUCTION-Brick

ROOF TYPE-Assembly construction from top down: Aggregate-surface asphalt built-up roof (BUR) (three plies of glass fiber felts); 3 in. of rigid roof insulation adhered to metal deck using hot asphalt. No mechanical fasteners noted.

DECK-Metal

SLOPE— $1 / 4: 12$

ROOF HEIGHT- $16 \mathrm{ft}$

ROOF WIDTH- $150 \mathrm{ft}$

ROOF LENGTH-200 ft

WIND SPEED-90-100 mph

BUILDING CONSTRUCTION_Built in 2001; metal deck on bar joist "T" metal stud wall with brick veneer

METHOD OF ATTACHMENT —Cap flashing attached with 1 in. screws (see photo 6.01-5).

NOTED DAMAGE-Parapet coping became detached and portions of flashing were found in the northern parking lot; coping was attached with 1in. screws (see photo 6.01-5).

DAMAGE INITIATION AND PROPAGATION_-Primary cause of damage was blowoff of the northern downwind side (rear) parapet metal coping.

ADDITIONAL COMMENTS—This building was located on hilly terrain. The parapet metal coping was fastened with three 1 in. screws (on roof-facing side) into wood blocking. The front face of the coping was clipped onto a 26-gauge galvanized cleat (too light for this purpose), fastened $4 \mathrm{ft}$ o.c. (should be continuous) with $1 \frac{1}{2} 2$ in. shingle nails on top of the parapet nailer. The modified bitumen membrane, used for wall flashing, remained intact on the wall and was wrapped over the parapet nailer and front face. 


\section{Photographs of Roof Damage}

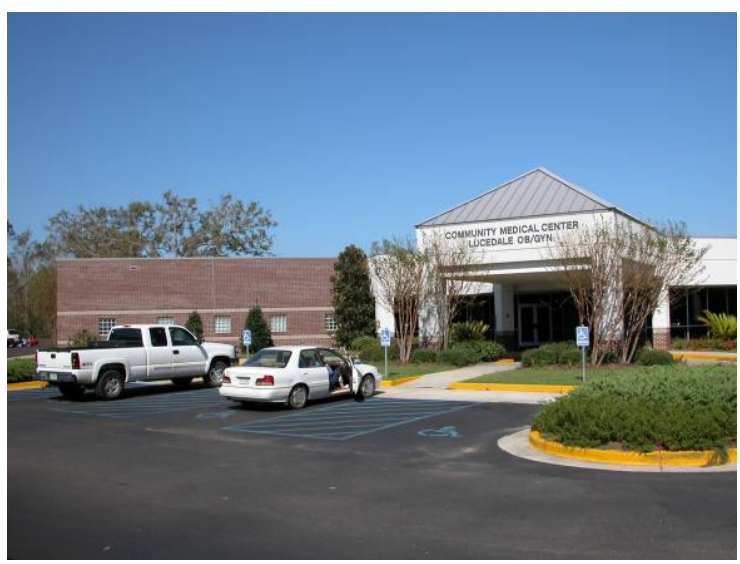

6.01-1. Community Medical Center. Overview of the facility.

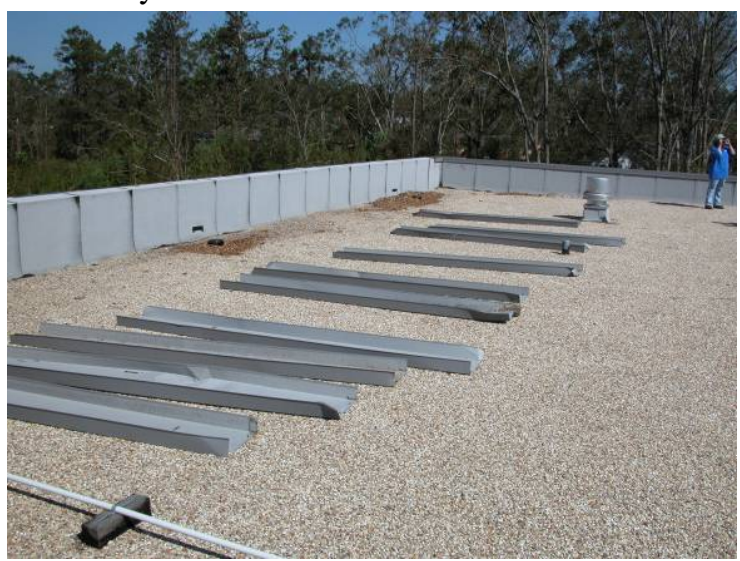

6.01-3. Community Medical Center. Recovered sheet metal coping pieces were stored on the roof.

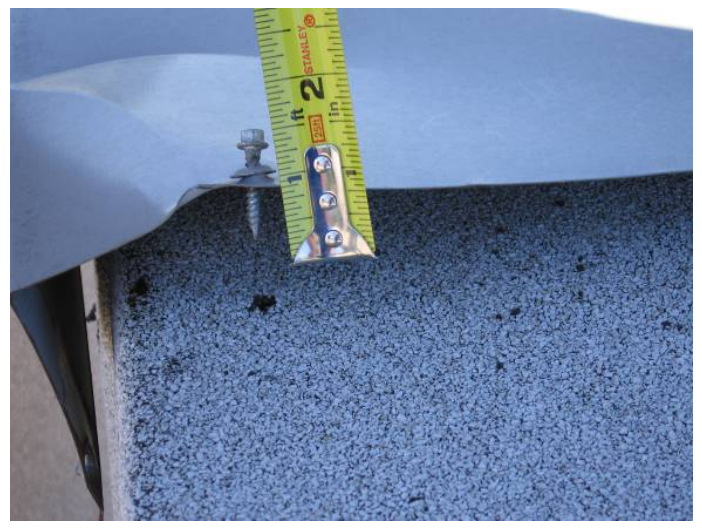

6.01-5. Community Medical Center. Close-up of a fastener used to hold coping in place.

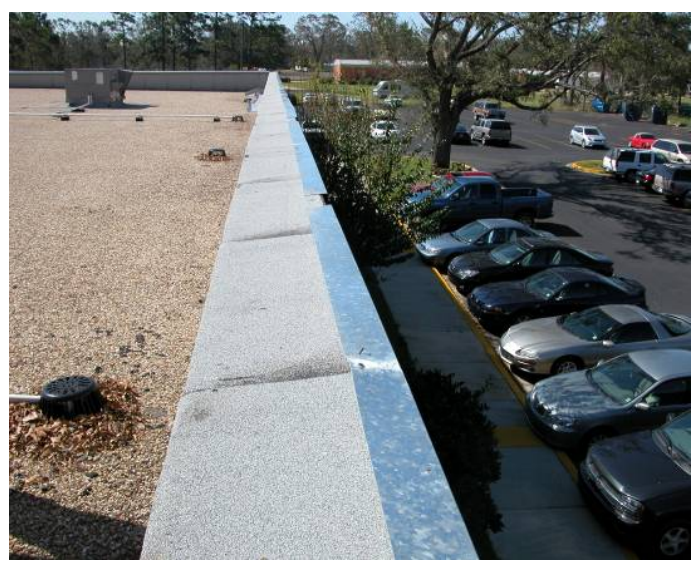

6.01-2. Community Medical Center. Metal coping was missing from the parapet.

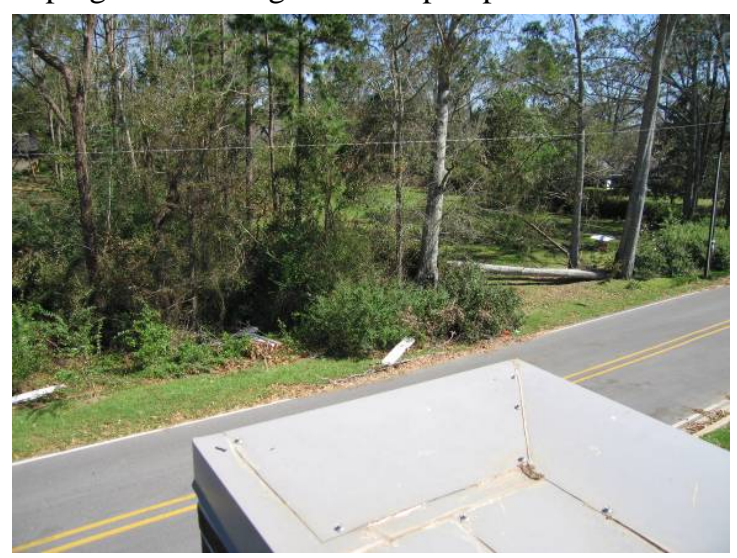

6.01-4. Community Medical Center. Note the location of windborne debris and the direction of tree fall (looking north across the road from the subject property).

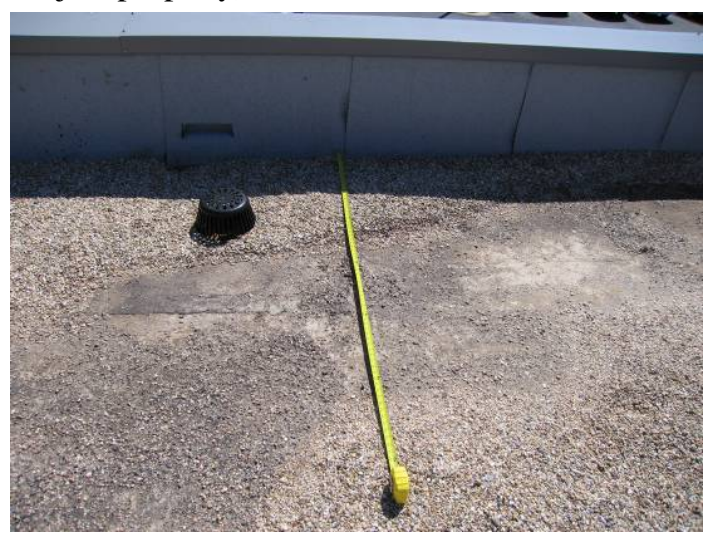

6.01-6. Community Medical Center. Evidence of wind scour damage to aggregate layer is evident. 


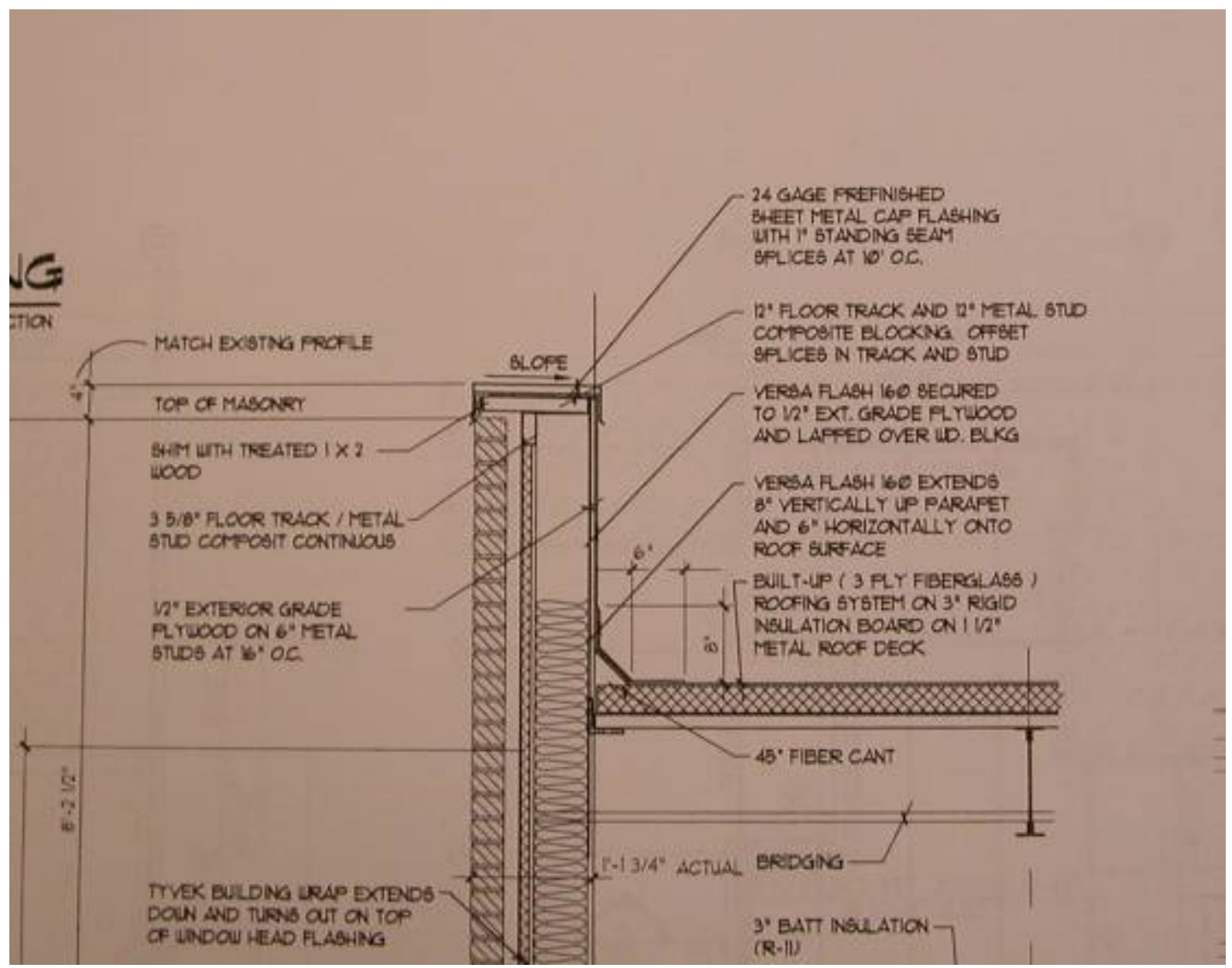

6.01-7. Community Medical Center. An architectural detail of the metal coping.

\subsection{George County Hospital, 859 Winter Street, Lucedale, MS}

TYPE OF STRUCTURE-Hospital

EXPOSURE-B

SITE COORDINATES-N30 $55^{\prime} \mathrm{W} 88^{\circ} 35^{\prime}$

WALL CONSTRUCTION—Brick façade

ROOF TYPE-Assembly construction from top down: Torch-applied modified bitumen (atactic polypropylene [APP]) over an existing BUR; dead level with ponded water.

SLOPE— $0: 12$ (dead level)

ROOF HEIGHT-14 ft

ROOF WIDTH-60 ft

ROOF LENGTH-80 ft

DECK-Monolithic concrete

WIND SPEED-90-100 mph

BUILDING CONSTRUCTION_Built in 1957; concrete block with brick veneer 
METHOD OF ATTACHMENT_-Insulation (beneath BUR) mopped to deck using hot asphalt NOTED DAMAGE-No damage to the hospital building or roof, as it was located between, and partially sheltered by, the Medical Center and the Maintenance Building. The covered walkway behind the main structure was constructed of lightweight aluminum panels and was damaged.

DAMAGE INITIATION AND PROPAGATION—Structural attachment of light purlins

ADDITIONAL COMMENTS_-Building was located on generally level, smooth terrain. Shade porticos in hurricane zones can become dangerous wind-blown missiles. Resulting debris from damaged construction components was evident in many places.

\section{Photographs of Roof Damage}

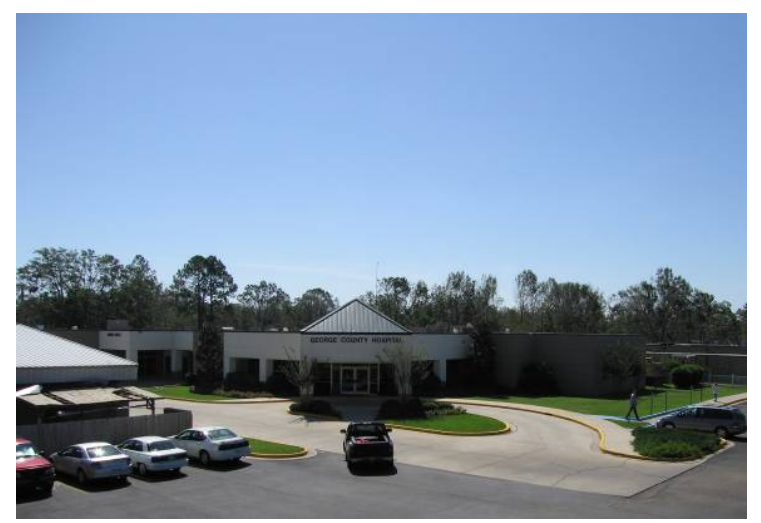

6.02-1. George County Hospital. Overview of the facility-northwest corner.

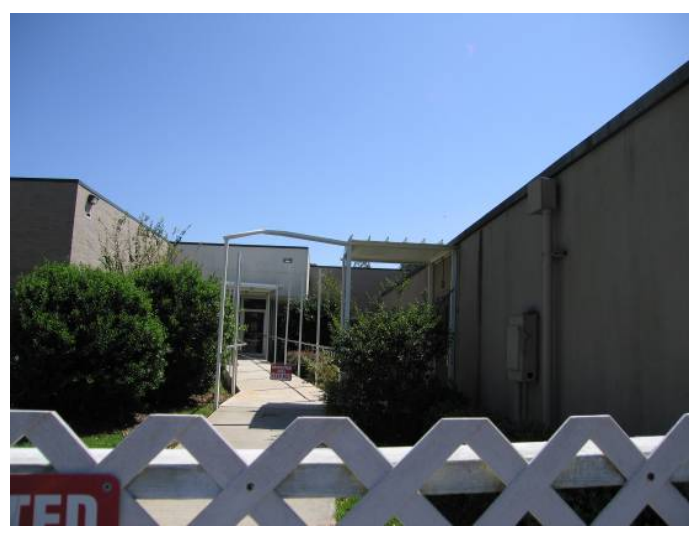

6.02-2. George County Hospital. The covered walkway structure shown is missing its roof covering.

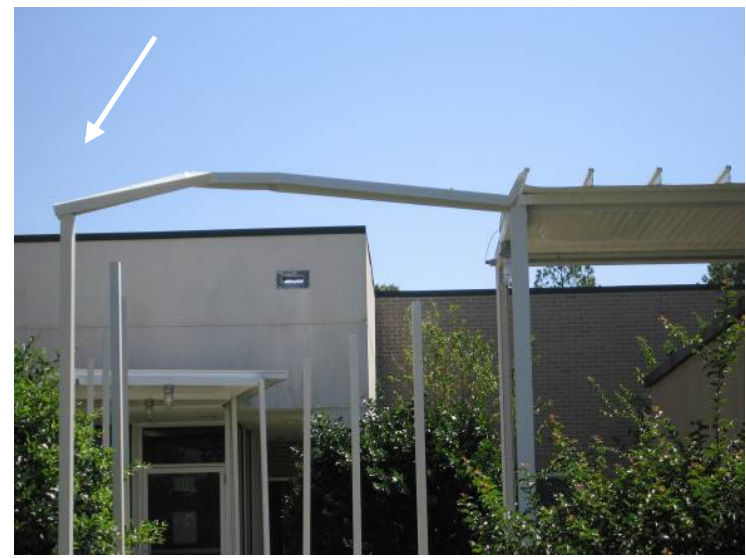

6.02-3. George County Hospital. Close-up of the covered walkway structure, showing both intact and missing roof covering sections.

\subsection{George County Hospital Maintenance Building, 859 Winter Street, Lucedale, MS}

TYPE OF STRUCTURE-Commercial

\section{EXPOSURE-B}

SITE COORDINATES-N30 $55^{\prime}$ W8 $88^{\circ} 35^{\prime}$

WALL CONSTRUCTION_Brick veneer concrete block structure 
ROOF TYPE—-(Assembly construction from top down): Modified bitumen assembly (APP) torchapplied (retrofitted) over original hot-mopped BUR (no core tests taken; information supplied by maintenance personnel).

SLOPE-2-3: 12

ROOF HEIGHT-14 ft

ROOF WIDTH-30 ft

ROOF LENGTH-50 ft

DECK-Monolithic concrete

WIND SPEED-90-100 mph

BUILDING CONSTRUCTION—Concrete masonry unit (CMU) walls with brick veneer; appears to be relatively old construction.

METHOD OF ATTACHMENT—Roof assembly: Original was hot-mopped; re-roof is torch-applied APP.

NOTED DAMAGE—-Metal coping and wall flashing at the southeast corner; loose membrane in the field of the roof.

DAMAGE INITIATION AND PROPAGATION-Air infiltration at the wall/deck juncture caused wall flashing to pressurize, followed by blowoff of some of those components. This infiltration appears to have been exacerbated by a poor bond of APP flashing membrane to parapet.

ADDITIONAL COMMENTS - The torch-grade granulated flashing membrane was loose-laid on the wall and tacked in place $4 \mathrm{ft}$ o.c. with a $4 \times 4$ in. aluminum plate and two 1 in. concrete screws. This construction method is inadequate for a hurricane zone.

\section{Photographs of Roof Damage}

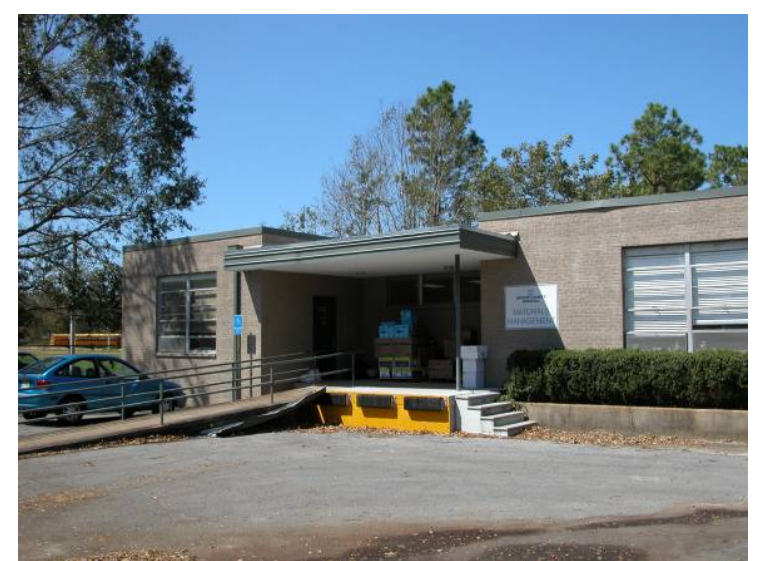

6.03-1. George County Hospital Maintenance Building. View of the front elevation. Note beginning of coping failure to the right of the canopy.

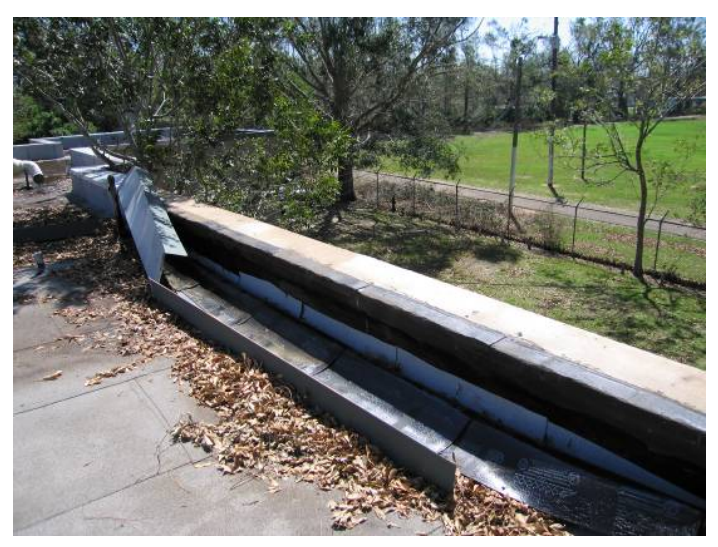

6.03-2. George County Hospital Maintenance Building. Photo shows coping and flashing attachment failure along this section of parapet. 


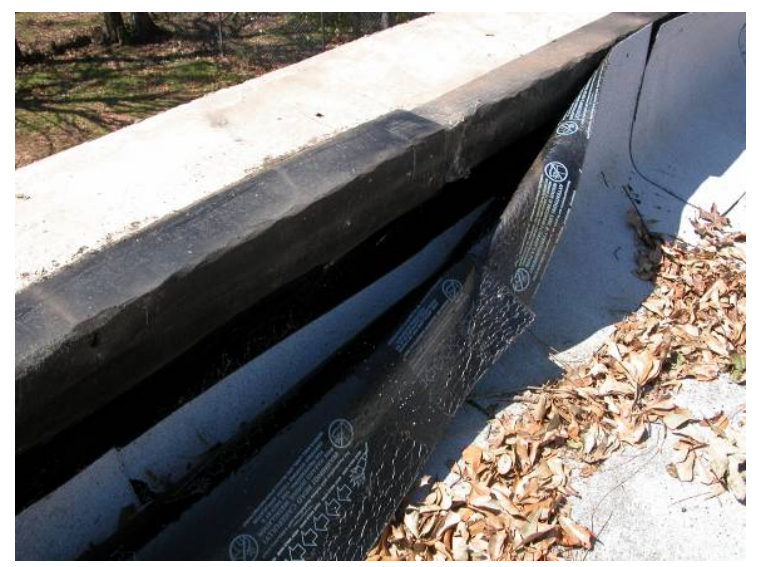

6.03-3. George County Hospital Maintenance

Building. Adhesive failure of the flashing membrane to the parapet is visible.

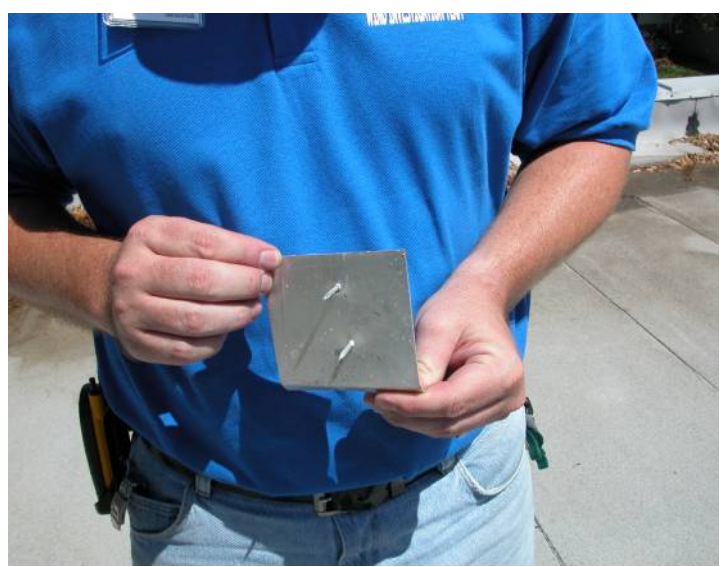

6.03-4. George County Hospital Maintenance Building. Pull-out failure was seen in clips such as this one that were used to attach flashing to brick. Flashing was modified bitumen membrane to the concrete cap. This .032 aluminum clip was also used as the catch cleat, $4 \mathrm{ft}$ o.c., for the aluminum coping cap that blew off.

\subsection{4(a) Stone Elementary School—Roof A, 1652 East Central Avenue, Wiggins, MS}

TYPE OF STRUCTURE-School classrooms (Roof A)

EXPOSURE-B

\section{SITE COORDINATES-N30 $50^{\prime}$ W89 $06^{\prime}$}

WALL CONSTRUCTION_Concrete block with brick veneer; end walls and some non-classroom walls were brick; most classroom walls were glass windows from floor to ceiling.

ROOF TYPE-The lower one story classroom roof wings from the deck up: Classroom wings were re-roofed. Existing roof had been completely torn off down to the Tectum deck; a base sheet was fastened with simplex expansion fasteners. Taper ISO insulation was hot-mopped to the base sheet and $1 / 2$ in. perlite cover board was hot-mopped to the ISO. A 2-ply modified bitumen (styrene butadiene styrene [SBS]) was hot-mopped to the perlite insulation.

SLOPE- $-1 / 4: 12$

ROOF HEIGHT- $15 \mathrm{ft}$

ROOF WIDTH-50 ft

ROOF LENGTH-200 ft

DECK - Cementitious wood fiber (CWF) Tectum in bulb Ts

WIND SPEED-110-120 mph

BUILDING CONSTRUCTION—Concrete block with brick veneer

METHOD OF ATTACHMENT - 30 \# base sheet fastened to CWF deck using simplex expansion fasteners. CWF panels were only cement-grouted into steel framing and had no mechanical attachment. Perimeter fascia board $(3 / 4 \times 6$ in.) was screwed to exterior "L" channel 24 in. o.c., horizontally installed providing a 6 in. vertical face. Roof membrane perimeter nailer $3 / 4 \times 4 \mathrm{in}$. was horizontally nailed into the $3 / 4$ in. thick vertical fascia board with 4 in. box nails sporadically spaced 14 to 24 in. 
NOTED DAMAGE-Lower classroom section of Roof A [photos 6.04(a)-1 thru 6.04(a)-4]; southeast rear section; southwest middle section.

DAMAGE INITIATION AND PROPAGATION—CWF deck panels in the classroom roof section A [photos 6.04(a)-1 thru 6.04(a)-4] with membrane attached blew completely over the width of the roof and landed upside down in front of the building. The membrane was separated from the perlite as a result of a combination of strong uplift forces and cohesive failure of this inherently weak insulation material. The separated membrane peeled away and was expelled into the front yard. Observation: 2-ply SBS membrane delaminated from the perlite cover board interior roof; perimeter edge base sheet insulation and modified membrane blew off $18 \mathrm{ft}$ back from the perimeter.

Another explanation for the failure is that the membrane peel-back occurred from air infiltration through the CWF deck that caused delamination of the modified bitumen waterproofing membrane from the perlite insulation board. This delamination continued to spread back from the perimeter edge until three-quarters of the roof was affected, making a huge balloon. This balloon membrane pulled the perimeter CWF decking and fascia metal loose from the rear L-channel perimeter edge. The detached area quickly inflated and folded back onto itself before landing in the front of the school. The displaced decking remained attached to the membrane except where it was sheared off from its impact with the front edge of the building. Had the decking been properly secured, the rear perimeter membrane might have just folded over to the interior roof section with relatively minor edge damage, rather than major failure.

The southwest middle section suffered some detachment of membrane from the perlite insulation board, resulting in peel-back, but the membrane folded back onto the roof deck itself, as compared with the deck failure mentioned above. Where the perimeter edge metal and CWF decking fell back onto the roof, it damaged the decking.

ADDITIONAL COMMENTS-The building was located on generally smooth and level terrain. The perimeter edge did not have a secure perimeter termination nailer for the membrane and the gravel stop edge. Lower classroom structural attachment of CWF panels at the perimeter eave overhang was deficient.

In repairing the system, the CWF should be attached more securely, and provision should be made to limit air infiltration that causes pressurization under the SBS finished roof membrane.

Recommended repairs to the lower classroom roof would start with removal of all remaining roofing assembly down to the CWF decking and then properly securing all CWF deck panels.

Hot-mopping or slow-rise adhesive foam application of a membrane to the Tectum deck to stop air infiltration will mitigate future wind uplift damage to the roof assembly; then a new roof could be installed. 


\section{Photographs of Roof Damage}

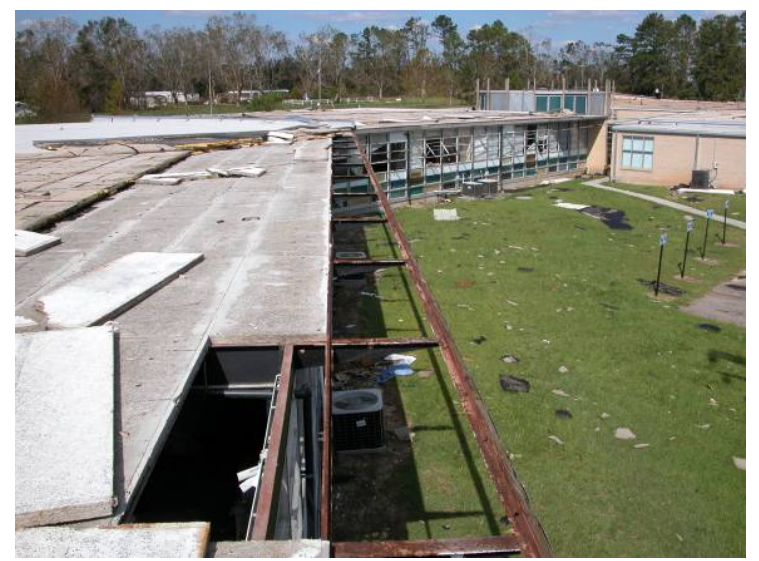

6.04 (a)-1. Stone Elementary School roof A. Southwest corner damage is visible, including missing deck panels. (Note: the gymnasium is located to the right, just out of this photo.)

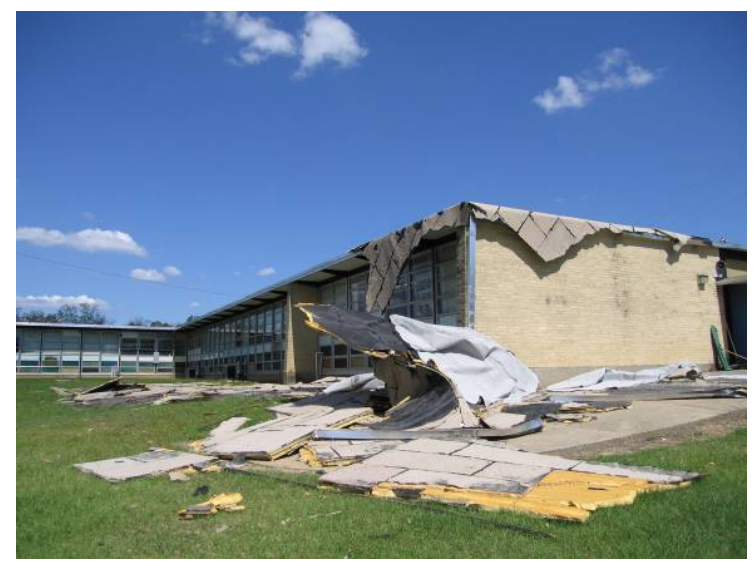

6.04 (a)-3. Stone Elementary School roof A. Roof membrane and decking material in this photo are draped over the roof edge, and lying on the ground.

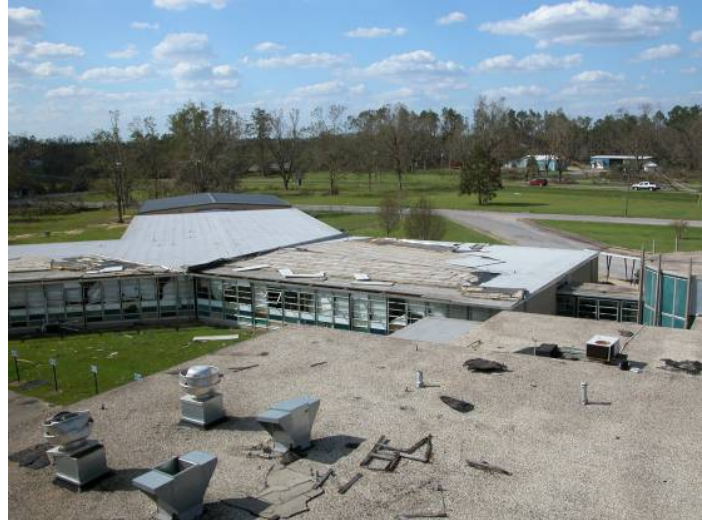

6.04 (a)-2. Stone Elementary School roof A. Southwest corner damage is shown from a different angle. Note the damaged HVAC units on the roof of the gymnasium (foreground).

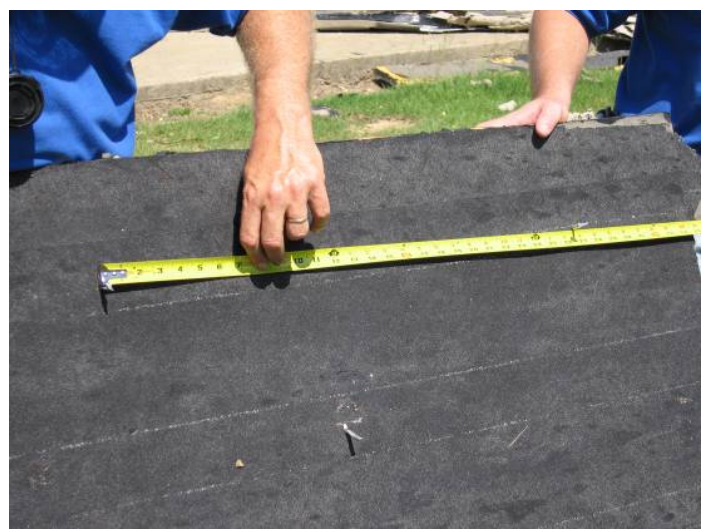

6.04 (a)-4. Stone Elementary School roof A. Fasteners pulled out of Tectum.

\subsection{4(b) Stone Elementary School Gymnasium-Roof B, 1652 East Central Avenue, Wiggins, MS}

TYPE OF STRUCTURE—School gymnasium (Roof B)

EXPOSURE-B (open ball fields and parking lots facing southeast corner damage section)

SITE COORDINATES-N30 $50^{\prime} \mathrm{W}^{\circ} 9^{\circ} 06^{\prime}$

WALL CONSTRUCTION-Concrete block with brick veneer

ROOF TYPE-Assembly of first roof: Constructed of red rosin paper \#30 base sheet cap nailed with spreading anchors-two rows 24 in. o.c.; first ply around $3 \mathrm{ft}$ perimeter; 4-ply \#15 finishing felts on base sheet. Pea stone gravel installed in a flood coat of asphalt. 
Assembly of second re-roof over first: Swept loose gravel, 3/4 in. perlite loose-laid over existing gravel ballast, and a 4-ply \#15 finishing felt hot-mopped to perlite finished with a flood coat of asphalt and pea stone gravel.

SLOPE-1/8: 12

ROOF HEIGHT-Approximately $35 \mathrm{ft}$

ROOF WIDTH-60 ft

ROOF LENGTH-80 ft

DECK-CWF, Tectum

WIND SPEED-110-120 mph

BUILDING CONSTRUCTION—Steel truss

METHOD OF ATTACHMENT-Not identified; some cap nailing of original roof noted $3 \mathrm{ft}$ in on the perimeter only; no mechanical attachment in the field; spread anchors through metal cap.

NOTED DAMAGE - Southeast corner and east side $(25 \times 60 \mathrm{ft}$ area $)$

The upper gymnasium roof ( $35 \mathrm{ft}$ high) was damaged at the southeast corner. Along the south and east overhangs, CWF panels (and attached roof membrane and insulation) were pulled out of the bulb Ts structural framework, folding the entire assembly back onto the roof edge. Unlike the lower sections, the upper gymnasium roof folded back onto itself a short distance from the perimeter edge.

DAMAGE INITIATION AND PROPAGATION-Perimeter overhang of CWF decking blew back with two roof assemblies. On top, there was no hot-mopping of the top roof's insulation boards to the underlying gravel surface; i.e., the second roof was loose-laid, making it more prone to blowoff.

ADDITIONAL COMMENTS—See Roof A.

\section{Photographs of Roof Damage}

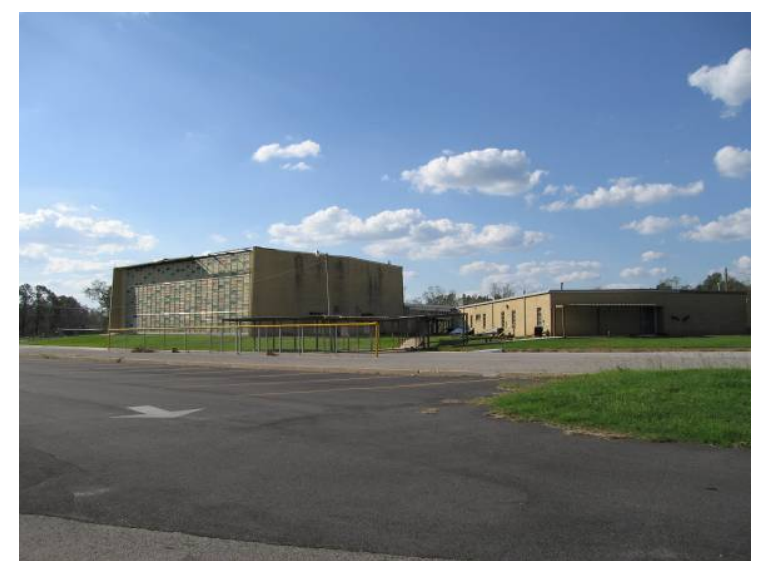

6.04 (b)-1. Stone Elementary School Gymnasium roof $\mathbf{B}$. The view from southeast to northwest.

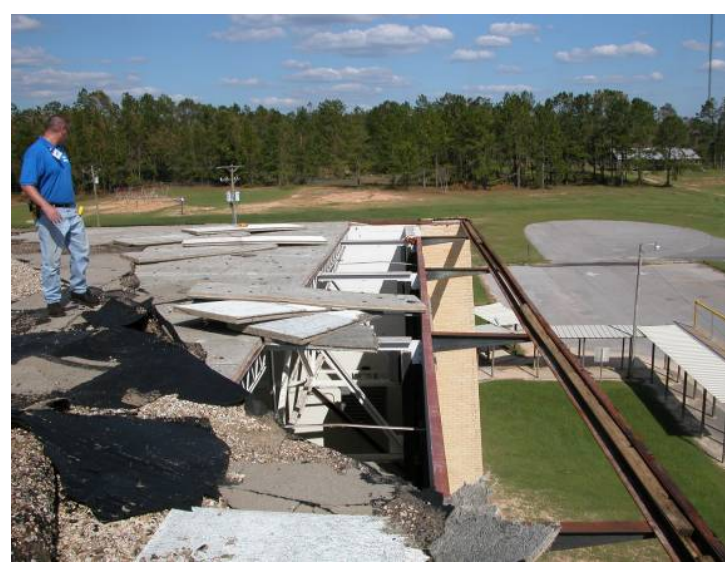

6.04 (b)-2. Stone Elementary School Gymnasium roof B. Southeast corner damage, including missing deck panels, is shown.

\subsection{Lumberton School, 7922 Highway 11, Lumberton, MS}

TYPE OF STRUCTURE—Single story school building — rear cafeteria

EXPOSURE-B (open ball fields) 
SITE COORDINATES-N30 59' W89 27'

WALL CONSTRUCTION-Brick veneer

ROOF TYPE-Assembly construction from top down: White coating and fabric over 4-ply hotmopped BUR to concrete deck.

SLOPE—0 : 12—dead level

ROOF HEIGHT- $12 \mathrm{ft}$

ROOF WIDTH-60 ft

ROOF LENGTH-180 ft

DECK - Poured-in-place, monolithic concrete deck with no open joints for internal air permeation WIND SPEED-110-120 mph

BUILDING CONSTRUCTION-Concrete block with brick veneer, poured-in-place concrete deck; original roof is 4-ply \#15 finishing felts hot-mopped to unprimed concrete deck.

METHOD OF ATTACHMENT_BUR hot-mopped directly to concrete deck

NOTED DAMAGE-Approximately $25 \%$ of the roof membrane was damaged.

DAMAGE INITIATION AND PROPAGATION-It appears that the BUR on the south half of the building separated from the substrate, starting at the southeast edge, then peeled back. The separation was likely due to poor adhesion of the BUR to concrete.

ADDITIONAL COMMENTS - The concrete deck surface had no evidence of concrete primer, and less than $10 \%$ of asphalt remained adhered to the concrete. Primer is normally used to ensure good adhesion.

\section{PhOtographs of RoOF DAMAge}

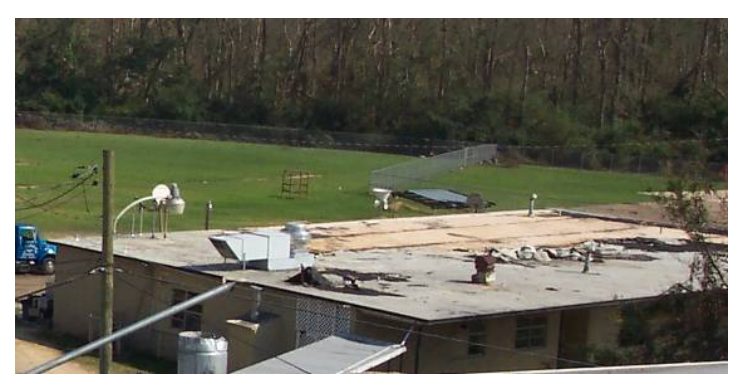

6.05-1. Lumberton School. Looking down from the administration building, large areas of roofing are missing below.

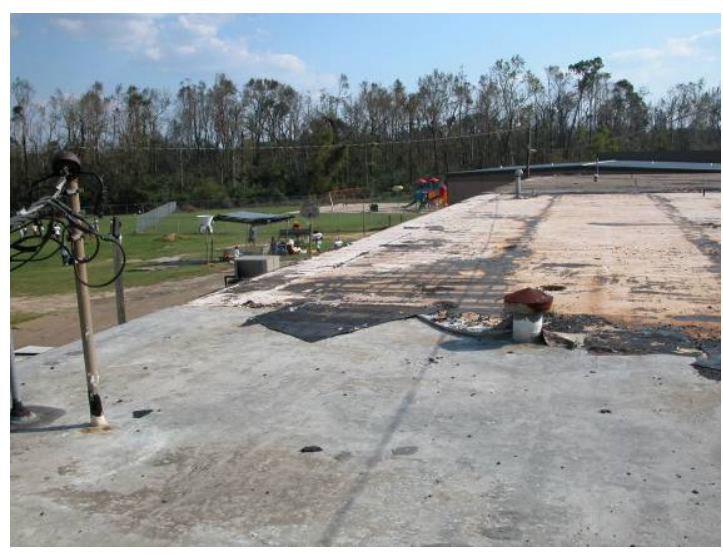

6.05-2. Lumberton School. A closer look at the roof (north to south). 


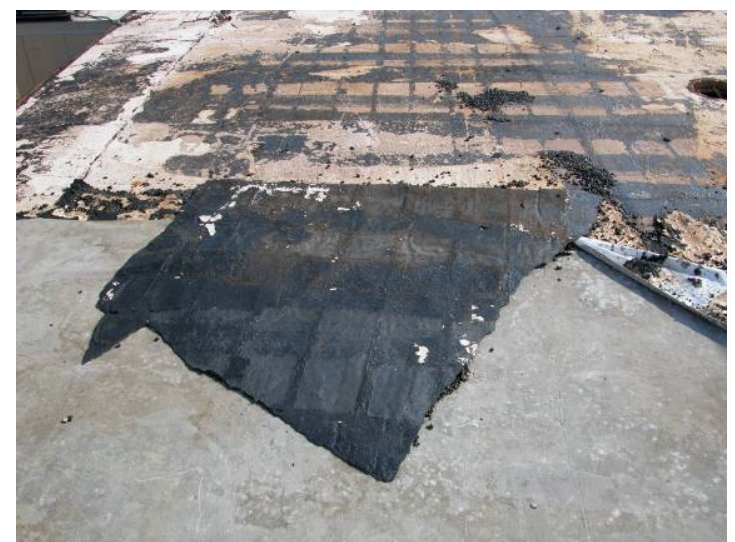

6.05-3. Lumberton School. View of the BUR peeled back from the decking.

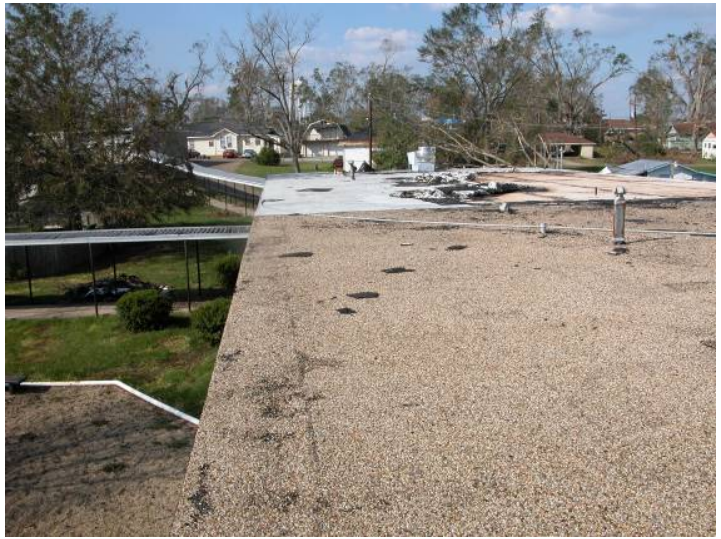

6.05-5. Lumberton School. A south to north view shows some relatively unscathed gravel-surface BUR.

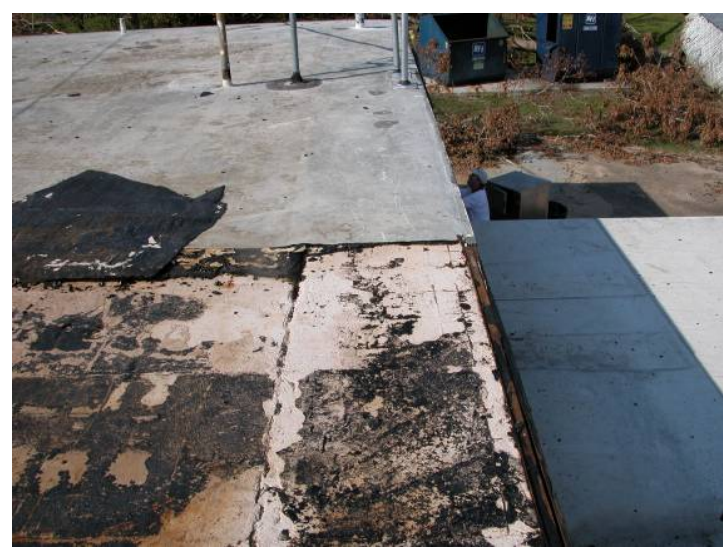

6.05-4. Lumberton School. Close-up view of the roof edge.

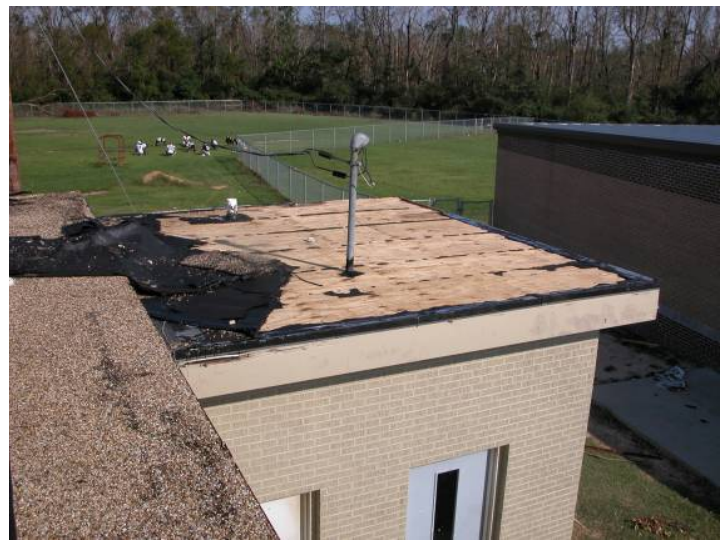

6.05-6. Lumberton School. This entrance roof was blown off.

\subsection{Lumberton Public School Administration Building, $10710^{\text {th }}$ Avenue, Lumberton, MS}

TYPE OF STRUCTURE—Single story school building converted to offices (with walk-out basement on south side)

EXPOSURE—B (Note: South face of building constructed on a $30 \mathrm{ft}$ embankment with open, grassy terrain.)

SITE COORDINATES-N30 $59^{\prime}$ W89 $27^{\prime}$

WALL CONSTRUCTION-Stucco probably on concrete block

ROOF TYPE-Assembly from the top down: Mineral-surface modified bitumen (SBS) membrane hot-mopped to tapered polyisocyanurate insulation boards, installed over a 30 \# base sheet.

SLOPE— $1 / 4: 12$

ROOF HEIGHT-20 ft; building height is $18 \mathrm{ft}$ on south and east elevations and $12 \mathrm{ft}$ on north and west elevations.

ROOF WIDTH-60 ft

ROOF LENGTH-150 ft

DECK-Dimensional lumber (wood plank) deck, probably $1 \times 10$ in.; deck is not tongue and groove but open joints, i.e., very air-permeable. 
WIND SPEED-110-120 mph

BUILDING CONSTRUCTION—Wood frame and masonry stucco

METHOD OF ATTACHMENT—Base sheet was mechanically fastened to the deck.

NOTED DAMAGE-Approximately two-thirds of the roof membrane was blown off the roof. About one-third of the tapered roof insulation was blown off. No deck damage was noted. There was significant interior water damage.

DAMAGE INITIATION AND PROPAGATION_-Initial failure appears to have occurred at the south roof edge where approximately $25 \mathrm{ft}$ of gutter and edge nailer separated from the structure. A vented $3 \mathrm{ft}$ deep soffit may have contributed to the damage by pressurizing the space between deck and roof assembly. However, the roof assembly may have been pressurized by failure of the south roof edge.

ADDITIONAL COMMENTS - The building had large windows on all sides, but none appeared to be breached during the storm. Cap-nailing of the 30 \# base sheet to an air-permeable wood deck would seem to make the base sheet attachment the weak link in the roof assembly.

\section{Photographs of Roof Damage}

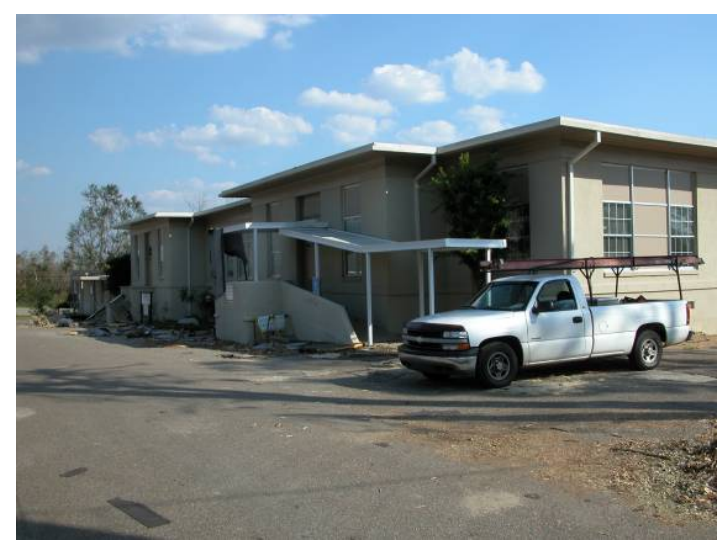

6.06-1. Lumberton School Administration

Building. This is the north elevation.

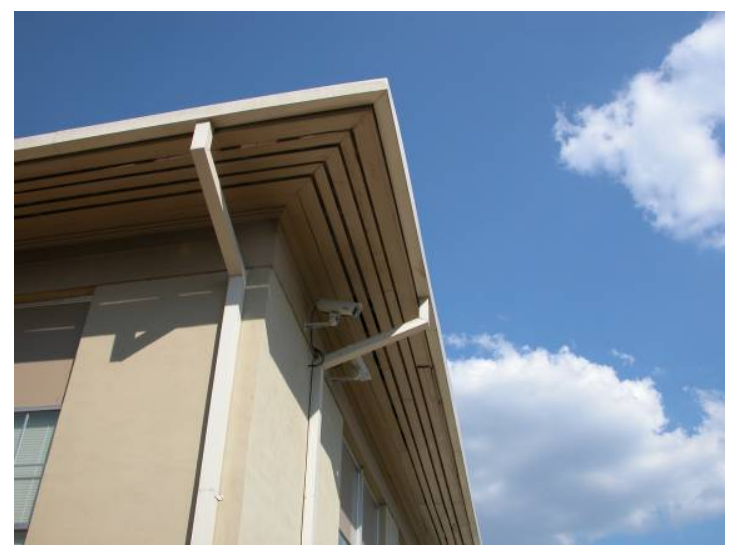

6.06-3. Lumberton School Administration Building. View of the soffits.

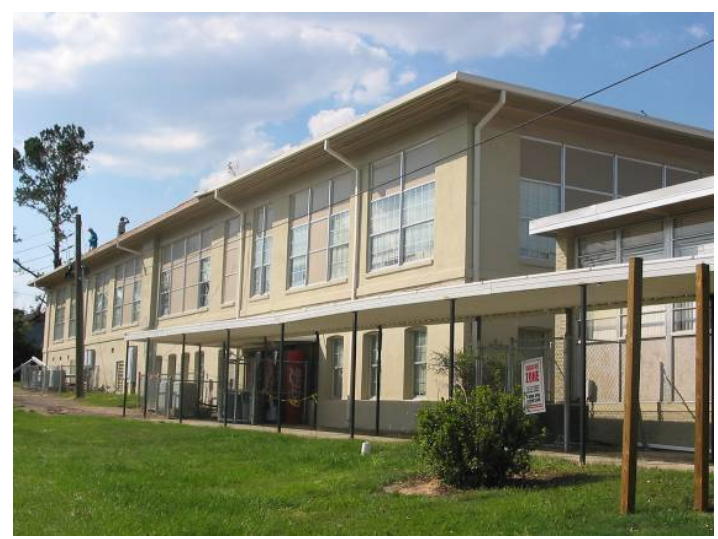

6.06-2. Lumberton School Administration

Building. The south elevation has more windows and soffit exposure.

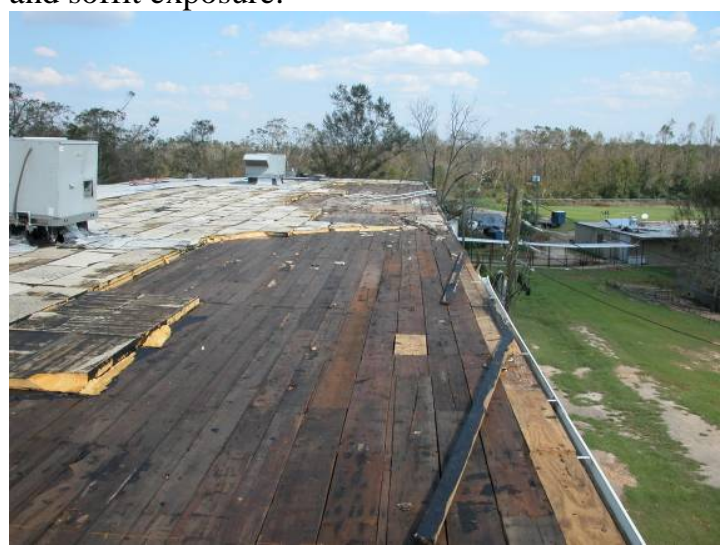

6.06-4. Lumberton School Administration

Building. Looking west to east, considerable roof damage is visible. 


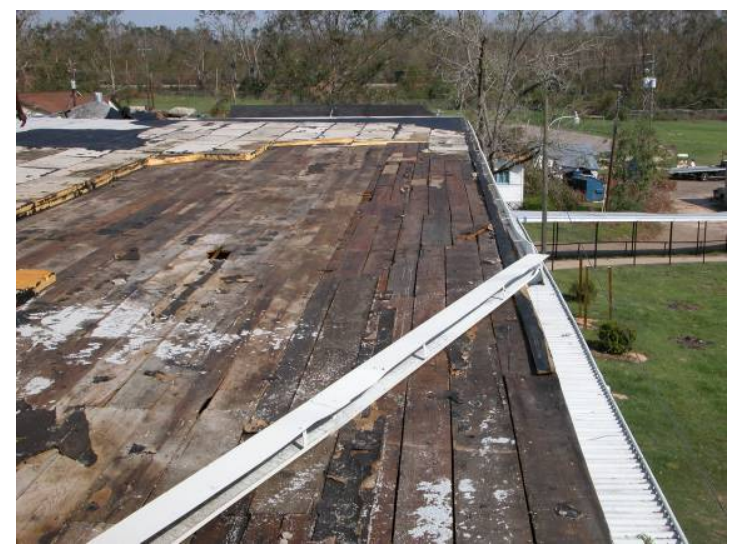

6.06-5. Lumberton School Administration

Building. South side roof edge failure is visible.

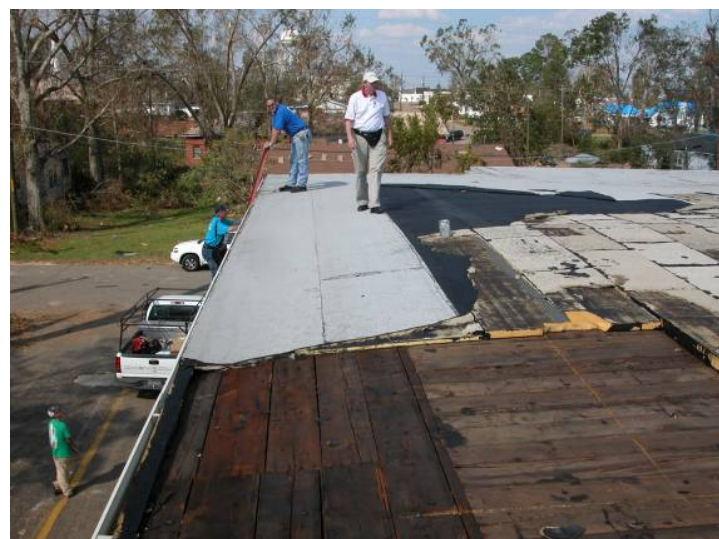

6.06-6. Lumberton School Administration

Building. Looking north across the roof shows some roof assembly that remained in place.

\subsection{Residence 5227 Lincoln Ext., Hattiesburg, MS}

TYPE OF STRUCTURE-One story single-family home with gable end roof shape

EXPOSURE-C

SITE COORDINATES-N30 $19^{\prime}$ W89 $24^{\prime}$

WALL CONSTRUCTION-Brick veneer and vinyl siding (probably on wood frame)

ROOF TYPE—Assembly from the top down: Dimensional asphalt shingle

SLOPE-6 : 12

ROOF HEIGHT $-8 \mathrm{ft}$ at eaves and $221 / 2 \mathrm{ft}$ at roof ridge

ROOF WIDTH-33 ft

ROOF LENGTH-82 ft

DECK-Plywood

WIND SPEED-110-120 mph

BUILDING CONSTRUCTION_-Building was built in 2001; wood frame, plywood deck with 16 in. o.c. joists.

METHOD OF ATTACHMENT_Four nails per shingle

NOTED DAMAGE-There was minor shingle loss on the east face of the garage roof. Temporary repairs had been performed. There was some minor vinyl siding damage on the north gable end of the garage.

DAMAGE INITIATION AND PROPAGATION—Some of the asphalt shingles that blew off appeared to have been inadequately fastened, with only two or three nails per shingle in some cases. This does not allow the seal strip to function adequately to resist the wind loads.

ADDITIONAL COMMENTS-Based on downed trees, it appears the strongest winds came out of the east. While the property sits on the edge of a large wooded area to the south, the house is in a generally open exposure. 


\section{PhOtographS OF RoOF DAMAge}

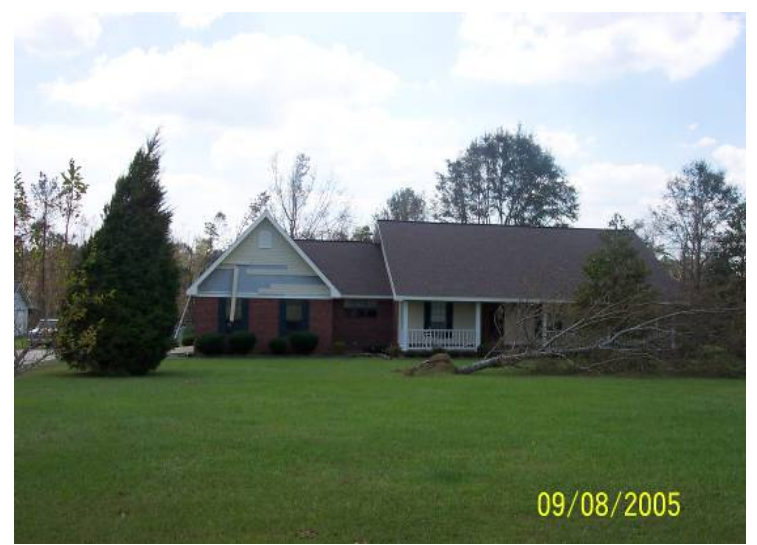

6.07-1. Residence. The north elevation.

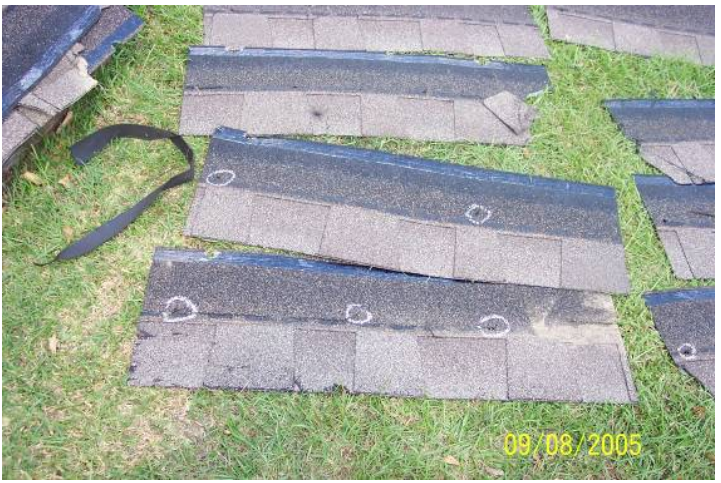

6.07-3. Residence. Encircled spots show where shingles pulled free of nails and the lack of nails.

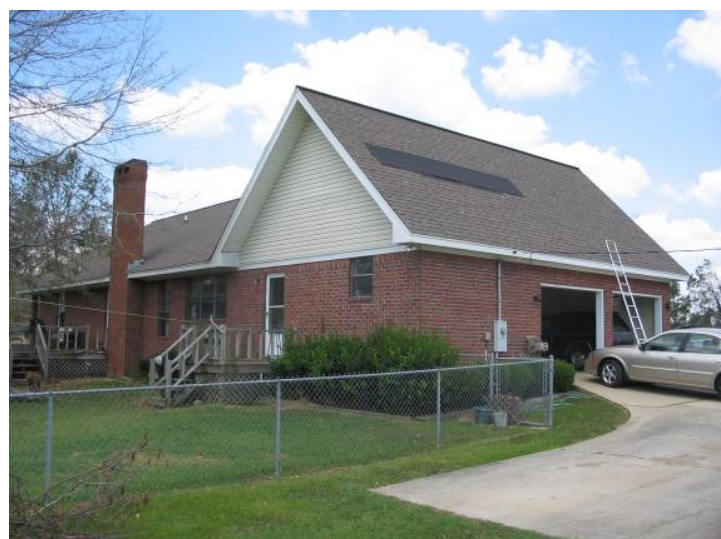

6.07-2. Residence. The east elevation of the garage.

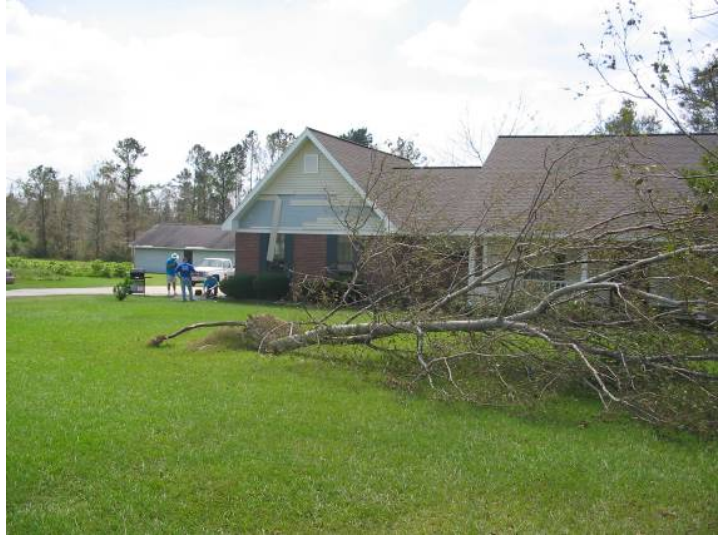

6.07-4. Residence. A downed tree shows the hurricane wind direction.

\subsection{Perry County High School Annex, Highway 98, New Augusta, MS}

TYPE OF STRUCTURE-School

EXPOSURE-B

SITE COORDINATES-N31 $12^{\prime} \mathrm{W} 88^{\circ} 60^{\prime}$

WALL CONSTRUCTION-Brick

ROOF TYPE-Assembly from the top down: Mineral-surface cap sheet (unknown whether it was modified bitumen or simply 90 \# roll roofing) hot-mopped over a BUR over insulation boards on a metal deck.

SLOPE- $-1 / 4: 12$

ROOF HEIGHT- $13 \mathrm{ft}$

ROOF WIDTH-30 ft

ROOF LENGTH-150 ft

DECK-22-gauge steel panel

WIND SPEED-110-120 mph 


\section{BUILDING CONSTRUCTION—CMU and brick veneer}

METHOD OF ATTACHMENT - Insulation mechanically fastened to deck; BUR hot-mopped to insulation.

NOTED DAMAGE-Roof membrane blowoff on east section of the main campus building. Repair work had already begun. Damage area was less than $10 \%$ of the total roof area on the main building. There was also interior water damage.

DAMAGE INITIATION AND PROPAGATION—Damage began at the northeast corner gravel stop, which was not anchored to a cleat. Edge metal pulled free of the nailer and peeled back the BUR and cap sheet membrane in a $20 \times 30 \mathrm{ft}$ area.

ADDITIONAL COMMENTS-None

\section{Photographs of Roof Damage}

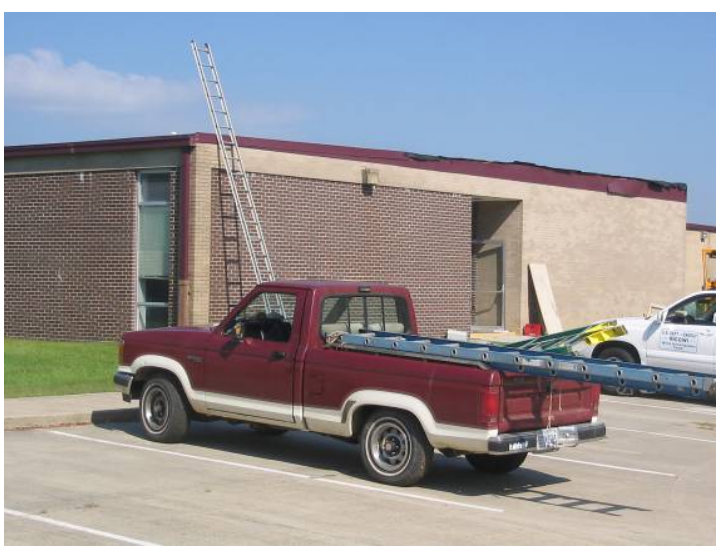

6.08-1. Perry County High School.

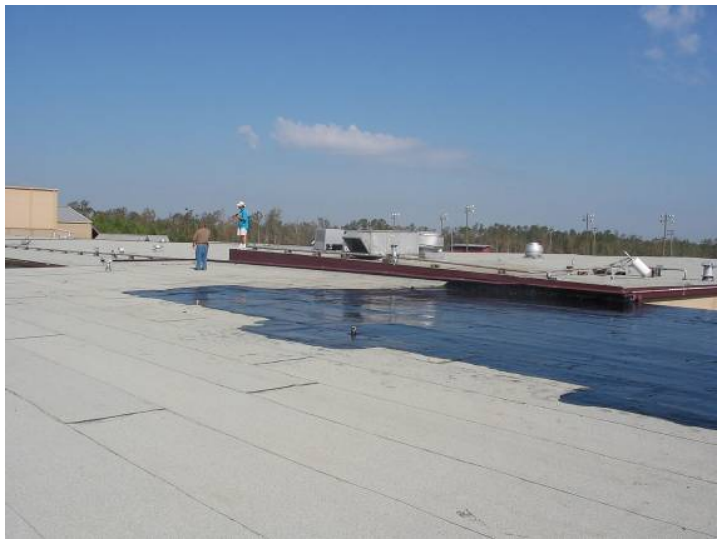

6.08-3. Perry County High School. This is a southeast to northwest view.

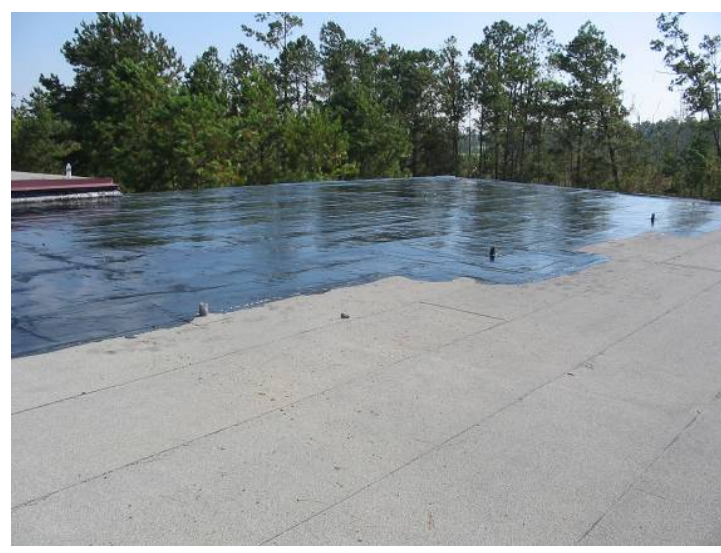

6.08-2. Perry County High School. This is a southwest to northeast view of damaged roofing. The mineral-surface cap sheet (foreground) appeared relatively undamaged.

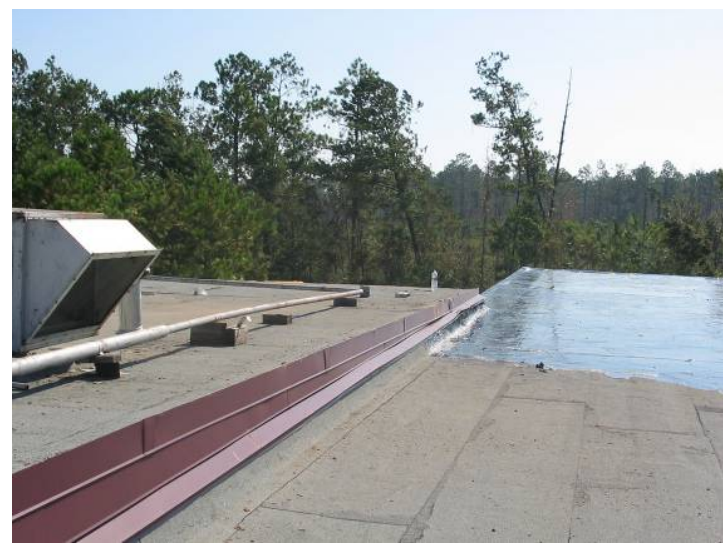

6.08-4. Perry County High School. Looking east. 


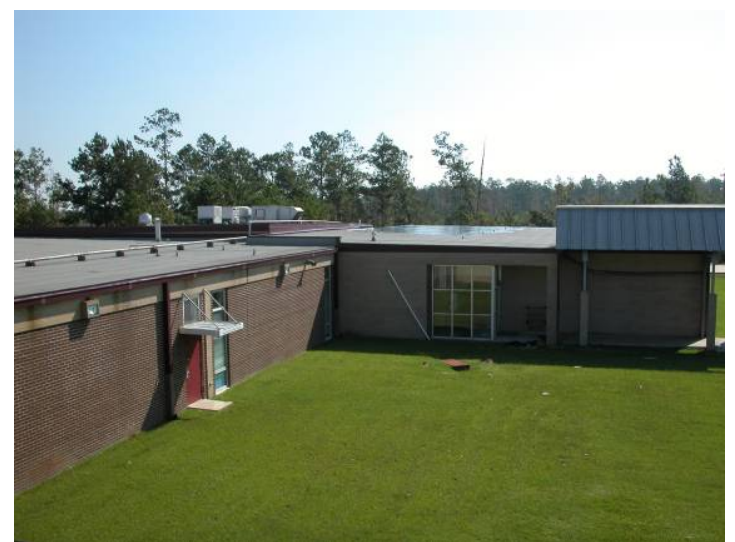

6.08-5. Perry County High School.

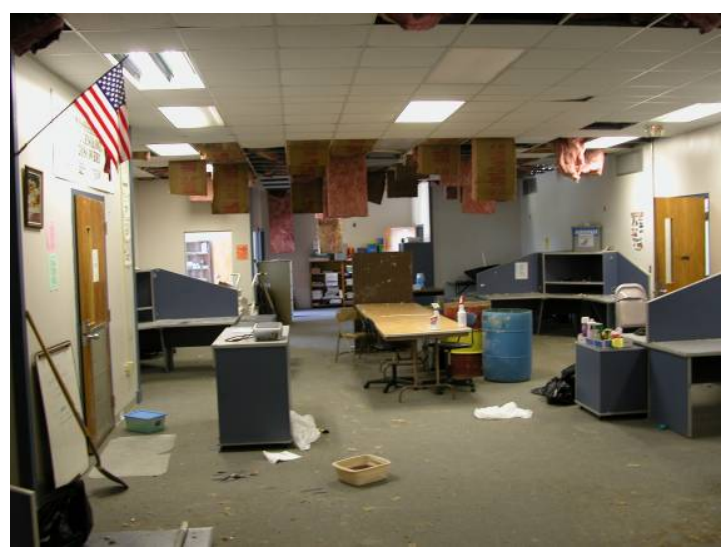

6.08-6. Perry County High School. Interior water damage is visible.

\subsection{Residence, 41 Corner Oaks Drive, Hattiesburg, MS}

TYPE OF STRUCTURE—Single-family home

EXPOSURE-B

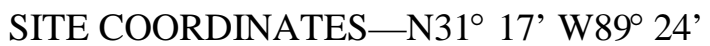

WALL CONSTRUCTION-Brick veneer on wood frame

ROOF TYPE-Assembly from the top down: Asphalt shingle, 3-tab

SLOPE-Approximately $6: 12$

ROOF HEIGHT_Eave height $8 \mathrm{ft}$; ridge height $20 \mathrm{ft}$

ROOF WIDTH $-50 \mathrm{ft}$

ROOF LENGTH-68 ft

DECK-Plywood

WIND SPEED—110-120 mph

BUILDING CONSTRUCTION—One story single-family home with hip roof design

METHOD OF ATTACHMENT_-Roofing nails

NOTED DAMAGE-Shingle damage was limited to between 10 and $25 \%$ of the total roof area. No other damage was noted, other than possible screen damage at the rear patio.

DAMAGE INITIATION AND PROPAGATION-Missing nails resulted in excess stress on shingle seal strips. This is an example of the typical failure due to the racking method of installation that often limits the shingles to three nails. The shingles are installed in a pattern that starts at the bottom of the slope and goes to the top of the roof in a vertical line, instead of the diagonal stair-stepped pattern recommended by manufacturers.

ADDITIONAL COMMENTS - Based on observations of downed trees near the home, it appears that the strongest winds came from the east. Wind direction likely determined which shingles failed. 


\section{Photographs of RoOF Damage}

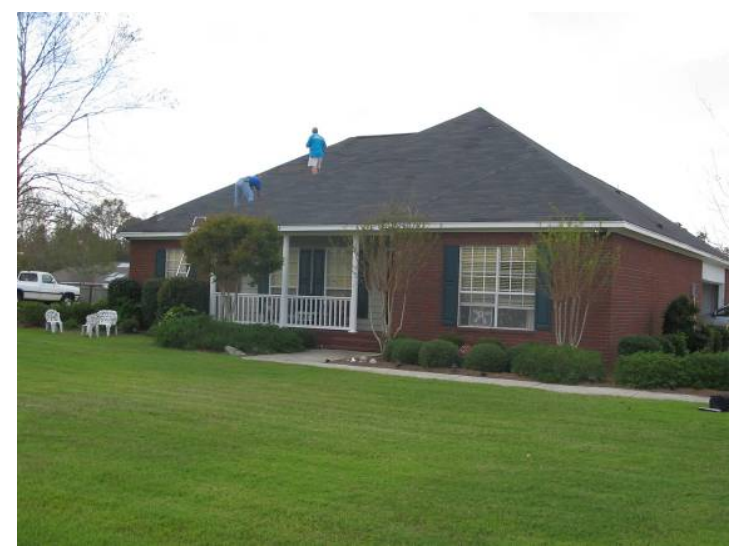

6.09-1. Residence. A west-facing view.

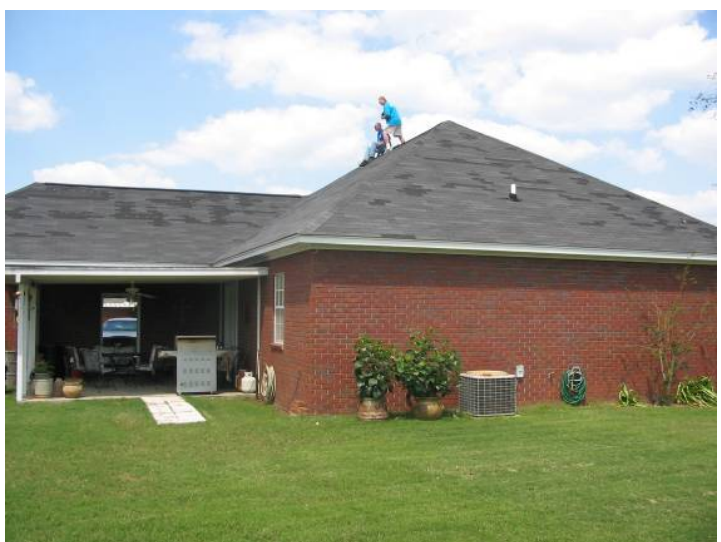

6.09-3. Residence. A north-facing view.

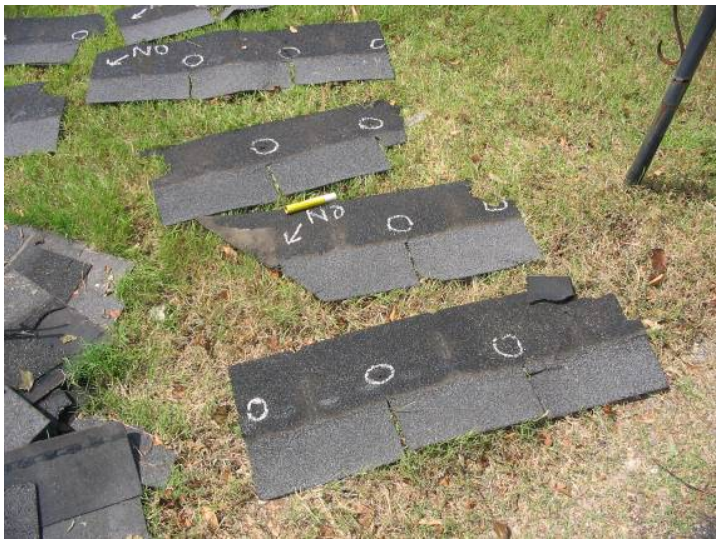

6.09-5. Residence. Missing nails and nail pullthrough anomalies are marked with chalk.

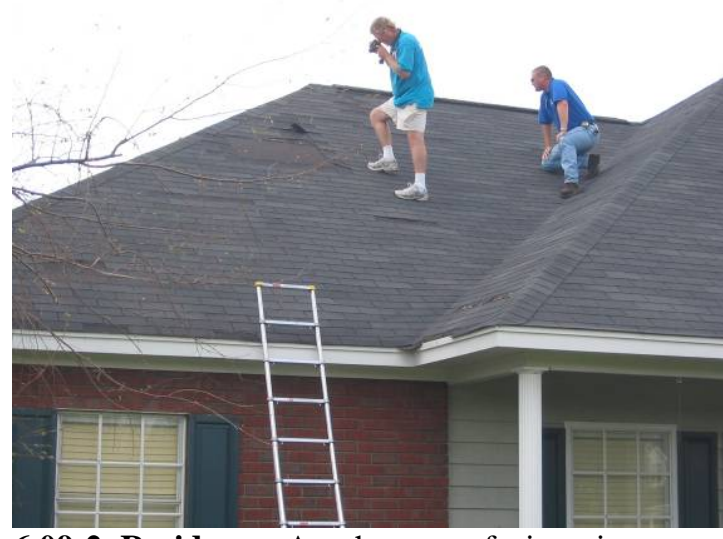

6.09-2. Residence. Another west-facing view shows team members performing close examination of damaged shingles.

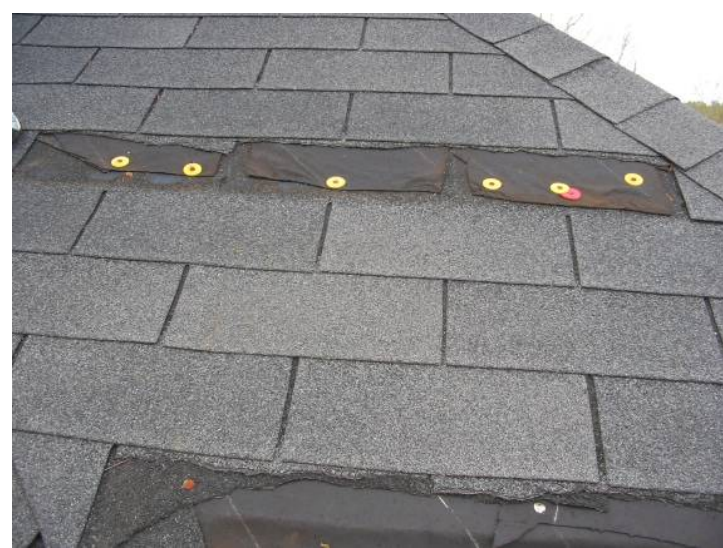

6.09-4. Residence. Ripped shingle tabs have been temporarily repaired in this photo.

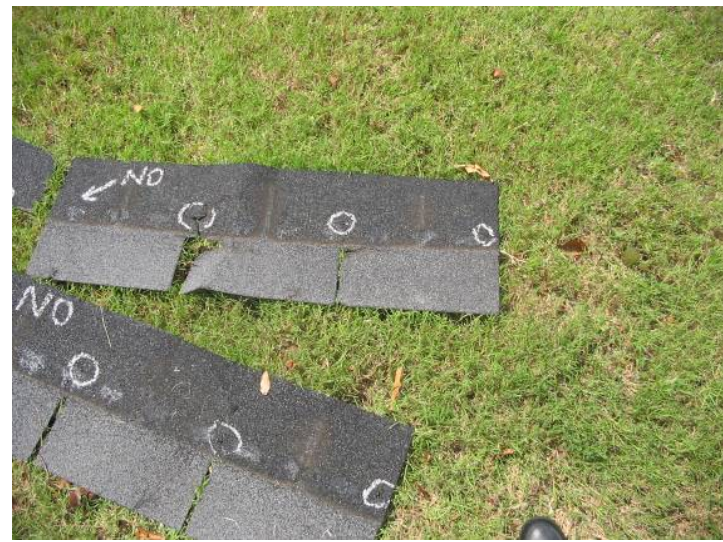

6.09-6. Residence. Missing nails and nail pullthrough spots help determine cause of failure. 


\subsection{New Welcome Hill Baptist Church, 709 East Central Avenue, Wiggins, MS}

TYPE OF STRUCTURE—Church: main building and annex

EXPOSURE-B

SITE COORDINATES-N30 $51^{\prime}$ W89 $07^{\circ}$

WALL CONSTRUCTION-Brick

ROOF TYPE $-4 \mathrm{ft}$ wide ribbed metal panel system, retrofitted over asphalt shingles

SLOPE- $4: 12$

ROOF HEIGHT-17-22 ft (building is on a hill)

ROOF WIDTH-50 ft

ROOF LENGTH-42 ft

DECK $-1 / 2$ in. plywood on wood joists

WIND SPEED-110-120 mph

BUILDING CONSTRUCTION—One story brick

METHOD OF ATTACHMENT - The metal roofing was screwed to wood nailers. Nailers were $4 \mathrm{ft}$ apart and ran the length of the building. Additional boards (assumed to be stiffeners, for foot traffic protection) were centered between nailers and were not attached to the metal roof covering. Nailers and stiffeners were nailed to the roof deck through the shingles.

NOTED DAMAGE-Main church roof had no damage. Church annex roof was a total loss. The metal roofing was completely uplifted on the windward (south) side, and many panels were missing on the leeward side. Some older shingles (underlying roof covering) were uplifted, primarily on the windward side.

DAMAGE INITIATION AND PROPAGATION—Loss of aluminum wrap over the windward eave fascia suggests that wind may have infiltrated from below. This likely caused a progressive lifting of roof panels from eave to ridge, and then from ridge to eave on the leeward side.

ADDITIONAL COMMENTS-The investigated roof was on an annex connected to a church.

Failure appears to have been inadequate fastening of nailers to the deck. Loss of nailers was due to the combination of insufficient fasteners and their low pull-out resistance. Nailers were attached to the deck only with pairs of nails at $4 \mathrm{ft}$ intervals. Since the metal roof panels were only connected to nailers $4 \mathrm{ft}$ o.c. vertically, each pair of nails had to resist uplift forces developed over approximately $16 \mathrm{ft}^{2}$.

Nail pull-out resistance suffered because the nails were generally driven into deck sheathing rather than into framing members (roof rafters). Resistance was developed only along the relatively short portion of the nail shank in contact with the deck thickness (approximately $1 / 2$ in.).

Performance of the annex metal roof can be compared with performance of the metal roof on the connected main church building and with the performance of the asphalt shingles over which the annex metal roof was applied. The main and annex roofs had ridges running in the same direction and had the same directional exposure and approximately equal heights and similar slopes. The metal roof on the church had no damage; the metal roof covering on the annex was lost.

The uncovered asphalt shingles on the annex roof withstood strong winds subsequent to the loss of metal panels, although the duration and magnitude of those winds were not known. Some shingles on the windward side of the annex roof were lost. Lack of rust on the nail heads suggests recent (Katrina) 
loss of shingles, rather than loss pre-dating application of the metal roof. This performance was in spite of deviations from typical installation recommendations, for example, improperly placing nails above asphalt shingle self-sealing strip and away from cutout.

\section{Photographs of RoOF DAMAge}

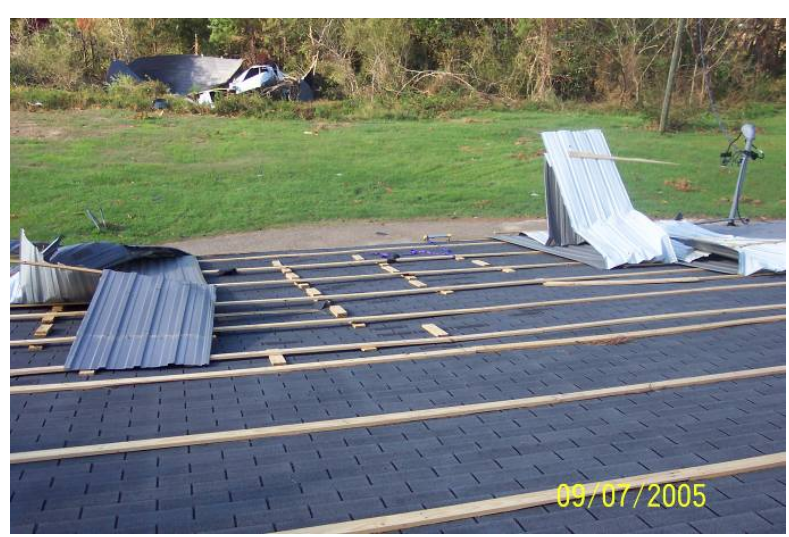

6.10-1. Baptist Church. Nailers are seen still attached to the metal roof sections on the leeward side.

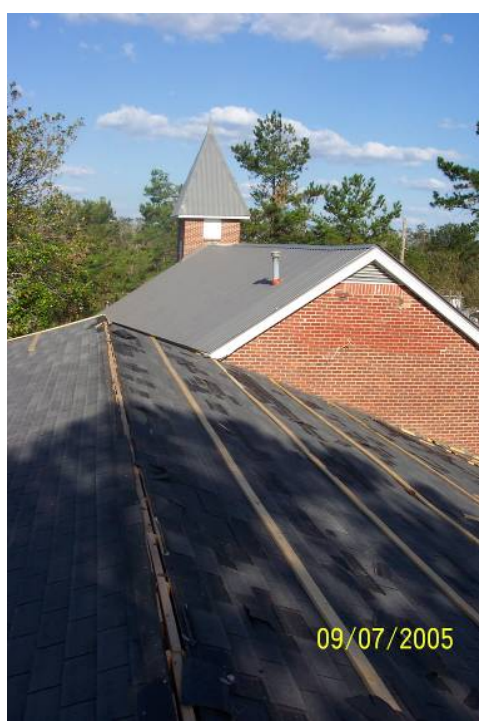

6.10-3. Baptist Church. The annex roof with no remaining metal panels. The metal roof on the adjoining church (in background) sustained no damage.

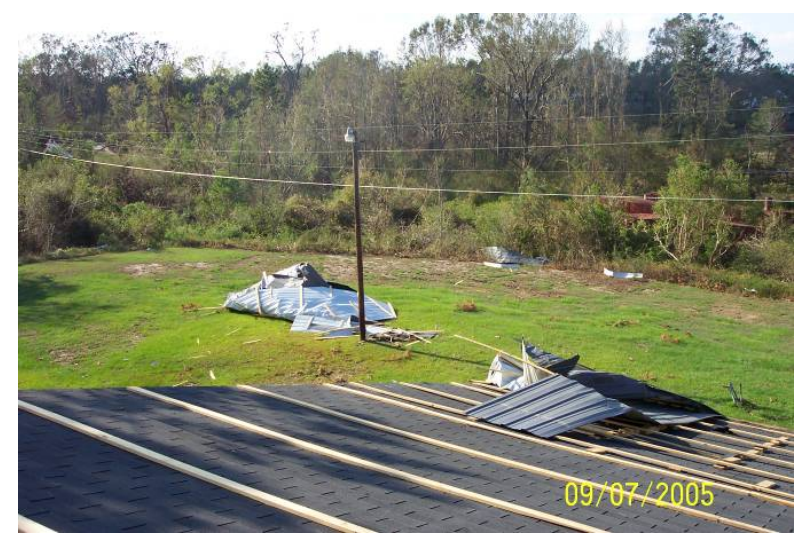

6.10-2. Baptist Church. Boards remaining on the roof were "stiffeners" between nailers lost to wind.

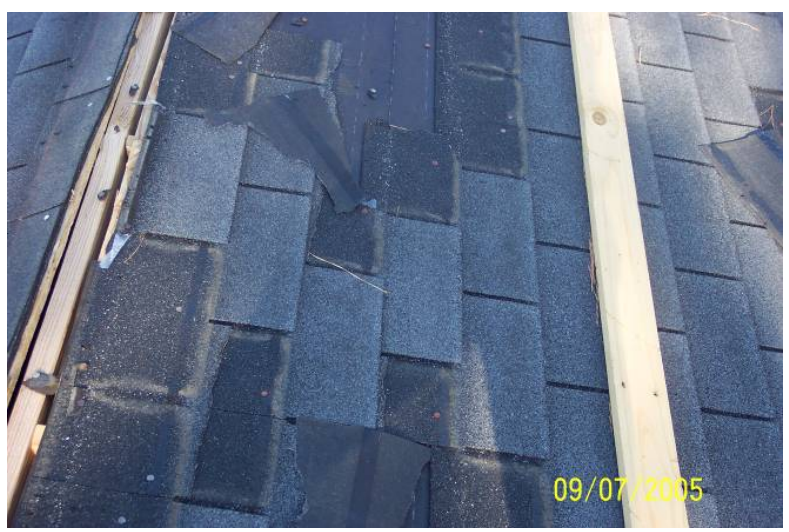

6.10-4. Baptist Church. Nails securing these wood nailers and stiffeners missed framing members, reducing pull-out strength. 


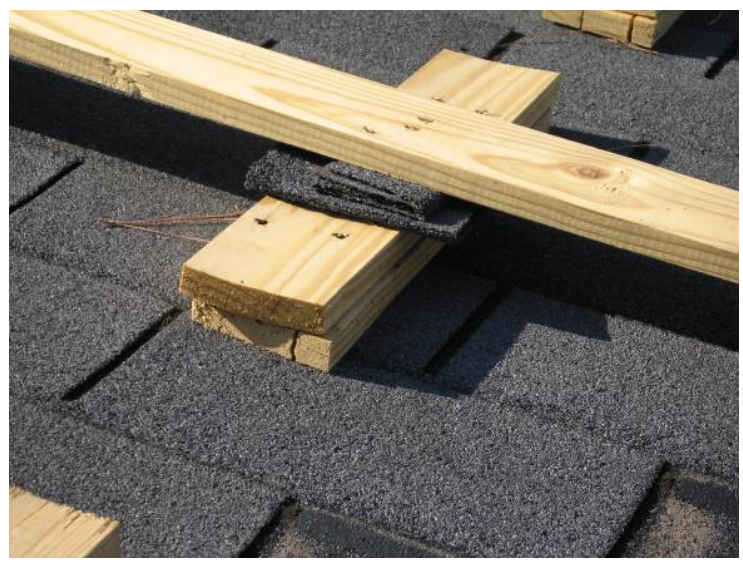

6.10-5. Baptist Church. The underlying shingle roof appeared to have low spots. Nailers were shimmed out in an unorthodox manner (with scrap asphalt shingles) to provide a level base for the metal roofing.

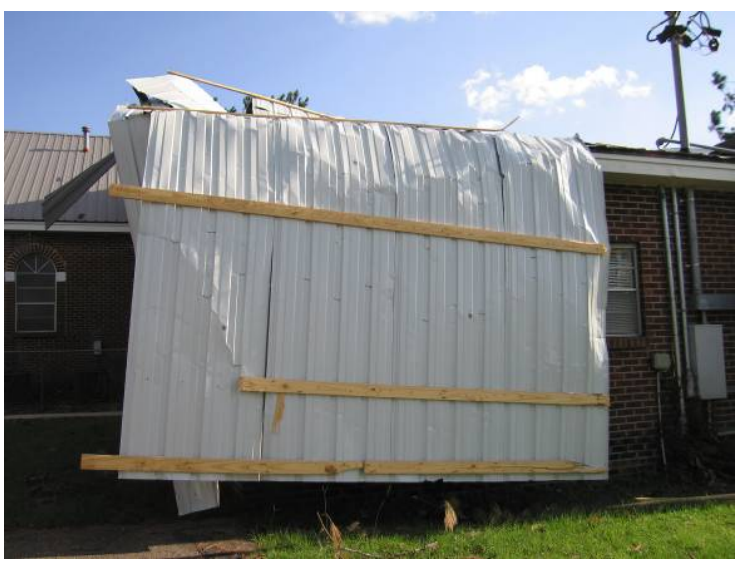

6.10-6. Baptist Church. In one location, the nails used to secure nailers pulled free, leaving nailers attached to the metal roofing. This was a good lesson in proper fastener selection and placement.

\subsection{Residence, 41 Hegwood, Hattiesburg, MS}

TYPE OF STRUCTURE-Single-family home

EXPOSURE-B to the north and west and $\mathrm{C}$ to the east and south

SITE COORDINATES-N31 $18^{\prime}$ W89 $24^{\prime}$

WALL CONSTRUCTION-Brick veneer on wood frame

ROOF TYPE—Asphalt composition 3-tab shingles

SLOPE-5 : 12

ROOF HEIGHT_Eave height $8 \mathrm{ft}$; roof ridge height $20 \mathrm{ft}$

ROOF WIDTH-Undetermined

ROOF LENGTH-Undetermined

DECK-Unknown

WIND SPEED-110-120 mph

BUILDING CONSTRUCTION—One story single-family home with all hip roof design

METHOD OF ATTACHMENT_-Undetermined

NOTED DAMAGE - There was minor roof covering damage. Fewer than $5 \%$ of the shingles were missing. No underlayment was lost and no roof deck exposed. Missing shingles were generally not near eaves or ridges. It is unknown whether there was any interior water damage. Shingle damage was limited to the south side of the roof.

DAMAGE INITIATION AND PROPAGATION—Based on maximum winds from the east, failure likely started at the bottom corners of shingles with wind blowing upward. The seal strip may not have been strong enough to resist the uplift on the shingle tabs. Once shingle corners lifted, numerous shingle tabs bent upward and broke off. 
ADDITIONAL COMMENTS - Based on observations of downed trees near the home, it appeared the strongest winds came from the east. It appears that wind direction played a role in shingle failure. This roof performed well based on the wind speeds.

\section{Photographs of RoOF Damage}

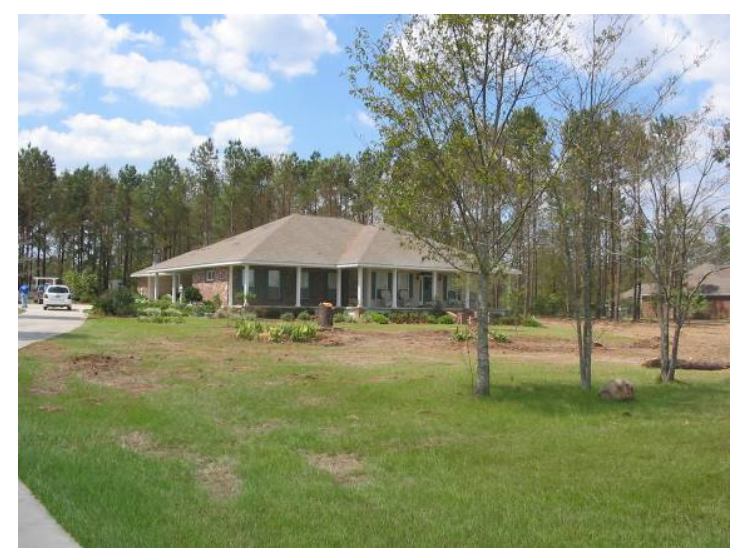

6.11-1. Residence. This is a west-facing view.

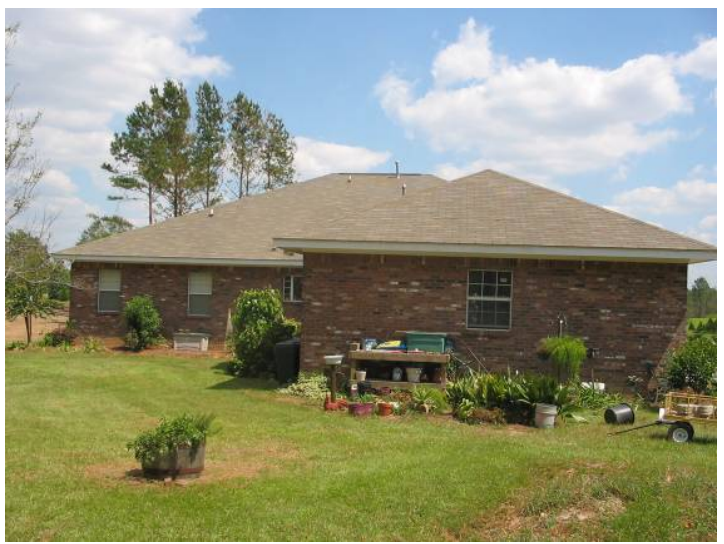

6.11-3. Residence. Facing east, these sections show no roof damage.

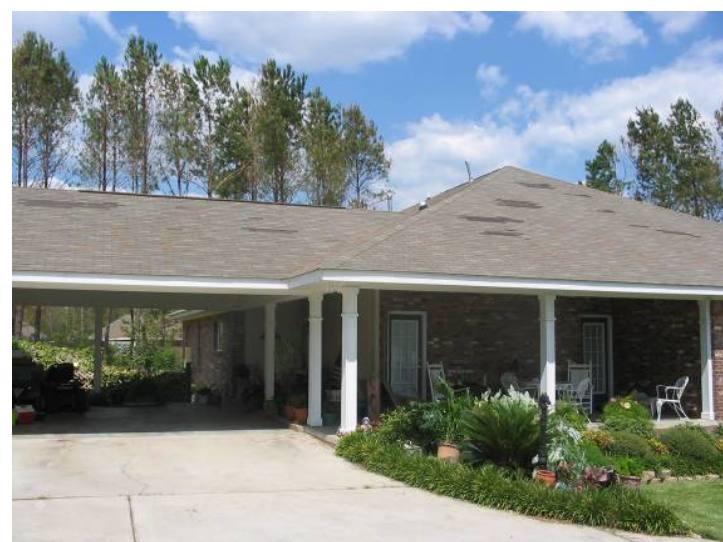

6.11-2. Residence. A view facing north. Shingle damage can be seen clearly.

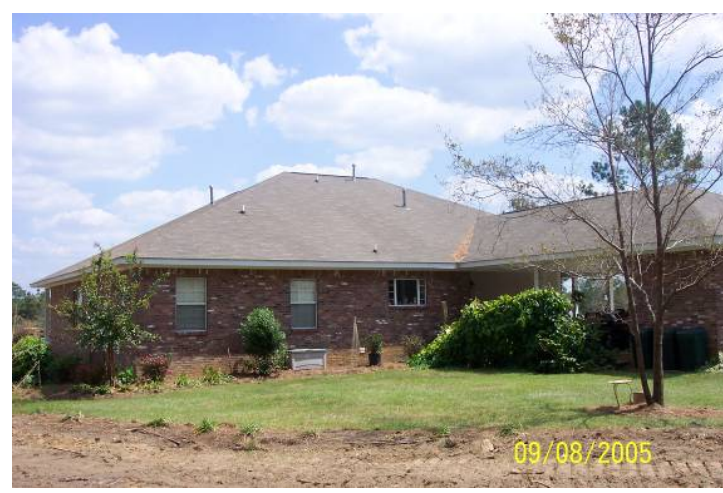

6.11-4. Residence. Facing northeast, this residence also shows no obvious damage.

\subsection{Lumberton Commercial Strip Mall, Highway 13, Lumberton, MS}

TYPE OF STRUCTURE-One story strip mall

EXPOSURE-C

SITE COORDINATES-N31 $11^{\prime} \mathrm{W}^{\circ} 9^{\circ} 26^{\prime}$

WALL CONSTRUCTION-Wood frame

ROOF TYPE-Lightweight sheet metal roofing on purlins

SLOPE-3 : 12 and $12: 12$

ROOF HEIGHT_Eave $10 \mathrm{ft}$; roof ridge $15 \mathrm{ft}$

ROOF WIDTH-30 ft

ROOF LENGTH-120 ft 
DECK-No deck; purlins only

WIND SPEED-110-120 mph

BUILDING CONSTRUCTION_-Wood frame with wood trusses; metal cladding and metal roofing

METHOD OF ATTACHMENT_Fastened to structural wood trusses using compression plates and coated screws.

NOTED DAMAGE-The building suffered major structural damage. Large portions of the metal roofing were blown off. Some trusses were displaced. A middle portion of the building collapsed.

DAMAGE INITIATION AND PROPAGATION-It is likely that wind from the south collapsed the lightweight metal soffit over the front elevation. This caused uplift over the roof. The combined forces of uplift (negative pressure) from wind blowing over the structure and wind blowing up on the bottom side of the roof (positive pressure) caused the wood roof trusses to separate from the tops of the bearing walls. Separation of trusses from walls caused the center portion of the building to collapse.

In other locations, the metal roofing came loose from trusses and blew out into the adjacent areas. The roof trusses remained upright. In some of these portions of the building, roofing separated from the top chord of the roof trusses.

Where the major building collapse occurred, the truss-to-wall connection failed for one of two reasons:

- Direct withdrawal from the end grain of the wood studs; i.e., the double top-plate, to which the trusses were toe-nailed, separated from the wood studs. This type of connection is assumed to have no uplift resistance.

- As a result of separation of the double top-plate, the top $2 \times 4$ in. separated from the bottom $2 \times 4$ in. because the nails joining them pulled loose because of uplift.

The lightweight soffit materials appear to have played a major role in this building failure. However, if they had not blown in, other cladding elements, like the metal roofing, may have failed at some point.

\section{ADDITIONAL COMMENTS-None}

\section{Photographs of Roof Damage}

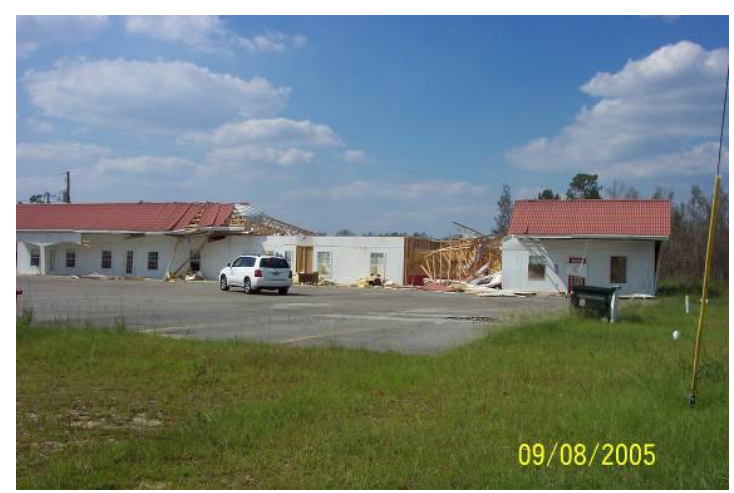

6.12-1. Strip mall. Facing north, damaged buildings are clearly in evidence.

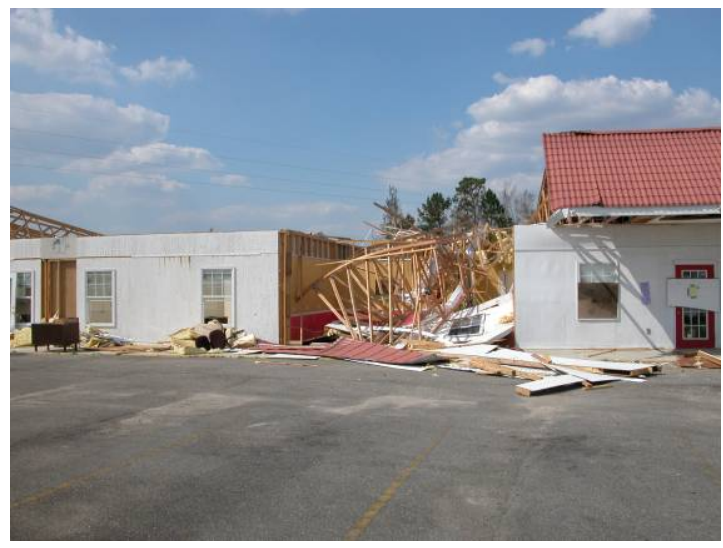

6.12-2. Strip mall. The center section collapse on the south elevation can be seen in this closer view. 


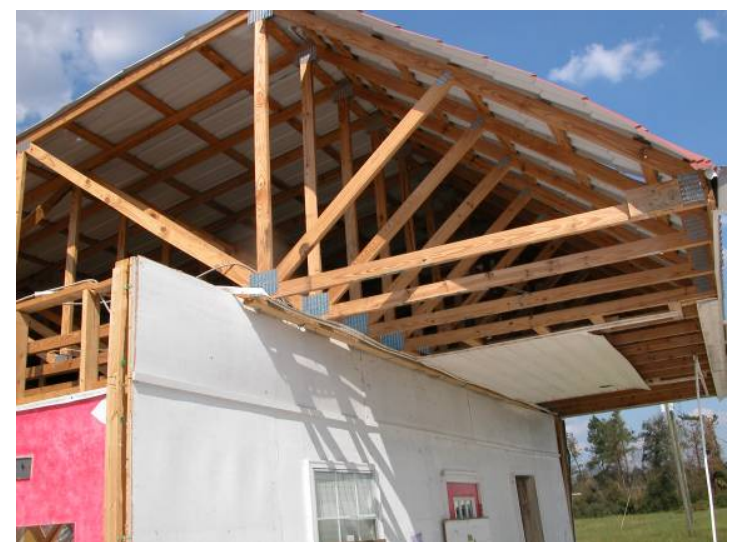

6.12-3. Strip mall. The soffit damage on the south side is visible in this photo.

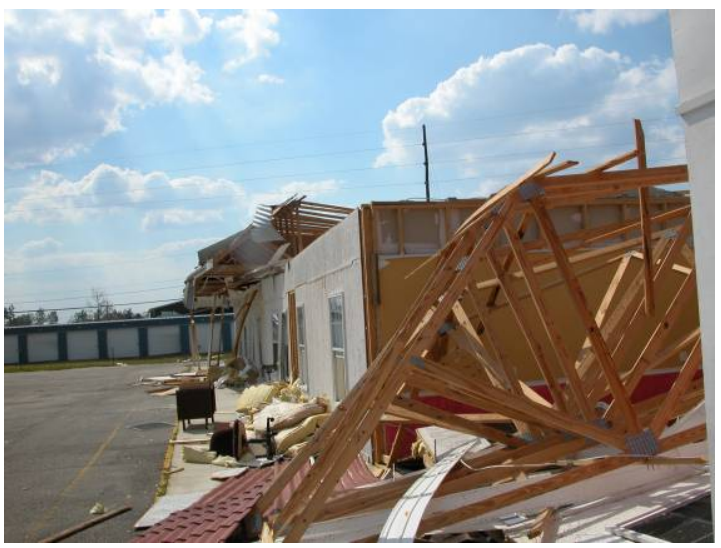

6.12-5. Strip mall. Damage was severe to this strip mall.

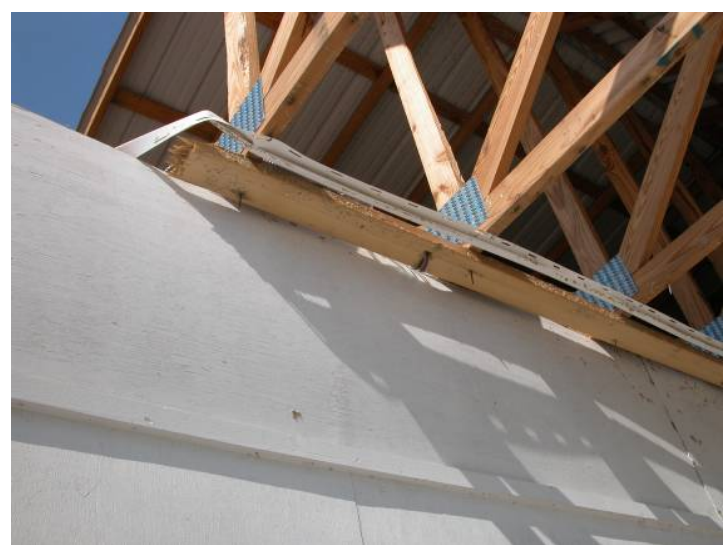

6.12-4. Strip mall. This photo shows a wall topplate failure.

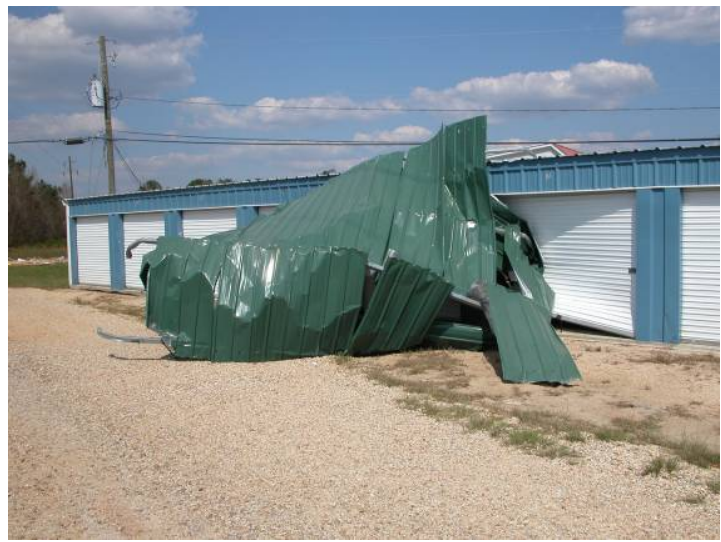

6.12-6. Strip mall. A large section of metal roofing came to rest against a nearby storage locker facility. 


\section{CONCLUSION}

\section{RESULTS}

The main lesson learned in the Katrina investigation appears to be that roofs designed and detailed according to current codes and standards will perform satisfactorily. Older roofs constructed with little concern for the magnitude of the wind pressures at eaves and corners, and roofs installed with poor practices that lead to progressive failure of the roof membrane, were consistently the ones with significant damage.

Many of the observations for Hurricane Katrina were very similar to those recorded for Hurricanes Charley and Ivan. The studies indicate that the same mistakes that were made in the Charley and Ivan damage areas are also being made in the Katrina damage area. Many roof designers do not seem to understand that winds produce uplift forces that affect not only the roofing system but also the roof deck. All elements of a composite system-which will consist of some or all of the following: deck, base sheet, insulation layers, cap sheet, and membrane-must be adhered or fastened to resist the wind uplift loads.

Some progress has been made in roofing technology, codes and standards, and installation inspection. Information gained from wind damage investigations such as Katrina and others will help identify the problems with the design and construction process. The problems will not be solved until the information gets into practice through extensive educational activities directed to everyone from the architects to the installers who apply the fasteners or mop on the hot mix.

\section{FUtURE RESEARCH}

Certainly there is a need for continuing research to develop new and less expensive materials. Given the current emphasis on "green buildings," the use of recycled roofing materials should be of interest to both researchers and manufacturers. The practice of reroofing with reusable materials continues to cause problems that result in wind damage. This practice would be less popular if there were economical uses for the old roofing materials.

Much work has been done on in situ testing of roofs to determine uplift resistance. Simple practical tests need to be developed and calibrated that would verify that a new roof possesses the codespecified resistance.

A fresh look at wind loads on coping and metal edge flashing is needed. Testing in wind tunnels at full scale is very difficult but needs to be done. With a better knowledge of the loads, construction details can be improved.

A better fastening system is needed for cementitious wood fiber panels. Numerous damage investigations besides the current one have shown the anchorage to be inadequate and susceptible to improper installation.

Aggregate and stone blowoff was not identified as a major problem in this investigation. Most buildings inspected in the investigation would not have qualified for aggregate covering of built-up roofing systems or stone ballast for single ply roofs, as use of these systems is now limited by current building codes. 
The protection of buildings from water intrusion after a roof has been damaged should be researched. Better methods for temporary protection, other than the blue plastic sheeting or tarps, should be available.

\section{Need for Engineered Edge Design}

Perimeter and corner areas of low slope roofs have long been recognized as the most vulnerable areas of the roof. The relatively higher uplift forces that can occur in these areas have been factored into the model national building codes, and resisting these loads has been a requirement of the codes for many years. However, wind damage continues to occur at these vulnerable parts of the buildings because both design and installation practices are inadequate. The negative forces at the perimeter must be resisted by adequate mechanical attachment or bonding of the roofing membrane to the substrate and deck. Many designs allow building pressurization, which can significantly increase the design load. Roof systems must be evaluated through testing to resist the design loads. The wind loads to be resisted are dynamic, yet most tests used to evaluate roofing systems are static or quasi-static. Current tests also focus on the vertical force of uplift; but the vertical forces, once they break the initial bond or mechanical attachment, become peel forces that are not measured. In current testing, the first mechanical failure (screw withdrawal) or separation of the membrane stops the test. In reality, roofs often survive with limited amounts of damage if propagation of damage by peel forces is resisted. Without damage propagation by peel forces, catastrophic damage is usually avoided.

\section{FUTURE INVESTIGATIONS}

RICOWI and ORNL/DOE have renewed their Cooperative Research and Development Agreement and are prepared to conduct another hurricane investigation event. The most important element is the publication of the report on a timely basis. To this end, RICOWI has purchased new software for the teams' report writers. A FileMaker Pro training workshop was held March 2, 2007. In addition to the report writers, several of RICOWI's trained investigators purchased the software and also took the course. This improved method for data input in the field will accelerate the production of future reports. 


\section{BIBLIOGRAPHY}

\section{Updated Manufacturer Application Guidelines, Manuals, Codes, AND TEChNical Publications}

ARMA Asphalt Roofing Residential Manual and New Wind Standards for Asphalt Shingles, Asphalt Manufacturers Association, Washington D.C., 2006.

Concrete and Clay Roof Tile Installation Guide, Fourth Edition, Florida Roofing, Sheet Metal and Air-Conditioning Association, Winter Park, FL, and Tile Roofing Institute, Chicago, 2005.

Flexible Membrane Roofing: A Professional's Guide to Specifications, Single Ply Roofing Industry, Inc., Waltham, Massachusetts, 2004.

2004 Florida Building Code, Florida Department of Community Affairs, Tallahassee, Florida, 2005.

A Guide for Selection of Elastomeric Protective Coatings Over Sprayed Polyurethane Foam, AY 102, Spray Polyurethane Foam Alliance, Fairfax, VA, May 2004.

"FM Global Loss Prevention Data Sheet I-49," FM Global, Norwood, Massachusetts, September 2000.

Guide Specifications for Residential Metal Roofing, Metal Construction Association, Glenview, Illinois, 1995 (rev. March 31, 2004).

International Building Code, International Code Council, Inc., Falls Church, Virginia, 2003.

Metal Building Systems Manual, Metal Building Manufacturers Association, Cleveland, Ohio, 2006.

Metal Roofing Systems Design Manual, Metal Building Manufacturers Association, Cleveland, Ohio, 2002.

Minimum Design Loads for Buildings and Other Structures, ASCE-7, Structural Engineering Institute of the American Society of Civil Engineers, Reston, Virginia.

New Roof Construction Manual, Cedar Shake and Shingle Bureau, Sumas, Washington, April 2007.

Spray Polyurethane Foam Systems for New and Remedial Roofing, AY 104, Spray Polyurethane Foam Alliance, Fairfax, Virginia, May 2004.

RoofNav, FM Approvals, Norwood, Massachusetts.

Wind Design Guide for Edge Systems Used with Low Slope Roofing Systems, ES-1-2003, American National Standards Institute/Single Ply Roofing Industry, Inc., 2003. 



\section{ACKNOWLEDGMENTS}

RICOWI thanks several organizations, corporations, and individuals for supporting the program and contributing to our third successful hurricane investigation.

Our gratitude extends to

- The RICOWI Sponsor Members who provided monetary and/or personnel support for the project: Asphalt Roofing Manufacturers Association; Cedar Shake and Shingle Bureau; Insurance Institute for Business and Home Safety; International Staple, Nail, and Tool Association; Metal Building Manufacturers Association; Metal Construction Association; National Research Council of Canada; Roof Consultants Institute, Inc./The Institute of Roofing, Waterproofing, and Building Envelope Professionals; Oak Ridge National Laboratory; Spray Polyurethane Foam Alliance; Single Ply Roofing Institute; and Tile Roofing Institute.

- RICOWI Affiliate Members that provided input on the ongoing program development.

- UT-Battelle/Department of Energy (DOE) and Oak Ridge National Laboratory (ORNL), which continues to carry the identification badges and published the report. Specifically, we are very grateful for André Desjarlais' assistance in facilitating the program under DOE. Our appreciation extends to Deborah Counce (ORNL) for formatting and compiling the final report.

- Teresa Williams (ORNL), for excellent ongoing program support and production of the hard copies of the report.

- The investigation team members for their hard work and long hours in the field:

Bas Baskaran/National Research Council of Canada

Jerry Beall/Seaman Corporation

James Bush/Atas International, Inc.

André Desjarlais/Oak Ridge National Laboratory

Paul Fogarty/Soprema

Sean Foley/Ashland Chemicals

John Goveia/Technical Roof Services, Inc.

Rose Grant/State Farm Insurance Company

Bruce Hackmeyer/Alsan \& Associates

Eric Haefli/State Farm Insurance Company

Mike Hamilton/Michael L. Hamilton, Inc.

Jerry Hatch/Ceco Buildings

Dave Hunt/Revere Copper Products, Inc.

Tom Kelly/2001 Company, Inc.

Mason Knowles/Spray Polyurethane Foam Alliance

John Kurtz/International Staple, Nail, and Tool Association

Cheri Panasik/ITW Buildex

Dave Roodvoets/DLR Consultants, Single Ply Roofing Industry

Walter Rossiter/National Institute of Standards and Technology

Joe Russo/RGM Products, Inc.

Lee Shoemaker/Metal Building Manufacturers Association

Robb Smith/Amtech Roofing Consultants, Inc.

Dan Walker/Metal Building Manufacturers Association

Joe Wilson/Metro Roof Products, Metal Construction Association

Patty Wood-Shields/RICOWI, Inc.

- The photographers for the long hours required to sort and caption photographs. 
- Phil Mayfield, who once again took on the task of editing the first draft of all team reports.

- Peer reviewers James McDonald and Robert Wardlaw.

- Mark Powell, National Oceanic \& Atmospheric Administration Hurricane Research Division, for his ongoing assistance over the past several years.

- Applied Research Associates for providing wind speed maps.

- We give special recognition to the Roof Consultants Institute Foundation for a grant to supplement the publication costs of this report; of special significance is that the grant was issued in the name of the late James Sheahan, one of RICOWI's founding members and past president of the Roof Consultants Institute.

- Thanks to the Mississippi Emergency Management Agency and local jurisdictions for their cooperation in providing our teams with clearance documents into the declared and non-declared disaster areas consistent with public safety.

- Thanks to the National Guard for their assistance on investigation sites and staging areas.

- The cooperation of facility managers for the properties inspected was most appreciated.

- Most important, we are grateful to the people in the hurricane-ravaged areas for their cooperation and hospitality. 


\section{APPENDICES}

\section{A. KATRINA-3-SECOND PEAK GUST WIND SPEED MAP Courtesy of Applied Research Associates}

B. NOAA-NATIONAL DATA BUOY CENTER C-MAN PROGRAM Courtesy of NOAA Experimental Research Products

C. KATRINA INVESTIGATION TEAM GROUP PHOTO

D. THE SAFFIR-SIMPSON HURRICANE SCALE Courtesy of the National Hurricane Center

\section{E. RICOWI INFORMATION}





\section{APPENDIX A}

\section{KATRINA-3-SECOND PEAK GUST WIND SPEED MAP WEATHER MONITORING STATIONS}

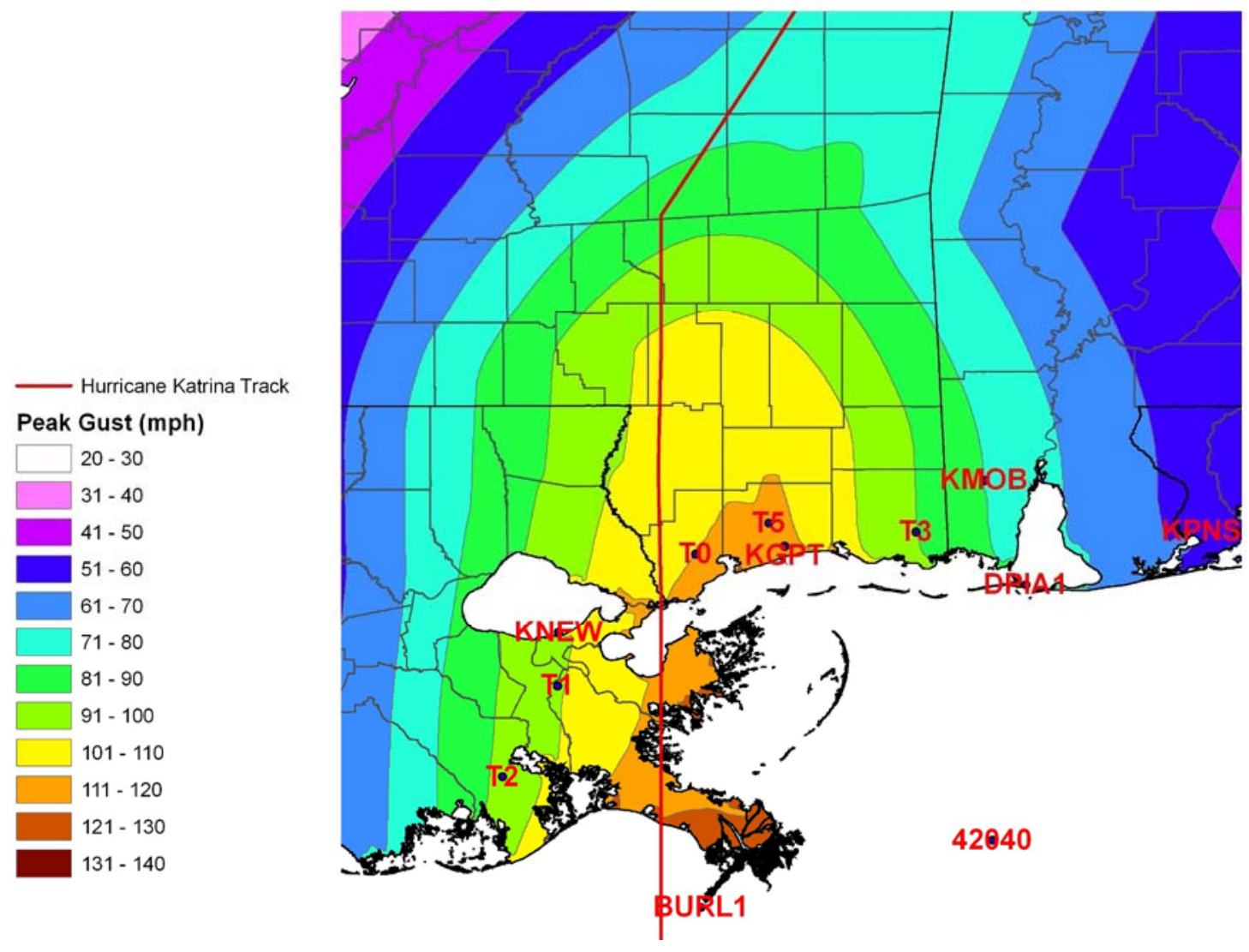

Map used courtesy of Applied Research Associates (www.ara.com).

\section{Legend}

T.0-T.5 Florida Coastal Monitoring Program anemometer sites

Airports: $\quad$ KNEW-New Orleans, LA

KGPT-Gulfport, MS

KMOB-Mobile, AL

KPNS-Pensacola, FL

C-Man Stations: DRIA1

BURL1

Data Buoy $\quad 42040$ 



\section{APPENDIX B}

\section{NOAA-NATIONAL DATA BUOY CENTER C-MAN PROGRAM}

The Coastal-Marine Automated Network (C-MAN) was established by the National Buoy Data Center (NBDC) for the National Weather Service (NWS) in the early 1980s. The development of C-MAN was in response to a need to maintain meteorological observations in U.S. coastal areas. Such observations, which had been made previously by U.S. Coast Guard personnel, would have been lost as many Coast Guard navigational aids were automated under the Lighthouse Automation and Modernization Program. In all, approximately 60 stations make up C-MAN.

C-MAN stations have been installed on lighthouses, at capes and beaches, on near-shore islands, and on offshore platforms (see the NDBC station location map for all station locations).

NWS forecasters need frequent, high-quality marine observations to examine conditions for forecast preparation and to verify their forecasts after they are produced. Other users rely on the observations and forecasts for commercial and recreational activities. The NBDC provides hourly observations from a network of about 90 buoys and 60 C-MAN stations to help meet these needs. All stations measure wind speed, direction, and gust; barometric pressure; and air temperature. In addition, all buoy stations, and some C-MAN stations, measure sea surface temperature and wave height and period. Conductivity and water current are measured at selected stations Some C-MAN stations are designed also to measure water level, relative humidity, precipitation, and visibility.

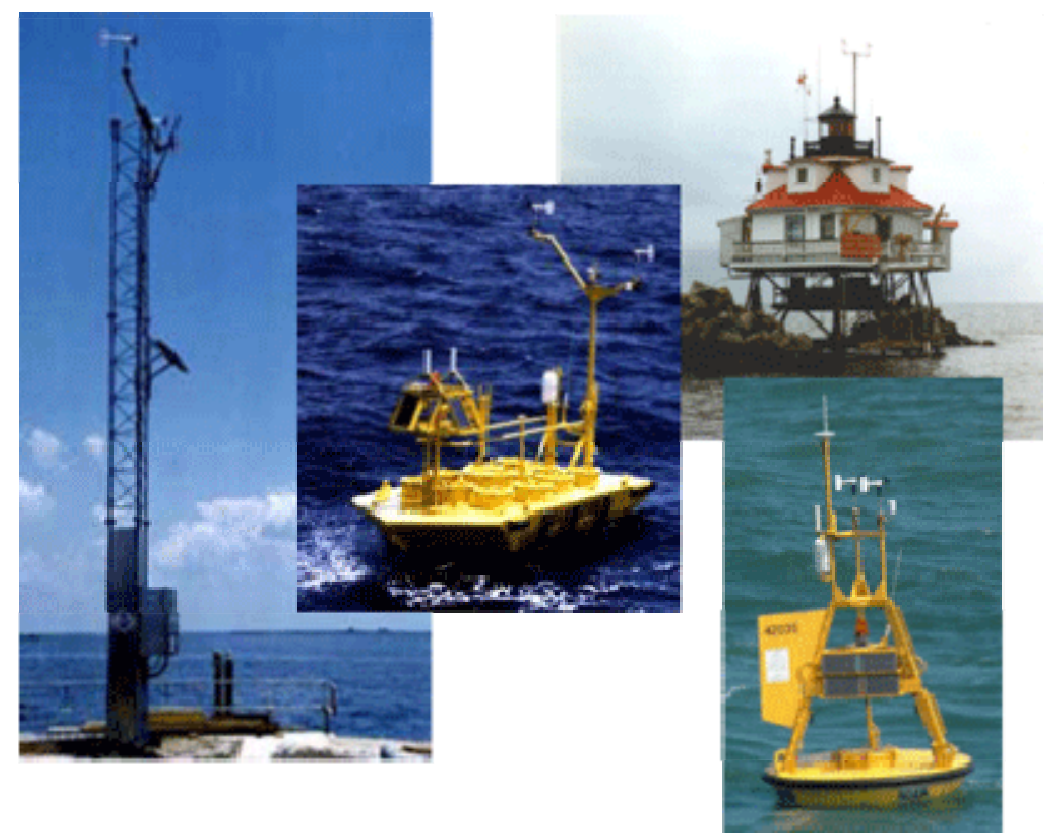

Typical buoy and C-MAN stations. 
These data are processed and transmitted hourly to users almost exactly as moored buoy data are. In addition to the conventional method of data transmission, certain C-MAN stations are equipped with telephone modems that allow more frequent data acquisition, data quality checking, and remote payload reconfiguration or restarting.

To support this network and other engineering/data collection projects, NDBC employs engineers, meteorologists, oceanographers, computer scientists, and other professionals. Coast Guard members serve on the staff to provide unique skills and interface with the Coast Guard for transportation support. An NDBC technical services contractor supports NDBC with a staff of approximately 110 employees.

Article courtesy of NOAA.

(See map in Appendix A for C-MAN data buoy locations.) 


\section{APPENDIX C}

\section{KATRINA INVESTIGATION TEAM GROUP PHOTO}

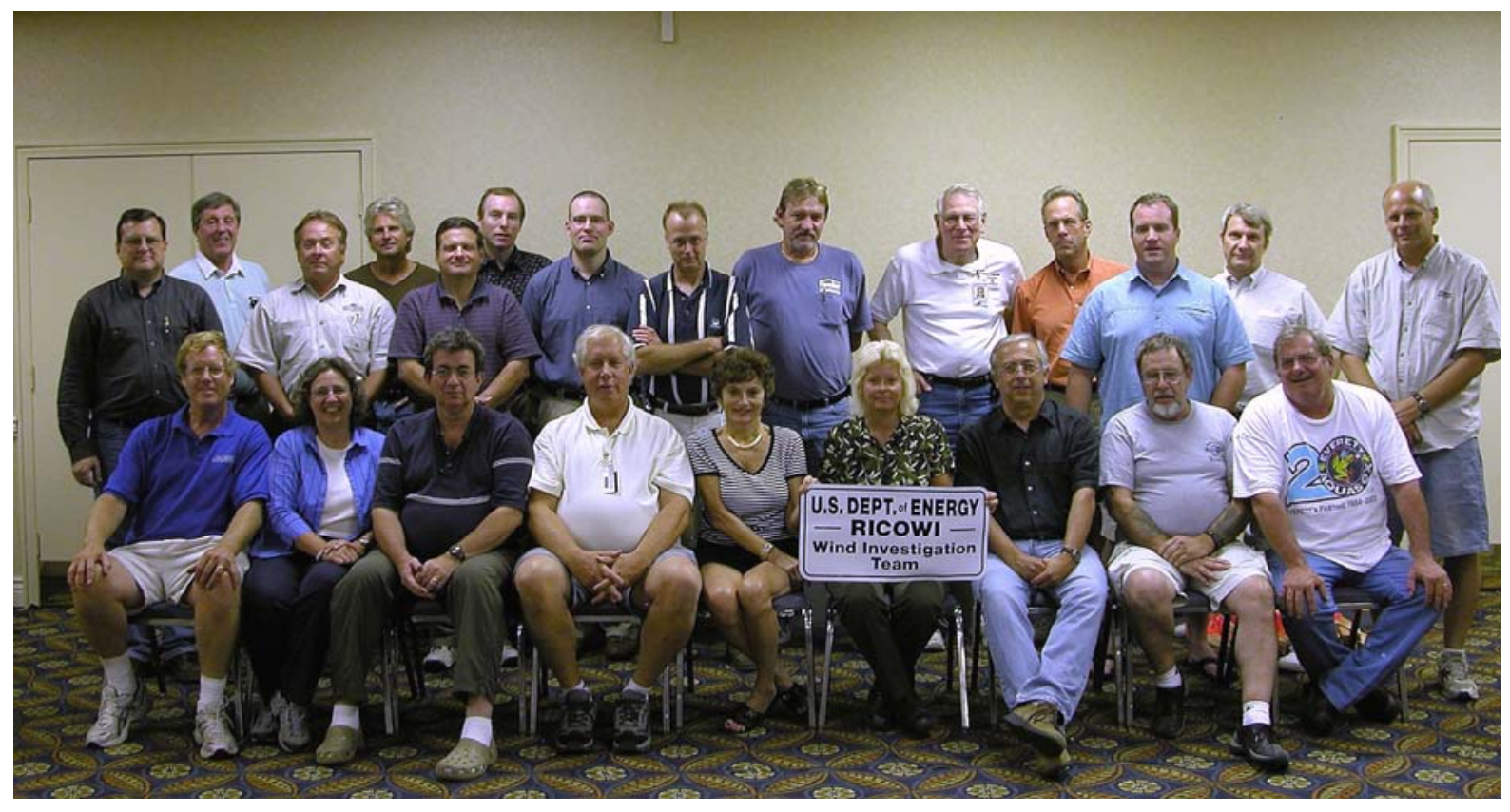

\section{Seated, left to right:}

Tom Kelly, Rose Grant, Bruce Hackmeyer, Robb Smith, Patty Wood-Shields, Cheri Panasik, André Desjarlais. John Goveia, Joe Russo

\section{Standing, left to right:}

Jerry Hatch, Walt Rossiter, Mike Hamilton, Mason Knowles, Lee Shoemaker, Eric Haefli,

Dan Walker, Jim Bush, Jerry Beall, Dave Roodvoets, Dave Hunt, Sean Foley, John Kurtz, Joe Wilson

\section{Not pictured:}

Bas Baskaran, Paul Fogerty 



\section{APPENDIX D}

\section{THE SAFFIR-SIMPSON HURRICANE SCALE}

The Saffir-Simpson Hurricane Scale is a 1-5 rating based on a hurricane's present intensity. It is used to give an estimate of the potential property damage and flooding expected along the coast from a hurricane landfall. Wind speed is the determining factor in the scale, as storm surge values are highly dependent on the slope of the continental shelf in the landfall region. Note that all winds are using the U.S. 1-minute average.

\section{Category One Hurricane}

Winds $74-95 \mathrm{mph}$ (64-82 kt or 119-153 km/hour). Storm surge generally $4-5 \mathrm{ft}$ above normal. No real damage to building structures. Damage primarily to unanchored mobile homes, shrubbery, and trees. Some damage to poorly constructed signs. Also some coastal road flooding and minor pier damage. Hurricane Lili of 2002 made landfall on the Louisiana coast as a Category One hurricane. Hurricane Gaston of 2004 was a Category One hurricane that made landfall along the central South Carolina coast. In 2005 Hurricane Katrina made its first landfall in the US as a Category One hurricane near the border of Miami-Dade County and Broward County, Florida (see Category Four notes).

\section{Category Two HurRicane}

Winds 96-110 mph (83-95 kt or 154-177 km/hour). Storm surge generally 6-8 feet above normal. Some roofing material, door, and window damage to buildings. Considerable damage to shrubbery and trees, with some trees blown down. Considerable damage to mobile homes, poorly constructed signs, and piers. Coastal and low-lying escape routes flood 2-4 hours before arrival of the hurricane center. Small craft in unprotected anchorages break moorings. Hurricane Frances of 2004 made landfall over the southern end of Hutchinson Island, Florida, as a Category Two hurricane. Hurricane Isabel of 2003 made landfall near Drum Inlet on the Outer Banks of North Carolina as a Category Two hurricane.

\section{Category Three Hurricane}

Winds 111-130 mph (96-113 kt or 178-209 km/hour). Storm surge generally 9-12 ft above normal. Some structural damage to small residences and utility buildings with a minor amount of curtain wall failure. Damage to shrubbery and trees, with foliage blown off trees and large trees blown down. Mobile homes and poorly constructed signs are destroyed. Low-lying escape routes are cut by rising water 3-5 hours before arrival of the center of the hurricane. Flooding near the coast destroys smaller structures, and larger structures are damaged by battering from floating debris. Terrain continuously lower than $5 \mathrm{ft}$ above mean sea level may be flooded inland for 8 miles $(13 \mathrm{~km})$ or more. Evacuation of low-lying residences within several blocks of the shoreline may be required. Hurricanes Jeanne and Ivan of 2004 were Category Three hurricanes when they made landfall in Florida and in Alabama, respectively.

\section{Category Four Hurricane}

Winds 131-155 mph (114-135 kt or 210-249 km/hour). Storm surge generally 13-18 ft above normal. More extensive curtain wall failures with some complete roof structure failures on small residences. Shrubs, trees, and all signs are blown down. Complete destruction of mobile homes. 
Extensive damage to doors and windows. Low-lying escape routes may be cut by rising water 3-5 hours before arrival of the center of the hurricane. Major damage to lower floors of structures near the shore. Terrain lower than $10 \mathrm{ft}$ above sea level may be flooded, requiring massive evacuation of residential areas as far inland as 6 miles $(10 \mathrm{~km})$. Hurricane Charley of 2004 was a Category Four hurricane that made landfall in Charlotte County, Florida, with winds of $150 \mathrm{mph}$. Hurricane Dennis of 2005 struck the island of Cuba as a Category Four hurricane. Hurricane Katrina of 2005 made its second landfall as a Category Four hurricane in Plaquemines Parish near Buras, Louisiana.

\section{Category Five Hurricane}

Winds greater than $155 \mathrm{mph}$ (135 kt or $249 \mathrm{~km} / \mathrm{hour}$ ). Storm surge generally greater than $18 \mathrm{ft}$ above normal. Complete roof failure on many residences and industrial buildings. Some complete building failures with small utility buildings blown over or away. All shrubs, trees, and signs blown down. Complete destruction of mobile homes. Severe and extensive window and door damage. Lowlying escape routes are cut by rising water 3-5 hours before arrival of the center of the hurricane. Major damage to lower floors of all structures located less than $15 \mathrm{ft}$ above sea level and within 500 yards of the shoreline. Massive evacuation of residential areas on low ground within 5-10 miles $(8-16 \mathrm{~km})$ of the shoreline may be required. Only three Category Five hurricanes have made landfall in the United States since records began: The Labor Day Hurricane of 1935, Hurricane Camille (1969), and Hurricane Andrew in August, 1992. The 1935 Labor Day Hurricane struck the Florida Keys with a minimum pressure of $892 \mathrm{mb}$ - the lowest pressure ever observed in the United States. Hurricane Camille struck the Mississippi Gulf Coast, causing a 25-foot storm surge that inundated Pass Christian. Hurricane Andrew of 1992 made landfall over southern Miami-Dade County, Florida, causing $\$ 26.5$ billion in losses - the costliest hurricane on record. In addition, Hurricane Wilma of 2005 was a Category Five hurricane at peak intensity and is the strongest Atlantic tropical cyclone on record with a minimum pressure of $882 \mathrm{mb}$.

\section{Courtesy of the National Hurricane Center}




\section{APPENDIX E}

\section{RICOWI INFORMATION}

\section{BACKGROUND}

In 1989, Oak Ridge National Laboratory (ORNL) held two workshops devoted to identifying and discussing roof wind uplift issues and alternatives. Important technical issues that were discussed included

- Dynamic testing of roof systems

- The importance of sample size for tests

- The roles of wind tunnels and air retarders

- The need for acceptable procedures for ballasted systems.

- Field data and response team reports

- The general lack of communication within the roofing industry as to what the problems are, what is being done and should be done to alleviate them, and how effectively information is transferred within the roofing industry and to others in the building community

At the conclusion of the workshops, a consensus recommendation was to form a committee to address these matters. The Roofing Industry Committee on Wind Issues (RICOWI) was established, and the charter was approved on October 11, 1990.

In 1996, RICOWI was incorporated as a nonprofit corporation devoted to research and education on wind issues. After a review of the need for similar types of education and research in the areas of hail, energy efficiency, and durability effects, the organization's objectives were broadened in 1999 to include other weather topics; and "Wind" in RICOWI's name was changed to "Weather" to reflect the expanded scope. RICOWI is assisted by ORNL, the banner organization.

\section{MISSION}

RICOWI is committed to

1. Encouraging and coordinating research to provide a more comprehensive information base on roof issues, including wind, hail, energy efficiency, and durability effects

2. Accelerating the establishment of new or improved industry consensus standard practices for weather design and testing where they are needed

3. Improving the understanding of roof weather concepts and issues within the building community in general

\section{Meetings}

RICOWI meetings are held twice a year, in the spring and fall. The spring meeting is usually in conjunction with the spring seminar, which is scheduled to coincide with the annual convention of the Roof Consultants Institute. RICOWI meetings are attended by people who are concerned about roofing and weather issues.

The meetings include a business session in which the direction and business of RICOWI are discussed, as well as a technical forum. During the latter segment, the Sponsor and Affiliate members have an opportunity to report on the latest developments in their organizations and on technical 
subjects of common interest. Participants can bring knowledge or concerns to a group of experts who can review ideas, suggest tests or procedures, or provide feedback on the efficacy of proposed designs, approaches, or solutions.

\section{SeMINARS}

Seminars on the proper design, installation, and testing procedures for specific roofing materials are held once or twice a year. Fall seminars are usually held at research, testing, or educational facilities and include a tour. They are of interest to roofing professionals, architects, contractors, engineers, facility managers, and those in the insurance industry.

\section{Hurricane and Hail Investigation Programs}

RICOWI has implemented two strategic investigation programs:

- Wind Investigation Program (WIP)

- Hail Investigation Program (HIP)

The purpose of these programs is to

- investigate the field performance of roofing assemblies after major hurricane and hailstorm events

- factually describe roof assembly performance and modes of damage

- formally report the results for substantiated hurricane/hail events

The data collected provide unbiased, detailed information on the wind and hail resistance of low slope and steep slope roofing systems from credible investigative teams. The goal is to have a greater industry understanding of what causes roofs to perform or fail in severe wind and hail events. This understanding can lead to overall improvements in roof system durability, reduction of waste generation from re-roofing, and reduction of insurance losses, which may lead to lower overall costs for the public. The reports and multimedia presentations document roofing systems that fail or survive major weather events and provide educational materials to help roofing professionals design windand hail-resistant roofing systems. All data are available to be used to improve building codes and roofing design and to educate the industry and the public.

\section{Wind InVestigation Program}

Subsequent to RICOWI's formation, other concerns were raised. The insurance industry conveyed its concern regarding excessive property loss from wind damage. Industry experts estimated that from 1986 to 1995, hurricanes and high winds accounted for $78 \%$ of catastrophic losses. Estimated insured losses from hurricanes have averaged $\$ 10$ billion per year since 1989. In August 1992, Hurricane Andrew caused $\$ 16$ billion in insured losses in South Florida. (Post-Andrew, several other hurricanes, including Charley and Ivan, have hit the South Florida area, resulting in catastrophic losses).

There is an essential link between product research, performance, and the model building codes. The model code groups are moving more toward "objective-based codes" versus "prescriptive codes." Performance requirements are generally perceived to be requirements stated in a way that allows flexibility in the choice of solutions to satisfy the requirements. As such, they are based upon explicit objectives. Code changes are being adopted by the model code groups without adequate industry input. In addition, there is a general feeling that the right types of data have not been gathered following events that cause extensive damage from wind. 
There is no question that all roofing products and systems of all roofing associations must meet more rigorous requirements. These products and systems will be subject to tougher scrutiny by building departments, as we have already seen in Dade and Broward counties in Florida. Industry involvement in follow-up of wind events is imperative.

RICOWI and the U.S. Department of Energy (DOE)/ORNL responded to these concerns by entering into a Cooperative Research and Development Agreement (CRADA) to facilitate the WIP. The Program includes all of the major roofing trade associations in North America.

This Program puts credible people in the field who have the required product knowledge and program training to ensure that sound, scientific, and unbiased reporting occurs. RICOWI's goal is that buildings will be safer, property losses will be reduced, and the industry will meet the challenge with clear insight as to the needed direction. The reports generated by our investigation teams and findings will be used to educate, as well as to improve products, installation techniques, and safety. They should also reduce overall roofing and insurance costs for the industry, as well as provide a valuable resource to the Federal Emergency Management Agency and state emergency management agencies.

\section{CRADA ANd U.S. Government PARTICIPATION}

In 1996 RICOWI entered into a CRADA with UT-Batelle, LLC (the contractor that manages ORNL) under the auspices of DOE. The CRADA is jointly funded by DOE's Office of Energy Efficiency and Renewable Energy, Building Technologies Program; state and community sector programs; and industry partners. The sponsoring associations supplied other major funding, and their individual companies provided in-kind funds to support the CRADA by covering inspectors' costs for travel and labor.

The scope of work under the CRADA is to investigate and report the field performance of low-slope and steep-slope roofing systems after major hurricanes (i.e., those with wind speeds of $95 \mathrm{mph}$, sustained for 1 minute or more) make landfall on the continental United States in populated areas.

ORNL has been working with private industry to accelerate the acceptance of more energy-efficient and durable roofing systems. ORNL facilitated the training and issuance of identification badges for RICOWI team members.

Following this report will be the development of educational tools illustrating how to design and construct more durable and energy-efficient roofs, and pointing out the consequences of falling short. A profile will be developed of the performance of various roofing systems in severe wind events, leading to overall improvement in roof system durability, the reduction of waste generation from reroofing, and reduction in insurance losses. These should lead to lower overall costs for the public.

\section{Published Report}

RICOWI published the Hurricane Charley and Ivan Wind Investigation Report in March 2006. The report is available on CD and on RICOWI's web site. This Hurricane Katrina Wind Investigation Report will also be posted on RICOWI's web site.

\section{Contact Information}

Patty Wood-Shields

Executive Director

Email: paws01@ricowi.com

www.ricowi.com 
